\title{
WINTERTIME PRECIPITATION CLIMATE OF CENTRAL SOUTHWEST ASIA: DIAGNOSTICS AND FORECASTING
}

BY

SAPNA RANA

\begin{abstract}
A thesis
submitted to the Victoria University of Wellington in fulfilment of the requirements for the degree of

Doctor of Philosophy in Geophysics
\end{abstract}

Victoria University of Wellington (2019) 


\begin{abstract}
Central Southwest Asia $\left(\mathrm{CSWA} ; 20^{\circ}-47^{\circ} \mathrm{N}, 40^{\circ}-85^{\circ} \mathrm{E}\right)$ is a water-scarce and a societally vulnerable region, prone to significant variations in precipitation during the winter months of November-April. Wintertime precipitation variations have a direct impact on CSWA's water resources, agricultural productivity, energy use, and human society. Because of the close relationship between climate and human well-being, an improved understanding of winter season precipitation and its variability over CSWA is of critical importance. However, due to multiple regional challenges (e.g. sociopolitical instability, extreme topographical heterogeneity, poor coverage of in situ stations, and others) analysis of precipitation in this region has been limited.
\end{abstract}

In an attempt to bridge the existing knowledge gap, this thesis aims to advance our understanding of CSWA's wintertime precipitation climate through three separate, but inter-related studies on 1) evaluation of multi-source gridded precipitation dataset, 2) investigation of spatial and temporal patterns of precipitation and its links with largescale modes of climate variability, 3) development of a statistical forecast model. Additionally, precipitation evaluation is also relevant to the overlapping and important region of the Indian subcontinent; a detailed seasonal analysis for which is also presented.

First, the performance of several commonly used gridded precipitation products from multiple sources: gauge-based, satellite-derived, and reanalysis is analysed for all four seasons over the Indian Subcontinent. Results show that the degree of uncertainty in all precipitation estimates varies by region (e.g. topographic relief) and the type of precipitation (e.g. convective, orographic). At the seasonal scale, satellite-products perform better, while reanalyses generally overestimate precipitation. Greater discrepancies occur in areas with low gauge densities, owing to which a complete understanding of the accuracy and limitations of precipitation estimates is hampered for the northwestern region of the Indian subcontinent.

In an extension study, ten multi-source precipitation products are evaluated against an ensemble of four gauge-only datasets. This analysis is carried out for CSWA, which also includes the northwestern region of the Indian subcontinent. Spatial and temporal analysis of results shows that GPCC is a suitable observational dataset for studying long-term wintertime precipitation variations over CSWA. The satellite-derived TRMM 3B42-V7 is a potentially reliable alternative to gauge measurements, while the performance of MERRA reanalysis is satisfactory.

Further, the spatial-temporal patterns of wintertime precipitation variability over CSWA are explored. Three leading patterns are identified by empirical orthogonal function (EOF) analysis, and the associated time series are related to global SST and other large-scale atmospheric circulation fields. The leading patterns of winter precipitation are significantly linked with the El Niño-Southern Oscillation (ENSO); East Atlantic-Western Russia (EA-WR); Siberian High; North Pacific Oscillation (NPO); Scandinavian pattern; and the long-term warming of the Indian Ocean SST. The inter-decadal change of relationship between the first-mode of winter precipitation and ENSO is also investigated, which shows that CSWA precipitation 
variability was closely related to the extratropical EA-WR (tropical ENSO) teleconnection before (after) the 1980's.

Finally, the level and origin of seasonal forecast skill of wintertime precipitation anomalies over CSWA are examined using the statistical method of canonical correlation analysis (CCA). The preceding months' (September-October) SST is used as predictors, and CCA experiments are performed for two sets of time periods, 1950/51-2014/15 and 1980/81-2014/15. For both prediction periods, the potential source of predictability originates largely from SST variations related to ENSO and the Pacific Decadal Oscillation (PDO). A higher (lower) correlation skill of 0.71 $(0.38)$ is obtained between observations and cross-validated precipitation forecasts for the period 1980/81-2014/15 (1950/51-2014/15); which shows that ENSO played a dominant role in creating skillful predictions for CSWA wintertime precipitation in recent years. 


\section{ACKNOWLEDGEMENTS}

This thesis would not have been possible without the considerable help of many people. First and foremost, I would like to thank my supervisors, Dr James McGregor and Dr James Renwick for their sage guidance and unwavering support throughout my $\mathrm{PhD}$.

I am also grateful to Victoria University of Wellington for the Victoria Doctoral Scholarship, without which this $\mathrm{PhD}$ would not have been possible. Special thanks to Dr James McGregor for organising the financial support in the final year of my $\mathrm{PhD}$, and to Dr James Renwick for providing the funds for publications. Thanks are also due to Aleksandr Beliaev for solving my computer and software related problems, to Monika Hanson for helping with matters related to international travel research grant, and to Miranda Voke for administrative issues.

I would also like to acknowledge the World Meteorological Organization, the Abdus Salam International Centre for Theoretical Physics, The APEC Climate Center, and the Meteorological Society of New Zealand for their financial support to attend conferences, which has helped me to grow as a scientist and provided me with opportunities to build collaborative networks.

Countless thanks to my family for their unconditional support and encouragement throughout life. This thesis is a dedication to you 'Papa' - for all your love, sacrifices, guidance, and blessings. We miss you!

Last, but not the least, I would never have got to the end of this thesis if it were not for the continual love, support and care from Amit and our little sunshine Aaria. 


\section{TABLE OF CONTENTS}

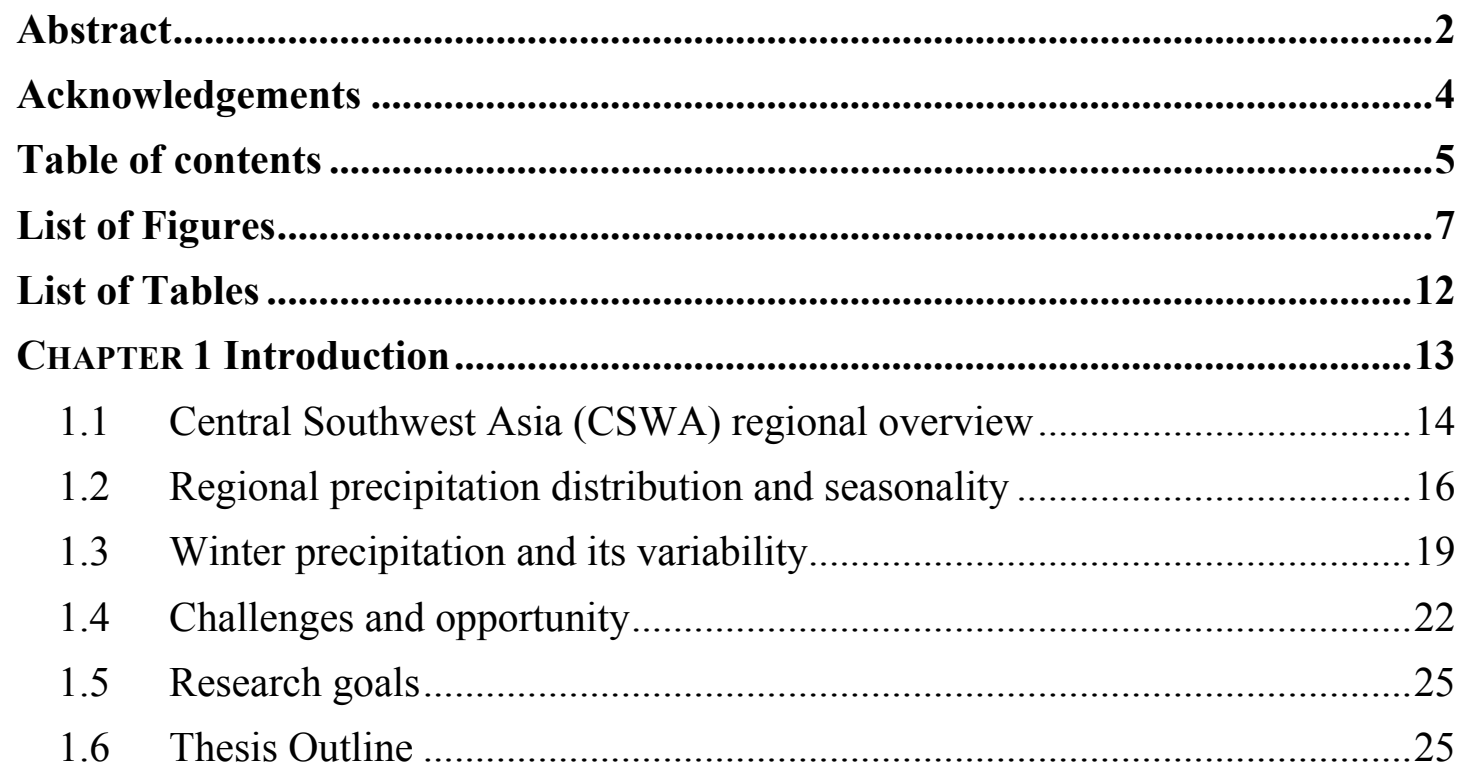

ChAPTER 2 Precipitation Seasonality over the Indian Subcontinent: An Evaluation of Gauge, Reanalyses, and Satellite Retrievals ......................................28

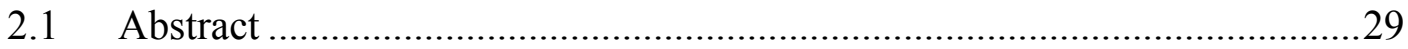

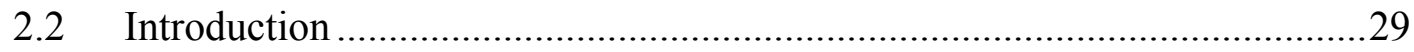

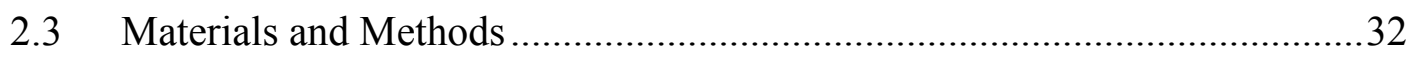

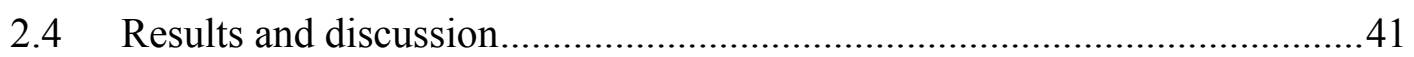

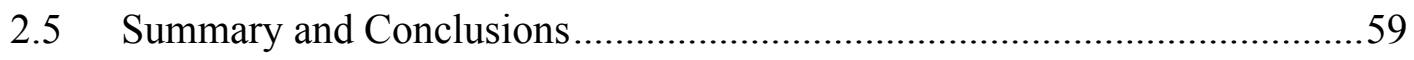

2.6 Our interpretation of seasonal comparisons ................................................60

CHAPTER 3 Wintertime precipitation climatology and ENSO sensitivity over central southwest Asia ...................................................................................62

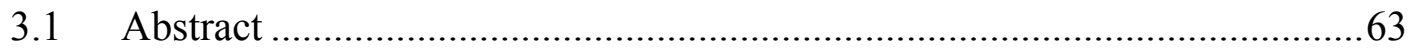

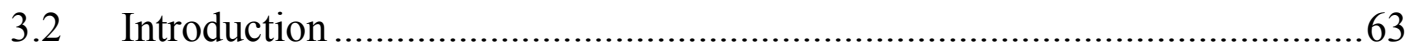

3.3 Study region, precipitation data sets and methodology...............................65

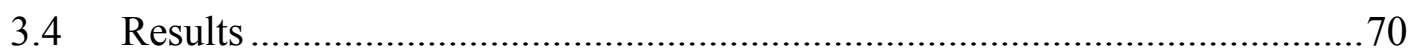

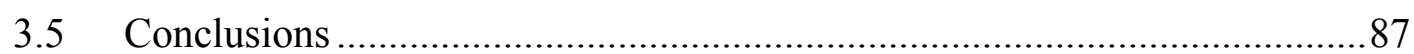

Chapter 4 Dominant Modes of Winter Precipitation Variability over Central Southwest Asia and inter-decadal change in the ENSO teleconnection ...............90

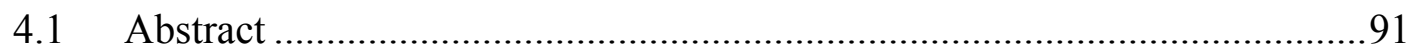

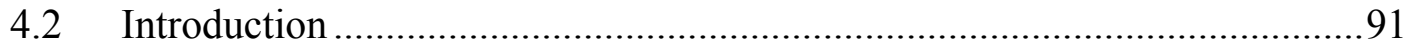

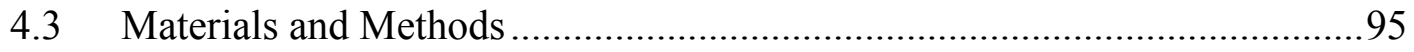

4.4 Characteristics of leading three EOF modes of CSWA winter precipitation 98

4.5 Association with global SST and large-scale atmospheric circulation anomalies 100 
4.6 Inter-decadal change of connection between the wintertime ENSO and EOF-

1

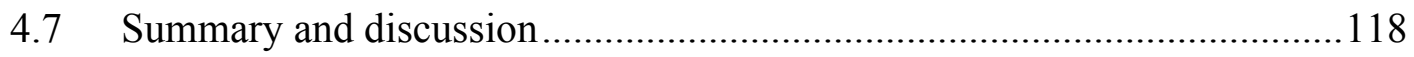

Chapter 5 Seasonal Prediction of Winter Precipitation Anomalies over Central Southwest Asia: A Canonical Correlation Analysis Approach ...........................122

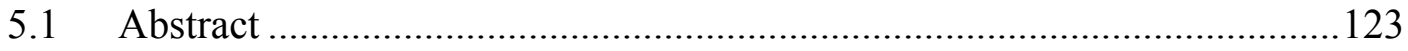

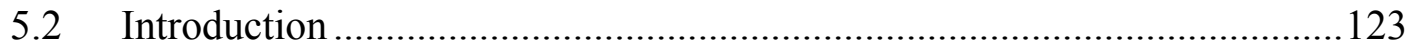

5.3 Materials, Method of analysis and prediction model development ............127

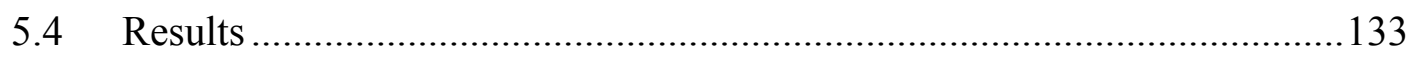

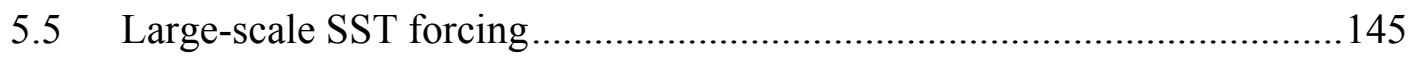

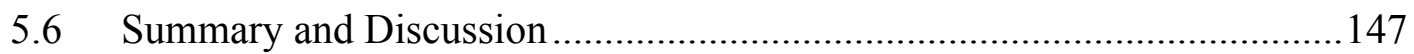

CHAPTER 6 Research Summary and Future Work............................................150

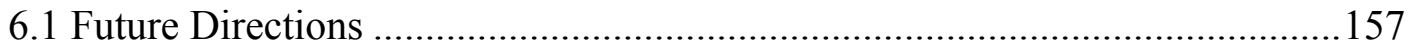

References......................................................................................................................158

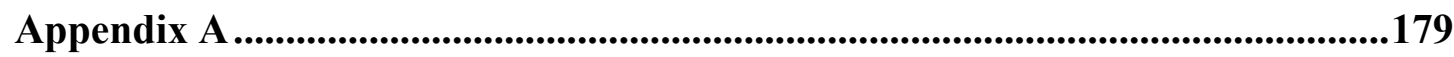




\section{LIST OF FIGURES}

Figure 1.1: Location of countries covered under Asia (Source: Cruz et al. 2007). The highlighted region represents the Central and Southwest Asia sub region, referred as Central Southwest Asia (CSWA)

Figure 1.2: Physical and economical water scarcity areas. Source: The International Water Management Institute (IWMI, 2008).

Figure 1.3: Topography $(\mathrm{km})$ of CSWA region. The high mountain ranges of the region are marked in yellow and major deserts in red.

Figure 1.4: Spatial distribution of CSWA annual mean precipitation $(\mathrm{mm})$ for the period 1950/51 - 2014/15.

Figure 1.5: Spatial distribution of CSWA seasonal mean precipitation ( $\mathrm{mm} /$ day) for the period 1950/51 - 2014/15 (a) Winter (b) Summer. ............................................. 18

Figure 1.6: The 1999-2001 drought, as measured by 12-month standardized precipitation index, calculated based on precipitation from the CPC Merged Analysis of Precipitation relative to the 1979-2010 period. (Source: Barlow et al. 2016).........20

Figure 1.7: Spatial distribution of stations underlying GPCC dataset released in Dec 2011 for the period 1951-2000, with climatological precipitation normal from 67,200 stations (Source: Schneider et al. 2014). The area enclosed within the red and green circles represent the two study regions of CSWA and the Indian Subcontinent, respectively, for which precipitation data evaluation has been performed within this thesis.

Figure 2.1: Location and topography $(\mathrm{m})$ of the Indian Subcontinent. 35

Figure 2.2: Distribution of rain gauge stations used by APHRODITE for the year 1998. GTS stations (blue), precompiled datasets (black), and data individually collected by the APHRODITE project team (red).Figure reference: Yatagai et al. (2009).

Figure 2.3: Spatial distribution of seasonal mean precipitation $(\mathrm{mm} /$ day) over the Indian Subcontinent, for each precipitation product for the period 1997/98 to 2006/07.

Figure 2.4: Mean monthly precipitation cycle ( $\mathrm{mm} /$ day) averaged over the Indian Subcontinent, for each precipitation product for the period 1997/98 to 2006/07.

Figure 2.5: Standard deviation of seasonal mean precipitation $(\mathrm{mm} /$ day) over the Indian Subcontinent, for each precipitation product for the period 1997/98 to 2006/07.

Figure 2.6: Percentage Precipitation difference (PPD) with respect to APHRODITE seasonal mean precipitation over the Indian Subcontinent for the period 1997/98 to 2006/07. 
Figure 2.7: Anomaly Correlation of seasonal mean precipitation over the Indian Subcontinent, compared to APHRODITE for the period 1997/98 to 2006/07.

Figure 2.8: Percentage Root Mean Square Error (PRMSE) with respect to APHRODITE seasonal mean precipitation over the Indian Subcontinent for the period $1997 / 98$ to $2006 / 07$.

Figure 2.9: Leading EOF of standardized seasonal mean precipitation over the Indian Subcontinent, for each precipitation product for the period 1997/98 to $2006 / 07$........55

Figure 2.10: Principal Component (PC) time series for the leading EOFs of standardized seasonal mean precipitation (a) winter, (b) pre-monsoon, (c) monsoon and (d) post-monsoon over the Indian Subcontinent for each precipitation product for the period $1997 / 98$ to $2006 / 07$.

Figure 3.1: Topography (m) of Central southwest Asia (CSWA) 65

Figure 3.2: Spatial distribution of winter (DJFMA) precipitation ( $\mathrm{mm} /$ day) over CSWA. The time period of analysis for APHRODITE, CPC-uni, CRU, GPCC, CFSR, ERA-Interim and MERRA is (1979-2007); and for 3B42-V6, 3B42-V7 and GPCP1DD is (1998-2007). The domain average mean values are given in the parentheses.

Figure 3.3: Interannual variability of winter (DJFMA) precipitation (mm/day) over CSWA. The time period of analysis for APHRODITE, CPC-uni, CRU, GPCC, CFSR, ERA-Interim and MERRA is (1979-2007); and for 3B42-V6, 3B42-V7 and GPCP1DD is (1998-2007).

Figure 3.4: Ensemble Mean of winter (DJFMA) precipitation ( $\mathrm{mm} /$ day) over CSWA: EM1 (1979-2007) is the reference ensemble mean for gauge-only/reanalysis products; and EM2 (1998-2007) is the reference ensemble mean for the satellite-derived datasets. The domain average mean values are given in the parentheses.

Figure 3.5: Spatial distribution of winter (DJFMA) mean bias (mm/day) against the corresponding reference ensemble mean (EM1/EM2) over CSWA. The time period of analysis for APHRODITE, CPC-uni, CRU, GPCC, CFSR, ERA-Interim and MERRA is (1979-2007); and for 3B42-V6, 3B42-V7 and GPCP-1DD is (1998-2007). The domain average mean values are given in the parentheses.

Figure 3.6: Spatial distribution of winter (DJFMA) root mean square error (mm/day) against the corresponding reference ensemble mean (EM1/EM2) over CSWA. The time period of analysis for APHRODITE, CPC-uni, CRU, GPCC, CFSR, ERAInterim and MERRA is (1979-2007); and for 3B42-V6, 3B42-V7 and GPCP-1DD is (1998-2007). The domain average mean values are given in the parentheses.

Figure 3.7: Spatial distribution of winter (DJFMA) temporal correlation coefficient over CSWA. The time period of analysis for APHRODITE, CPC-uni, CRU, GPCC, CFSR, ERA-Interim and MERRA is (1979-2007); and for 3B42-V6, 3B42-V7 and 
GPCP-1DD is (1998-2007). The pattern correlation values are given in the parentheses.

Figure 3.8: Interannual variation of winter (DJFMA) (a) mean bias, (b) correlation coefficient and (c) RMSE, over the CSWA. The time period of analysis for APHRODITE, CPC-uni, CRU, GPCC, CFSR, ERA-Interim and MERRA is (19792007); and for 3B42-V6, 3B42-V7 and GPCP-1DD is (1998-2007).

Figure 3.9: Scatter plots of winter (DJFMA) precipitation over CSWA, for (a) gaugeonly, (b) reanalysis and (c) satellite-derived datasets, against the corresponding reference ensemble mean (EM1/EM2).

Figure 3.10: Empirical cumulative distribution functions of winter (DJFMA) precipitation over CSWA, for (a) gauge-only, (b) reanalysis and (c) satellite-derived datasets, against the corresponding reference ensemble mean (EM1/EM2).

Figure 3.11: Spatial distribution of winter (DJFMA) precipitation anomalies (mm/day) over CSWA, expressed as a difference between El Niño and neutral years. For APHRODITE, CPC-uni, CRU, GPCC, CFSR, ERA-Interim and MERRA the El Niño and neutral years were chosen from 1979-2007; and for 3B42-V6, 3B42-V7 and GPCP-1DD the El Niño and neutral years were chosen from 1998-2007. 84

Figure 3.12: Spatial distribution of winter (DJFMA) precipitation anomalies $(\mathrm{mm} /$ day) over CSWA, expressed as a difference of La Niña and neutral years. For APHRODITE, CPC-uni, CRU, GPCC, CFSR, ERA-Interim and MERRA the La Niña and neutral years were chosen from (1979-2007); and for 3B42-V6, 3B42-V7 and GPCP-1DD the La Niña and neutral years were chosen from (1998-2007).

Figure 3.13: The ensemble mean (EM2) spatial distribution of winter (DJFMA) precipitation anomalies ( $\mathrm{mm} /$ day) over CSWA, expressed as a difference of El Niño/La Niña and neutral years. For composite analysis the El Niño/La Niña and neutral years were chosen from (1998-2007).

Figure 4.1: (a) Topography (km) of CSWA $\left(20^{\circ}-47^{\circ} \mathrm{N}, 40^{\circ}-85^{\circ} \mathrm{E}\right)$, (b) spatial distribution of winter season precipitation ( $\mathrm{mm} /$ day), and (c) percentage contribution of NDJFMA precipitation to the total annual precipitation over CSWA for 1950/51$2014 / 15$.

Figure 4.2: The spatial patterns and their corresponding normalized $\mathrm{PC}$ time series for the (a) first (EOF-1: 19\%), (b) second (EOF-2: 15\%), and (c) third (EOF-3: 10\%) EOF modes of CSWA wintertime (NDJFMA) precipitation for the period 1950/51$2014 / 15$.

Figure 4.3: Regression maps of (a) SST, (b) SLP, (c) geopotential height at 500-hPa, (d) geopotential height at $200-\mathrm{hPa}$, (e) zonal wind at $200-\mathrm{hPa}$, (f) meridional wind at $200-\mathrm{hPa}$, and (g) wind vectors at $700-\mathrm{hPa}$ onto PC1 time-series associated with EOF1 for the period 1950/51-2014/15. Solid (dashed) contours denote positive (negative) values and zero lines are omitted. The contour interval is $0.1^{\circ} \mathrm{C}$ in (a); $0.2 \mathrm{hPa}$ in (b); $3 \mathrm{~m}$ in (c); $4 \mathrm{~m}$ in (d); $0.4 \mathrm{~m} / \mathrm{s}$ in (e) and 0.3 in (f). The light and dark shadings in the 
figures $(a-f)$ indicate that the correlation coefficients are significant are significant at $\mathrm{p}<0.10$ and $\mathrm{p}<0.01$, respectively.

Figure 4.4: As in Figure 4.3, but for PC2 time-series associated with EOF-2 ........105

Figure 4.5: As in Figure 4.3, but for PC3 time-series associated with EOF-3. ........108

Figure 4.6: (a) Time series of the wintertime (NDJFMA) Niño-3.4 index and the normalized PC1 time-series associated with EOF-1 during 1950/51-2014/15. (b) Sliding correlations between Niño-3.4 index and the PC1 time-series displayed at the central year of a 17-year window. The horizontal dotted lines in (b) indicates the correlation is significant at the $10 \%(0.41)$ and $1 \%(0.61)$ confidence level.

Figure 4.7: The regression maps of ( $a$ and $b$ ) SST and (c and d) SLP onto the PC1 time series associated with EOF-1 for P1 (Figure a and c) and P2 (Figure b and d). Solid (dashed) contours denote positive (negative) values and zero lines are omitted. The contour interval is $0.1^{\circ} \mathrm{C}$ in (a), (b); and $0.2 \mathrm{hPa}$ in (c), (d). The light and dark shadings in the figures $(\mathrm{a}-\mathrm{d})$ indicate that the correlation coefficients are significant are significant at $\mathrm{p}<0.10$ and $\mathrm{p}<0.01$, respectively.

Figure 4.8: Regression maps of (a and b) geopotential height at 500-hPa and (c and d) geopotential height at 200-hPa SLP onto the PC1 time series associated with EOF-1 for P1 (Figure a and c) and P2 (Figure b and d). Solid (dashed) contours denote positive (negative) values and zero lines are omitted. The contour interval is $3 \mathrm{~m}$ in (a), (b); and $4 \mathrm{~m}$ in (c), (d). The light and dark shadings in the figures (a-d) indicate that the correlation coefficients are significant are significant at $p<0.10$ and $p<0.01$, respectively.

Figure 4.9: Regression maps of (a and b) zonal winds at 200-hPa, (c and d) meridional winds at $200-\mathrm{hPa}$, and (e and f) wind vectors at $700-\mathrm{hPa}$ onto the $\mathrm{PC} 1$ time series associated with EOF-1 for P1 (Figure a, c and e) and P2 (Figure b, d and f). Solid (dashed) contours denote positive (negative) values and zero lines are omitted. The contour interval is $0.7 \mathrm{~m} / \mathrm{s}$ in (a), (b); and $0.3 \mathrm{~m} / \mathrm{s}$ in (c), (d). The light and dark shadings in the figures $(\mathrm{a}-\mathrm{d})$ indicate that the correlation coefficients are significant are significant at $\mathrm{p}<0.10$ and $\mathrm{p}<0.01$, respectively.

Figure 4.10: The regression maps of ( $a$ and b) SST, (c and d) SLP and (e and f) geopotential height at 200-hPa onto Niño-3.4 index for P1 [1950/51-1983/84] (Figure a, c, and e) and P2 [1984/85-2014/15] (Figure b, d, and f). Solid (dashed) contours denote positive (negative) values and zero lines are omitted. The contour interval is $0.1^{\circ} \mathrm{C}$ in (a), (b); $0.2 \mathrm{hPa}$ in (c), (d); and $5 \mathrm{~m}$ in (e), (f). The light and dark shadings in the figures $(\mathrm{a}-\mathrm{f})$ indicate that the correlation coefficients are significant at $\mathrm{p}<0.10$ and

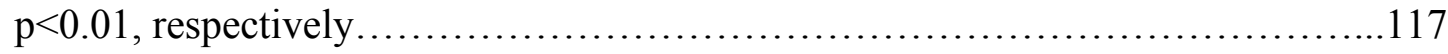

Figure 5.1:Topography $(\mathrm{km})$ of central southwest Asia (CSWA) region. 124

Figure 5.2: (a) Area-averaged winter season (November-April \{NDJFMA\}) standardized precipitation anomaly, (b) Spatial distribution of winter season precipitation ( $\mathrm{mm} /$ day), and (c) Precentage contribution of NDJFMA precipitation to the total annual precipitation over CSWA for 1950/51 - 2014/15. 
Figure 5.3: Covariance map between CSWA winter precipitation $(\mathrm{mm} /$ day $)$ and the preceding months (September-October) mean SST $\left({ }^{\circ} \mathrm{C}\right.$ ) for 1950/51 - 2014/15. Stippling indicates covariance significant at 5\% level (F-statistics).

Figure 5.4: Sliding correlation between CSWA winter precipitation anomalies and (September-October) Niño-3.4 (solid line) and NAO (dotted line) index on 17-year window. Values are plotted at the centre of each 17-year period and statistical significance at $10 \%$ and $1 \%$ confidence level is achieved by two tailed Student's t-test for correlations greater than 0.41 and 0.61 , respectively, indicated by horizontal dashed lines.

Figure 5.5: The Predictor (September-October: SSTs) and Predictand (NDJFMA: CSWA precipitation) loading patterns for CCA-Mode1 (a and b); Mode-2 (c and d); and the corresponding canonical component normalized time series (SST: dotted, Precipitation: solid) for 1950/51 - 2014/15.

Figure 5.6: The Predictor (September-October: SSTs) and Predictand (NDJFMA: CSWA precipitation) loading patterns for CCA-Mode1 (a and b); Mode-2 (c and d); and the corresponding canonical component normalized time series (SST: dotted, Precipitation: solid) for 1980/81 - 2014/15.

Figure 5.7: Standardized wintertime (NDJFMA) precipitation time series of observation and forecasts over CSWA region for 1950/51 - 2014/15 (top) and 1980/81 - 2014/15 (bottom), usin g the leave-one-out approach.

Figure 5.8: The wintertime (NDJFMA) precipitation ( $\mathrm{mm} /$ day) anomaly composites for the seven driest and wettest years in the observed (left) and SST-predicted (right) precipitation for 1980/81 - 2014/15. Stippling indicates composite anomalies significant at 5\% level....

Figure 5.9: The spatial maps for (a) Bias, (b) RMSE and (c) Anomaly correlation between the observed and SST-predicted winter precipitation over CSWA for 1980/81 - 2014/15.

Figure 5.10: Composite of SST $\left({ }^{\circ} \mathrm{C}\right)$ anomalies for (September-October) months preceding the seven driest and wettest years winter (NDJFMA) precipitation years for 1980/81 - 2014/15. Stippling indicates composite anomalies significant at 5\% level.

Figure 5.11: Wintertime (NDJFMA) wind (m s-1) anomaly composites for the seven driest and wettest precipitation years for $1980 / 81-2014 / 15$ at $300-\mathrm{hPa}$ (top); $500-\mathrm{hPa}$ (middle) and 850-hPa (bottom) level. 146 


\section{LIST OF TABLES}

Table 2.1: Main characteristics of the precipitation products examined in this study 32

Table 3.1: Main characteristics of precipitation products used in this study 66 


\section{Chapter 1 Introduction}

In the recent past, climate change has emerged as the single most pressing issue facing the society on a global basis. Since the conclusion of the Second Assessment Report (SAR) of the Intergovernmental Panel on Climate Change (IPCC, 1995) there has been increasing interest and research in attempting to understand the changes in climate systems and its impact on the environment, economies and societies all around the globe.

The two most important parameters for studying the extent and magnitude of climate change and variability are temperature and precipitation (IPCC, 2007), of which precipitation is one of the critical diagnostics of the water cycle and also a key component in hydrological modelling studies (Bosilovich et al. 2011). Integrating the past and present trends, climate variability is found to have a direct influence on precipitation, in particular, the characteristics of precipitation - amount, frequency, intensity, duration, type and extremes (Trenberth, 2011). Changes in precipitation pattern have been observed across most regions globally, and are expected to continue with an overall increase in the severity of wet and dry extremes (IPCC 2007; 2013). These changes are however expected to differ from region-to-region, eventually affecting the ecosystem, food production, water resources, human health, and the well- being of people through several mechanisms.

One such region that is already water scarce and societally vulnerable to the hydrological impacts of climate change is the Central Southwest Asia (CSWA) region (Agrawala et al. 2001; Cruz et al. 2007; Qi and Evered 2008; Carius et al. 2009; Kaniewksi et al. 2012; Hijioka et al. 2014; Barlow et al. 2016; Deng and Chen 2017; Tabari and Willems 2018).

Geographically, CSWA is a region of Asia extending from the east coast of the Black Sea to western China in the east, and from southern Kazakhstan in the north to northwest India in the south; mainly including the countries of - Afghanistan, Iran, Pakistan, Iraq, Syria, Azerbaijan, Armenia, Georgia, Bahrain, Kuwait, Oman, Qatar, Uzbekistan, Turkmenistan, Tajikistan, Kyrgyzstan, Saudi Arabia, United Arab Emirates, the arid regions of western China and northwest India (Figure 1.1). The approximate boundary or the exact list of countries that make up the CSWA region is purely conventional, and no one definition of the region has been universally 
accepted. A detailed discussion on the various definition and the geographic terms used to define this part of the world can be found in Cowan (2007).

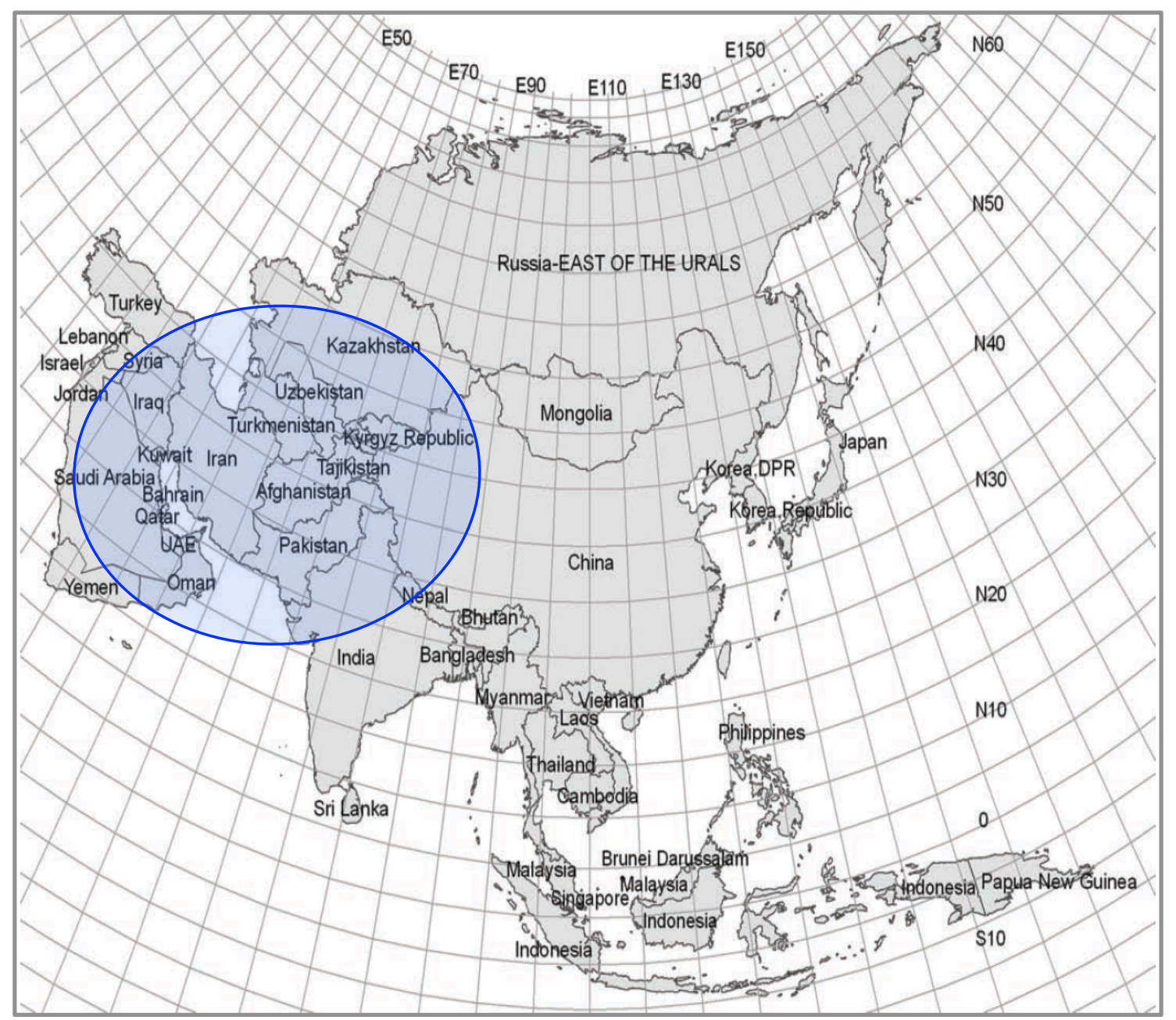

Figure 1.1: Location of countries covered under Asia (Source: Cruz et al. 2007). The highlighted region represents the Central and Southwest Asia sub region, referred as Central Southwest Asia (CSWA).

\subsection{Central Southwest Asia (CSWA) regional overview}

For the purposes of this study, CSWA - defined here as a domain bounded by $20^{\circ}-47^{\circ} \mathrm{N}$ and $40^{\circ}-85^{\circ} \mathrm{E}$ is a relatively broad region associated with generally similar climatic conditions (Huang et al. 2012; Barlow et al. 2016). Characterised by a semiarid to arid climate, CSWA is physiographically diverse and ecologically rich in biodiversity. The region's complex ecology and unique geography featuring vast deserts, high mountains, grasslands, glaciers, and river basins, gives way to a diverse ecosystem that is rich in natural resources and hydrocarbon reserves. These reserves, 
for some of the countries of the CSWA region, have been a foundation of their economic growth both as a source of export revenue and for meeting domestic energy requirements.

With the region's high level of natural resource dependency and rapid economic development over the past few decades, over-exploitation of land resources without consideration of the environmental consequences has led to an extensive humaninduced natural resource degradation, conflicts and ecological catastrophe within the CSWA region (Carius et al. 2009; Novikov and Kelly 2017). Within this fragile ecosystem, where environmental sustainability and political stability are already under stress, one of the major growing concerns across the entire region is related to water scarcity and stress (Cruz et al. 2007; Thomas 2008; Fricke et al. 2009; Lioubimtseva and Henebry 2009; Bernauer and Siegfried 2012; Zyadin 2013; Karthe et al. 2015; Reyer et al. 2015; Mohtar et al. 2017).

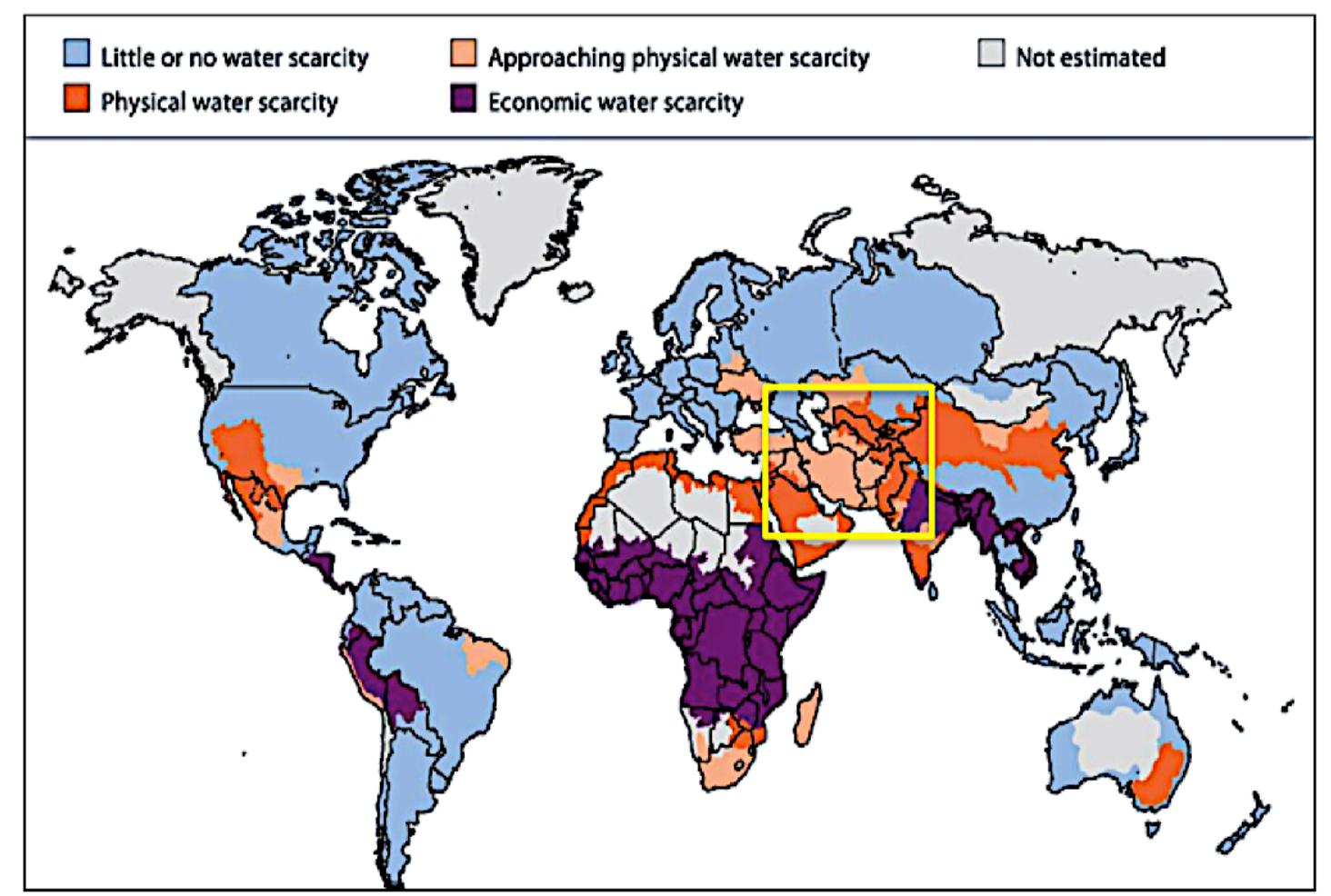

Figure 1.2: Physical and economical water scarcity areas. Source: The International Water Management Institute (IWMI, 2008).

Figure 1.2 shows that a large part of CSWA is experiencing physical water scarcity, where more than $75 \%$ of the river runoff is being used for agriculture, industrial, and domestic purposes (IWMI, 2008). It is expected that the existing 
pressure on the region's water resources will increase substantially over time due to rise in anthropogenic water demands and the projected changes in the regional climatic means and extremes.

The direct effect of climate variability across CSWA is associated with a steady rise in temperature throughout the region (Zhang et al. 2005; Almazroui et al. 2013; Hu et al. 2014; Davi et al. 2015, Chen et al. 2016; Jiang et al. 2017), while the indirect impact is related to the enhanced variability of the regional precipitation regime (Lioubimtseva et al. 2005; Droogers et al. 2012; Lelieveld et al. 2012; Mannig et al. 2013; Huang et al. 2014; Bucchignani et al. 2018). At the regional scale, the year-toyear and long-period variability of these climatic drivers, in particular precipitation, is expected to have a potentially critical impacts on the region's water resources, agriculture, industrial activities and people's wellbeing (El-Fadel and Bou-Zeid 2001; Oki and Kanae 2006; Lioubimtseva and Henebry 2009; Bates et al. 2008; Wegerich 2011; Droogers et al. 2012; Karthe et al. 2015; Deng and Cheng 2017).

Both observational and modelling studies over CSWA agree that in comparison to temperature trends and projections, changes in regional precipitation pattern are relatively uncertain and exhibit a high degree of spatial and seasonal dependence (Lioubimtseva and Henebry 2009; Mannig et al. 2013; Hijioka et al. 2014; Hung et al. 2014; Tabari and Willems 2018). However, despite the uncertainty, a majority of climate change studies suggest a decrease in the spring and summer precipitation over Iraq, Iran, Afghanistan, Arabian Peninsula, Pakistan, Turkmenistan, Uzbekistan, southwestern Kazakhstan, and the northern parts of India; while an increase has been observed and projected for winter precipitation in the eastern and northern parts of Central Asia, northern Pakistan, the Hindu-Kush Karakoram Himalayas, Iraq, Iran and throughout the Arab region (Watson et al. 1998; Lioubimtseva and Henebry 2009; Roshana and Grab 2012; Mannig et al. 2013; Palazzi et al. 2013; Hartmann and Buchanan 2014; Hung et al. 2014; Amin et al. 2017; Osman et al. 2016; Ozturk et al. 2017; Bucchignani et al. 2018).

\subsection{Regional precipitation distribution and seasonality}

As shown in Figure 1.3, CSWA is a region of complex topography with high mountain ranges (e.g. the Alborz, the Zagros, the Hindu Kush, the Pamirs, the Karakoram and the Himalayas) and vast deserts (e.g. the Arabian desert, the Iranian 
salt deserts, the Thar desert, the Kyzylkum desert and Taklamakan desert). The elevation ranges from less than $0.5 \mathrm{~km}$ in the flat low-level plains to greater than $6 \mathrm{~km}$ in the high mountain ranges of the region. This topographical heterogeneity of the region plays an important role in shaping the climate characteristics of the region and profoundly controls the spatial distribution and seasonality of precipitation across CSWA (Barlow et al. 2016; Rana et al. 2015, 2017).

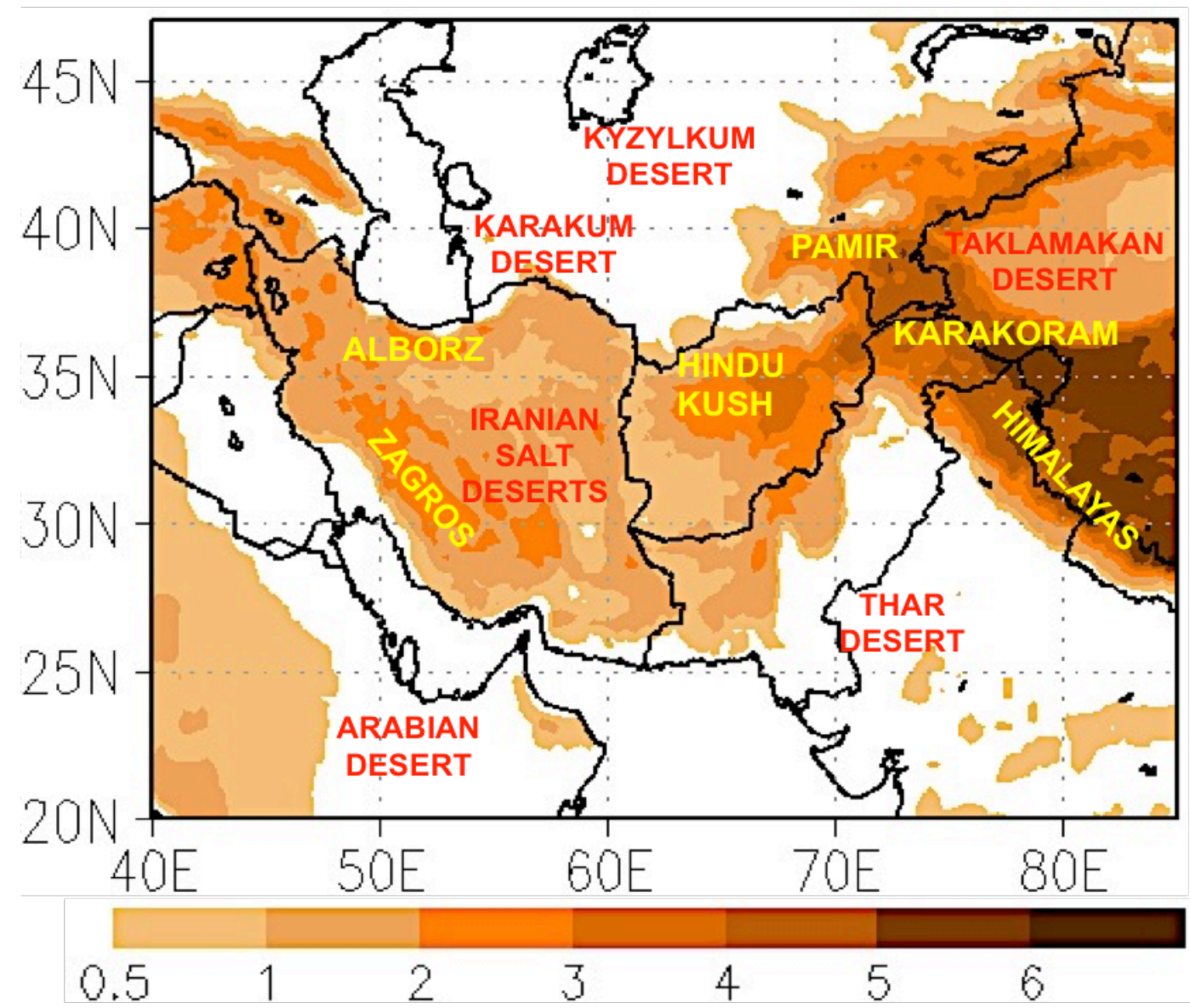

Figure 1.3: Topography $(\mathrm{km})$ of CSWA region. The high mountain ranges of the region are marked in yellow and major deserts in red.

As one of the most arid regions in the world (Cruz et al. 2007; Guo et al. 2018) the annual mean precipitation (Figure 1.4) amounts to $120 \mathrm{~mm}$ or less in the arid deserts of CSWA. This amount increases to $200-700 \mathrm{~mm}$ in the low elevation and foothill areas, and further exceeds $1200 \mathrm{~mm}$ in the western slopes of the high mountainous ranges and along the southern (eastern) shores of the Caspian (Black) Sea. 


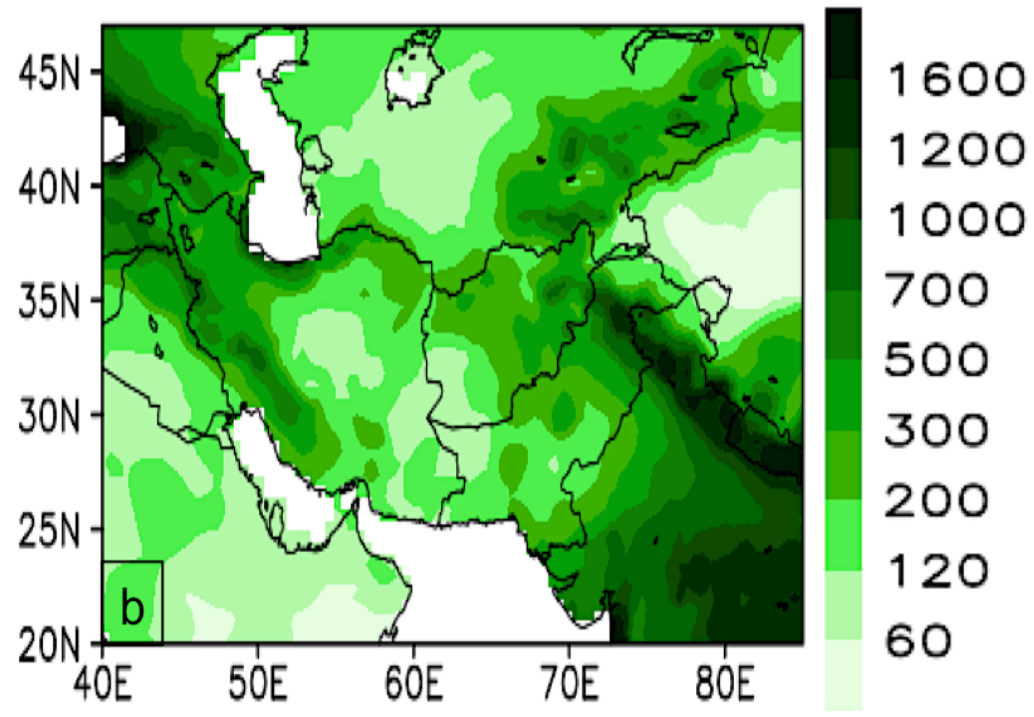

Figure 1.4: Spatial distribution of CSWA annual mean precipitation (mm) for the period 1950/51 - 2014/15.

Contributing to the region's annual precipitation totals, the two main seasonal precipitation mechanisms influencing CSWA are the cold winter and early spring season November-April (NDJFMA) synoptic precipitation, and the Indian summer June-September (JJAS) monsoon rainfall (Lioubimtseva and Henebry 2009; Rana et al. 2015; Barlow et al., 2016) shown in Figure 1.5(a) and Figure 1.5(b), respectively.

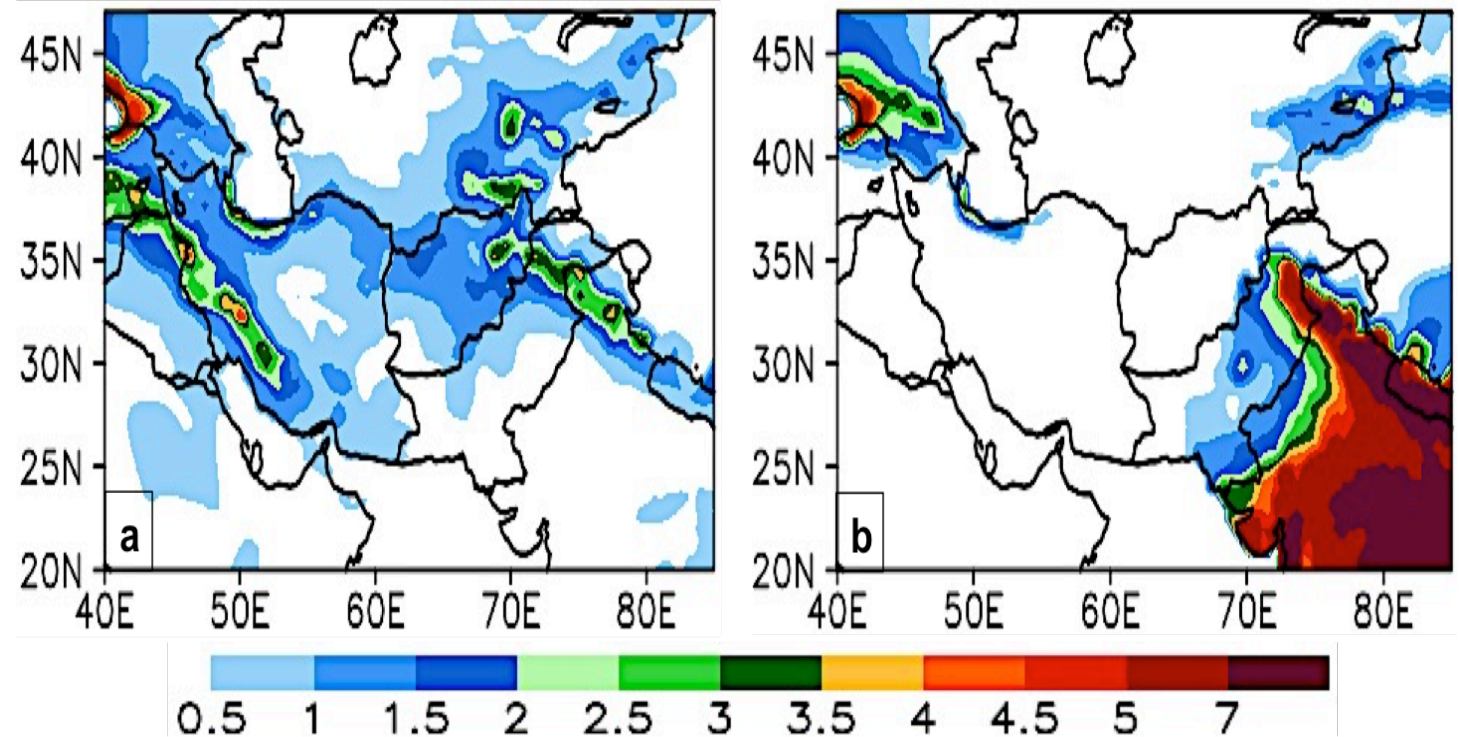

Figure 1.5: Spatial distribution of CSWA seasonal mean precipitation ( $\mathrm{mm} /$ day) for the period 1950/51 - 2014/15 (a) Winter (b) Summer. 
Precipitation over much of the CSWA region primarily occurs during the winter and early spring months of November-April (November-April) when the region is within the subtropical belt of the upper-tropospheric westerly jet stream (Krishnamurti 1961). The intensification and southward excursions of the subtropical westerly jet bring the moisture-bearing mid-latitude synoptic storms into CSWA and generate precipitation via upslope lifting (Cannon et al. 2016; Barlow et al. 2016). This wintertime precipitation displays a high degree of spatial coherence throughout the entire domain (Hoell et al. 2015a). During the summer (JJAS) months, however, the Himalayas play a critical role in confining much of the monsoonal rainfall within the Indian landmass to as far as Pakistan in the north. As a result, the western and the northern flanks of the CSWA domain are beyond the usual reach of the summer monsoon rainfall, with little to no precipitation during the warm summer months.

\subsection{Winter precipitation and its variability}

During the winter months of November-April (NDJFMA), CSWA receives a significant amount of the total annual precipitation due to the passage of the midlatitude synoptic storms systems that travel in the form of waves from west to east (Treydte et al., 2006). As these depressions traverse eastwards, they pass through a dense upper-air observing array over Europe, the Middle East, the Black Sea and the Caspian Sea regions (Sachar et al. 2004) modifying the regional circulation pattern and producing precipitation over a large part of the CSWA region (Barlow et al. 2005; Cannon et al. 2015; Rana et al. 2017).

Winter precipitation is of considerable importance for CSWA, as it brings a lot of snow over the high mountain ranges, which accumulates in glaciers and as seasonal snowpack throughout the cold months, and provides water in the downstream densely populated areas of the region (Aizen et al. 1997; Immerzeel et al. 2010; Sorg et al. 2012; Karthe et al. 2015). The glacier and snowmelt is an important source of water during the peak summer season, which happens to coincide with the time of year when the regional water demand is highest, and precipitation is limited. In addition to snow, winter rainfall in the sub-mountainous and low elevation areas is crucial for the region's widespread rain-fed subsistence farming, industrial needs, and livelihood (Ramankutty et al. 2008; Ryan et al. 2012; Reyer et al. 2015). 
Previous work shows that CSWA's winter precipitation variability has an important control on the regional water resources, agricultural productivity and human society (Agrawala et al. 2001; Barlow and Tippett 2008; Kaniewksi et al. 2012; Lioubimtseva 2015). Interannual variability of wintertime precipitation is relatively large and includes periods of severe droughts in many parts of the CSWA region (Tippett et al. 2003; Lioubimtseva and Henebry 2009; Barlow et al. 2002; 2016; Hoell et al.2015a; Rana et al. 2018). For example, CSWA has experienced two catastrophic droughts in 1999-2001 (see Figure 1.6) (Barlow et al. 2002; 2016; Hoerling and Kumar 2003) and 2007-2008 (Trigo et al. 2010; Hoell et al. 2012; Kaniewksi et al. 2012), embedded within a decade of predominantly dry wintertime conditions (Hoell and Funk 2014; Lyon et al. 2014). The clustering of these regional droughts has amply demonstrated the very high human vulnerability of CSWA to precipitation deficits by adversely affecting the region's water supplies, crops, food supplies, livestock, and quality of life, further resulting in large population migration and political (Agrawala et al. 2001; Gall 2008; Lioubimtseva 2015). In addition, a number of local drought disasters have also been identified in the literature, but the dynamics of most of those droughts and their regional coherence is not yet clear (Barlow et al. 2016).

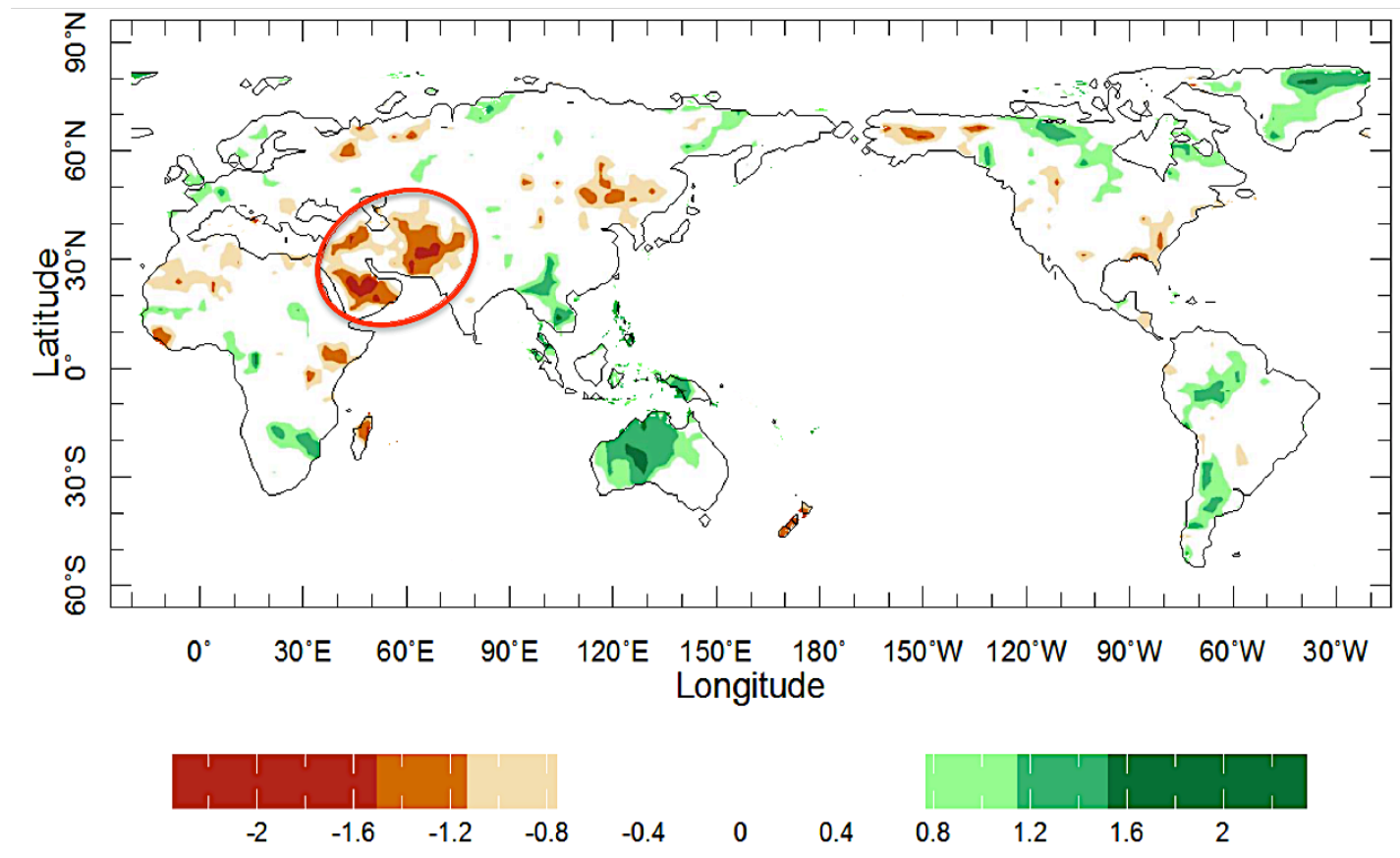

Figure 1.6: The 1999-2001 drought, as measured by 12-month standardized precipitation index, calculated based on precipitation from the CPC Merged Analysis of Precipitation relative to the 1979-2010 period. (Source: Barlow et al. 2016) 
It has been identified that one of the most dominant perturbations responsible for CSWA year-to-year wintertime precipitation variability is related to the El NiñoSouthern Oscillation (ENSO) (Barlow et al. 2002; Hoerling and Kumar 2003; Mariotti 2007; Syed et al. 2006; 2009; Barlow and Tippett 2008; Hoell and Funk 2013; Hoell et al. 2012; 2013; 2017; Yin et al. 2014; Cannon et al. 2017; Rana et al. 2017). Additionally, other modes of variability such as the North Atlantic Oscillation (NAO) (Cullen et al. 2002; Filippi et al. 2014; Kar and Rana 2014), the east Atlanticwestern Russia (EAWR) pattern (Yin et al. 2014; Krichak et al. 2014), the Siberian High (Lioubimtseva and Henebry 2009; Cannon et al. 2015); the Scandinavian pattern (Bothe et al. 2012); the Madden-Julian Oscillation (MJO) (Barlow et al. 2005; Nazemosadat and Ghaedamini 2010; Hoell et al. 2012), Pacific decadal variability (PDV), and long-term change in global sea surface temperatures (Hoell et al. 2015b; Rana et al. 2018) have also been linked to CSWA precipitation variations at various time scales.

As cited above, numerous observational and model analysis studies have investigated the impact of ENSO on the CSWA's winter precipitation variability. In all of these studies, there is a general agreement that the anomalous warming in the equatorial eastern (western) Pacific Ocean associated with El Niño (La Niña) conditions force stronger region-wide cyclonic (anticyclonic) circulations with southwesterly (northeasterly) winds and moisture fluxes from the Arabian Sea (Tibetan Plateau) that increases (reduces) the regional precipitation over CSWA. Here the teleconnection mechanism connecting the tropical Pacific sea surface temperature (SST) variability to CSWA precipitation modification is through the changes in the mean position and intensity of the jet stream while shifting it slightly southward (northward) during the warm (cold) ENSO phase (Syed et al. 2006; Kumar and Ouarda 2014; Cannon et al. 2017).

The Pacific decadal sea surface temperature (SST) variability has also been linked to the CSWA winter precipitation variations (Lyon et al. 2014; Hoell et al. 2015b; Rana et al. 2018) indicating that from 1999 onward a cold phase change of PDO occurred, which was in line with the increased frequency of La Niña events and recurrent drought episodes over CSWA. In a more recent study, Hoell et al. (2017) noted that the intensification of the wintertime ENSO signal on CSWA's precipitation variations is linked with the changes in the strength of the temporal relationship between the two, which varied throughout time (1901 to 2012) and was strongest after 
the 1980s. Consistent with the above, Rana et al. (2018) showed that the influence of springtime ENSO (NAO) on CSWA winter precipitation strengthened to (weakened from) a statistically significant level around the early 1980s and continued to increase (decrease) thereafter.

While the impact of NAO on CSWA winter season precipitation is not as significant as the ENSO, there are indications that the strong positive phase of NAO was one of the important factors responsible for the recent (2013-2014) drought over CSWA (Barlow and Hoell 2015). Studies have shown that positive (negative) NAO phase is associated with more meridional (zonal) surface winds and storm tracks in the North Atlantic sector, resulting in cool/dry (warm/wet) winters in the Mediterranean region further extending into the Middle East and parts of CSWA (Cullen and deMenocal 2000; Aizen et al. 2001; Filippi et al. 2014). Additionally, Yin et al. (2014) noted that the negative (positive) phase of EAWR contributes towards reduced (enhanced) precipitation activity over CSWA by modulating the midtropospheric westerly flow over the CSWA region. Variations in the Siberian High intensity also play a significant role in controlling the moisture transport into the CSWA region. A strengthened Siberian High tends to push the mid-latitude westerlies further south, resulting in comparably drier (wetter) conditions in the north (south) areas of the CSWA region (Wolff et al. 2017).

Given CSWA's propensity for drought and marked variations in wintertime precipitation, the above relationships are of considerable value and an important basis for improving the predictability of regional precipitation and, ultimately, droughts. However, the sparseness of observed precipitation data across CSWA region makes assessing the long-term stability of these linkages particularly challenging; as a result of which predictability of precipitation in this region has not yet been well established (Barlow et al. 2016).

\subsection{Challenges and opportunity}

CSWA is a region with sparse observational network and complex topography (Schiemann et al. 2008; Becker et al. 2013; Mannig et al. 2013; Karthe et al. 2015; Barlow et al. 2016). In situ meteorological stations are extremely uneven in many parts of the region, and the number of monitoring stations decline considerably with increased elevation and remoteness (Cannon et al. 2015). Figure 1.7 shows the station 
data availability underlying the Global Precipitation Climatology Centre (GPCC) precipitation climatology data released in Dec 2011, for the period 1951-2000.

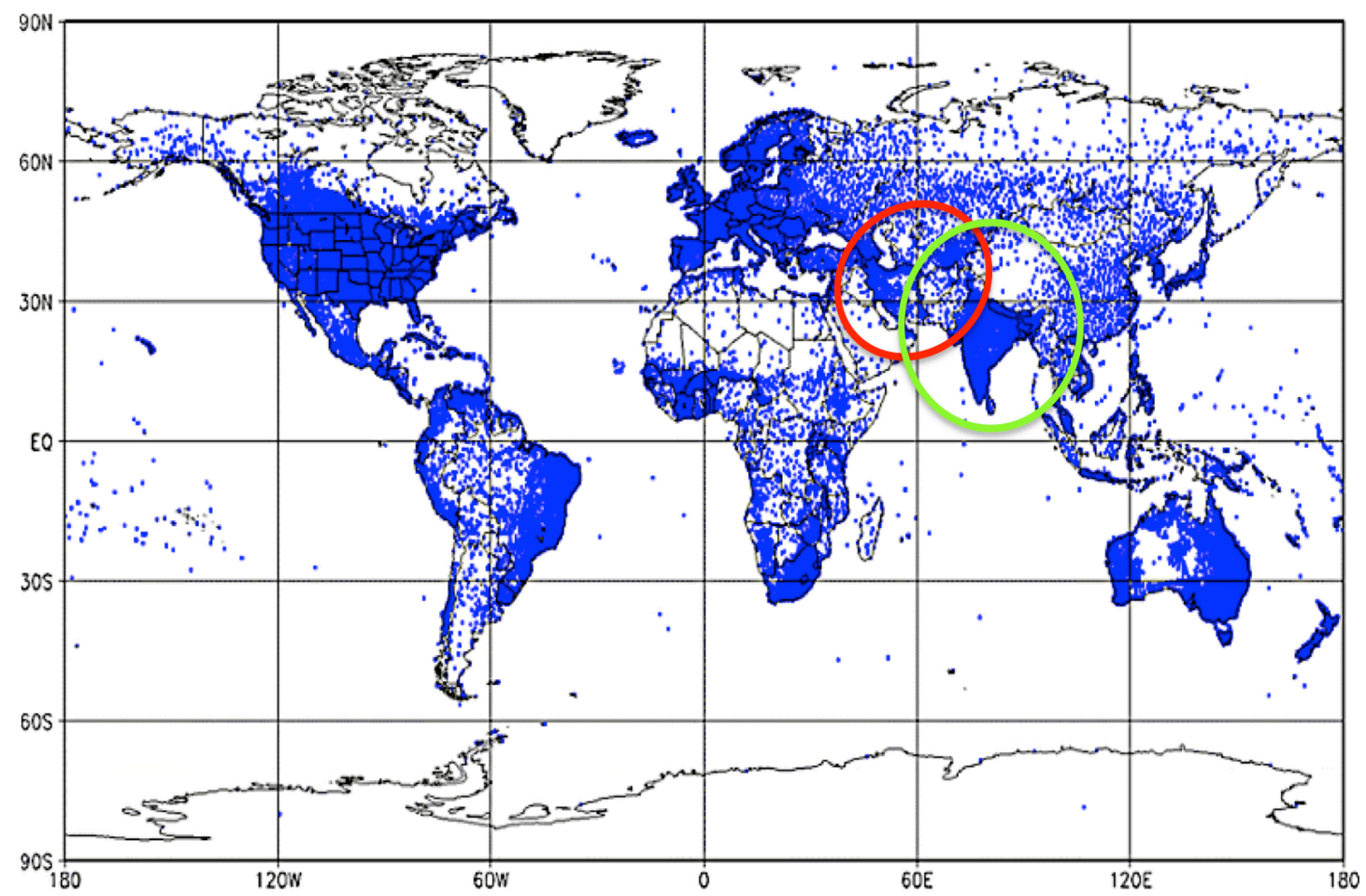

Figure 1.7: Spatial distribution of stations underlying GPCC dataset released in Dec 2011 for the period 1951-2000, with climatological precipitation normal from 67,200 stations (Source: Schneider et al. 2014). The area enclosed within the red and green circles represent the two study regions of CSWA and the Indian Subcontinent, respectively, for which precipitation data evaluation has been performed within this thesis.

Because of the spatial and temporal inhomogeneity of precipitation observations over CSWA, regional analysis of precipitation has been largely limited (Barlow et al. 2016; Hoell et al. 2015b; 2017). Greater uncertainty exists in the region's historical trends and future projections of precipitation changes (Fowler and Archer 2006; Zhang et al. 2005; Lioubimtseva and Cole 2006; Christensen et al. 2007; Mannig et al. 2013; Pallazi et al. 2013; Huang et al. 2014; Barlow et al. 2016; Tabari and Willems 2018) with apparent discrepancies between previous studies due to the precipitation data sets used ( $\mathrm{Li}$ et al. 2017). Owing to the data limitations, some 
studies either excluded the arid regions of CSWA (Yohe et al. 2006; Russo and Sterl 2012) or focused on specific subareas of the domain and/or on a shorter analysis period (e.g. Mann et al. 2002; Zhang et al. 2005; Anders et al 2006; Syed et al 2006; Nazemosadat and Ghaedamini 2010; AlSarmi and Washington 2011; Pallazi et al. 2013; Kar and Rana 2014; Cannon et al. 2017; Iqbal and Athar 2017; and others). As a result, up to now the full exploitation of the huge amount of information that exists for this sensitive region has not been thoroughly explored; thereby creating a gap in our understanding of the regional precipitation climate and its variability.

The recent development in the emergence of regional and global precipitation products at high spatial and temporal resolution has resulted in the availability of uninterrupted precipitation records that are highly useful over data-sparse or ungauged remote locations, where surface measurements have been difficult. These precipitation estimates from multiple sources: gauge, satellite and numerical weather models give us a unique opportunity to closely investigate spatial and temporal precipitation trend/patterns at the global, regional and local scale. More importantly for the CSWA region as a whole, a comprehensive analysis of the available precipitation datasets has not been performed previously (Barlow et al. 2016).

At this point it has become increasingly clear that an improved understanding of CSWA's wintertime precipitation climate is of high importance; however, it is worth mentioning that the preliminary study that motivated the analyses on CSWA presented in this thesis was carried out on the neighbouring region of the Indian Subcontinent (encircled in green in Figure 1.7). From this study, one of the most important results that emerged was the outstanding issue of observational data scarcity and the related knowledge gap in our understanding of the wintertime precipitation climate over the northwestern extent of the Indian Subcontinent. The above-raised research questions warranted further investigation at the sub-regional scale, and this led to a new line of inquiry into the less explored northwestern sector of the Indian Subcontinent, referred to as CSWA in this thesis. As seen in Figure 1.7, the relatively large CSWA domain, which includes the immediate surrounding northwestern region of the Indian Subcontinent is selected for further analysis because in this region both the monthly and seasonal wintertime spatial precipitation patterns displayed a high degree of coherence. 


\subsection{Research goals}

This thesis is designed to explore some of the research gaps highlighted in the previous literature, and contribute to a better understanding of CSWA's wintertime precipitation climate by focussing on the following three goals:

1) Assess the performance, and provide useful insights on the reliability and usability of some of the widely used gridded precipitation data sets for Central Southwest Asia (CSWA) and the neighbouring Indian subcontinent.

2) Perform an in-depth analysis of the long-term spatial and temporal variability of CSWA's wintertime precipitation.

3) Develop a statistical forecast model for the seasonal prediction of wintertime precipitation anomalies over the CSWA region.

\subsection{Thesis Outline}

Chapters 2, 3, 4 and 5 of this thesis are written as independent manuscripts for publication. To date (September 2018), Chapter 2 has been published in the Journal of Hydrometeorology (Rana et al. 2015). Chapter 3 has been published in the International Journal of Climatology (Rana et al. 2017), Chapter 5 has been published in the Journal of Climate (Rana et al. 2018), and the most recent work, Chapter 4, is published in Climate Dynamics (Rana et al. 2019).

1) Chapter 2 presents a comprehensive review of some of the widely used and freely available gridded precipitation data sets generated from different data sources - gauge observations, satellite-derived data, and reanalyses estimates over the Indian Subcontinent. As mentioned above, this work is not strictly confined to the CSWA domain but is a highly relevant contribution that provides the first seasonal (winter, pre-monsoon, monsoon, and post-monsoon) assessment of precipitation products over the Indian Subcontinent. Apparently, in the case of Indian Subcontinent, most studies have focused their analysis on the Indian summer monsoon rainfall 
and its variability, with considerably less attention given to other seasons/regions. Therefore, one of the key highlights of the results discussed in Chapter 2 is that it helped to identify the large amount of uncertainty that exists in precipitation estimates over the northwestern regions of the Indian Subcontinent, where precipitation occurs primarily during the winter months. It is for this reason that a detailed comparison of various precipitation estimates and an in-depth investigation focusing on the variability and predictability CSWA's wintertime precipitation climate has been performed in the subsequent chapters of this thesis.

2) Chapter 3 builds directly on the findings presented in Chapter 2, with a focus on the immediate surrounding CSWA region. Given the complex topography and poor spatial coverage of the observational network over CSWA, this work closely assesses the capabilities and limitations of multiple precipitation datasets over the study region both geographically and temporally. The results presented in this study provide the necessary guidance to the choice of a preferable precipitation dataset for long-term climatological analysis of precipitation in the CSWA region.

3) Chapter 4 focuses on a more detailed understanding of the long-term spatial-temporal variability of CSWA winter precipitation by identifying the dominant modes of the seasonal precipitation variability and associated relationships with large-scale atmospheric and oceanic flow patterns and mechanisms.

4) Chapter 5 is based on the development of a statistical prediction model for CSWA winter precipitation on a seasonal timescale, using the lead-lag relationship between the predictor and predictand fields.

5) Chapter 6 provides a summary of the research findings and proposes suggestions for future research. 


\section{A NOTE TO THE READER}

This thesis incorporates several manuscripts written for publication in scientific journals, which are presented here as a series of separate chapters. Each Chapter (2 to 5) encompasses a complete scientific manuscript, including abstract, introduction, material and methods, results, and summary/conclusions. At the end of each chapter, the findings of that particular study are summarized. As these are stand-alone works, the reader should expect a certain amount of content repetition in the introductory section including the study region, motivation, and some of the datasets used. 


\section{Chapter 2 Precipitation Seasonality over the Indian Subcontinent: An Evaluation of Gauge, Reanalyses, and Satellite Retrievals}

Published in the Journal of Hydrometeorology (Rana et al. 2015)

\section{CITATION}

Rana, S., J. McGregor, and J. Renwick, 2015: Precipitation Seasonality over the Indian Subcontinent: An Evaluation of Gauge, Reanalyses, and Satellite Retrievals. J. Hydrometeor., 16, 631-651, https://doi.org/10.1175/JHM-D-14-0106.1

Authorship contributions to this research article include the following:

Sapna Rana - Wrote the manuscript and managed all co-author feedback, reviewer comments, and editing of proofs. This author collated and processed all data, developed initial interpretations, and produced all figures.

James McGregor - Academic Supervisor; provided feedback on drafts and aided in the interpretation of the results and text edits. Helped to outline the discussion and result section of the manuscript.

James Renwick - Academic Supervisor; provided feedback on drafts and aided in the interpretation of the results and text edits. 


\subsection{Abstract}

This study investigates the seasonal (winter, premonsoon, monsoon, and postmonsoon) precipitation climate and variability over the Indian subcontinent, using seven recent, high-quality, well-documented precipitation products from three different sources: gridded station data, satellite-derived data, and reanalyses for a period of 10 years (1997/98-2006/07). The study employs several verification methods to determine consistency and reliability associated with each precipitation product, in terms of availability, resolution, accuracy, retrieval technique, and quality control. The evaluated precipitation products are the Asian Precipitation-HighlyResolved Observational Data Integration Towards Evaluation of the Water Resources (APHRODITE), the Climate Prediction Center unified (CPC-uni), the Global Precipitation Climatology Project (GPCP), the Tropical Rainfall Measuring Mission (TRMM) post-real-time research products (3B42-V6 and 3B42-V7), the Climate Forecast System Reanalysis (CFSR), and the European Centre for Medium-Range Weather Forecasts (ECMWF) interim reanalysis (ERA-Interim). The results are mainly presented in the form of maps that highlight the key characteristics and regional differences associated with particular precipitation products over the study region. All datasets capture the large-scale characteristics of the seasonal mean precipitation distribution, albeit with pronounced seasonal and/or regional differences. Compared to APHRODITE, the gauge-only (CPC-uni) and the satellite-derived precipitation products (GPCP, 3B42-V6, and 3B42-V7) capture the summer monsoon rainfall variability better than CFSR and ERA-Interim. Similar conclusions are drawn for the postmonsoon season, with the exception of 3B42-V7, which underestimates postmonsoon precipitation. Over mountainous regions, 3B42-V7 shows an appreciable improvement over 3B42-V6 and other gauge-based precipitation products. Significantly large biases/errors occur during the winter months, which are likely related to the uncertainty in observations that artificially inflate the existing error in reanalyses and satellite retrievals.

\subsection{Introduction}

There is growing evidence that the statistical characteristics of precipitation are changing at several places around the globe (Brunetti et al. 2001; Goswami et al. 2006; Trenberth 2011; Wang and Ding 2006; Yao et al. 2012). To understand the 
extent of these changes, accurate and timely knowledge of the space-time variability of precipitation is essential. Rain gauges provide direct and accurate point measurements of precipitation over land and are often the most used and trusted source of information for hydrological studies. However, one of the major shortcomings of gauge measurements is that they do not provide complete areal coverage and are often sparse or nonexistent in remote or politically unstable regions of the world. In addition, it is well known that gauge measurements are also prone to several sources of systematic and random error (Sevruk 1985; Kuligowski 1997). Given the importance of gauge-based precipitation estimates as "ground truth" for other products, significant progress has been made to develop and construct gridded global and regional gauge-based precipitation analyses.

Satellite-derived precipitation products have been developed that fill some of the data gaps by providing more spatially homogeneous and temporally complete coverage over large areas of ocean and land (Yilmaz et al. 2005; Dinku et al. 2007; Kucera et al. 2013). However, the accuracy of these products is limited, largely because they are derived from other observables (i.e., cloud-top reflectance or thermal radiance; Richards and Arkin 1981; Petty and Krajewski 1996). Satellite products can also suffer from various discontinuities between different platforms and instruments and are not available before the 1970s. Recently, various "merged" satellite and gauge analyses have been assembled that maximise (and minimise) the relative benefits (and shortcomings) of each data type (New et al. 2001).

Spatially homogeneous and temporally continuous precipitation estimates are also available from the reanalysis systems that use advanced data assimilation techniques to merge estimates from global circulation models with observations. Reanalysis products are widely used in climate research, even though the products are known to have biases, particularly in the estimation of precipitation (Ma et al. 2009; Lorenz and Kunstmann 2012).

In spite of their shortcomings, satellite-derived and reanalysis precipitation products offer an exciting opportunity to better understand the characteristics and variability of precipitation throughout the globe. However, before this potential can be fully realised, we need to validate these datasets and gain a better understanding of their inherent biases (Bosilovich et al. 2013; Turk et al. 2008). Intercomparisons of satellite-derived datasets and reanalyses with gauge observations have been used to assess the reliability of precipitation products at individual sites and for specific 
regions (Bosilovich et al. 2008; Ebert et al. 2007; Joshi et al. 2012; Kidd et al. 2012; Ma et al. 2009; Palazzi et al. 2013; Rahman et al. 2009; Shah and Mishra 2014; Shen et al. 2010). They showed that the performance of reanalyses and satellitebased precipitation estimates vary for different regions and for different precipitation regimes. In general, reanalyses showed greatest skill during winter seasons while satellite estimates were best over wet regions and for warm seasons.

Previous studies of precipitation over the Indian subcontinent have focused on the genesis, dynamics, diagnostics, and predictability of precipitation and have put most emphasis on the Indian summer monsoon rainfall (ISMR; Krishnamurthy and Shukla 2000; Goswami and Ajaya Mohan 2001; Mishra et al. 2012; Turner and Annamalai 2012). Far less effort has focused on pre- and postmonsoon precipitation in spite of its importance to water resources, agriculture, and livelihoods in the northwestern/Himalayan and southern peninsular regions of the subcontinent (Immerzeel et al. 2009; Bookhagen and Burbank 2010). The magnitude and mechanistic explanation of precipitation and its variability during these seasons and/or regions remains unclear and poorly investigated (Kripalani and Kumar 2004; Sen Roy 2006; Rajeevan et al. 2012; Kar and Rana 2013).

In this study, we investigate the seasonal (winter, premonsoon, monsoon, and postmonsoon) precipitation climate and variability over the Indian subcontinent, using seven recent, high-quality, well-documented precipitation products from three different sources: gridded station data, satellite-derived data, and reanalyses. The study employs several verification methods to determine consistency and reliability associated with each precipitation product, in terms of availability, resolution, accuracy, retrieval technique, and quality control.

The main goals of this study are to 1) provide an intercomparison of the various precipitation datasets over our study region, 2) provide insights into data reliability and usability for a region that contains subregions that are not well provisioned by rain gauges, and 3) examine precipitation and its variability for all seasons throughout the year.

The results are mainly presented in the form of maps that highlight the key characteristics and regional differences associated with particular precipitation products. The work is organized as follows: Section 2.3 describes the datasets used, with a brief description of methodology and choice of reference dataset; section 2.4 
outlines the results and discussion, followed by the summary and conclusions in section 2.5 .

\subsection{Materials and Methods}

The main characteristics of the datasets used in this study are shown in Table 2.1.The basic selection criteria are based on spatial coverage over the study region, spatial resolution, and temporal availability.

Table 2.1: Main characteristics of the precipitation products examined in this study

\begin{tabular}{|c|c|c|c|c|c|c|}
\hline Datasets used & Product & Format & Unit & $\begin{array}{l}\text { Spatial } \\
\text { Domain }\end{array}$ & $\begin{array}{l}\text { Spatial Resolution } \\
\text { used }\end{array}$ & $\begin{array}{c}\text { Temporal Domain } \\
\text { used }\end{array}$ \\
\hline APHRODITE & $\begin{array}{l}\text { APHRO_V1101 } \\
\text { (Monsoon Asia) }\end{array}$ & NetCDF & $\mathrm{mm} /$ day & $\begin{array}{c}\text { Land } \\
60^{\circ} \mathrm{E}-150^{\circ} \mathrm{E} \\
15^{\circ} \mathrm{S}-55^{\circ} \mathrm{N}\end{array}$ & $0.5^{\circ}$ (Lat-Lon) & $\begin{array}{c}\text { Daily } \\
(1951-2007)\end{array}$ \\
\hline CPC-UNI & V1.0 & Binary & $\mathrm{mm} /$ day & Land-Global & $0.5^{\circ}$ (Lat-Lon) & Daily (1979-2010) \\
\hline GPCP & V1.2 & Binary & $\mathrm{mm} / \mathrm{day}$ & Global & $1^{\circ}$ (Lat-Lon) & $\begin{array}{c}\text { Daily } \\
(10 / 1996-2010)\end{array}$ \\
\hline 3B42-V6 & $\begin{array}{l}\text { (Research } \\
\text { Product) }\end{array}$ & Binary & $\mathrm{mm} / 3 \mathrm{hr}$ & $\begin{array}{c}\text { Tropics } \\
50^{\circ} \mathrm{S}-50^{\circ} \mathrm{N}\end{array}$ & $0.25^{\circ}$ (Lat-Lon) & $\begin{array}{c}3 \text { hourly } \\
(1998-2010)\end{array}$ \\
\hline $3 \mathrm{~B} 42-\mathrm{V} 7$ & $\begin{array}{l}\text { (Research } \\
\text { Product) }\end{array}$ & Binary & $\mathrm{mm} / 3 \mathrm{hr}$ & $\begin{array}{c}\text { Tropics } \\
50^{\circ} \mathrm{S}-50^{\circ} \mathrm{N}\end{array}$ & $0.25^{\circ}$ (Lat-Lon) & $\begin{array}{c}3 \text { hourly } \\
(1998-2010)\end{array}$ \\
\hline ERA-INTERIM & Reanalysis & Grib1 & $\mathrm{m}$ & Global & $\begin{array}{c}\mathrm{T} 255(\sim 79 \mathrm{~km}) \\
1.5^{\circ} \times 1.5^{\circ}\end{array}$ & Daily (1979-2010) \\
\hline CFSR & Reanalysis & Grib2 & $\mathrm{Kg} / \mathrm{m}^{-2} / \mathrm{s}^{-1}$ & Global & $\begin{array}{c}\mathrm{T} 382(\sim 38 \mathrm{~km}) \\
0.313^{\circ} \times 0.313^{\circ}\end{array}$ & Daily (1979-2010) \\
\hline
\end{tabular}

1. Asian Precipitation-Highly-Resolved Observational Data Integration Towards Evaluation of the Water Resources (APHRODITE) was developed by a consortium of the Research Institute for Humanity and Nature (RIHN), Japan, and the Meteorological Research Institute of the Japan Meteorological Agency (MRIJMA). APHRODITE is made up of high-quality daily precipitation products of varying resolution $\left(0.25^{\circ}, 0.5^{\circ}\right)$ for several Asian subregions. Here, we use the latest version of daily precipitation data (APHRO_V1101) at $0.5^{\circ}$ latitudelongitude resolution for the Asian monsoon domain $\left(15^{\circ} \mathrm{S}-55^{\circ} \mathrm{N}, 60^{\circ}-150^{\circ} \mathrm{E}\right)$ during the period 1951-2007 (available fromwww.chikyu.ac.jp/precip/products/). The product does not discriminate between rain and snow but incorporates an improved quality-control method and orographic correction of precipitation. Details on the gridding procedure and reliability of APHRODITE daily 
precipitation data can be found in Hamada et al. (2011) and Yatagai et al. $(2009,2012)$.

2. Climate Prediction Center unified (CPC-uni) is a global gauge-based daily precipitation product from the National Oceanic and Atmospheric Administration (NOAA) Climate Prediction Center (CPC). Gauge reports from over 30000 stations are collected from multiple sources, including Global Telecommunications System (GTS), Cooperative Observer (COOP) network, and other national and international agencies, and quality control is performed. CPC-uni uses optimal interpolation (OI) with orographic consideration to represent the area-averaged values of precipitation over the grid boxes (Chen et al. 2008). Here, we used the CPC-uni, version 1.0 (v1.0), global land data at a $0.5^{\circ}$ latitude-longitude spatial resolution available from 1979 to the present.

3. The Global Precipitation Climatology Project (GPCP), sponsored by the World Climate Research Programme and Global Energy and Water Cycle Experiment, provides global precipitation products based on satellite and gauge information at daily (Huffman et al. 2001), pentad (Xie et al. 2003), and monthly (Adler et al. 2003) time scales. The GPCP 1-Degree Daily (1DD), version 1.2 (v1.2), dataset covers the period from October 1996 up to the present and is a companion to the GPCP, version 2.2, satellite-gauge (SG) combination. Information on individual components used as an input in the GPCP-1DD precipitation product can be obtained online (http://precip.gsfc.nasa.gov/gpcp_daily_comb.html).

4. The Tropical Rainfall Measuring Mission (TRMM) is a joint mission between the Japan Aerospace Exploration Agency (JAXA) and the U.S. National Aeronautics and Space Administration (NASA) designed to monitor precipitation and its variability within the tropics. The TRMM Multisatellite Precipitation Analysis (TMPA) algorithm merges a variety of satellite-based observations and ground observations to yield high spatiotemporal resolution and quasi-global quantitative precipitation estimation (QPE) products. The 3-hourly TMPA precipitation estimates are available as a real-time version (3B42-RT) and a gauge-adjusted post-real-time research version (3B42). There are two generations of 3B42 products: version 6 (3B42-V6), which is available to June 2012; and version 7 
(3B42-V7), which was retrospectively processed using the updated algorithm back to 1998 and released in May 2012 and is ongoing. The newly released 3B42-V7 incorporates several important changes over 3B42-V6, including use of Global Precipitation Climatology Centre (GPCC) analyses and additional satellite data (Huffman and Bolvin 2014). For this study, we use both the research versions (hereafter referred to as 3B42-V6 and 3B42-V7) available through the NASA interface (mirador.gsfc.nasa.gov). Both datasets have a spatial (temporal) resolution of $0.25^{\circ} \times 0.25^{\circ}\left(3 \mathrm{~h}\right.$ ) over latitudes $50^{\circ} \mathrm{N}-50^{\circ} \mathrm{S}$ (Huffman et al. 2007, 2011).

5. The Climate Forecast System Reanalysis (CFSR) is a third-generation reanalysis product developed at the National Centers for Environmental Prediction (NCEP; Saha et al. 2010). The advantages of CFSR relative to previous NCEP reanalyses include (i) higher horizontal ( $\sim 38 \mathrm{~km}, \mathrm{~T} 382)$ and vertical (64 sigmapressure hybrid levels) resolution, (ii) the guess forecast is generated from a coupled atmosphere-land-ocean-ice system, and (iii) historical satellite radiance measurements are assimilated. In addition, the CFSR is forced with observed estimates of evolving greenhouse gas concentrations, aerosols, and solar variations (http://cfs.ncep.noaa.gov/cfsr/). This study uses daily precipitation at $\sim 0.313^{\circ}$ Gaussian latitude-longitude, available for the period of 1979-2010 from the National Center for Atmospheric Research (NCAR).

6. The European Centre for Medium-Range Weather Forecasts (ECMWF) interim reanalysis (ERA-Interim) is the most recent global atmospheric reanalysis produced by ECMWF covering the period from 1979 onward (Dee et al. 2011). ERA-Interim uses four-dimensional variational data assimilation (4D-Var), a revised humidity analysis, variational bias correction for satellite data, and other improvements in data handling. ERA-Interim precipitation estimates are produced by the forecast model based on temperature and humidity information derived from assimilated observations. The dataset is freely available at a global daily resolution of $\sim 1.5^{\circ}$ regular Gaussian grid. 


\subsubsection{Data processing}

No standard format or grid resolution exists among the various precipitation products (Table 2.1). To facilitate direct comparison of precipitation datasets, a common $0.5^{\circ} \times 0.5^{\circ}$ regular latitude-longitude grid was chosen and bilinear interpolation was used in which, each point of the output grid is generated from its four neighbouring points in the input grid using a weighted approach. CFSR and ERA-Interim were extracted from the Gaussian grid gridded binary (GRIB) format and remapped to the $\left(0.5^{\circ} \times 0.5^{\circ}\right)$ regular grid. Seasonal averages were calculated from daily precipitation values and extracted for the region of interest, the Indian subcontinent $\left(5^{\circ}-38^{\circ} \mathrm{N}, 60^{\circ}-100^{\circ} \mathrm{E}\right.$; Figure 2.1$)$.

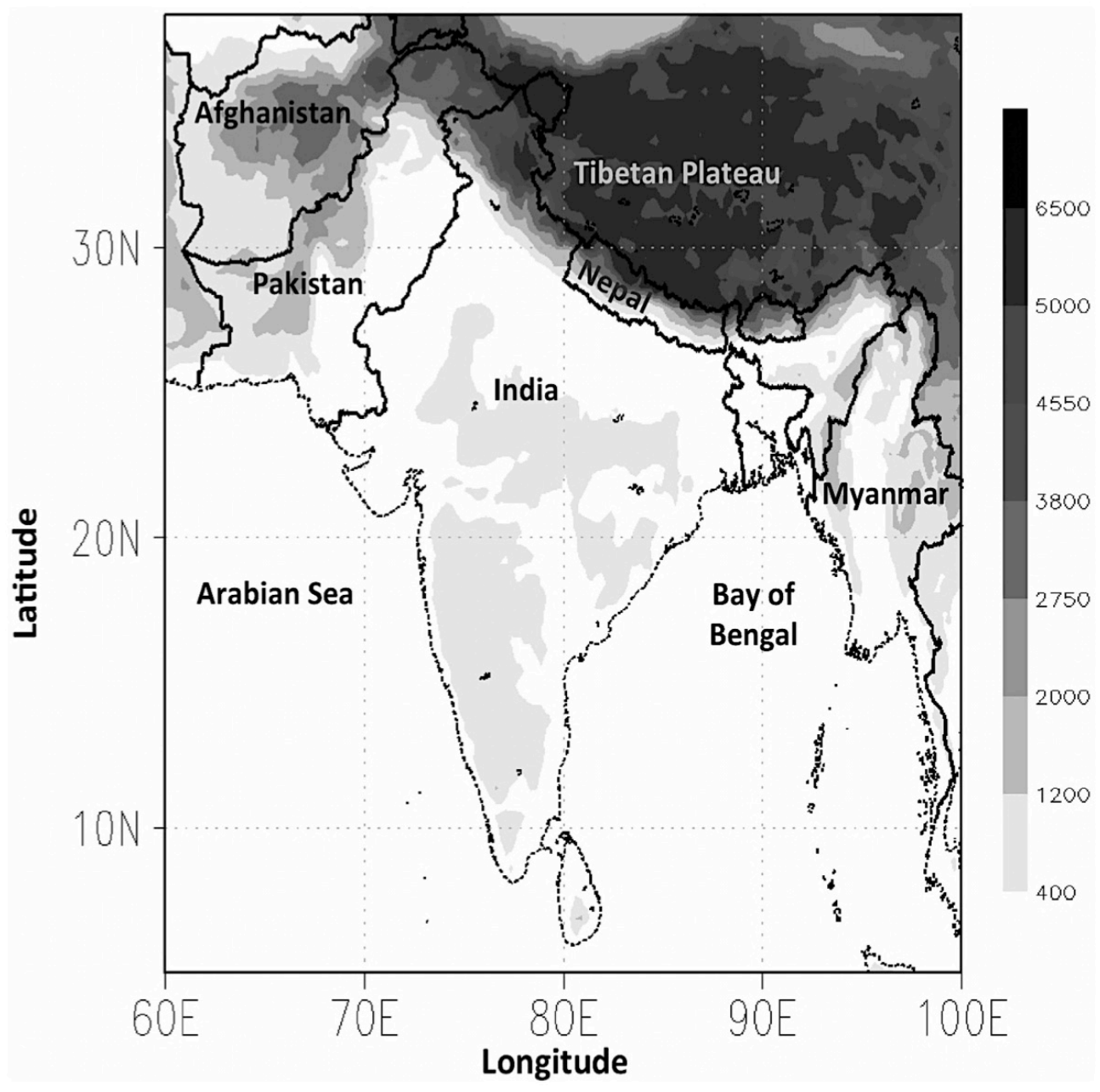

Figure 2.1: Location and topography $(m)$ of the Indian Subcontinent.

Only land points are considered here and the seasons are defined as winter [December-February (DJF)], premonsoon [March-May (MAM)], monsoon [June- 
September (JJAS)], and postmonsoon [October-November (ON)]. These seasonal designations best segment the large-scale annual variations of the major components of the subcontinent's climate, such as surface wind/surface pressure, temperature, and precipitation (Shea and Sontakke 1995). A common overlap period of 10 years (1997/98-2006/07) was chosen to enable a consistent comparison.

\subsubsection{Error analysis}

Several statistical methods are employed to analyse the precipitation products compared to the reference APHRODITE data. Maps are generated for seasonal and monthly mean climatology, standard deviation (std dev), and anomaly correlation coefficients (ACC).

$\operatorname{Mean}\left(\overline{X)}=\frac{1}{n} \sum_{i=1}^{n} X\right.$

Standard Deviation $(\sigma)=\sqrt{\frac{1}{n} \sum_{i=1}^{n}\left(X_{i}-\bar{X}\right)^{2}}$

where $n$ is number of data points, $X$ is the precipitation product (gauge, satellite, or reanalyses) under comparison, and $X_{i}$ is its $i^{\text {th }}$ value.

Anomaly correlation coefficient $(A C C)=\frac{\sum_{i=1}^{n} P_{i}^{\prime} O_{i}^{\prime}}{\left[\sum_{i=1}^{n}\left(P_{i}^{\prime}\right)^{2} \sum_{i=1}^{n}\left(O_{i}^{\prime}\right)^{2}\right]^{1 / 2}}$
$P_{i}^{\prime}=P_{i}-C$ and $O_{i}^{\prime}=O_{i}-C$

$P_{i}$ represents the precipitation products (CPC-uni, GPCP, 3B42-V6, 3B42-V7, CFSR, and ERA-Interim); $O_{i}$ represents the reference (APHRODITE) data; and $C$ represents the climatology of the respective dataset over time $(i)=1, \ldots ., n$.

In addition, Percentage precipitation difference (PPD) and percentage root-meansquare error (PRMSE) are computed to measure the biases in all examined products, relative to the seasonal mean of the reference dataset using the following equations. 


$$
\begin{gathered}
P P D=100 \frac{\sum_{i=1}^{n}\left(P_{i}-O_{i}\right)}{\sum_{i=1}^{n} O_{i}} \\
P R M S E=100 \frac{\sqrt{\frac{1}{n} \sum_{i=1}^{n}\left(P_{i}-O_{i}\right)^{2}}}{\sum_{i=1}^{n} O_{i}}
\end{gathered}
$$

\subsubsection{Empirical Orthogonal Function (EOF) analysis}

To examine the spatial-temporal variability of precipitation in each dataset, empirical orthogonal function (EOF) analysis is applied. This multivariate technique reduces the dimensionality of a dataset by finding a new set of variables that captures most of the observed variance in the data through a linear combination of original variables (Wilks 1995). The technique has been widely used in the field of atmopheric science and climate research for many years (Ding and Wang 2005; Hannachi et al., 2007; Mishra et al. 2012; Zhang et al. 2013).

EOF analysis seeks structures that explain the maximum amount of variance in a two-dimensional data set. One dimension in the data set represents the dimension (e.g., spatial) in which we are seeking to find structure (EOFs), and the other dimension (e.g., time) represents the dimension in which realizations of this structure are sampled (the Principal Components or PC's), and they are related one-to-one to the EOF's. Both sets of structures are orthogonal in their own dimension (Hartmann 2016).

Let us consider a gridded data set composed of a space-time field $X(t, s)$ representing the value of the field $X$ at time $t$ and spatial position $s$. The value of the field at discrete time $t_{i}$ and grid point $s_{j}$ is denoted $x_{i j}$ for $i=1, \ldots, n$ and $j=1, \ldots p$. The observed field $X$ is then represented by the matrix 


$$
X=\left(x_{1}, x_{2}, x_{3}, \ldots . ., x_{n}\right)^{T}=\left(\begin{array}{cccc}
x_{11} & x_{12} & \ldots & x_{1 p} \\
x_{11} & x_{12} & \ldots & x_{1 p} \\
\ldots & \ldots & \ldots . & \ldots . \\
x_{n 1} & x_{n 2} & \ldots & x_{n p}
\end{array}\right)
$$

where $x=\left(x_{1}, x_{2}, x_{3}, \ldots . ., x_{n}\right)^{T}, t=1, \ldots n$, represents the map, or the value of the field at time $t$. Let us denote by $\overline{x_{i}}$ the time average of the field at the $i^{\text {th }}$ spatial grid point. This time average is given by:

$$
\overline{x_{. i}}=\frac{1}{n} \sum_{k=1}^{n} x_{k i}
$$

and the climatology is defined by

$$
\bar{x}=\left(\bar{x}_{.1}, \ldots . ., \bar{x}_{. p}\right)=\frac{1}{n} 1_{n}^{T} X
$$

where $1_{n}=(1, \ldots 1)^{T}$ is the (column) vector of length $n$ containing only ones. The anomaly field, or departure from the climatology is defined at $\left(t, s_{k}\right), t=1, \ldots n$, and $k=$ $1, \ldots p$, by:

$x_{t k}^{\prime}=x_{t k}-\bar{x}_{. k}$

in the matric form equation 2.9 can be written as:

$$
Y=X=X-1_{\mathrm{n}} \bar{x}=\left(I_{n}-\frac{1}{n} 1_{n} 1_{n}^{T}\right) X=H X
$$

where $\mathrm{I}_{\mathrm{n}}$ is the $n \times n$ identity matrix, and $H$ is the centring matrix of order $\mathrm{n}$ (Mardia et al., 1979). After the anomaly data matrix $Y$ is determined from equation 2.10 , the EOFs of $Y$ are obtained by finding the eigenvalues of the covariance matrix $S$ defined as:

$S=\frac{1}{n} Y^{T} Y=U \Lambda U^{T}$

where $U$ and $\Lambda$ are the orthonormal matrix of eigenvectors and the diagonal matrix of 
the eigenvalues, respectively. The EOFs, also know as the PC loadings are the columns of $U$. The first EOF (EOF-1) is the unit-length vector defining the linear combination of the columns of $Y$ that explain maximum variability. Subsequent EOFs are determined similarly, with an orthogonality constraint for all other EOFs in both space and time. The matrix $\Lambda$ of eigenvalues contains the variance associated with each EOF, in descending order. The projection of the anomaly field $Y$ onto the matrix $U$ determines the principal components (PCs) for each EOF defined by:

$Z=Y U$

$Z$ is also known as the EOF expansion coefficients, EOF time series amplitude, PC time series, or PCs score. In this study we use the terminology EOFs and PCs for the spatial and temporal patterns respectively.

\subsubsection{Why APHRODITE as the reference?}

In this work, we have considered APHRODITE as our primary surface reference (i.e., benchmark) dataset. Yatagai et al. $(2008,2009)$ recommended APHRODITE as a reliable dataset for studying rainfall variations over Asia and suggested that it can be considered as observations and ground truth around the Himalayas, the Middle East, and central Asian regions. Rajeevan and Bhate (2009), in a study over the Indian region, compared the India Meteorological Department (IMD) rain gauge data (comprising 6000 stations) against the APHRODITE_V0804 rainfall product ( 2000 stations) and found that APHRODITE data could capture the largescale features of the ISMR, exhibiting strong correlations $(>0.6)$ with IMD data over most of India. For monitoring large-scale precipitation variations over East Asia, Sohn et al. (2012) quantified the reliability of six precipitation datasets over the region considering APHRODITE as the ground truth. Andermann et al. (2011) compared gridded precipitation products along the complex relief zone of the Himalayan front and concluded that for all seasons the APHRODITE dataset gives the best precipitation estimates with minimal difference from independent ground observations. However, the authors noted that the lack of gauge stations at higher elevations of the study region limits the accuracy of APHRODITE. Recently, Prakash et al. (2015) performed a seasonal (JJAS) intercomparison of six observational 
rainfall datasets against IMD gridded data and found that APHRODITE and GPCC are the two best performers in terms of statistical skill scores, with APHRODITE's root-mean-square error $(39.31 \%)$ being lower than that of GPCC $(42.68 \%)$ for allIndia JJAS rainfall.

These studies, together with the validation work carried out by Yatagai and Xie (2006) and Yatagai et al. (2009), give us a sound basis to consider APHRODITE as a reliable reference dataset for studying precipitation variations over the Indian subcontinent and other regions, where the dataset contains a dense network of rain gauges. Figure 2.2 shows the distribution map of rain gauge stations used by APHRODITE for the year 1998 (Yatagai et al. 2009). As seen in Figure 2.2, the dataset benefits from a dense network of rain gauges over a large part of India and Nepal, giving greater confidence for diagnostic studies and validation work. However, over the northwestern region of the subcontinent (including northwestern India, Pakistan, and Afghanistan), the eastern part of peninsular India, and the Tibetan Plateau, the distribution of gauge stations is sparse, which may limit the accuracy of observations and might introduce uncertainties in gauge-based precipitation products.

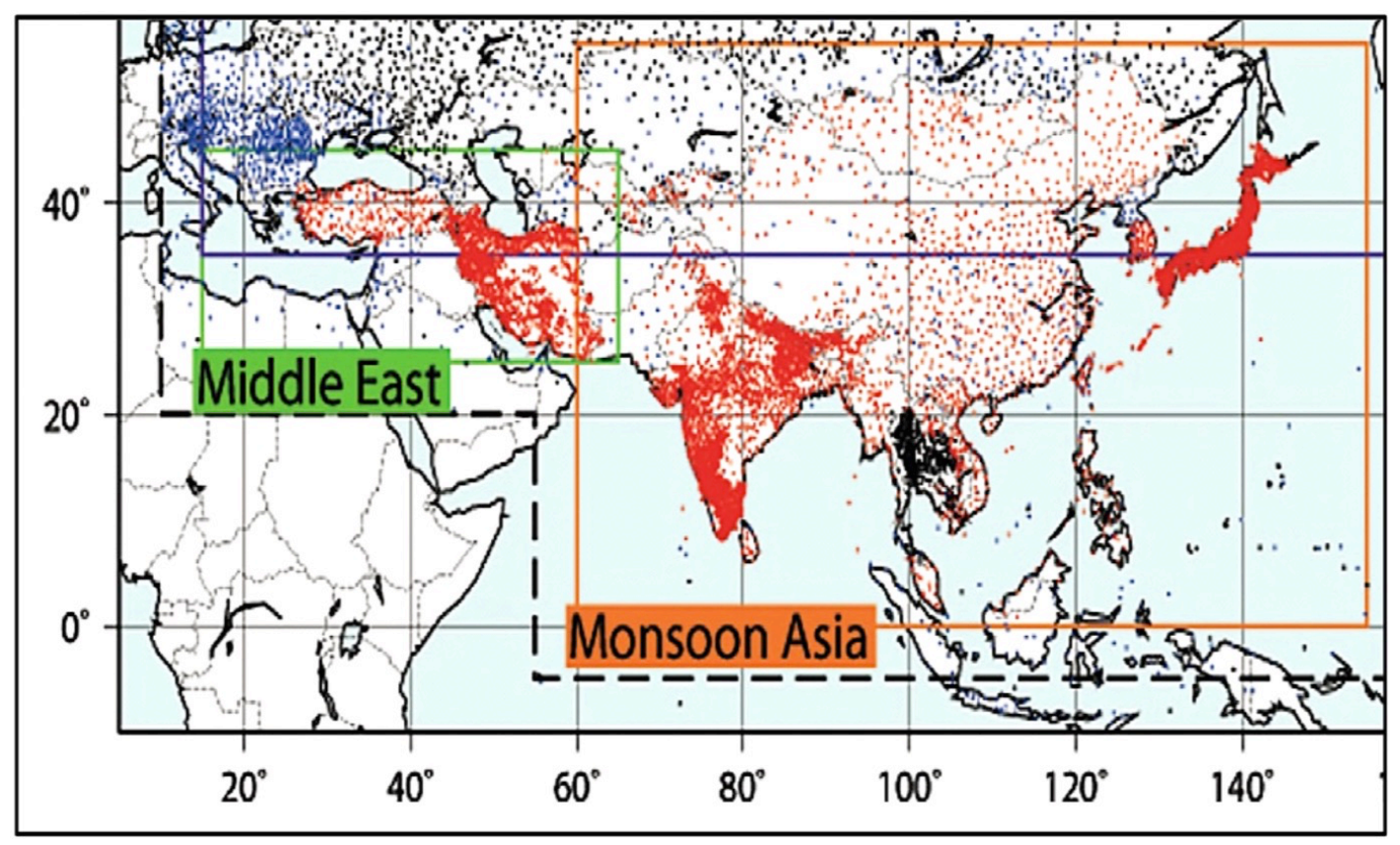

Figure 2.2: Distribution of rain gauge stations used by APHRODITE for the year 1998. GTS stations (blue), precompiled datasets (black), and data individually collected by the APHRODITE project team (red).Figure reference: Yatagai et al. (2009). 


\subsection{Results and discussion}

\subsubsection{Seasonal to interannual variability}

The Indian subcontinent exhibits a wide range of seasonal precipitation regimes across different regions. To visualize this distribution of total annual precipitation, daily precipitation values for the time period from December 1997 to December 2007 are segmented into four seasons (DJF, MAM, JJAS, and ON) and spatial fields of seasonal precipitation distribution are generated for all datasets (Figure 2.3). The most pronounced spatial precipitation pattern represents the southwest monsoon (JJAS) rainfall that contributes $\sim 70 \%-75 \%$ of the total annual precipitation across the entire domain. Rainfall during the southwest monsoon is a result of both the seasonally changing thermal contrast between land and ocean and the seasonal migration of the intertropical convergence zone (ITCZ). The highest climatological mean for JJAS rainfall occurs over the western coast of peninsular India and over the northeastern region; both are associated with orographic lifting and intense convection (Pattanaik and Rajeevan 2010).

The JJAS rainfall gradually decreases northwestward from east-central India, with areas along the southeastern coast of peninsular India being comparatively dry. It is during the postmonsoon season that large parts of the southeastern coast of peninsular India and neighboring Sri Lanka receive a significant amount of rain due to the retreating southwest monsoonal winds, also known as the northeast monsoon. With the retreat of the southwest monsoon, surface pressure and the upper wind circulation patterns change rapidly and a trough of low pressure is established over the southern Bay of Bengal, resulting in a northeasterly wind flow across the subcontinent (Srinivasan and Ramamurthy 1973). During this time, the northernnorthwestern part of the subcontinent is generally dry but receives a significant amount of precipitation during winter (DJF) and premonsoon (MAM) months because of the occurrence of midlatitude disturbances and premonsoon thunderstorms (TSs), respectively. Winter precipitation is usually limited in spatial extent and total amount and is largely confined to the northwestern region of the Indian subcontinent and follows a general decline from west to east (Sen Roy 2009). An interesting feature observed during the premonsoon months is the shift in rainfall activity to the northeastern region of the subcontinent as a result of the TS activity before the advancement of the southwest monsoon over the region (Mahanta et al. 2013). 

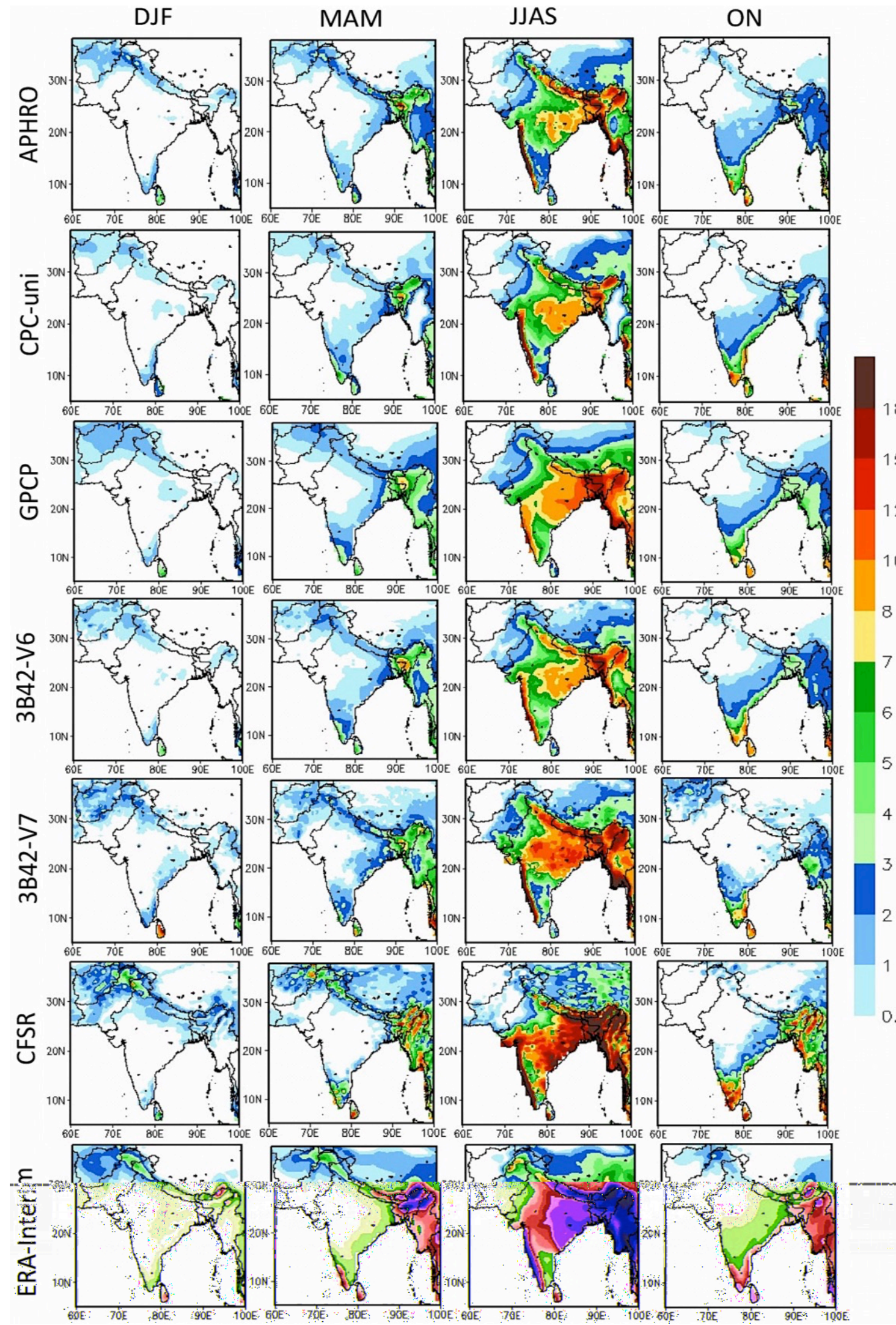

Figure 2.3: Spatial distribution of seasonal mean precipitation $(\mathrm{mm} / \mathrm{day})$ over the Indian Subcontinent, for each precipitation product for the period 1997/98 to 2006/07. 
Figure 2.3 shows that all products are capable of coherently reproducing the key features of the seasonal and regional precipitation distribution reasonably well and are roughly in agreement with the APHRODITE dataset. However, significant regional differences can be observed in all precipitation products, especially along the topographically induced high rainfall regional features (e.g., over northern Pakistan, the foothills of the Himalayas, the extreme northeast, and along the Western Ghats). Comparing APHRODITE with other products, we find that CPC-uni, GPCP, and 3B42-V6 capture the seasonal distribution pattern of DJF and MAM precipitation, but the datasets fail to capture the maxima of orographic precipitation over the complex topography of northwestern India. In addition, the products slightly underestimate (overestimate) the rainfall amounts over the windward (leeward) side of the western coast of India during the JJAS season.

In mountainous regions, 3B42-V7 exhibits slightly higher precipitation and hence performs better than 3B42-V6, CPC-uni, and GPCP. According to Huffman and Bolvin (2014), the largest difference between 3B42-V7 and 3B42-V6 occurs in mountainous regions owing to the major changes in 3B42-V7's Precipitation Radar algorithm, which uses a higher-resolution elevation map based on Shuttle Radar Topography Mission data with 30-arc-s spacing (SRTM30) over India, Tibet, and South America (TRMM Precipitation Radar Team 2011). The newer product (3B42V7) displays the rain-shadow region of the Western Ghats reasonably well but fails to capture the distribution pattern of postmonsoon rainfall along the eastern coast of peninsular India. Moreover, 3B42-V7 exhibits slightly higher precipitation over the core monsoon zone and the northeastern region of the subcontinent, including Myanmar. Reasons for overestimation in 3B42-V7 could be bias in the full usage of GPCC gauge data, which, according to Prakash et al. (2015), overestimates ( $\sim 5$ $\mathrm{mm}$ /day) the monsoon rainfall over northeastern India and along the Western Ghats compared to IMD gauge data, or because of the occurrence of heavy convective rainfall, which may cause signal attenuation and might lead to overestimation of nearsurface rainfall (Amitai et al. 2004).

In contrast to CPC-uni and the satellite-derived precipitation products (GPCP, 3B42-V6, and 3B42-V7), the two reanalysis products (CFSR and ERA-Interim) appear to reproduce high seasonal precipitation values over regions of pronounced precipitation activity. For example, high precipitation totals are observed in the northwestern and northeastern regions of the subcontinent for DJF and MAM. In 
addition, regions of spuriously high rainfall are also seen during JJAS, particularly over the northeastern region and the core monsoon zone. Monsoon precipitation in these regions is mainly associated with the presence of a moist convective regime related to the monsoon flow and also to the propagation of low pressure systems from the Bay of Bengal along the core monsoon zone (Rajeevan et al. 2010). Therefore, overestimation of precipitation in these regions, especially by reanalysis datasets, could be associated with overestimation of moisture fields and hence precipitable water (Trenberth et al. 2011; Shah and Mishra. 2014). CFSR tends to overestimate seasonal precipitation in the southern part of peninsular India during MAM, JJAS, and $\mathrm{ON}$ and to underestimate JJAS precipitation over the semiarid region of northwestern India (including Pakistan), consistent with Shah and Mishra (2014).

The reanalyses illustrate the strong influence of orography on precipitation. While ERA-Interim shows a smooth spatial distribution of precipitation, CFSR reproduces finer-scale regional patterns, which may be due to the improved representation of the orographically influenced precipitation and the high spatial resolution of this dataset (Saha et al. 2010). A close comparison of precipitation products illustrates that 3B42-V6 and CPC-uni display the highest degree of spatial agreement to APHRODITE's (JJAS and ON) seasonal climatology. For the entire subcontinent, the seasonal JJAS (ON) domain-averaged mean is 4.29 (1.31) for APHRODITE, 3.98 (1.22) for CPC-uni, 5.2 (1.84) for GPCP, 4.35 (1.36) for 3B42V6, 5.9 (1.11) for 3B42-V7, 7.1 (2.03) for CFSR, and 5.8 (1.89) mm/day for ERAInterim.

The mean monthly precipitation cycles over the region for the period 1997/982006/07 are compared in Figure 2.4. All products capture the unimodal distribution of the annual cycle fairly well, albeit with different amplitude. With respect to the APHRODITE, CPC-uni (GPCP) tends to slightly underestimate (overestimate) the monthly precipitation amount, while CFSR and ERA-Interim significantly overestimate mean monthly precipitation from May to December. The 3B42-V7 closely agrees with APHRODITE's averages for the winter and premonsoon months, but overestimates (slightly underestimates) the JJAS $(\mathrm{ON})$ precipitation amounts over the core monsoon zone (eastern coast) of India. The results seen here are a clear manifestation of the spatial climatology patterns depicted in Figure 2.3. 


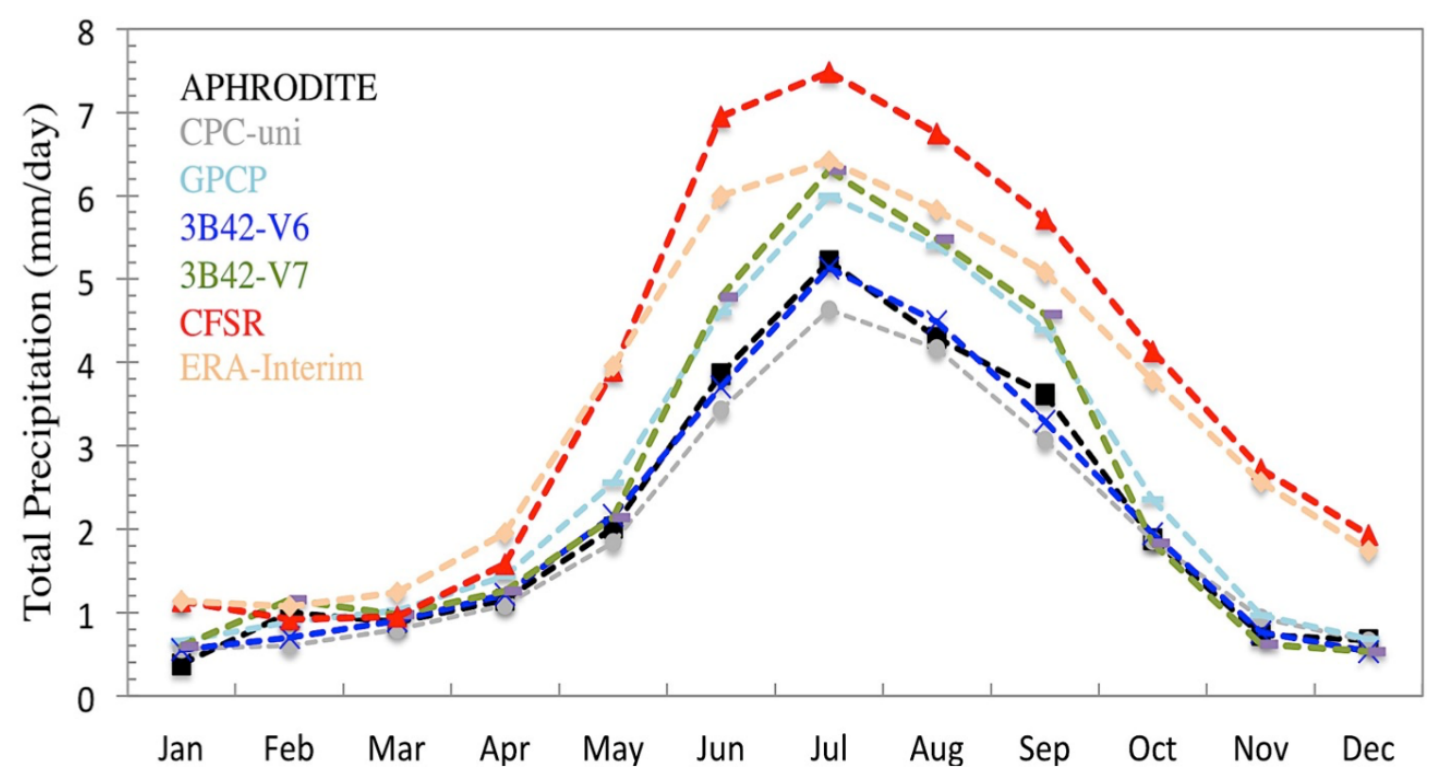

Figure 2.4: Mean monthly precipitation cycle ( $\mathrm{mm} /$ day) averaged over the Indian Subcontinent, for each precipitation product for the period 1997/98 to 2006/07.

To represent the interannual variability of precipitation at each grid point, we generate interannual std dev plots for each season in Figure 2.5, shown below. All datasets reveal large std dev values over regions that receive large amounts of seasonal precipitation. For example, the western coast of peninsular India and the northeastern region exhibit large std dev values during JJAS, while southeastern peninsular India displays high interannual variability during ON. Similarly for DJF and MAM, comparatively high (>5 mm/day) std dev values appear over the northwestern region and in some parts of northeastern and southern peninsular India. In comparison to APHRODITE, the overall magnitude of rainfall variability is fairly well reproduced by all datasets for all seasons and/or regions, with the exception of CFSR. During JJAS, CFSR displays large ( $>18 \mathrm{~mm} /$ day) interannual variability over north-central India and northeastern regions of the subcontinent, where CFSR produces excess precipitation totals (Figure 2.3). Misra et al. (2012) commented that CFSR displays the strongest interannual variation of precipitable water over central India (with nearly $11 \%$ difference between wet and dry years), which they associated with the anomalous oceanic sources of moisture from the adjacent Bay of Bengal and Arabian Sea. In the JJAS (std dev) pattern, an important feature in ERA-Interim is the region of suppressed ( $<9 \mathrm{~mm} /$ day) rainfall variability along the western coast of India 
and comparatively high $(16 \mathrm{~mm} /$ day $)$ variability over the northeastern region.
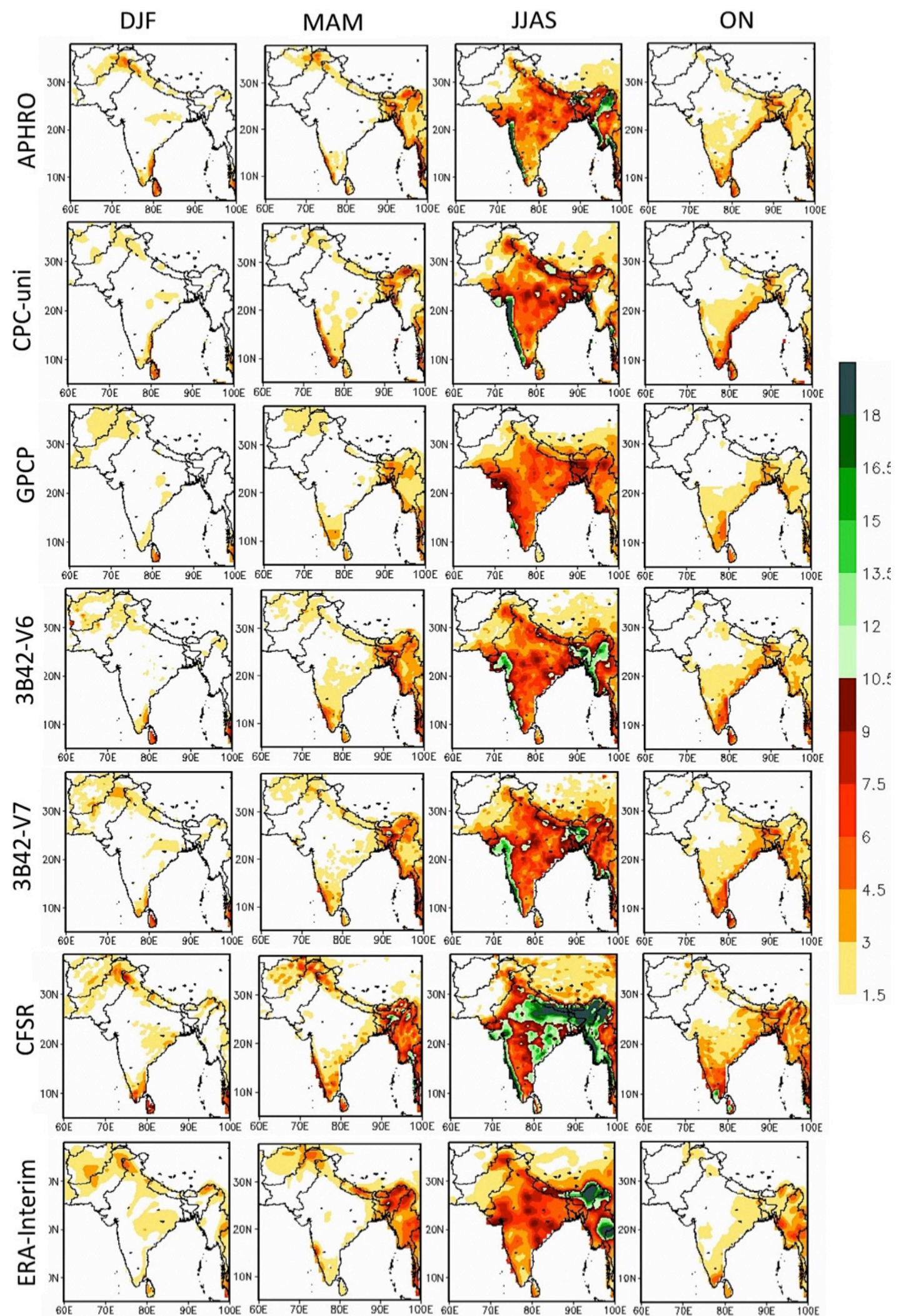

Figure 2.5: Standard deviation of seasonal mean precipitation $(\mathrm{mm} /$ day) over the Indian Subcontinent, for each precipitation product for the period 1997/98 to 2006/07. 
The results obtained here are consistent with the finding of Shah and Mishra (2014), who reported that both CFSR and ERA-Interim overestimated monsoon rainfall variability over eastern regions compared to IMD gauge observations. For the monsoon season, the domain-averaged std dev is APHRODITE $=10.4, \mathrm{CPC}$-uni $=10.2, \mathrm{GPCP}=9.6,3 \mathrm{~B} 42 \mathrm{-V} 6=11.2,3 \mathrm{~B} 42-\mathrm{V} 7=11.4, \mathrm{CFSR}=17.3$, and ERAInterim $=11.3 \mathrm{~mm} /$ day. In comparison to GPCP, the relative superiority of CPC-uni, $3 \mathrm{~B} 42-\mathrm{V} 6$, and $3 \mathrm{~B} 42-\mathrm{V} 7$ is evident, as these products show close agreement to APHRODITE's precipitation variability and can capture the pattern of large std dev values over the Western Ghats (eastern coast) of India during JJAS (ON). Rahman et al. (2009) and Joshi et al. (2012) also reported that in comparison to IMD gauge data, 3B42-V6 performs better than GPCP for the monsoon period over the Indian region. Among the reanalysis datasets, the performance of ERA-Interim looks somewhat better than CFSR in terms of both domain-averaged mean and std dev for the JJAS period. For DJF and MAM, CPC-uni and GPCP do not provide any useful information with regard to the interannual variability of seasonal precipitation over the northwestern region of the Indian subcontinent and along the foothills of the Himalayas. Despite the similar std dev distribution pattern for both 3B42-V6 and 3B42-V7, differences are notable over mountainous regions, where 3B42-V7 more successfully captures the interannual variability of the DJF and MAM precipitation as seen in APHRODITE. The domain-averaged std dev values for DJF are APHRODITE $=3.4$, CPC-uni $=2.9$, GPCP $=3.1,3 \mathrm{~B} 42-\mathrm{V} 6=3.1,3 \mathrm{~B} 42-\mathrm{V} 7=3.6$, $\mathrm{CFSR}=4.3$, and ERA-Interim $=4.3 \mathrm{~mm} /$ day.

\subsubsection{Error assessment}

To explore the skill of the precipitation products on a regional basis, a relative bias or PPD (relative to APHRODITE) is computed on a seasonal scale. Figure 2.6 indicates that CPC-uni exhibits a general tendency to underestimate seasonal precipitation along the foothills of the Himalayas, the Tibetan Plateau, and Myanmar in all seasons. The poor performance of the CPC-uni indicates that the total number of active rain gauges and their spatial distribution used to construct the CPC-uni dataset is not enough to capture the seasonal precipitation pattern and interannual variability over the above-mentioned regions. According to Gebregiorgis and Hossain (2015), 
APHRODITE uses an extensive network of gauges from various partner organizations, which is more than CPC-uni.
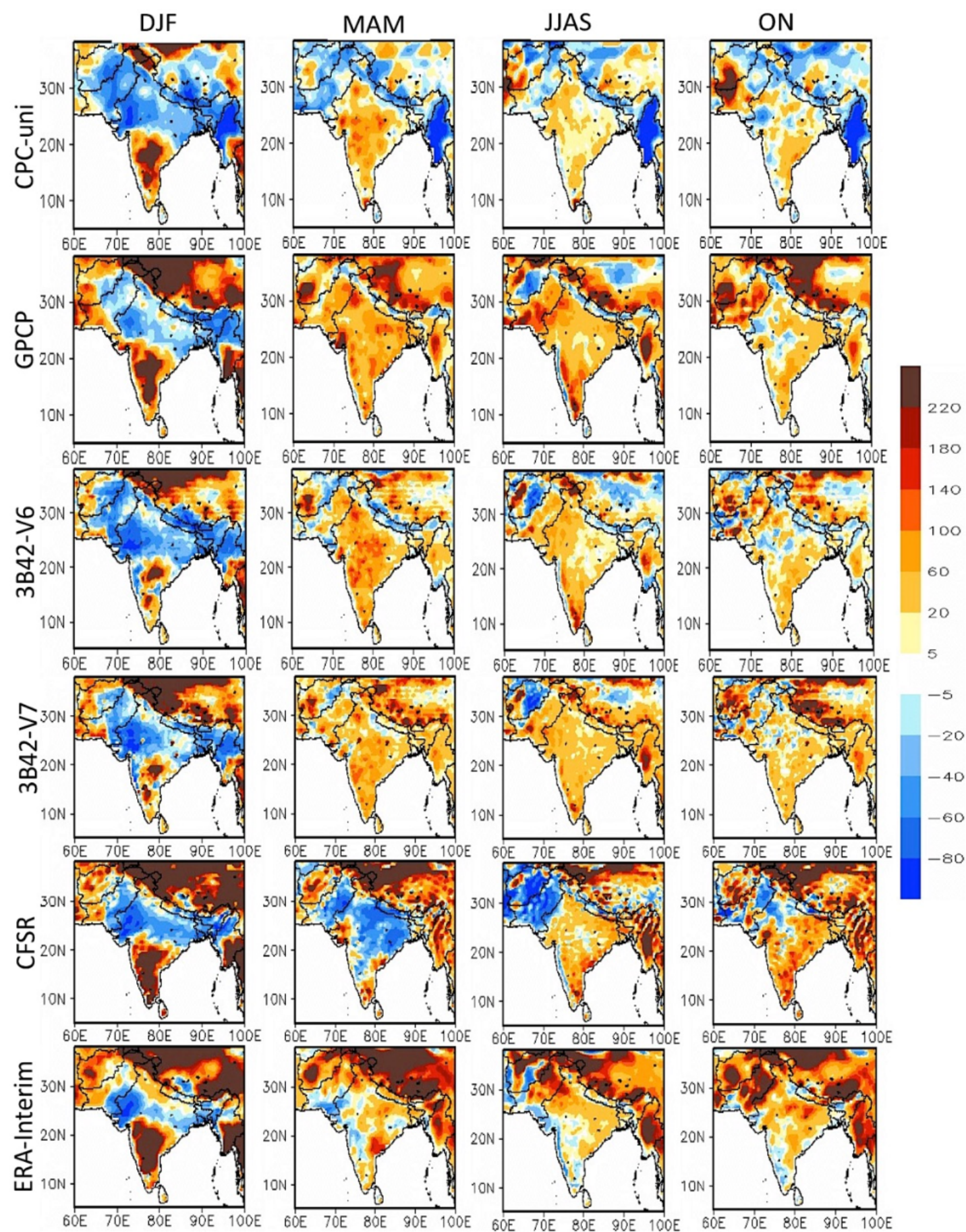

Figure 2.6: Percentage Precipitation difference (PPD) with respect to APHRODITE seasonal mean precipitation over the Indian Subcontinent for the period 1997/98 to 
Large PPDs appear over the data-sparse and topographically complex Tibetan Plateau and the Hindu Kush-Karakoram mountain ranges in the northwestern region of the subcontinent. The domain-averaged PPDs are maximum (minimum) for the winter (monsoon) season with values of 13\% (4\%), 142\% (53\%), 43\% (25\%), 72\% (38\%), 243\% (41\%), and 234\% (84\%) for CPC-uni, GPCP, 3B42-V6, 3B42-V7, CFSR, and ERA-Interim, respectively. Similarly, for MAM (ON), the domainaveraged PPDs are 2\% (4\%), 63\% (68\%), 33\% (28\%), 40\% (45\%), 79\% (103\%), and $123 \%$ (114\%), respectively. The large positive bias over the above-mentioned regions appears to be consistent in the reanalysis datasets throughout the year. The large positive bias in CFSR and ERA-Interim could be related to 1) the inability of the models to resolve orographic precipitation in complex terrain with large elevation changes (Ma et al. 2009), 2) differences in the land-atmosphere interaction and land surface model schemes (Misra et al. 2012), and 3) the fact that reanalysis products estimate total precipitation (rainfall plus snow; Palazzi et al. 2013). However, for the satellite-derived precipitation products, the large bias seems to gradually decrease from the cold winter months (DJF) to the warm summer season (JJAS). This result closely agrees with the conclusions reported by Ebert et al. (2007) that satellite algorithms perform best during summers, when rainfall is more convective, than in winters when it is more synoptically forced. Apparently, the occurrence of comparatively smaller positive bias for the satellite-derived precipitation products could be related to the difficulty of in situ station data, satellite estimates, and their combinations in detecting the snow component of precipitation (Rasmussen et al. 2012).

All datasets (except for the gauge-only CPC-uni) display distinctly large winter PPDs over the northern flank of the subcontinent and the Tibetan Plateau. This implies an additional source of uncertainty (i.e., gauge measurements) might be contributing toward the existing errors in the reanalysis estimates and satellite retrievals. According to Lorenz and Kunstmann (2012), gauge undercatch error for solid precipitation, which is especially large in high latitudes or mountainous regions during the winter season, can lead to an underestimation of the true precipitation of up to $50 \%$. Moreover, sampling errors between $15 \%$ and $100 \%$ could be expected for sparsely gauged regions with less than three gauges per $2.5^{\circ} \times 2.5^{\circ}$ grid cell (Rudolf and Rubel 2005). Therefore, depending on the environmental conditions (season) and geographic location, it is likely that the uncertainties and inhomogeneities in 
observational/reference data are artificially inflating or deflating the existing biases in all datasets. Furthermore, a comparison of the spatial and domain-averaged PPDs indicates that 3B42-V6 and 3B42-V7 outperform GPCP in all seasons. This can be associated first to the fact that, in regions with low gauge density, the GPCP analysis is influenced more by the gauges (Gruber et al. 2000), while 3B42 estimates are influenced more by the satellite measurements, and second, to the coarser resolution of GPCP, which spreads any errors over larger geographical areas. CFSR displays large negative PPDs over Afghanistan and Pakistan and some parts of northwestern India during JJAS. Misra et al. (2012) found that during the monsoon season the cross-equatorial and the southwesterly flow of monsoonal $(950 \mathrm{hPa})$ winds is weak in CFSR, which, according to our understanding, could result in the weakening of the monsoon flow and hence less advection of moisture to the far northwestern regions (including Pakistan), as seen in Figure 2.3.

Spatial patterns of ACC are generated for the period from 1997/98-2006/07 in Figure 2.7 to analyse how the examined products relate to the seasonal anomalies in APHRODITE data at each grid point. Results indicate that for a season, the ACCs are significantly high ( $>0.632$ at $95 \%$ significance level) over regions exhibiting less interannual variability and vice versa. Reasonably high (low) ACCs are observed during ON (JJAS) over most of the regions and for all products. In comparison to other precipitation products, CPC-uni displays relatively high and significant ACC values $(>0.65)$ along the western (eastern) coast of peninsular India during JJAS $(\mathrm{ON})$, suggesting that the two-gauge products have similar anomaly pattern. The domain-averaged ACC for CPC-uni and APHRODITE is found to be DJF $=0.36$, $\mathrm{MAM}=0.57, \mathrm{JJAS}=0.47$, and $\mathrm{ON}=0.63$. In addition, 3B42-V6 and 3B42-V7 also show a close agreement to APHRODITE during MAM, JJAS, and ON, indicating a comparably good anomaly correlation in regions exhibiting high precipitation variability (e.g., Western Ghats and northeastern region including Myanmar). The domain-averaged ACCs for 3B42-V6 (3B42-V7) during DJF, MAM, JJAS, and ON are found to be $0.21(0.21), 0.54(0.57), 0.46(0.48)$ and $0.67(0.68)$, respectively. Unlike other precipitation products, 3B42-V6 and 3B42-V7 exhibit the lowest domain-averaged ACCs (i.e., 0.21) and display a different anomaly correlation pattern during the DJF season. The diagonal correlation pattern with positive-negativepositive ACC values is similar to the high-low-high regional precipitation seasonality pattern generated in Figure 2.3. However, the negative ACC values in 3B42-V6 and 
3B42-V7 are of concern, indicating in some cases the reversed anomalies of winter precipitation over the Indian subcontinent.
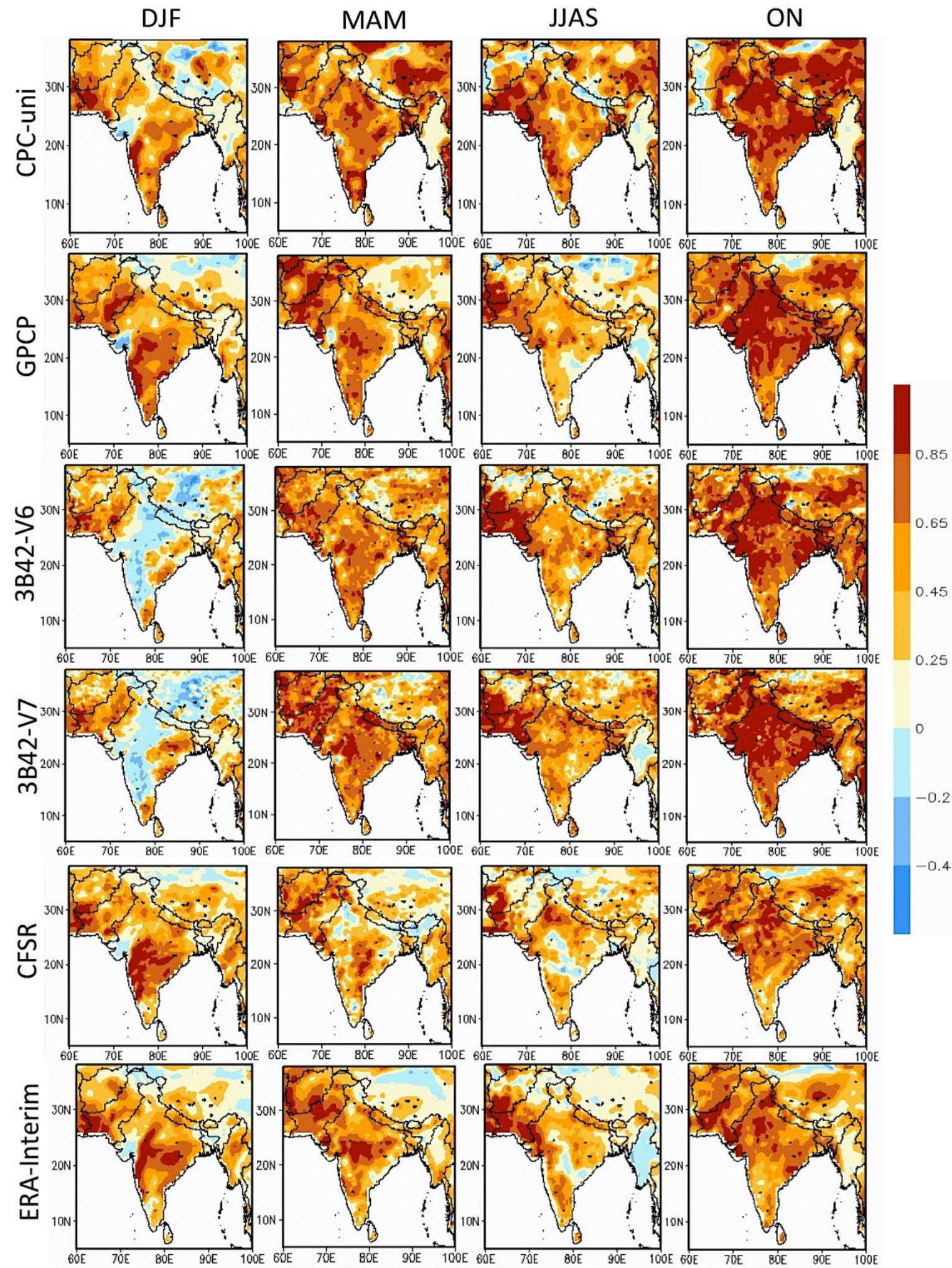

Figure 2.7: Anomaly Correlation of seasonal mean precipitation over the Indian Subcontinent, compared to APHRODITE for the period 1997/98 to 2006/07. 
In general, it appears that all individual precipitation products have a relatively low and seasonally variable ACC spatial pattern over the northwestern region of subcontinent, the entire Himalayan belt, the Tibetan Plateau, and Myanmar. The two reanalyses products more or less represent similar characteristic features in their ACC patterns and produce poor correlations during MAM $(\mathrm{CFSR}=0.35$, ERA-Interim $=$ 0.42 ) and JJAS (CFSR $=0.29$, ERA-Interim $=0.30$ ) as compared to other precipitation products. This result perhaps can be attributed entirely to the strong overestimation of precipitation (Figure 2.3 and Figure 2.4) and high interannual variability (Figure 2.5) over the core monsoon zone and the northeastern region of the Indian subcontinent, which largely reduces the skill of the reanalyses products over these regions.

Figure 2.8 shows the seasonal PRMSE with respect to the climatological mean of the APHRODITE dataset. The PRMSE ranges from zero to infinity, with lower values indicating closer agreement with APHRODITE. The maximum (minimum) error/uncertainty in precipitation estimates exists during the winter (monsoon) period. More or less consistent with the PPD results, the spatial comparison of PRMSE reveals that, regardless of the season, PRMSEs and PPDs are large and distinct over the topographically complex and data-sparse northwestern region of the Indian subcontinent, Myanmar, and the Tibetan Plateau. Conversely, the spatial spread of PRMSE is homogeneous and generally smaller over low-elevation plain areas where moderate to dense gauge stations are available. For the subcontinent as a whole, the domain-averaged PRMSEs for the winter season are much greater in the reanalysis datasets $(\mathrm{CFSR}=335 \%$, ERA-Interim $=311 \%)$, than for CPC $(104 \%)$, 3B42-V6 (143\%), 3B42-V7 (161\%), and GPCP (209\%). Similarly, for the JJAS season, the PRMSEs for CPC-uni, GPCP, 3B42-V6, 3B42-V7, CFSR, and ERA-Interim are found to be $61 \%, 78 \%, 62 \%, 65 \%, 100 \%$, and $171 \%$, respectively. For the pre- and postmonsoon seasons, the PRMSE is $<90 \%$ for CPC-uni, 3B42-V6, and 3B42-V7; and $>150 \%$ for CFSR, ERA-Interim, and GPCP. Apparently for the monsoon season, the PRMSE spatial spread and domain-averaged score is a minimum in CPC-uni over the Indian region, while among the reanalysis products, ERA-Interim appears to be slightly better than CFSR in terms of the spatial spread of PRMSEs over the Indian region alone. Additionally, 3B42-V6 and 3B42-V7 seem to outperform GPCP again, with regard to the spatial representation of comparatively smaller errors over the 
Western Ghats, the foothills of the Himalayas, and Myanmar during the monsoon season.
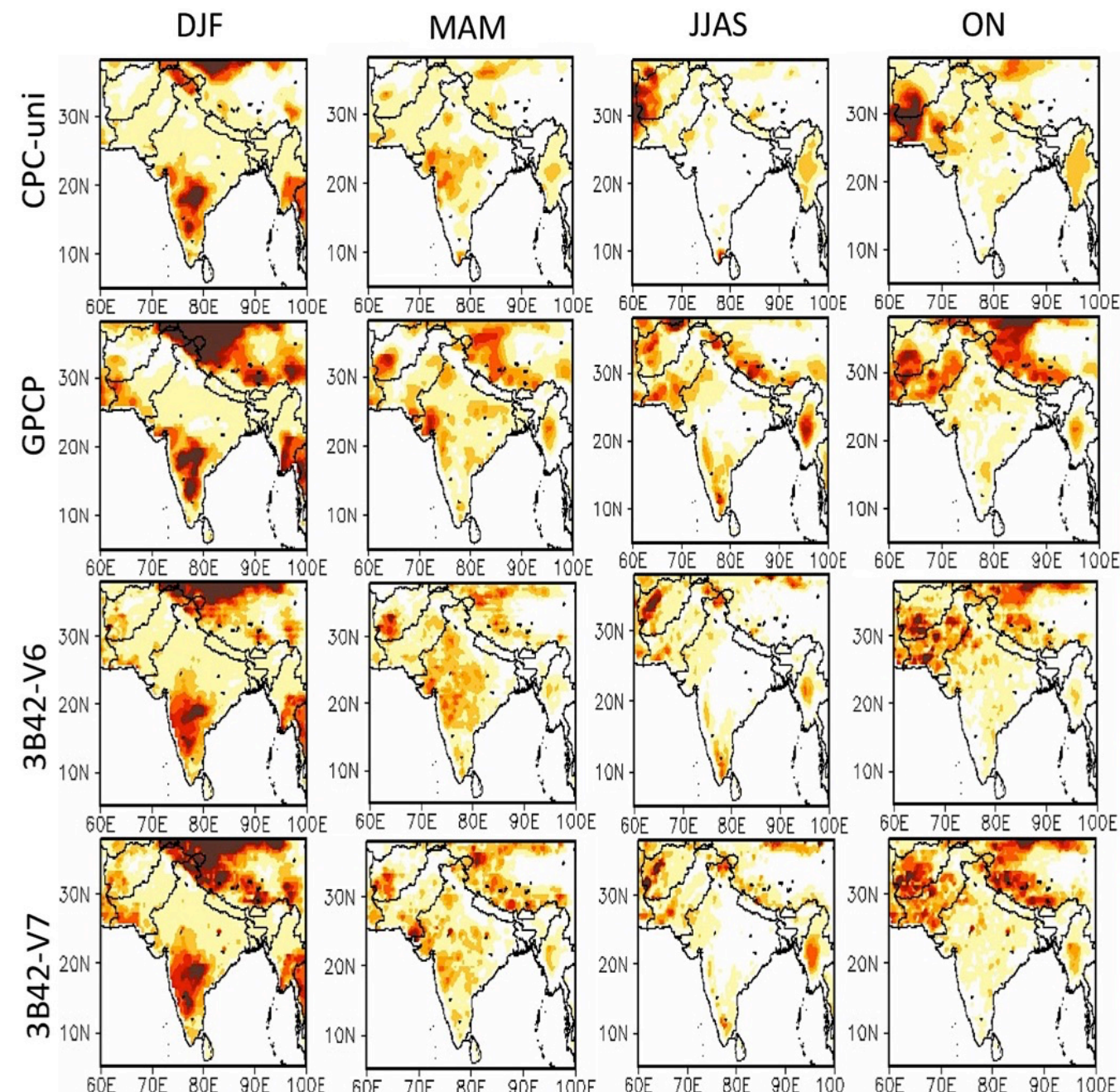

GOE $70 \mathrm{E} \quad 80 \mathrm{E} \quad 90 \mathrm{E} \quad 100$
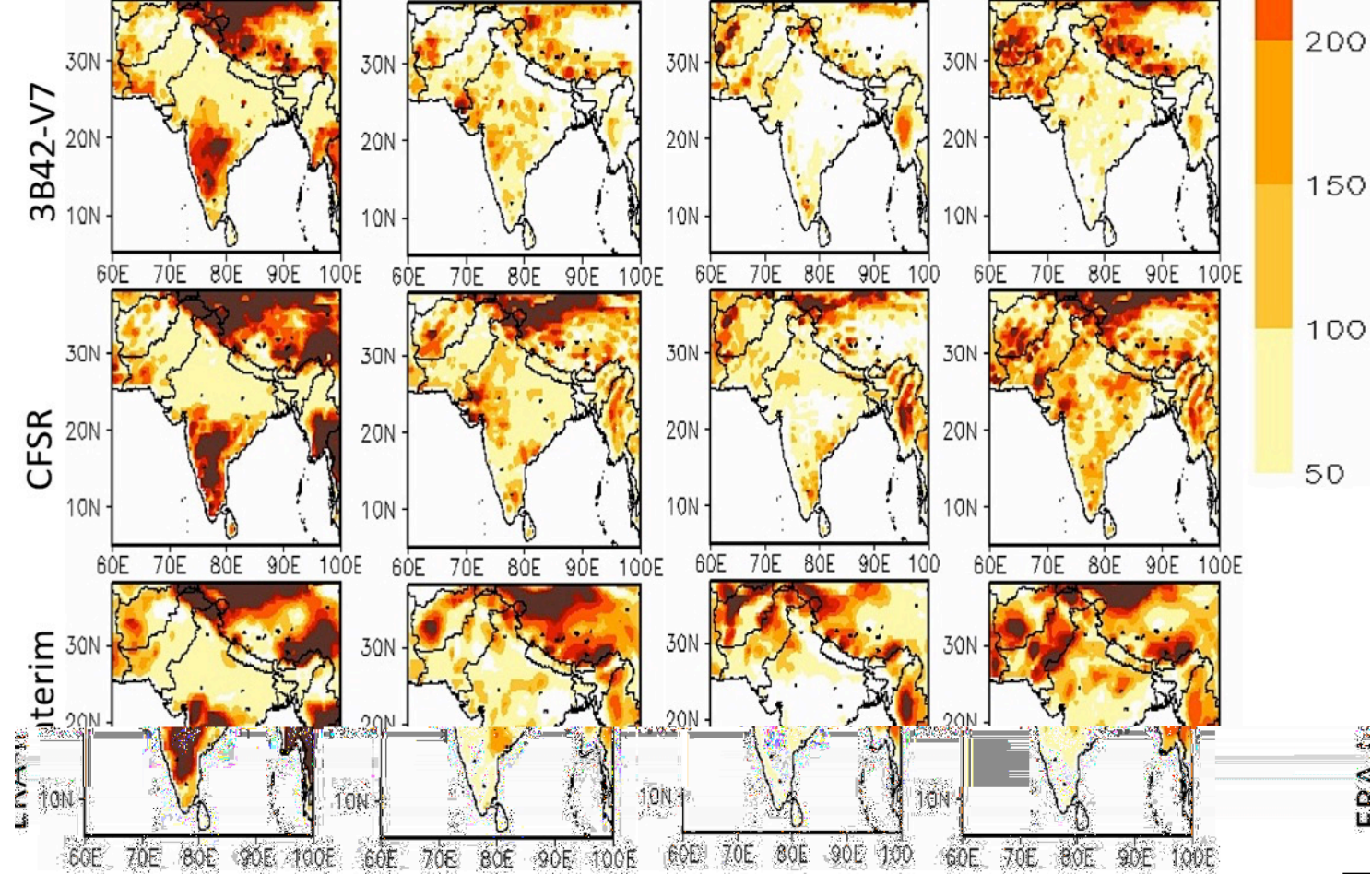

$100 \%$

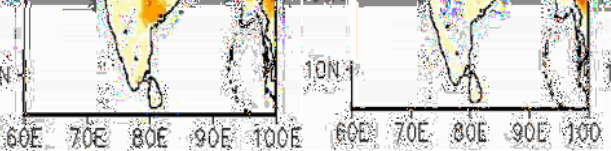

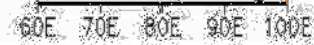

Figure 2.8: Percentage Root Mean Square Error (PRMSE) with respect to APHRODITE seasonal mean precipitation over the Indian Subcontinent for the period $1997 / 98$ to $2006 / 07$. 
The extreme spatial PRMSEs observed during the "cold" winter season mentioned above illustrate important limitations in all gridded precipitation products examined here (including the APHRODITE dataset). Based on the results obtained in Figure 2.6 and Figure 2.8, together with the well-known fact that gauge observations are subject to several sources of systematic and random errors, it is likely that an additional source of error could be associated with the gauge input data (especially when and where gauge stations are sparse and/or snow makes up a large portion of the total precipitation).

\subsubsection{EOF analysis}

To explore the structure of large-scale coherence within the precipitation datasets, we use EOF analysis on the standardized seasonal precipitation anomalies. Results are shown in Figure 2.9. Here we have focused on the first leading mode (EOF1), which accounts for the largest percentage of the total precipitation variance, represented at the bottom left of each spatial plot. While interpreting the EOF patterns, it must be kept in mind that the sign of the patterns is arbitrary (the temporal mean of their PC time series is zero). The spatial pattern of the leading EOF during DJF reveals a large-scale pattern of negative loading over most of the Indian subcontinent with some positive loading over the southern tip of peninsular India, north of the Tibetan Plateau, and over some parts of Myanmar. For APHRODITE, the first winter EOF explains $53 \%$ of the total variance, which is comparable to that of GPCP (50\%). The loading patterns of EOF1 are very much similar for 3B42-V6 and 3B42-V7 in all seasons, albeit with differences in the percentage of variance explained (always higher for 3B42-V7). For DJF, the EOF pattern obtained from CFSR and ERA-Interim resembles APHRODITE's spatial pattern more closely than the one obtained from GPCP, 3B42-V6, and 3B42-V7.

Kar and Rana (2013) used EOF analysis to investigate the impact of the Asian jet on interannual variability of winter precipitation over northwestern India. The authors found that the PC1 and PC2 time series corresponding to EOF1 and EOF2 of DJF zonal winds at $200 \mathrm{hPa}$ represented a pattern similar to El Niño-Southern Oscillation (ENSO) and the North Atlantic Oscillation (NAO)-Arctic Oscillation (AO), respectively, with a statistically significant correlation between the PC time series and winter precipitation. Syed et al. (2009) also found that both ENSO and 
NAO have a significant influence on winter precipitation over southwest-central Asia (including northern Pakistan, Afghanistan, and Tajikistan), where winter precipitation increases (decreases) during the warm (cold) ENSO phase and positive (negative) NAO phase.

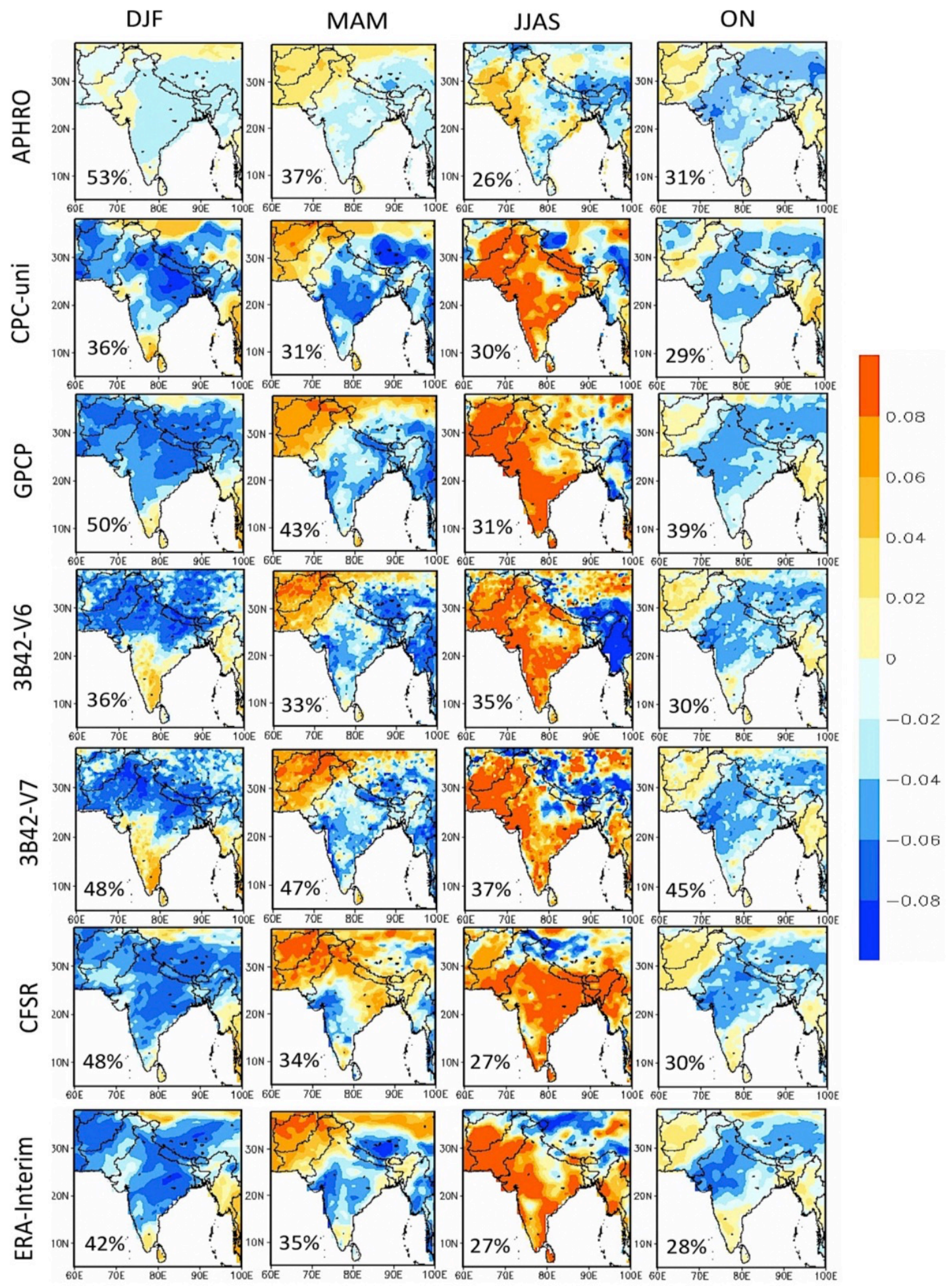

Figure 2.9: Leading EOF of standardized seasonal mean precipitation over the Indian Subcontinent, for each precipitation product for the period 1997/98 to 2006/07. 


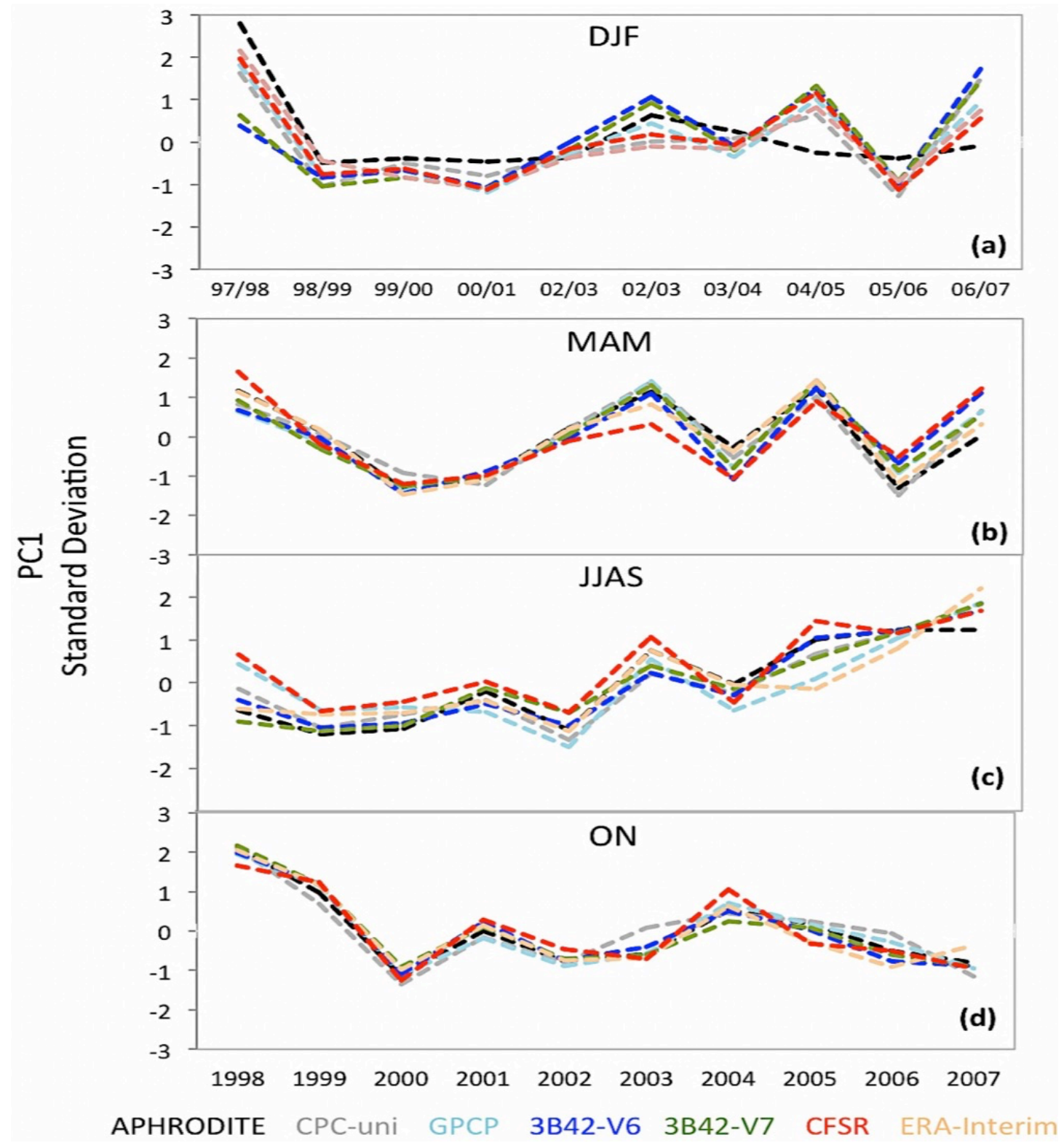

Figure 2.10: Principal Component (PC) time series for the leading EOFs of standardized seasonal mean precipitation (a) winter, (b) pre-monsoon, (c) monsoon and (d) post-monsoon over the Indian Subcontinent for each precipitation product for the period $1997 / 98$ to $2006 / 07$

The time coefficient of our leading EOF, that is, the PC1 of the standardized DJF precipitation anomalies, is shown in Figure 2.10(a). Consistent with the above, we found that the DJF-PC1 time series obtained for all precipitation products corresponds well with the DJF-Niño-3.4 index obtained from the CPC (www.cpc.ncep.noaa.gov/products/analysis_monitoring/ensostuff/ensoyears.shtml) for the period 1997/98-2006/07. The correlation between the DJF-PC1 time series 
and the Niño-3.4 index is found to be statistically significant and greater than 0.7 for all datasets used here.

In MAM, we find that the small area of positive loading over the northwestern region of the subcontinent seen in DJF is persistent and more prominent during MAM for all precipitation products. The loading represents a seesaw-like pattern of positive (negative) loading over the northwestern region (the rest of the subcontinent), which shows similarities with the seasonal mean precipitation distribution pattern over the subcontinent (Figure 2.3). The percentage variance explained by the precipitation products is either comparable to or higher than that of APHRODITE (37\%). However, the structure of loading pattern is slightly different for the reanalysis datasets, with a broader region of positive loading over the northeastern domain, which is not very prominent in any other dataset. Therefore, during MAM the structure of EOF1 from APHRODITE most closely resembles those generated from CPC-uni and the satellite-derived products. The corresponding MAM-PC1 time series (Figure 2.10(b)) is similar to the DJF-PC1 sequence and exhibits the interannual variability present in the premonsoon domain-averaged precipitation time series (figure not shown). All datasets capture the 3-yr (1998-2001) extended winter and premonsoon drought that lasted over Afghanistan, Iran, and Pakistan. According to Barlow et al. (2002), the prolonged drought was linked to the cold phase of ENSO (La Niña) and the unusually warm pool region in the western Pacific Ocean.

The JJAS-EOF1 patterns (Figure 2.9) are characterised by uniform variability over the entire Indian subcontinent. In general, for all precipitation products, the JJAS pattern reveals positive loading over a large part of the subcontinent, with small areas of negative loading over central India and in the northeastern region of the subcontinent. Mishra et al. (2012) reported that the region, for which the JJAS monsoon rainfall oscillates in phase with the leading PC1 time series, includes a large part of the Indian region along with Pakistan, most of the Arabian Sea, and the Bay of Bengal. The percentage of variance explained by the leading EOFs for the satellitederived products $(\mathrm{GPCP}=31 \%, 3 \mathrm{~B} 42-\mathrm{V} 6=35 \%$, and $3 \mathrm{~B} 42-\mathrm{V} 7=37 \%)$ are close to one another but higher than the variance obtained for the two reanalyses products (27\%) and APHRODITE (26\%) dataset. Surprisingly, the APHRODITE JJAS-EOF1 pattern differs in its spatial structure when compared to other products. The expected pattern [as reported by Krishnamurthy and Shukla (2000), Guhathakurta and Rajeevan 2008, Joshi et al. (2012), and Mishra et al. (2012)] is quite well captured by CPC-uni 
and the satellite-derived products, exhibiting a uniform structure of positive loading (0.02-0.08) over a large part of the Indian region and some pockets of negative loading over central and northeastern India. We further investigated the EOF pattern obtained for APHRODITE using a longer time series (1979-2007) and found that the leading EOF showed a close resemblance to the expected pattern. Therefore, it can be suggested that the observed difference in APHRODITE's EOF1 pattern is likely due to the short time of analysis considered here. Most studies cited above show that the PC1 time series of JJAS rainfall is strongly correlated with the all-India-averaged rainfall index; which suggests that EOF1 is a good representation of the dominant mode of the JJAS precipitation variation (flood and drought years). When the standardized JJAS-PC1 series (Figure 2.10(c)) are correlated with their respective seasonal precipitation mean time series, the maximum correlation is found for CPCuni (0.98) and minimum for APHRODITE (0.38). Apparently for the APHRODITE dataset, the relatively poor correlation relates to the inability of the dataset to accurately capture the leading JJAS-EOF1 pattern. Additionally, for GPCP, 3B42-V6, and 3B42-V7 the correlation is found to be $>0.75$, while for CFSR and ERA-Interim it is 0.68 and 0.5 , respectively.

For the postmonsoon season, the spatial structure of EOF1 is similar to that in MAM but with a pronounced northwest-east and northwest-southeast gradient of positive-negative-positive loading over the subcontinent. The region of positive loading over southern peninsular India is relatively small for all products except for CFSR and ERA-Interim. Nair et al. (2013) used EOF analysis of eight global circulation models and found that during October-December the southern peninsular zone remains spatially correlated to the first EOF mode with positive loading over a large region. Kumar et al. (2007) found that only in recent years (1976-2000) has there been an increased relationship between ENSO and the northeast monsoon rainfall occurring over the southern peninsular region of India. Here, PC1 time series (Figure 2.10(d)) is found to be significantly correlated at $95 \%$ confidence level with the corresponding seasonal precipitation time series over the entire subcontinent. However, we did not find a significant correlation between the ENSO index and the PC1 time series, which could possibly be related to the shorter time series of the examined products considered here or due to the problem of domain dependency of EOF solutions (Horel 1981; Richman 1986). 


\subsection{Summary and Conclusions}

The objective of this study was to perform an intercomparison of precipitation products over the Indian subcontinent and to provide useful insights on the reliability and usability of precipitation datasets, over regions that are not well provisioned by rain gauges. To this end, seven precipitation products (APHRODITE, CPC-uni, GPCP, 3B42-V6, 3B42-V7, CFSR, and ERA-Interim) were examined in regard to the seasonal (DJF, MAM, JJAS, and ON) precipitation climate and variability for the period 1997/98-2006/07.

\subsubsection{General comments}

All products performed reasonably well in capturing the main characteristic features of seasonal precipitation variability, particularly over low-elevation plain areas where APHRODITE contains a moderate to dense network of rain gauge stations. Referring to the gauge distribution map in Figure 2.2, there are certain regions/areas where the rain gauge network is dense and perhaps more reliable to intercompare and ascertain the accuracy and biases in the proxy datasets. Hence, over these regions, the data user can expect to have greater confidence in the accuracy and certainty of the results presented here.

Depending on the environmental conditions (season) and geographic location (complex terrain), gauge measurements are subject to several sources of errors that largely limit the accuracy of gauge measurements. Over regions where the spatial coverage of gauge observation is poor, proxy datasets can provide a potential source of information, but their accuracy and reliability can be considered as examined only. Our results show that over the topographically complex and data-sparse regions, pronounced regional and seasonal differences exist between the examined products and the APHRODITE dataset. Based on our relative comparisons (PPD and PRMSE), it may be concluded, though with lesser confidence that in gauge-sparse regions, a potential source of uncertainty in all gauge-based precipitation products is likely associated with the uncertainties and inhomogeneities in gauge measurements itself. 


\subsection{Our interpretation of seasonal comparisons}

For the monsoon season (JJAS), results indicate that the gauge-only (CPC-uni) and satellite-derived precipitation products (GPCP, 3B42-V6, and 3B42-V7) capture the JJAS rainfall variability better than the reanalyses (CFSR and ERA-Interim). The 3B42-V6 displayed a close agreement to APHRODITE, with regard to spatial and domain-averaged statistics for the entire Indian subcontinent. Additionally, 3B42-V7 and CPC-uni demonstrated a reasonable performance over the entire subcontinent and Indian region, respectively. Among the satellite-derived precipitation products, the two post-real-time research products of 3B42 (V6 and V7) outperformed GPCP not only for the monsoon period, but also throughout the year. On the contrary, CFSR and ERA-Interim exhibited a high positive bias over the northeastern region of the subcontinent and the northern flanks of the Tibetan Plateau.

Similar conclusions can be drawn for the postmonsoon season $(\mathrm{ON})$, where reanalyses (especially CFSR) overestimate the seasonal precipitation totals over parts of peninsular India, the northeastern region of the subcontinent, and the Tibetan Plateau. The 3B42-V6 product displays the most reasonable precipitation total, closer to APHRODITE, while 3B42-V7 underestimates the seasonal precipitation amount in comparison to APHRODITE and other examined products. Results show that the gauge-based CPC-uni largely underestimates precipitation along the foothills of the Himalayas, the Tibetan Plateau, and Myanmar in all seasons. To improve the quality of the product, both in accuracy and reliability over these regions, use of additional rain gauge stations is highly desirable.

Likewise, for the premonsoon season (MAM), the satellite-derived precipitation products perform better than the reanalyses estimate. Relative to the APHRODITE dataset, CFSR and ERA-Interim consistently overestimate precipitation over the topographically complex and data-sparse Tibetan Plateau and the Hindu KushKarakoram mountain ranges in the northwestern region of the subcontinent. Consequently, this could account for the fact that reanalysis datasets overestimate more in regions with complex terrain than in flatter regions. Impressively, with regard to the seasonal and interannual variability of premonsoon precipitation over the mountainous regions, the newly released 3B42-V7 appears to provide useful information in comparison to CPC-uni, GPCP, and 3B42-V6. 
For the winter season (DJF), all precipitation products display less agreement with respect to APHRODITE, illustrating important limitations in all the gridded precipitation, including our reference dataset. Based on the aforementioned reasons, a major source of uncertainty, particularly during the winter months over the datasparse regions, is likely the representativeness and undercatch error in gauge measurements that tends to artificially inflate the existing errors in satellite and reanalyses precipitation estimates. In spite of the large winter biases in reanalyses (CFSR and ERA-Interim) and the newly released 3B42-V7, we are fairly confident that these precipitation products could be a useful source of information over the datasparse regions. However, commenting on the accuracy and robustness of these products requires further investigation.

Nonetheless, the best approach to fill in these gaps is to recognise the relative strength and weaknesses of each precipitation product and to extract maximum possible information for their constructive applicability and usability. We anticipate that the outcomes of this study will benefit data users, model developers, and researchers of hydrology and climatology to understand the relevant seasonal characteristics of each precipitation product used in this study.

In closing, we would like to mention that future work will address the spatiotemporal variations of winter precipitation in the northwestern region of the Indian subcontinent using additional datasets and variables. 


\section{Chapter 3 Wintertime precipitation climatology and ENSO sensitivity over central southwest Asia}

Published in the International Journal of Climatology (Rana et al. 2017)

\section{CITATION}

Rana, S., J. McGregor, and J. Renwick, 2017. Wintertime precipitation climatology and ENSO sensitivity over central southwest Asia. International Journal of Climatology, 37(3), 1494-1509.

Authorship contributions to this research article include the following:

Sapna Rana - Wrote the manuscript and managed all co-author feedback, reviewer comments, and editing of proofs. This author collated and processed all data, developed initial interpretations, and produced all figures.

James McGregor - Academic Supervisor; provided feedback on drafts and aided in the interpretation of the results and text edits.

James Renwick - Academic Supervisor; provided feedback on drafts and aided in the interpretation of the results and text edits. 


\subsection{Abstract}

This study presents a detailed comparison of ten precipitation products over the central southwest Asia (CSWA) region. The spatial characteristics and temporal variations of wintertime precipitation over CSWA region are assessed using four gauge-only [Asian Precipitation - Highly Resolved Observational Data Integration Towards Evaluation of Water Resources (APHRODITE), Climate Prediction Center Unified Rain gauge (CPC-uni), Global Precipitation Climatology Center Full Data Reanalysis (GPCC) and Climate Research Unit (CRU)]; three satellite-derived (3B42V6, 3B42-V7 and GPCP-1DD) and three reanalysis [Climate Forecast System Reanalysis (CFSR), ERA-Interim and Modern-Era Retrospective Analysis for Research and Applications (MERRA)] precipitation products. The analysis is performed for two different periods: (1979-2007) for the gauge-only/reanalyses and (1998-2007) for the satellite-derived products. Using an ensemble average of four gauge-only observational data sets as our reference, we carry out comprehensive qualitative assessment of the uncertainties/biases associated with each data set. Additionally, we examine the relationship pattern between CSWA wintertime precipitation and El Niño-Southern Oscillation (ENSO) phases. In the gauge-only category, APHRODITE and GPCC perform better than CPC-uni and CRU data sets in terms of the spatial and temporal variations of skill matrices. Overall, GPCC shows the best performance (including the precipitation sensitivity to ENSO events) and is the preferable observational data set for long-term climatological analysis over the CSWA region. Among the satellite-derived precipitation products, 3B42-V7 displays the most realistic wintertime precipitation distribution pattern when compared to 3B42-V6 and GPCP-1DD; however, efforts are needed to further improve the accuracy of satellite-derived products over the dry arid and semi-arid areas of CSWA. In the reanalysis category, MERRA's performance is relatively better than CFSR and ERA-Interim, although significant biases exist in all of the reanalyses due to overestimation of precipitation over the mountainous regions of CSWA.

\subsection{Introduction}

This study builds on the findings of Chapter 2 [Rana et al. (2015)] which evaluated precipitation products from gauge, satellite and reanalyses over the Indian 
subcontinent. Key results from the study highlighted that all examined products perform reasonably well for all seasons and/or regions, except winters, when significant biases exist over the northwest region of the Indian subcontinent.

Winter precipitation is of considerable importance for the northwest region as it brings significant snowfall to the northern mountains, which serve as a strategic seasonal storage of water resources providing freshwater to the downstream areas (Barnett et al., 2005; Immerzeel et al., 2009). In addition to snow over the mountain areas, winter rain-bearing systems yield a substantial amount of rainfall in the submountainous and low elevation plains (Malik et al., 2012). Rainfall that occurs along the northern plains is of great importance for the region's agricultural economy and also to the lives of several hundred million people who directly depend on the seasonal precipitation for their domestic, agricultural and industrial needs (Eriksson et al., 2009).

Because of the importance of winter precipitation (rainfall and snow) in the northwest region of the Indian subcontinent (Bookhagen and Burbank, 2010; Singh et al., 2011; Kar and Rana, 2014), recent studies (Javanmard et al., 2010; Lorenz and Kunstmann, 2012; Tanarhte et al., 2012; Palazzi et al., 2013; Rana et al., 2015) have examined the reliability of precipitation data sets over the region/sub-regions; but their results are ambiguous in terms of performance. Findings from these studies have emphasized that in this part of the world, a range of factors (e.g. sparse or nonexistent gauge network, topographical relief, precipitation type [snow], political sensitivity, and so on) can introduce large uncertainties in observational data sets.

This work aims to extend Rana et al. (2015) by comprehensively assessing and documenting the characteristics of wintertime precipitation described by currently available data sets over the study region. We also examine the El Niño-Southern Oscillation (ENSO) - sensitivity of precipitation in the region, in each data set. An ensemble of multiple observational data sets is used as a 'reference' data set to qualitatively assess the uncertainties associated with each precipitation product. Here, we consider a geographically larger study domain than in Rana et al. (2015) referred as the central southwest Asia (CSWA) region.

The remainder of the chapter is structured as follows. Section 3.3 presents the study region, data sets used and the methodology adopted for analysis. Section 3.4 outlines the results and discussion followed by the conclusions in Section 3.5. 


\subsection{Study region, precipitation data sets and methodology}

\subsubsection{Study region}

The CSWA region, bounded by $20^{\circ}-47^{\circ} \mathrm{N} ; 40^{\circ}-85^{\circ} \mathrm{E}$ (Figure 3.1), is characterised by the interaction of complex topography and circulation patterns that strongly modulate the weather systems and precipitation patterns over the region. Dominated by mountain ranges from west to east-the Albroz, Zagros, Hindu Kush, Pamirs, Karakoram and Himalayas - the topography of the region isolates the western and the northern flanks of the domain from the moist air masses that originate in the Indian Ocean. Precipitation in the west is mainly dominated by westerly and southwesterly wind systems that travel eastward in the form of waves mostly through the Mediterranean and Caspian Sea regions (Treydte et al., 2006). During winter months, these mid-latitude depressions move to their lowest latitudes, and travel eastward across countries such as Iran, Afghanistan, Pakistan and northwest India, disturbing the normal circulation patterns (Dimri, 2007; Kar and Rana, 2014).

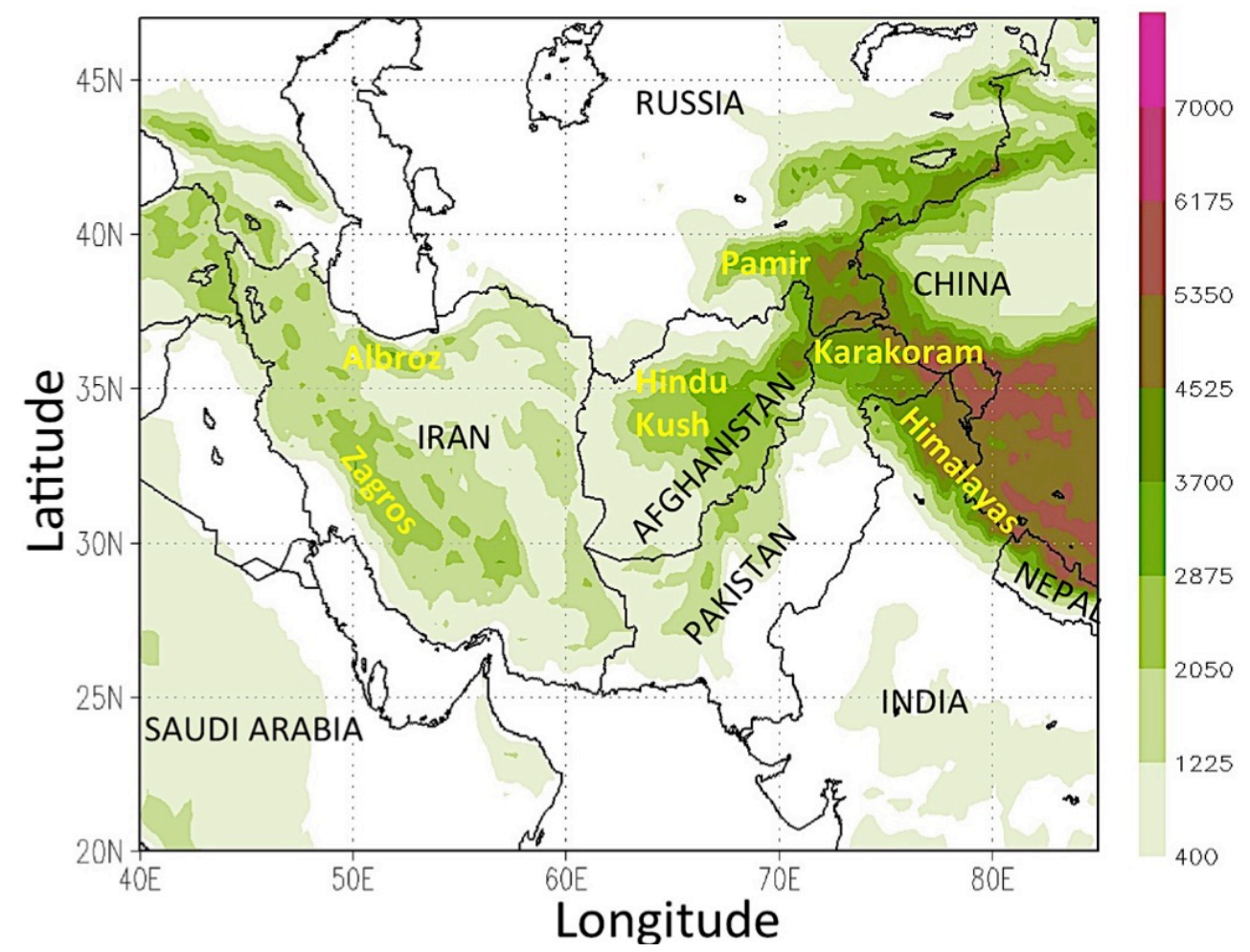

Figure 3.1: Topography (m) of Central southwest Asia (CSWA) 


\subsubsection{Precipitation data sets}

Ten data sets are analysed in this study: gauge-only, reanalyses and satellitederived. All data sets are widely used, freely available and well documented. The four gauge-only data sets are: (1) Asian Precipitation - Highly Resolved Observational Data Integration Towards Evaluation of Water Resources (APHRODITE) [hereafter APHRO], (2) Climate Prediction Center Unified Rain gauge (CPC-uni), (3) Climate Research Unit (CRU) and (4) Global Precipitation Climatology Center Full Data Reanalysis (GPCC). The three satellite-derived precipitation products are: (1) Tropical Rainfall Measuring Mission (TRMM) post real-time research product 3B42 Version 6 (hereafter 3B42-V6), (2) TRMM post real-time research product 3B42 Version 7 (hereafter 3B42-V7), and (3) Global Precipitation Climatology project (GPCP) 1 Degree Daily (1DD). The three reanalysis products are (1) Climate Forecast System Reanalysis (CFSR), (2) European Centre for Medium-Range Weather Forecasts (ECMWF) Interim Re-Analysis (ERA-Interim), and (3) Modern-Era Retrospective Analysis for Research and Applications (MERRA). A summary of the main characteristics, documentation and sources of all data sets used in this work is given in Table 3.1 .

Table 3.1: Main characteristics of precipitation products used in this study

\begin{tabular}{|c|c|}
\hline Datasets & Main characteristics \\
\hline APHRODITE & $\begin{array}{l}\text { Asian Precipitation }- \text { Highly Resolved Observational Data Integration Towards } \\
\text { Evaluation of Water Resources [APHRO_V1101] (Yatagai et al. 2012). } \\
\text { Available from: Research Institute for Humanity and Nature (RIHN) and the } \\
\text { Meteorological Research Institute of Japan Meteorological Agency (MRI/JMA). } \\
\text { Spatial/temporal resolution: } 0.5^{\circ} / \text { Daily }(1951-2007) \text {. Data source: Gauge. } \\
\text { Domain: Monsoon Asia domain }\left(60^{\circ} \mathrm{E}-150^{\circ} \mathrm{E}, 15^{\circ} \mathrm{S}-55^{\circ} \mathrm{N}\right) \text { and Middle East } \\
\left(20^{\circ} \mathrm{E}-65^{\circ} \mathrm{E}, 15^{\circ} \mathrm{S}-45^{\circ} \mathrm{N}\right) \text {. http://www.chikyu.ac.jp/precip/products/index.html. }\end{array}$ \\
\hline CPC-UNI & $\begin{array}{l}\text { CPC Climate Prediction Center Unified Rain gauge data Version 1.0. (Chen et } \\
\text { al. 2008) Available from: National Oceanic and Atmospheric Administration } \\
\text { (NOAA) Climate Prediction Center (CPC). Spatial/temporal resolution: } \\
0.5^{\circ} / \text { Daily (1979-present). Data source: Gauge. Domain: Global (land-only). } \\
\text { https://climatedataguide.ucar.edu/climate-data/cpc-unified-gauge-based- } \\
\text { analysis-global-daily-precipitation }\end{array}$ \\
\hline $\mathrm{CRU}$ & $\begin{array}{l}\text { Climate Research Unit Version 3.22. (Harris et al. } 2 \text { 014). Available from: } \\
\text { University of East Anglia Climatic Research Unit (CRU). Spatial/temporal } \\
\text { resolution: 0.5\%/Monthly (1901-2013). Data source: Gauge. Domain: Global } \\
\text { (land-only). } \\
\text { http://catalogue.ceda.ac.uk/uuid/3f8944800cc48e1cbc } 210 a 5 e e 12 \mathrm{~d} 8542 \mathrm{~d}\end{array}$ \\
\hline
\end{tabular}


GPCC

3B42-V6

3B42-V7

GPCP-1DD

CFSR

ERA-Interim

MERRA
Global Precipitation Climatology Center Full Data Reanalysis Version 6 (Schneider et al. 2014). Available from: Deutscher Wetterdienst (DWD, National Meteorological Service of Germany). Spatial/temporal resolution: 0.5\%/Monthly (1901-2010). Data source: Gauge. Domain: Global (land-only). http://www.esrl.noaa.gov/psd/data/gridded/data.gpcc.html.

Tropical Rainfall Measuring Mission (TRMM) post real-time research product 3B42 Version 6 (3B42-V6) (Huffman et al. 2007). Available from: National Aeronautics and Space Administration (NASA) Goddard Space Flight Center (GSFC). Spatial/temporal resolution: 0.25\%/3-hourly (1998-2011). Data source: Satellite-derived. Domain: Global $\left(50^{\circ}\right.$ to $\left.50^{\circ} \mathrm{S}\right)$. http://precip.gsfc.nasa.gov/

Tropical Rainfall Measuring Mission (TRMM) post real-time research product 3B42 Version 7 (3B42-V7) (Huffman et al. 2011). Available from: National Aeronautics and Space Administration (NASA) Goddard Space Flight Center (GSFC). Spatial/temporal resolution: 0.25\%/3-hourly (1998-present). Data source: Satellite-derived. Domain: Global $\left(50^{\circ}\right.$ to $\left.50^{\circ} \mathrm{S}\right)$. http://precip.gsfc.nasa.gov/

Global Precipitation Climatology Project Version 1.2 (Huffman et al. 2001). Available from: National Aeronautics and Space Administration (NASA) Goddard Space Flight Center (GSFC). Spatial/temporal resolution: 1\%/Daily (1996-present). Data source: Merged satellite and gauge. Domain: Global. http://precip.gsfc.nasa.gov/

Climate Forecast System Reanalysis (Saha et al., 2010). Available from: National Centers for Environmental Prediction (NCEP). Spatial/temporal resolution: $0.3125^{\circ} /$ Daily (1979-2010). Data source: Reanalysis. Domain: Global. http://rda.ucar.edu/datasets/ds093.1/

European Centre for Medium-Range Weather Forecasts (ECMWF) Interim ReAnalysis (Dee et al., 2011). Available from: ECMWF. Spatial/temporal resolution: $0.75^{\circ} /$ Daily (1979-present). Data source: Reanalysis. Domain: Global. http://rda.ucar.edu/datasets/ds627.0/

Modern-Era Retrospective Analysis for Research and Applications (Rienecker et al. 2011). Available from: National Aeronautics and Space Administration (NASA). Spatial/temporal resolution: 0.125\%/Daily (1979-present). Data source: Reanalysis. Domain: Global. http://disc.sci.gsfc.nasa.gov/daacbin/FTPSubset.pl

To examine the dependence of winter seasonal precipitation on the ENSO [warm (El Niño) and cold (La Niña)] phases, we use the Oceanic Niño Index (ONI) obtained from www.cpc.ncep.noaa.gov/products/analysis_monitoring/ensostuff/ensoyears.shtm 1 for the Niño-3.4 region $\left(5^{\circ} \mathrm{N}-5^{\circ} \mathrm{S}, 120^{\circ}-170^{\circ} \mathrm{W}\right)$.

\subsubsection{Methodology}

The precipitation products use varying formats or grid resolution (see Table 3.1), therefore to facilitate direct comparison, a common $0.5^{\circ} \times 0.5^{\circ}$ regular 
latitude/longitude grid was chosen. Reanalysis data sets were extracted from the Gaussian grid GRIB (GRIdded Binary) format and remapped to the $0.5^{\circ} \times 0.5^{\circ}$ grid. To perform spatial grid transformation, bilinear interpolation technique was used in which, each point of the output grid is generated from its four neighbouring points in the input grid using a weighted approach. Since the ground-based observational network is rather sparse over CSWA (Javanmard et al., 2010; Palazzi et al., 2013; Rana et al., 2015), we compute an ensemble average of four gauge only data sets to minimize the contribution of observational uncertainties. Recently, Tanarhte et al. (2012) adopted a similar methodology to intercompare precipitation and temperature data sets over the Mediterranean and the Middle East regions.

The ensemble mean (EM) is calculated using:

$$
(i, t)=\frac{1}{N} \sum_{n=1}^{N} o_{n}(i, t)
$$

$O_{n}(i, t)$ is the nth ensemble member at position $i$ and time $t$; and $N=4$ is the total number of ensemble members (i.e. the four gauge-only datasets).

Because of different availability period of precipitation products, a common overlap period of 1979-2007 was chosen for gauge-only/reanalysis data sets; while 1998-2007 was considered for satellite products. Using the above equation, two sets of reference ensemble means (EM1 and EM2) were computed. Hereafter, EM1 (1979-2007) is the reference for gauge-only/reanalysis data sets; and EM2 (19982007) is for satellite-derived precipitation products only.

Several statistics are calculated: averages ( $\mathrm{mm} /$ day), mean bias (MB, $\mathrm{mm} /$ day), correlation coefficient (CC) and root mean square error (RMSE, mm/day), to measure the uncertainty in individual precipitation products relative to their EM reference data set (EM1 or EM2).

$$
\text { Average } \overline{(X)}=\frac{1}{m} \sum_{t=1}^{m} X_{t}
$$

where $n$ is number of data points, and $X$ is the precipitation product under comparison from gauge, satellite, or reanalyses. 
$\operatorname{Bias}(M B)=\frac{1}{n} \sum_{i=1}^{n}\left(P_{i}-O_{i}\right)$

Correlation $(C C)=\frac{\sum_{i=1}^{n}\left(O_{i}-\bar{O}\right)\left(P_{i}-\bar{P}\right)}{\sqrt{\sum_{i=1}^{n}\left(O_{i}-\bar{O}\right)^{2} \sum_{i=1}^{n}\left(P_{i}-\bar{P}\right)^{2}}}$

Root mean square error $(R M S E)=\sqrt{\frac{1}{n} \sum_{i=1}^{n}\left(P_{i}-O_{i}\right)^{2}}$

$O_{i}=i^{\text {th }}$ value in the reference data; $P_{i}=i^{\text {th }}$ value of the precipitation product under comparison and $\mathrm{n}$ are the number of data points.

The analysis also includes scatter plots and empirical cumulative distribution function (cdf) for all data sets. A scatter plot is a simple two-dimensional data visualization technique that uses data points to represent the values obtained from two different variables - one plotted along the x-axis and the other plotted along the $y$ axis. The scatter plot helps to determine what kind of relationship there might be between the two variables. On the other hand, the cumulative distribution function $F$ for a real-valued random variable $X$, evaluated at $x$, is the probability that $X$ will take a value less than or equal to $x$. This is expressed as:

$F_{X}(x)=\operatorname{Pr}(X \leq x)$, for all $x \in R$

In a cdf plot, the vertical axis is the probability that falls between zero and one; and the horizontal axis is the allowable domain for the given probability function.

Based on the ONI index for the period 1979-2007, seven El Niño years (1982/1983, 1986/1987, 1987/1988, 1991/1992, 1994/1995, 1997/1998, 2002/2003) and five La Niña (1984/1985, 1988/1989, 1998/1999, 1999/2000, 2005/2006) are considered for preparing composites of winter precipitation anomalies. Composites are constructed by removing the mean for neutral years from the means for the 'warm' (El Niño) and the 'cold' (La Niña) years, using the classification of historical ENSO phases (warm, neutral and cold). Note that there are fewer ENSO events 
considered in the composite analysis for the satellite-derived data sets [i.e. two El Niño (1997/1998, 2002/2003) and three La Niña years (1998/1999, 1999/2000, $2005 / 2006)]$ due to the shorter (10-year) period of the data availability.

\subsection{Results}

\subsubsection{Climatology}

Winter precipitation climatology for each data set is shown in Figure 3.2. All products coherently reproduce the broad features of winter season precipitation distribution over the region. A number of topographically induced regional features can be seen, e.g. the zones of orographic maxima - one along the slopes of the Zagros Mountains, and a second over the Hindu-Kush Karakoram and the western Himalayan mountain ranges. Other less pronounced local features are also present along the southern (eastern) coast of the Caspian (Black) Sea.

Qualitative comparison of the results shows that among the gauge-only precipitation products, regional features appear particularly less pronounced in CPCuni. Also, CRU fails to reflect the orographic maxima but shows comparatively higher and regionally spread precipitation totals over the Hindu-Kush Karakoram and the Himalayan mountain slopes. APHRODITE and GPCC show a very similar spatial distribution and a better representation of regional features. Note that APHRODITE and GPCC include a higher density of stations in comparison to other individual gauge data sets considered in this study (Zhao and Dirmeyer, 2003; Yatagai et al., 2009; Schneider et al., 2014; Gebregiorgis and Hossain, 2015).

All three reanalysis products (CFSR, ERA-Interim and MERRA) illustrate a strong influence of orography. ERA-Interim shows a smooth spatial distribution of precipitation, while CFSR clearly reproduces small-scale topographic features likely due to the improved representation of the orography or the high spatial resolution of the data set (Saha et al., 2010). Similarly, MERRA also reflects the effect of underlying topography fairly well, which again may be related to the higher horizontal resolution of the product in comparison to ERA-Interim (see Table 3.1). Compared to ground-based measurements, the reanalysis data sets exhibit similar precipitation patterns and tend to show relatively higher precipitation values over the maximum precipitation zones. This is also reflected in the domain average mean 
values for $\mathrm{CFSR}=1.08$, ERA-Interim $=0.97$ and $\mathrm{MERRA}=0.82 \mathrm{~mm} / \mathrm{day}$. The tendency of reanalysis data sets to overestimate precipitation is possibly related to the fact that (1) reanalyses estimate total precipitation (rainfall plus snow), and thus may overestimate snow with respect to rainfall during winter season (Palazzi et al., 2013) and (2) snow underestimates are highly variable in the case of gauge-measured precipitation, and may reach a factor of 2 or more (Rasmussen et al., 2012).
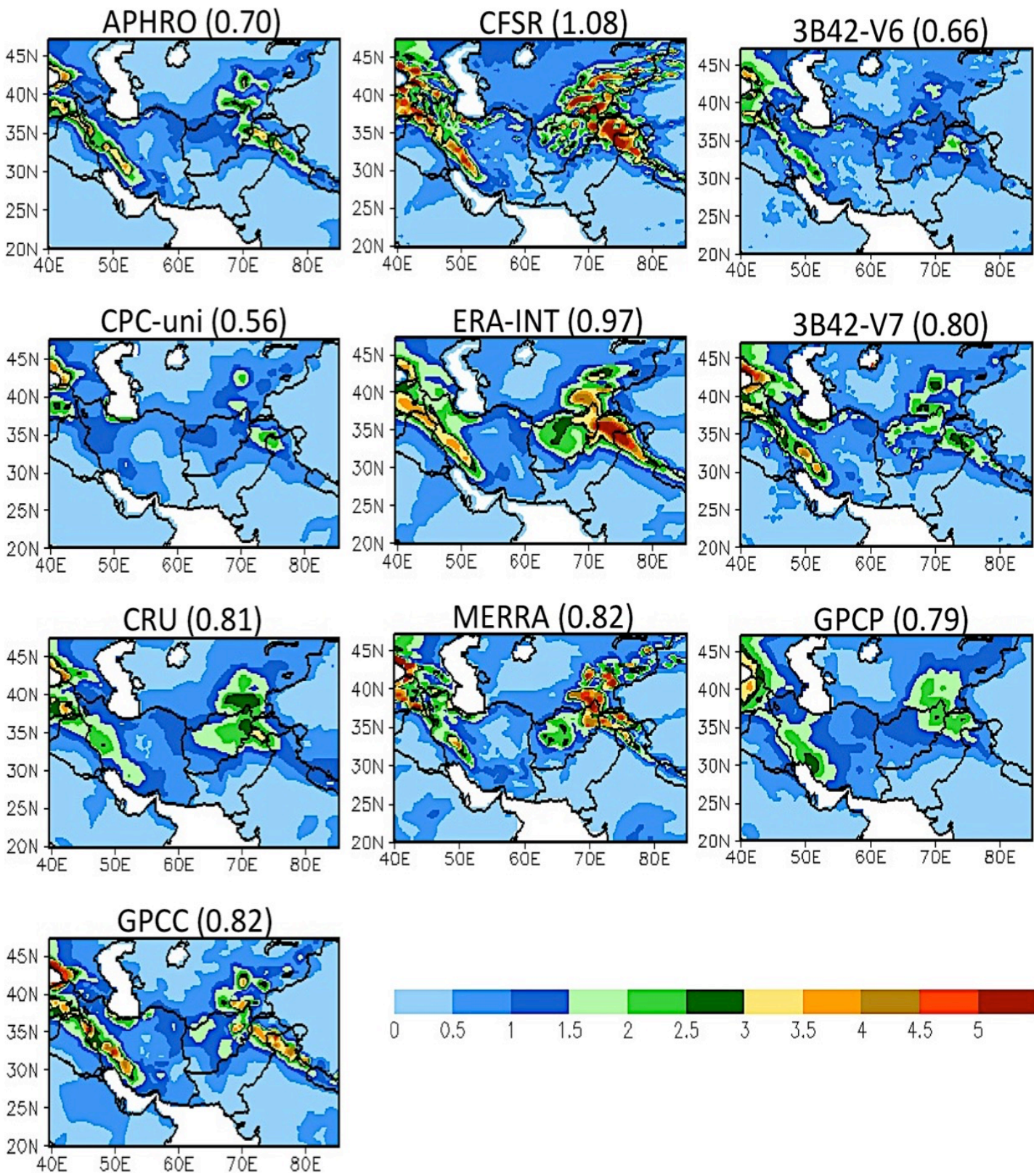

Figure 3.2: Spatial distribution of winter (DJFMA) precipitation ( $\mathrm{mm} /$ day) over CSWA. The time period of analysis for APHRODITE, CPC-uni, CRU, GPCC, CFSR, ERA-Interim and MERRA is (1979-2007); and for 3B42-V6, 3B42-V7 and GPCP1DD is (1998-2007). The domain average mean values are given in the parentheses. 
Among the satellite-derived products, 3B42-V7 exhibits a better spatial representation of precipitation than 3B42-V6 and GPCP-1DD. Though 3B42-V6 captures the seasonal distribution pattern of winter precipitation, the data set fails to capture the orographic precipitation over the Hindu-Kush Karakoram and the western Himalayan mountain ranges (as seen 3B42-V7). According to Huffman and Bolvin (2014), the largest difference between 3B42-V7 and 3B42-V6 occurs in mountainous regions due to the changes in 3B42-V7's Precipitation Radar algorithm, which uses a higher resolution elevation map based on Shuttle Radar Topography Mission data with 30-arc-seconds spacing (SRTM30) over India, Tibet and South America (TRMM Precipitation Radar Team, 2011). In addition, 3B42-V7 uses the new GPCC 'full' gauge analysis against its counterpart V6, which incorporates the previous GPCC monitoring product up through April 2005 and then the Climate Assessment and Monitoring System (CAMS) analysis (Huffman et al., 2011). Similar to CRU, GPCP1DD fails to resolve the orographic pattern of precipitation and exhibits relatively higher domain average totals $(\mathrm{CRU}=0.81$; GPCP-1DD $=0.79)$. The limitation of GPCP-1DD over the 3B42 precipitation estimates could be associated with (1) in regions with low gauge density, GPCP-1DD analysis seems to be influenced more by the gauges (Gruber et al., 2000), while TRMM estimates are influenced more by the satellite measurements and (2) to the coarser resolution of GPCP-1DD in comparison to TRMM estimates. The above conclusion is further supported by consideration of Figure 3.3, showing the performance of each data set for the period 1979-2007 relative to the ensemble mean (EM1) time series.

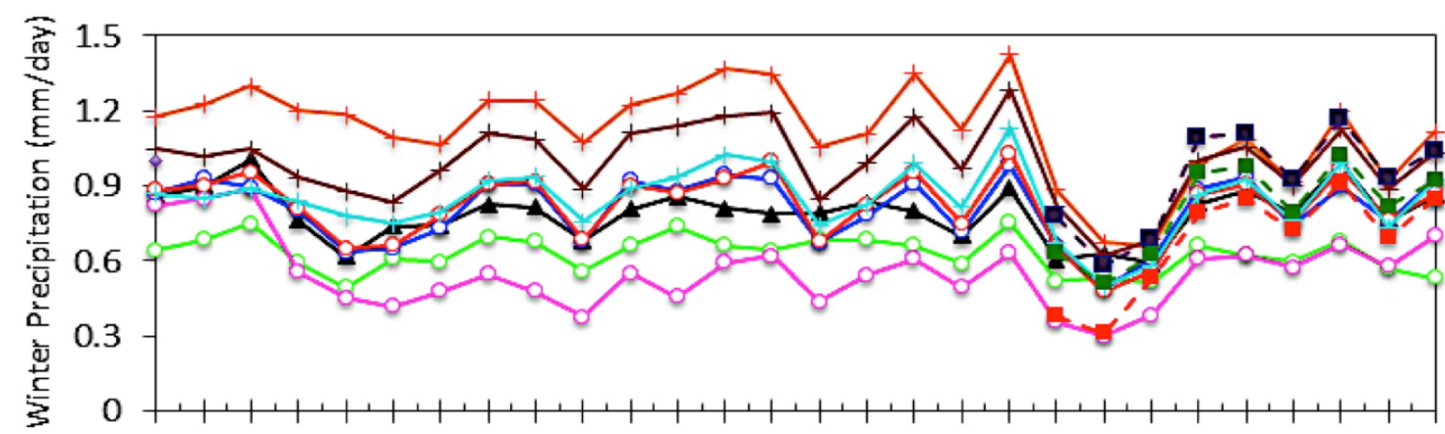

19791981198319851987198919911993199519971999200120032005

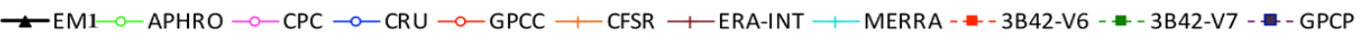

Figure 3.3: Interannual variability of winter (DJFMA) precipitation ( $\mathrm{mm} /$ day) over CSWA. The time period of analysis for APHRODITE, CPC-uni, CRU, GPCC, CFSR, ERA-Interim and MERRA is (1979-2007); and for 3B42-V6, 3B42-V7 and GPCPIDD is (1998-2007). 
APHRODITE and CPC-uni produce the lowest precipitation totals (between 0.3 and $0.9 \mathrm{~mm} /$ day), while GPCC and CRU measure slightly higher precipitation amounts compared to the EM1 values. In the satellite-derived category, 3B42-V6 (GPCP-1DD) tends to underestimate (overestimate) the seasonal precipitation values, whereas 3B42-V7 exhibits a good agreement with the EM1 time series, in phase and amplitude. Reanalysis products show a clear pattern of overestimation, but in comparison to CFSR and ERA-Interim estimates MERRA appears to capture the EM1 inter-annual variability more closely. In spite of these differences, Figure 3.3 shows that in recent years (post-1998) the error bar in reanalysis precipitation estimates has reduced appreciably. This improved phase-amplitude relationship noted in the mid-1990s is a direct result of the advent in the variational analysis techniques - 3DVAR, 4DVAR and the ensemble-based analysis method that brought advances in the quality of data-assimilation systems and improvements in the observational inputs, in particular satellite data (Uppala, 2007; Saha et al., 2010; Bosilovich et al., 2013). All three reanalyses (ERA-int, CFSR and MERRA) perform direct assimilation of large quantities of satellite radiances, and apply automated variational schemes for correcting biases in the satellite radiances (Saha et al., 2010; Dee et al., 2011; Rienecker et al., 2011).

\subsubsection{Spatial analysis}

Figure 3.4 presents the winter precipitation climatology for the gaugeonly/reanalysis reference (EM1) and the satellite data set reference (EM2). In comparison to CPC-uni and CRU precipitation climatology (see Figure 3.2), the two spatial EM's (EM1 and EM2) exhibit a close resemblance to the APHRODITE and GPCC spatial climatology plots and look realistic. This suggests that in regions with sparse gauge network coverage, an ensemble of data sets is more reliable than selecting any individual data set as a reference. For each analysis (Figure 3.2 and Figures 3.4 to 3.7 ), the corresponding domain average values are given in parentheses. 


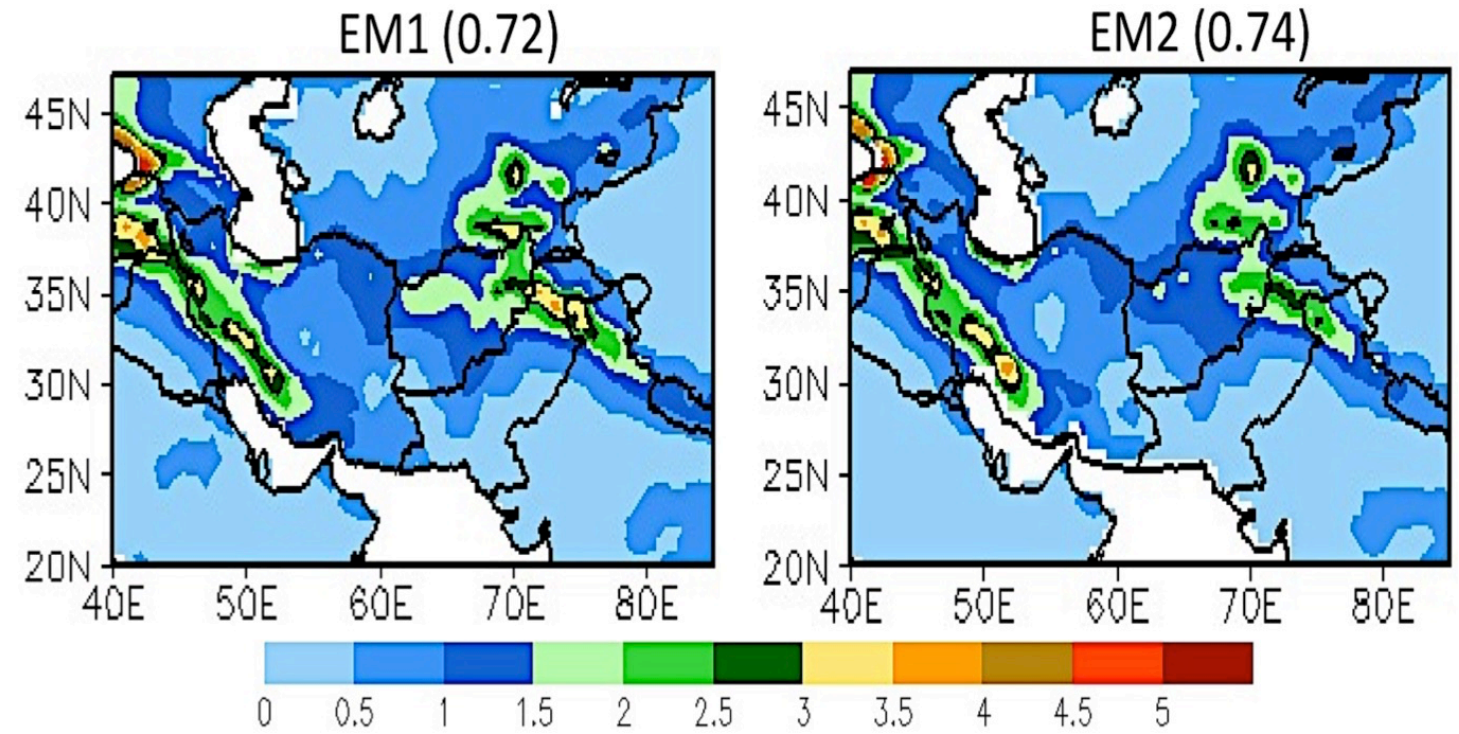

Figure 3.4: Ensemble Mean of winter (DJFMA) precipitation (mm/day) over CSWA: EM1 (1979-2007) is the reference ensemble mean for gauge-only/reanalysis products; and EM2 (1998-2007) is the reference ensemble mean for the satellitederived datasets. The domain average mean values are given in the parentheses.

Figure 3.5 presents the spatial distribution of the MB calculated for the gaugeonly/reanalyses (satellite-derived) products, against the corresponding spatial ensemble means EM1 (EM2). All products exhibit greater bias (positive and negative) in regions where the relief has a pronounced impact on precipitation. CPC-uni (CFSR) tends to underestimate (overestimate) winter precipitation considerably, with a maximum under- (overestimation) of -2.5 (8) $\mathrm{mm} /$ day. Similarly, APHRODITE (ERA-Interim and GPCP-1DD) exhibits spatially wide areas of negative (positive) values, resulting in an overall tendency to under- (overestimate) precipitation for the CSWA region as a whole. 3B42-V7 shows a better agreement than V6, especially over high-elevations and high-latitude regions. Overall, among all precipitation products, the performance of 3B42-V7 and GPCC appears to be relatively better, though the two data sets tend to slightly overestimate winter precipitation along the mountainous slopes in western and eastern periphery, respectively, of the CSWA region. 

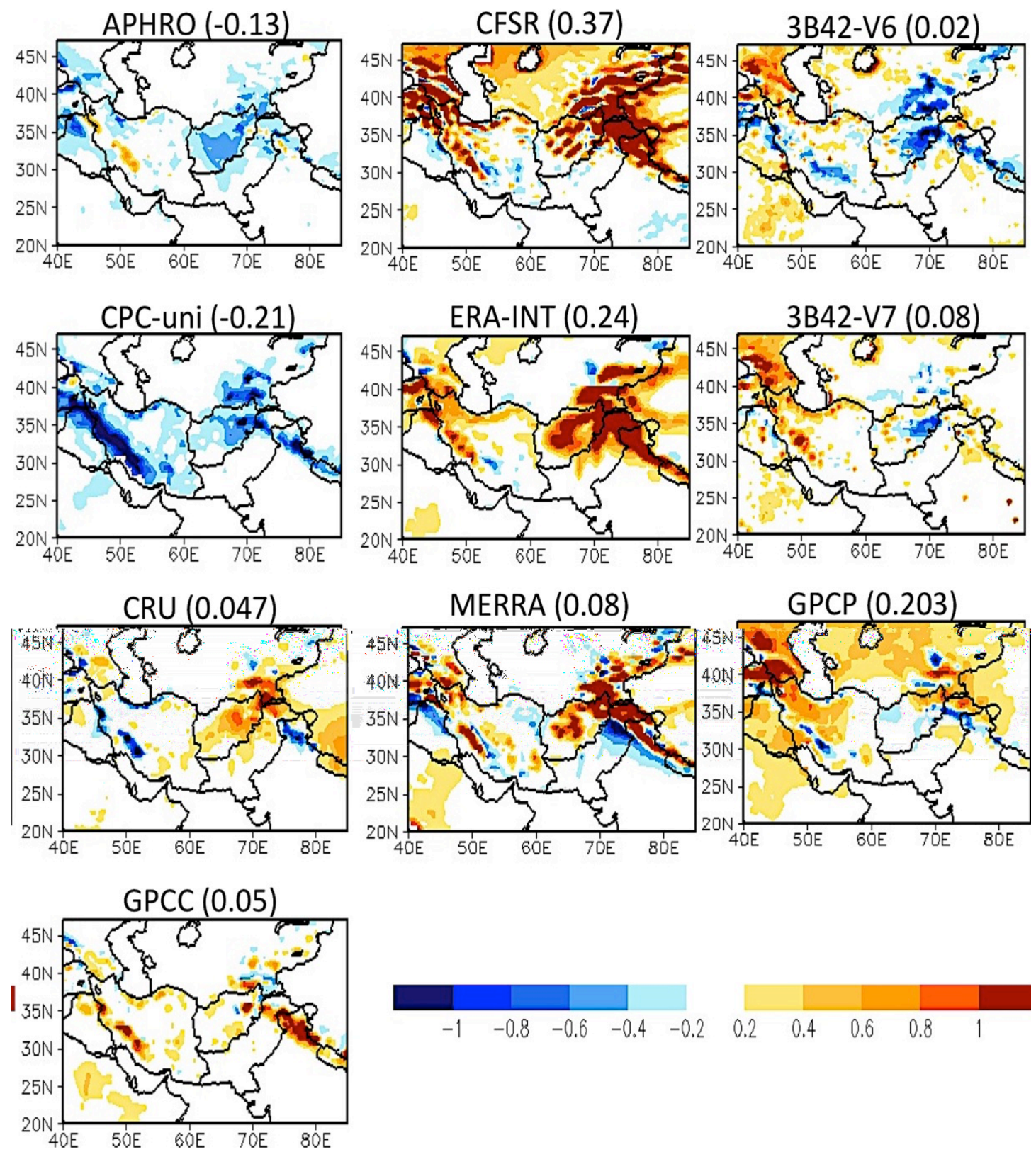

Figure 3.5: Spatial distribution of winter (DJFMA) mean bias (mm/day) against the corresponding reference ensemble mean (EM1/EM2) over CSWA. The time period of analysis for APHRODITE, CPC-uni, CRU, GPCC, CFSR, ERA-Interim and MERRA is (1979-2007); and for 3B42-V6, 3B42-V7 and GPCP-1DD is (1998-2007). The domain average mean values are given in the parentheses.

In addition, the spatial RMSE plot shown in Figure 3.6 is more-or-less consistent with the MB spatial plot presented in Figure 3.5, suggesting that the systematic error dominates over the random error in the total RMSE. The RMSE is much larger over mountainous regions than in low-lying areas, indicating that the 
accuracy of gridded precipitation data sets generally decreases with altitude. Over the high-elevation mountain slopes and tops, the RMSE values are generally higher for the reanalysis products than those obtained for the satellite and/or gauge-only data sets. The lower (higher) RMSE values for the gauge/satellite (reanalysis) products could be related to a range of issues varying from gauge errors to remote sensing limitations and/or model performance:

1. Sampling/representativeness error due to scarcity/irregular distribution of highelevation in situ stations (Schneider et al., 2008); and/or gauge undercatch error, which is especially large during winter season in high-latitude/mountainous regions (Rudolf and Rubel, 2005).

2. Indirect relationship of satellite retrievals with its observables (e.g. cloud top reflectance or thermal radiance as a measure of surface precipitation), which may limit the accuracy of satellite products (Richards and Arkin, 1981); and/or difficulty of satellite estimates and their combinations (merged products) in detecting the snow component of precipitation (Rasmussen et al., 2012).

3. In contrast to the gauge and satellite products, reanalysis overestimation could be due to the estimation of total precipitation (rainfall + snow). Other possibilities such as inability of models to properly resolve precipitation in regions with drastic elevation changes (Ma et al., 2009); and/or differences in the land-atmosphere interaction and land-surface model schemes may also contribute significant uncertainties (Misra et al., 2012). 

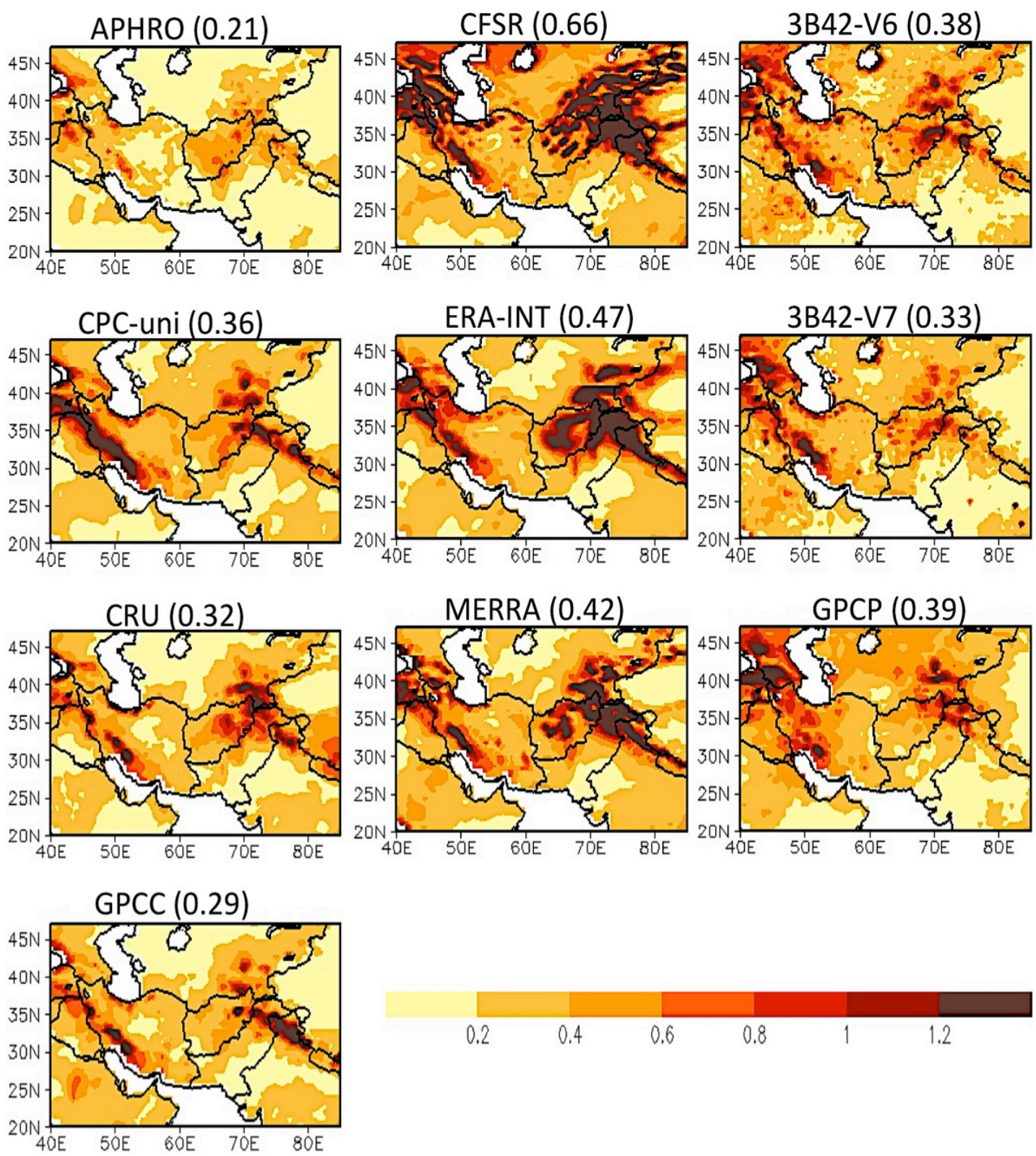

Figure 3.6: Spatial distribution of winter (DJFMA) root mean square error (mm/day) against the corresponding reference ensemble mean (EM1/EM2) over CSWA. The time period of analysis for APHRODITE, CPC-uni, CRU, GPCC, CFSR, ERA-Interim and MERRA is (1979-2007); and for 3B42-V6, 3B42-V7 and GPCP-1DD is (19982007). The domain average mean values are given in the parentheses.

Figure 3.7 compares the spatial maps of correlation generated for each precipitation product with the corresponding spatial EM's (EM1 and EM2). APHRODITE exhibits high spatial and domain average CC's over most parts of the CSWA regions, indicating a good level of agreement with EM1. However, the 
domain average CC's for the other gauge-only products is comparatively lower (CPCuni $=0.53, \mathrm{CRU}=0.52$ and $\mathrm{GPCC}=0.56$ ) but still statistically significant. For gaugeonly/reanalysis (satellite-derived) data sets, correlation values greater than $0.37(0.63)$ are statistically significant at $95 \%$ confidence level. For reanalyses, the comparatively lower spatial correlations are also evident in the domain average $\mathrm{CC}$ scores $(\mathrm{CFSR}=0.35$, ERA-Interim $=0.43$ and MERRA $=0.38)$. Unlike the reanalysis data sets, satellite-derived precipitation products show smaller pockets of strong CC's $(>0.8)$, with the spatial correlation pattern being somewhat similar. This similarity could perhaps be attributed to the use of similar retrieval procedures (Rahman et al., 2009); and/or due to the use of some common satellite and gauge sources (see Palazzi et al., 2013).

An interesting feature of Figure 3.7, for almost all precipitation products, is the occurrence of very low/negative CC's (in the range of 0.2 to -0.4 ) over the arid and semi-arid regions of Gujarat and Rajasthan in India, the Taklimakan Desert in northwest China, the Kavir Desert in central Iran and some pockets of Saudi Arabia. Precipitation in these regions is characterised by high spatial variability and limited seasonal totals that might affect the degree of agreement between different data sets, and may lead to low CC's. Moreover, over these regions, gauge-based precipitation products are usually affected by significant uncertainties due to the number and quality of observations available (Javanmard et al., 2010; Tanarhte et al., 2012; Palazzi et al., 2013; Rana et al., 2015). Satellite rainfall estimates also suffer major challenges of over- or underestimation over the dry/arid regions. Overestimation occurs when rainfall detected aloft by the satellite sensors evaporates before reaching the surface; while underestimation results when the average of certain area is misidentified as non-raining pixel due to the coarse spatial resolution of satellite products, which covers both rain areas and hot background surfaces (Dinku et al., 2011). Apparently in the case of reanalyses, observations (in situ and satellite retrieval) provide the essential information content; therefore, over a specific region or site, the reliability and accuracy of a reanalysis product will depend very much on the quality and availability of data sets being assimilated (Bosilovich et al., 2013). The corollary of this is that as for gauge and satellite precipitation products, the quality of reanalysis data sets is also less accurate and questionable over the arid and semi arid regions of CSWA. 

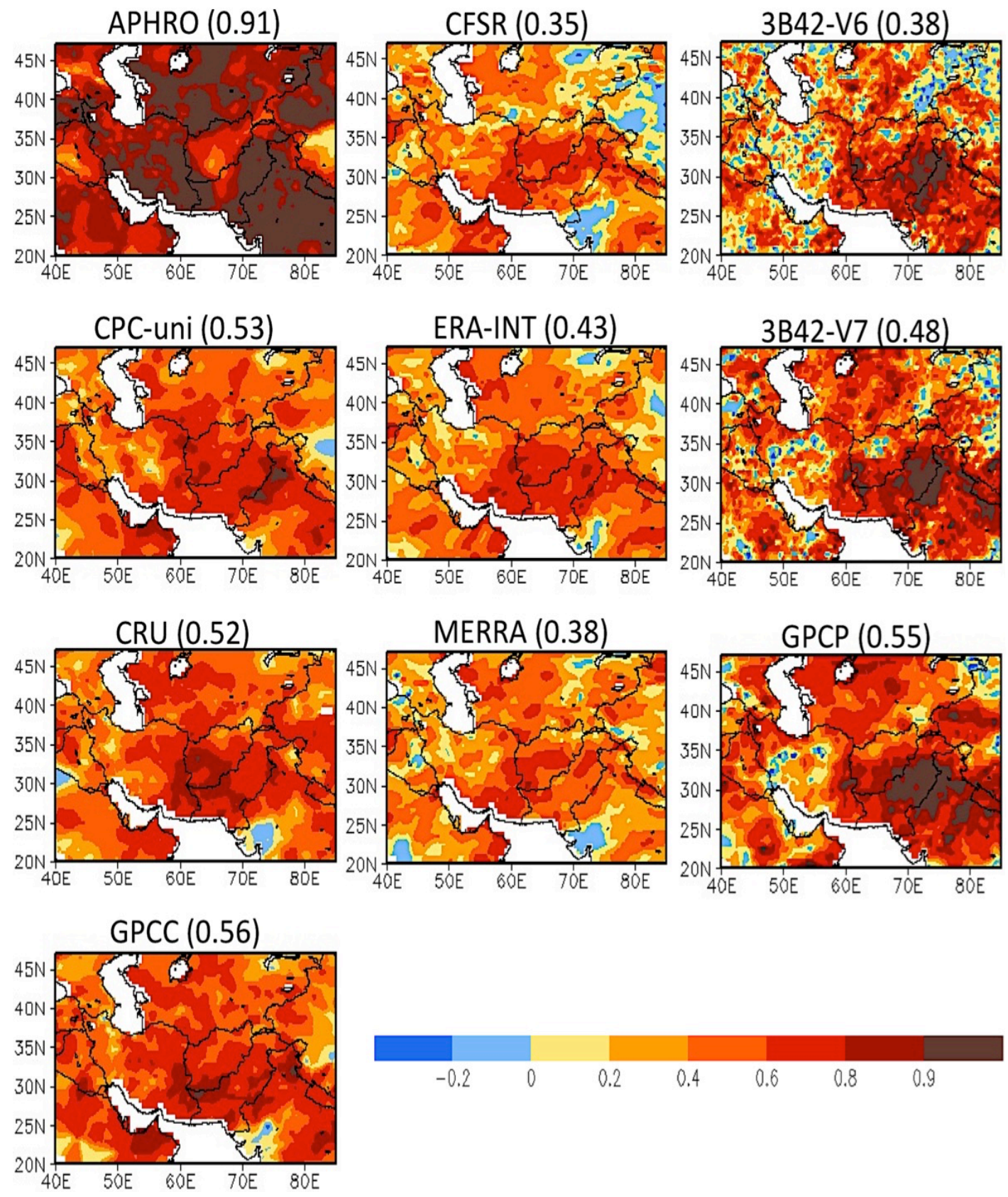

Figure 3.7: Spatial distribution of winter (DJFMA) temporal correlation coefficient over CSWA. The time period of analysis for APHRODITE, CPC-uni, CRU, GPCC, CFSR, ERA-Interim and MERRA is (1979-2007); and for 3B42-V6, 3B42-V7 and GPCP-1DD is (1998-2007). The pattern correlation values are given in the parentheses.

\subsubsection{Temporal analysis}

Here, we examine the time series variation for all precipitation products against the EM time series. 


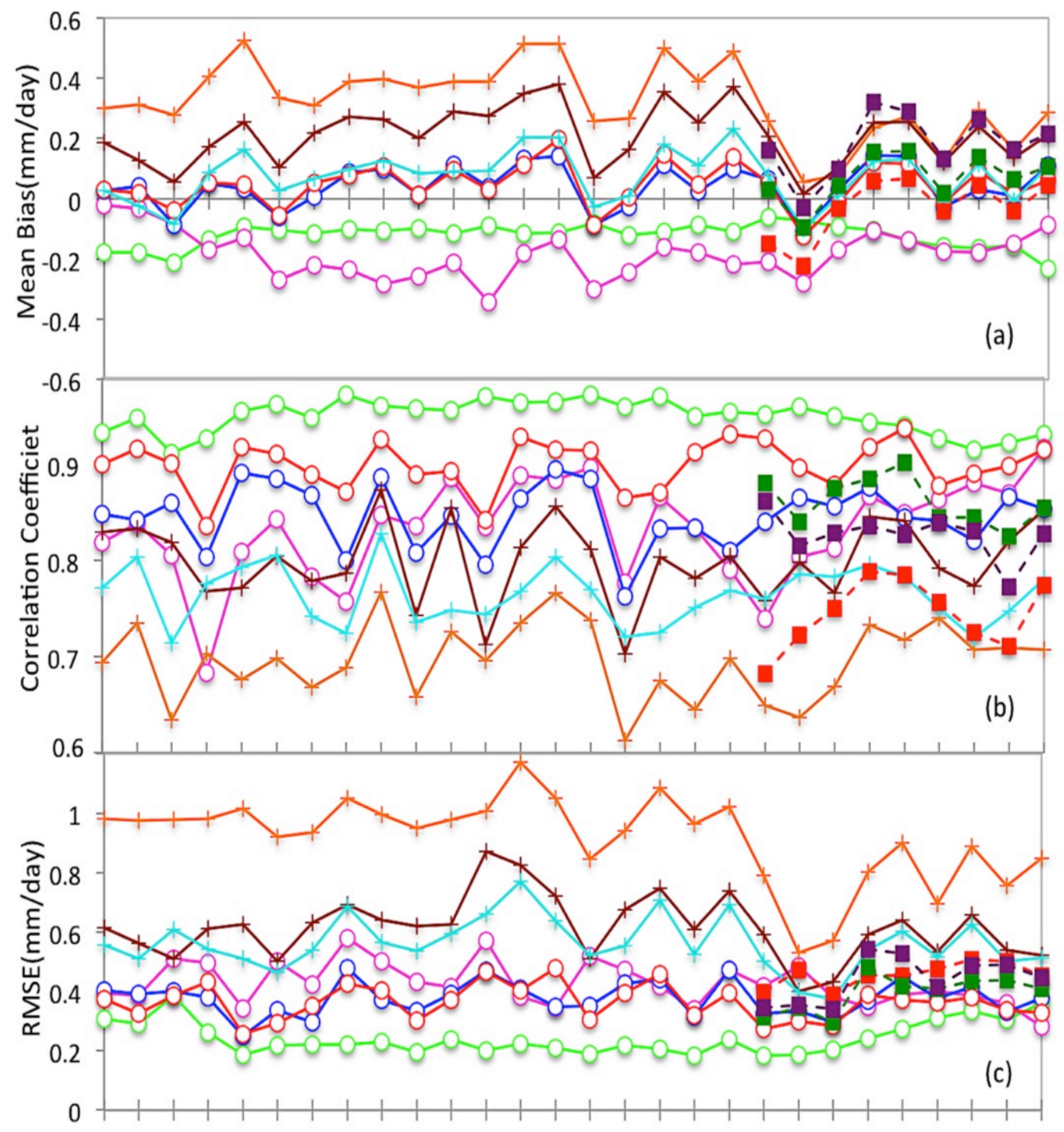

19791981198319851987198919911993199519971999200120032005

-O-APHRO -O-CPC -O-CRU -O-GPCC + CFSR + ERA-INT + MERRA - - 3B42-V6- - 3B42-V7- - GPCP

Figure 3.8: Interannual variation of winter (DJFMA) (a) mean bias, (b) correlation coefficient and (c) RMSE, over the CSWA. The time period of analysis for APHRODITE, CPC-uni, CRU, GPCC, CFSR, ERA-Interim and MERRA is (19792007); and for 3B42-V6, 3B42-V7 and GPCP-1DD is (1998-2007).

The inter-annual variation depicted in Figure 3.8(a) to (c) illustrates that in the gauge-only (reanalysis) category, CPC-uni (CFSR) exhibits serious under(overestimation) of winter precipitation resulting in maximum negative (positive) bias, together with lowest $\mathrm{CC}$ and highest RMSE. Furthermore in gauge-only category, GPCC and CRU show relatively small inter-annual bias scores (tending or 
close to zero), but overall, GPCC exhibits higher CC's and typically lower RMSE values during the analysis period. In comparison to GPCC, the inter-annual CC (RMSE) scores are relatively stable and consistently highest (lowest) for APHRODITE data set. This suggests that in the gauge-only category, even though APHRODITE (GPCC) tends to systematically under- (overestimate) winter precipitation, the two gauge-only data sets seem to provide close to reliable estimates of precipitation over the CSWA region in comparison CPC-uni and CRU data sets.

In terms of the inter-annual bias and RMSE skill scores, MERRA seems to perform better than CFSR and ERA-Interim. Surprisingly, ERA-Interim produces comparatively higher CC's than those exhibited by CFSR and MERRA (see Figure 3.8 (b)). The results obtained here are consistent with the finding of Palazzi et al. (2013) who reported that over the Hindu-Kush Karakoram region, the ERAInterim data set exhibits good correlation and significant high bias, when compared to the observational data sets during the winter months. For the satellite-derived precipitation products, comparison of statistical indices (RMSE and CC) reveals that 3B42-V7 exhibits a clear improvement over 3B42-V6 and GPCP-1DD. However, results (particularly from spatial analysis) suggest the need for efforts to further advance the accuracy of 3B42-V7.

\subsubsection{Scatter plot and empirical cdf}

Figure 3.9 compares the winter total precipitation scatter plots generated for the gauge-only (Figure 3.9 (a)), reanalyses (Figure 3.9 (b)) and satellite-derived (Figure 3.9 (c)) products against the reference ensemble means (EM1, EM2). The CC (r) between each data set and the corresponding EM time series is also indicated. The scatter plot data points are clustered most closely to the 1:1 best fit line (dashed black line) for the gauge-only products. Overall GPCC exhibits the best correspondence $(\mathrm{r}=0.99)$ with the reference EM1, followed by CRU $(\mathrm{r}=0.98)$, APHRODITE $(r=0.97)$ and CPC-uni $(r=0.88)$. For CPC-uni, persistent underestimation is also apparent, while for CRU, the data points fall close to the best-fit line despite the fact that the data set exhibits orographic inconsistencies. 

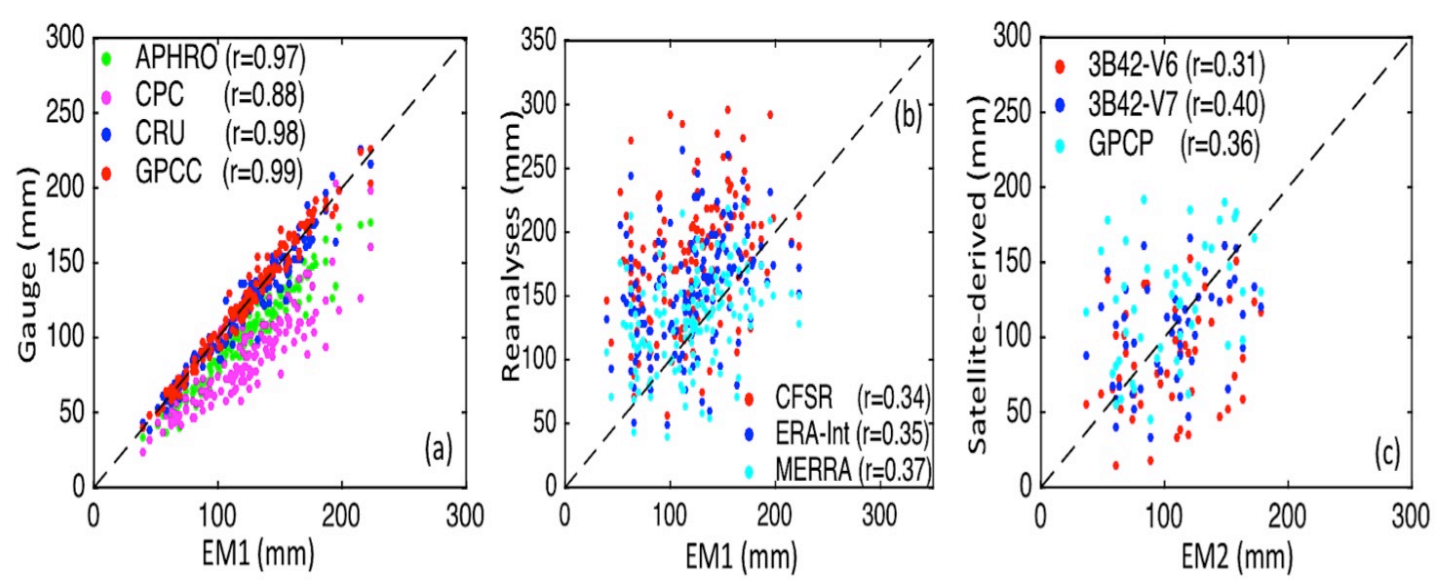

Figure 3.9: Scatter plots of winter (DJFMA) precipitation over CSWA, for (a) gaugeonly, (b) reanalysis and (c) satellite-derived datasets, against the corresponding reference ensemble mean (EM1/EM2).

For the reanalyses and satellite-derived precipitation products, the data points are widely scattered with moderate to lower correlations. CFSR $(r=0.34)$ and ERAInterim (0.35) exhibit similar performance with data lying mostly to the left (overestimation) of the 1:1 line; while MERRA $(r=0.37)$ shows a close association with EM1, with data lying much closer to the best-fit line. Among the satellitederived precipitation products, 3B42-V7 shows moderate correlation $(r=0.4)$ with EM2, higher than for GPCP-1DD $(r=0.31)$ and 3B42-V6 $(r=0.36)$. Although the data points for 3B42-V7 are relatively scattered; the overall better performance of the product over its previous counterpart (V6) can be attributed to the use of additional satellite observations and better incorporation of GPCC data set (with improved climatology and anomaly analysis), both of which lead to significant improvements over complex terrain (Chen et al., 2013).

The empirical cdf $\mathrm{F}(\mathrm{x})$ for winter precipitation over CSWA region are presented in Figure 3.10. The empirical $\operatorname{cdf} \mathrm{F}(\mathrm{x})$ is defined as the proportion of $\mathrm{X}$ values less than or equal to $\mathrm{x}$. Results show that in the gauge-only category GPCC and CRU follow the EM1 cdf line reasonably well, while the respective distributions of CPCuni and APHRODITE show an underestimation for precipitation accumulation lower than $70 \mathrm{~mm}$. For reanalysis data sets, the distribution shows that overestimation of accumulated precipitation $(>30 \mathrm{~mm})$ is relatively large in CFSR, followed by ERAInterim and MERRA. In the satellite-derived category, the cdf for 3B42-V7 follows the EM2 distribution fairly closely; while the distribution for 3B42-V6 (GPCP-1DD) 
shows that $90 \%$ of its data values are under- (overestimated) with respect to EM2. These results agree with the findings from the prior sections, giving us greater confidence on the accuracy and certainty of the results presented in this study.
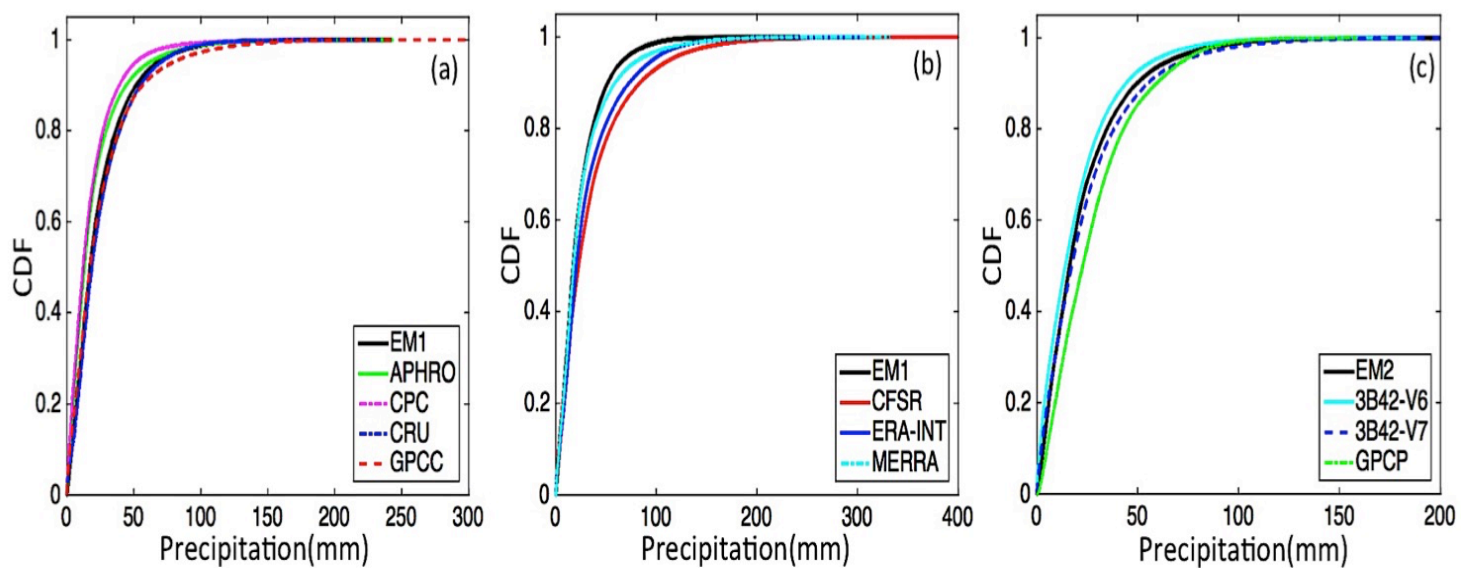

Figure 3.10: Empirical cumulative distribution functions of winter (DJFMA) precipitation over CSWA, for (a) gauge-only, (b) reanalysis and (c) satellite-derived datasets, against the corresponding reference ensemble mean (EM1/EM2).

\subsubsection{ENSO sensitivity}

To examine the performance of precipitation products over the CSWA region in terms of inter-annual variability and teleconnections, the ability of each product to capture the typical winter precipitation distribution pattern observed during ENSO events is assessed. To the best of our knowledge, no similar analysis has yet been published. A better understanding of the relative strengths and weaknesses of each product can provide useful information towards improving the quality of forecasts and warnings systems used in prediction of extreme weather events over CSWA. For instance, parts of southwest Asia experienced a very severe drought during 19982002 (Waple et al., 2002) for which a link to La Niña-like conditions were suggested (Barlow et al., 2002; Hoerling and Kumar, 2003). Other studies (Nazemosadat and Cordery, 2000; Syed et al., 2006; Mariotti, 2007; Kar and Rana, 2014) have discussed possible linkages/mechanisms for how ENSO influences precipitation variability over the CSWA region. Findings suggest that the inter-annual variability of winter precipitation occurs coherently with that of the ENSO phase, i.e. during El Niño (La Niña) events, positive (negative) precipitation anomalies typically occur in and around the study region. 

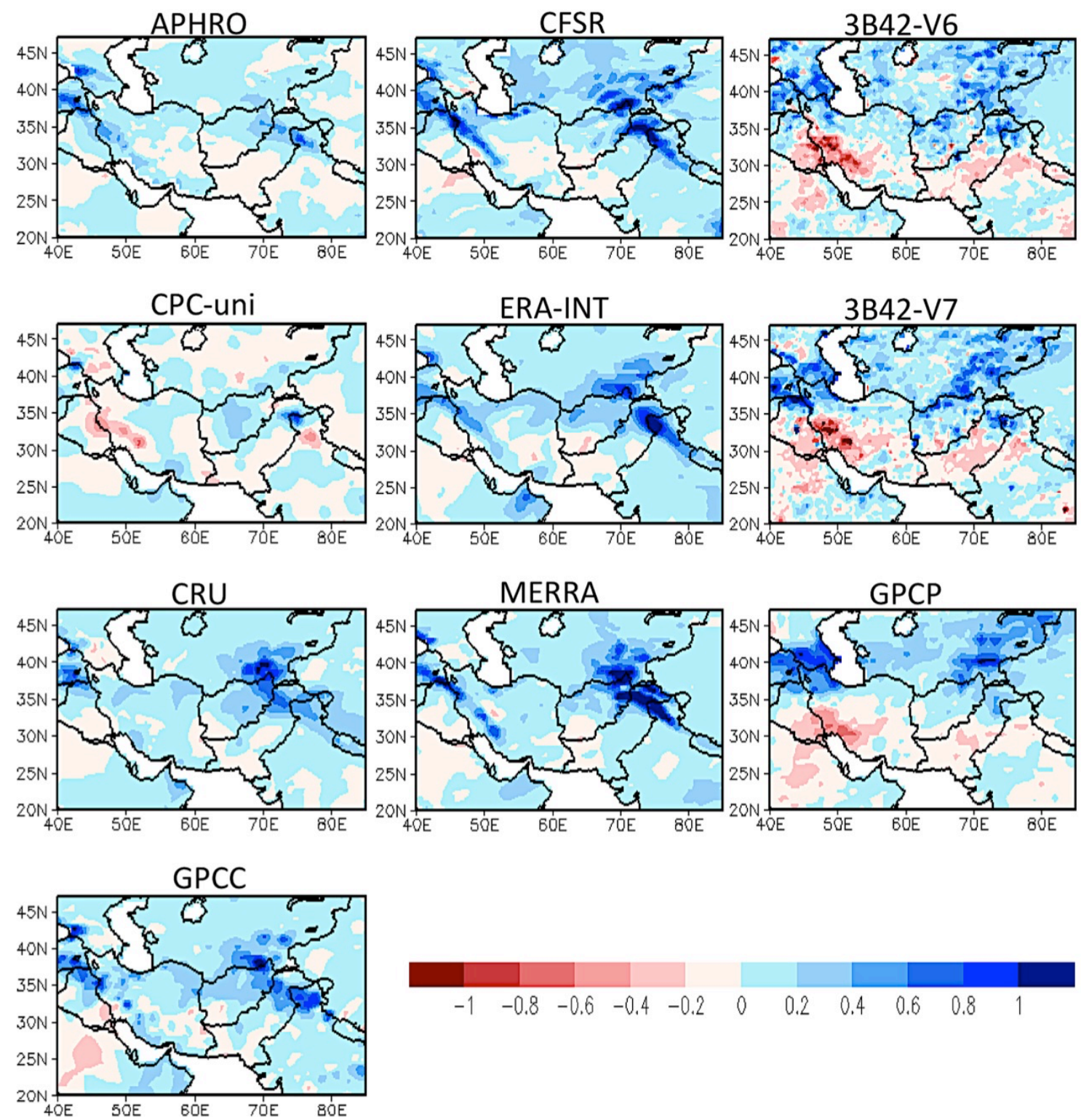

Figure 3.11: Spatial distribution of winter (DJFMA) precipitation anomalies (mm/day) over CSWA, expressed as a difference between El Niño and neutral years. For APHRODITE, CPC-uni, CRU, GPCC, CFSR, ERA-Interim and MERRA the El Niño and neutral years were chosen from 1979-2007; and for 3B42-V6, 3B42-V7 and GPCP-1DD the El Niño and neutral years were chosen from 1998-2007.

Consistent with the above, the composite precipitation anomaly maps generated for the El Niño (Figure 3.11) and La Niña (Figure 3.12) years revealed a similar precipitation anomaly distribution pattern for CSWA. The composite maps obtained for the gauge-only and/or reanalysis data sets are for the period 1979-2007, with seven El Niño years and five La Niña; while for the satellite-derived precipitation products, the period of analysis is 1998-2007, with two El Niño and three La Niña 
years. All precipitation products do a good job in capturing the typical impacts of the El Niño (La Niña) episodes, including the above (below) average precipitation anomalies over most parts of the domain. Notably, over certain region (e.g. the western Himalayan mountain, the Hindu-Kush Karakoram ranges and the Zagros Mountains), the positive/negative ENSO-precipitation relationship is found to be comparatively stronger for most of the products, suggesting that over these regions the ENSO signal could be used as one of the strong predictors to make better seasonal predictions.
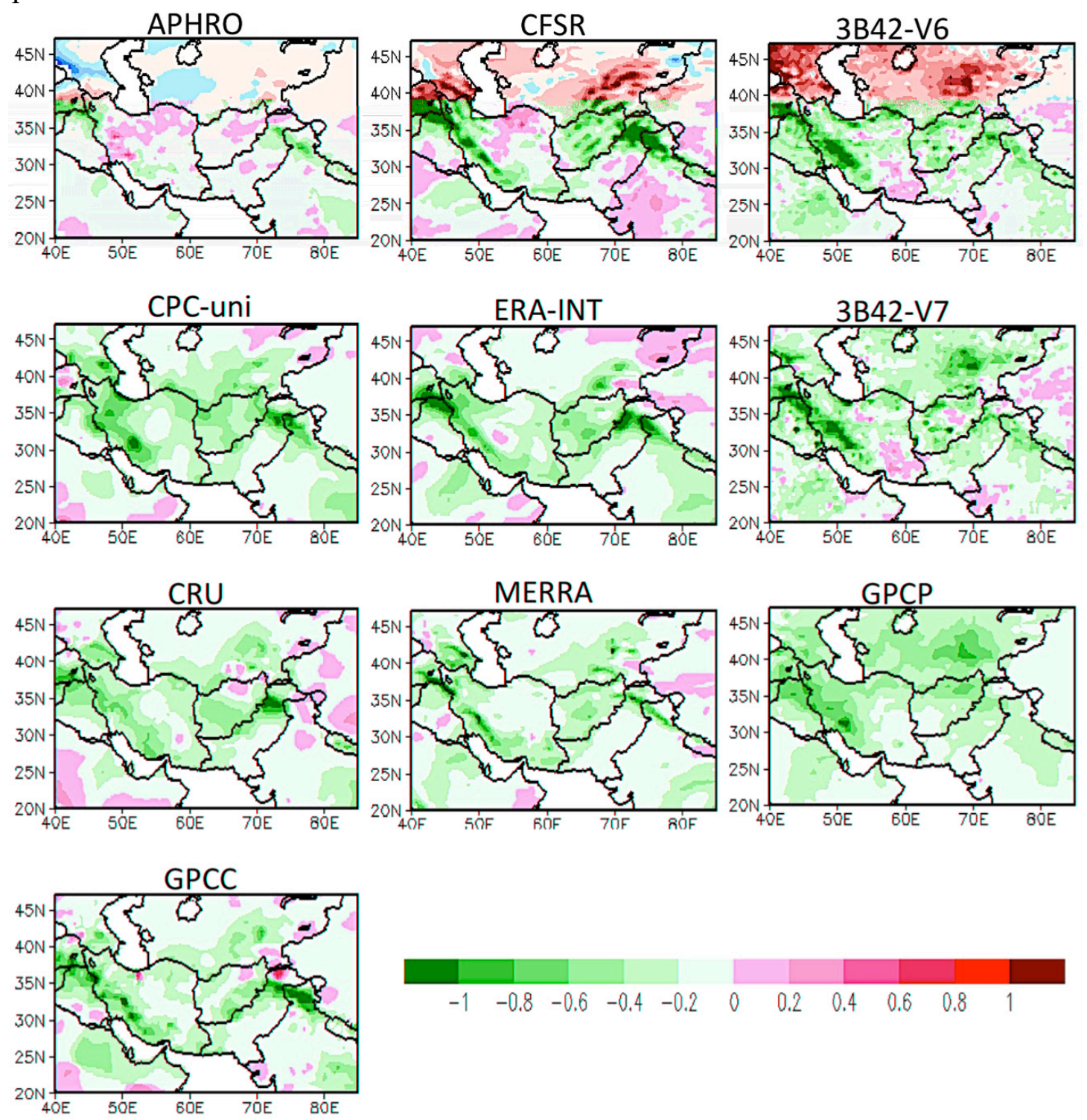

Figure 3.12: Spatial distribution of winter (DJFMA) precipitation anomalies (mm/day) over CSWA, expressed as a difference of La Niña and neutral years. For APHRODITE, CPC-uni, CRU, GPCC, CFSR, ERA-Interim and MERRA the La Niña and neutral years were chosen from (1979-2007); and for 3B42-V6, 3B42-V7 and GPCP-1DD the La Niña and neutral years were chosen from (1998-2007). 
A close spatial intercomparison of precipitation products in Figure 3.11 and Figure 3.12 reveal that APHRODITE shows comparatively much weaker or spatially limited precipitation anomalies for both, wet (El Niño) and dry (La Niña), conditions. CPC-uni also shows less precipitation variability (i.e. mostly dry conditions) during the positive ENSO phase; but the overall performance of the product seems to improve significantly during the La Niña period. The relatively poor (better) performance of CPC-uni observed during the positive (negative) phase of ENSO can be attributed to the consistent underestimation of winter precipitation by the product that further supports the negative departure of total precipitation during the La Niña episodes. In the gauge-only category, the performance of GPCC and CRU data sets appears to be similar; but in terms of the spatial details and magnitude of regional impacts, GPCC seems to provide a more realistic pattern (as seen in the above cited studies) for both, the El Niño and La Niña years.

All reanalysis products (CFSR, ERA-Interim and MERRA) manifest a strong orographic influence, yielding more detailed features at the regional scale. The typical characteristics of the positive/negative ENSO-precipitation relationship over the CSWA region are also well reproduced by the reanalysis data sets (with an exception that the amplitude of departure for MERRA precipitation anomaly is slightly underestimated during the negative ENSO phase). Because ENSO-precipitation relationships are a large-scale atmospheric-oceanic phenomenon, some of the disparities depicted in the reanalysis data sets can be related to different precipitation parameterisations and/or the use of different sea surface temperature (SST) data sets that are used in the development of the reanalyses (Kumar et al., 2013).

Among the satellite-derived precipitation products, 3B42-V6 and 3B42-V7 represent a very similar precipitation anomaly distribution pattern for the El Niño and La Niña years. GPCP-1DD also performs reasonably well in capturing the regional ENSO-precipitation signal; although the spatial pattern is much smoother, which can be ascribed to the coarser spatial resolution of the product. For La Niña episodes (Figure 3.12), GPCP-1DD displays a slightly different precipitation anomaly distribution pattern comprised of only negative (dry) precipitation anomalies for the entire CSWA region. According to Rahman et al. (2009), GPCP-1DD can reproduce the broad features of the Indian monsoon rainfall; but in terms of the shape and size of high- and low-rainfall regions, GPCP-1DD's representation may be considered as inadequate to those represented by TRMM products. Further comparison of results 
show that for the El Niño and La Niña years, all three satellite-derived precipitation products exhibit a band of negative precipitation anomalies over southwestern Iran. To have a clear understanding of the aforementioned finding, we investigated the ENSOprecipitation signal over the CSWA region using the gauge-only ensemble mean (EM2) for the period 1998-2007. Distinctly, the El Niño and La Niña composite precipitation anomaly patterns obtained for EM2 (Figure 3.13) showed a close resemblance to those obtained for the three satellite-derived precipitation products (see Figure 3.11 and Figure 3.12 ), suggesting that the observed pattern is likely due to the small sample of ENSO events (two El Niño and three La Niña years) for the 10year analysis period in the case of satellite data sets. In general, we can say that the teleconnection pattern of ENSO and CSWA winter precipitation appears to be fairly represented by 3B42-V6 and 3B42-V7, against the GPCP-1DD precipitation product.
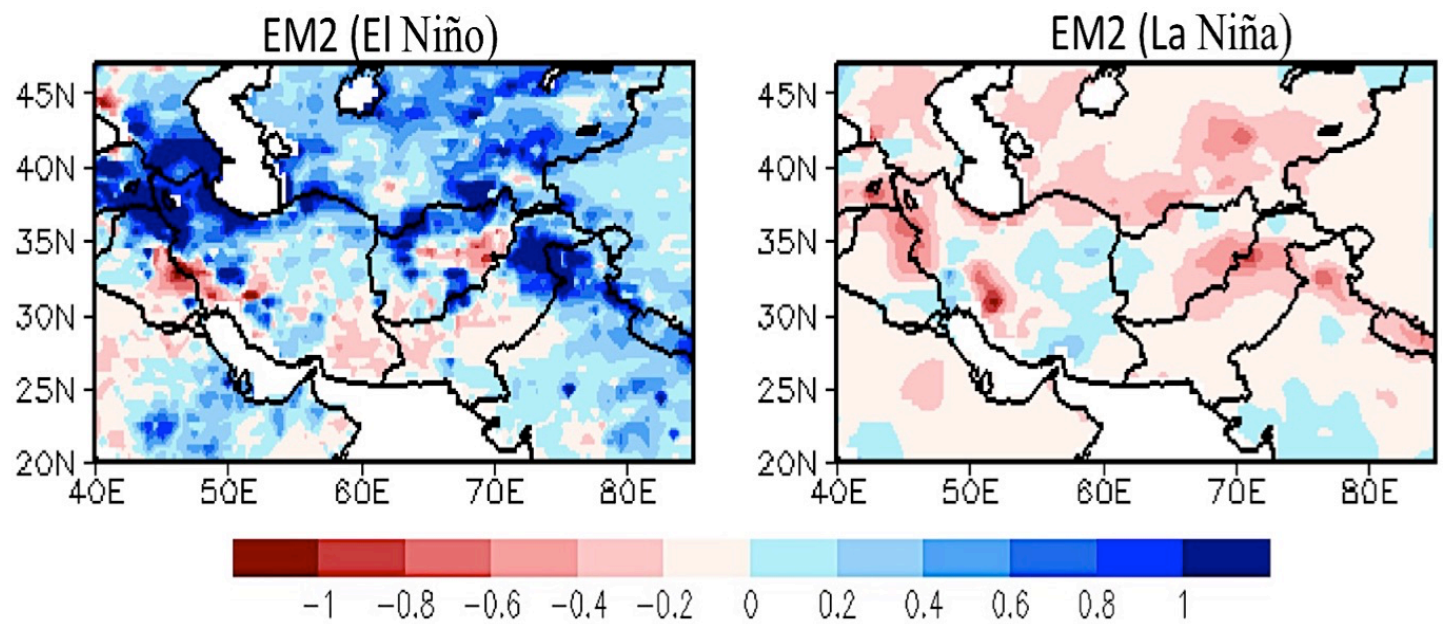

Figure 3.13: The ensemble mean (EM2) spatial distribution of winter (DJFMA) precipitation anomalies ( $\mathrm{mm} /$ day) over CSWA, expressed as a difference of El Niño/La Niña and neutral years. For composite analysis the El Niño/La Niña and neutral years were chosen from (1998-2007).

\subsection{Conclusions}

In this study, four gauge-only (APHRODITE, CPC-uni, CRU and GPCC), three reanalyses (CFSR, ERA-Interim and MERRA) and three satellite-derived (3B42-V6, 3B42-V7 and GPCP-1DD) precipitation products are used to examine the spatial pattern and temporal variations of wintertime precipitation over CSWA. Evaluation metrics, including $\mathrm{MB}, \mathrm{CC}$ and RMSE, were applied and subjective comparisons carried out using the gauge-only EM as the reference data set. Considering the time 
availability of each of the precipitation products, the analysis was performed for two different periods: 1979-2007 for the gauge-only/reanalysis and 1998-2007 for the satellite-derived products. Based on the investigation, the general conclusions are summarized as follows:

1. All of the ten precipitation products capture the overall spatial distribution and temporal variation patterns of winter precipitation. Results suggest that quality/accuracy of all gridded precipitation data sets generally decreases as altitude increases.

2. In the gauge-only category, APHRODITE and GPCC provide more reliable and realistic representation of the orographically influenced winter precipitation distribution over the study region. Even though APHRODITE (GPCC) tend to slightly under- (overestimate) the winter precipitation totals; but in comparison to CPC-uni and CRU, the data sets persistently perform better in terms of the spatial and temporal characterisation of skill metrics (i.e. higher $\mathrm{CC}$, smaller RMSE and close to zero MB) obtained over CSWA. Overall, our analysis emphasises that GPCC is most preferable for long-term climatological analyses over CSWA region

3. The reanalysis products (CFSR, ERA-Interim and MERRA) display a strong influence of topography along with the characteristic features of winter precipitation over CSWA. In all of the reanalyses, the total precipitation amount is overestimated over the high-altitude regions, which perhaps can be attributed to the estimation of total precipitation (rainfall and snow). With respect to the spatial climatology and inter-annual variability of EM1 (1979-2007), the seasonal precipitation amount is greatly overestimated by CFSR (50\%), followed by ERA-Interim (34\%) and MERRA (13\%). Overall, MERRA exhibits the most reasonable agreement in both, magnitude and phase of precipitation with relatively small MB and RMSE scores. These results suggest that new reanalyses are satisfactorily reliable for studying the regional spatial precipitation distribution over CSWA, although their absolute values are still questionable at the regional scale.

4. Among the satellite-derived precipitation products, 3B42-V7 exhibits the best performance in depicting the spatial pattern and temporal variations of winter precipitation over the study region. In comparison to 3B42-V6 and GPCP-1DD, 
the widespread spatial bias is significantly reduced over the mountainous regions in 3B42-V7, though the RMSE and CC are more-or-less same for all products. Results show that the improvements made in the newest version-7 of the TRMM research product demonstrate great potential for providing highresolution precipitation information over CSWA, where topography is complex and ground observations are sparse.

5. Finally, results for the evaluation of precipitation products in relation to ENSO effects show that all products perform satisfactorily in capturing the typical above (below) average seasonal precipitation anomalies over most parts of the CSWA region. Overall, in the gauge-only category, GPCC provides the most realistic precipitation anomaly distribution pattern, while the reanalyses resolve the fine scale features such as orographic precipitation in more detail. Among the satellite-derived precipitation products, the TRMM products represent the spatial features better than merged satellite-gauge GPCP-1DD; however, efforts are needed to improve the applicability of precipitation products over the dry arid and semi-arid plains of CSWA. 


\section{Chapter 4 Dominant Modes of Winter Precipitation Variability over Central Southwest Asia and inter- decadal change in the ENSO teleconnection}

Published in Climate Dynamics (Rana et al. 2019)

\section{CITATION}

Rana, S., J. McGregor, and J. Renwick, 2019: Dominant Modes of Winter Precipitation Variability over Central Southwest Asia and inter-decadal change in the ENSO teleconnection. Clim Dyn, https://doi.org/10.1007/s00382-019-04889-9

Authorship contributions to this research article include the following:

Sapna Rana - Wrote the manuscript and managed all co-author feedback, reviewer comments, and editing of proofs. This author collated and processed all data, developed initial interpretations, and produced all figures.

James McGregor - Academic Supervisor; provided feedback on the drafts and text edits.

James Renwick - Academic Supervisor; provided feedback on the drafts and text edits. 


\subsection{Abstract}

This study contributes to an improved understanding of Central Southwest Asia (CSWA) wintertime (November-April) precipitation by analysing the dominant spatial-temporal modes of the regional winter precipitation and examining their relationship with global sea surface temperature (SST) and large-scale atmospheric circulation fields, for 1950/51-2014/15. Empirical orthogonal function (EOF) analysis results show that the first mode (EOF-1) of winter precipitation is characterised by a mono-sign pattern, with significant links to El Niño-Southern Oscillation (ENSO). EOF-2 displays a north-south dipole related to the latitudinal shift in the jet stream position, while the west-east dipole in EOF-3 appears to be influenced by the thermal contrast between the equatorial regions and higher latitudes. Further, we focus on the inter-decadal change of connection between wintertime ENSO and EOF-1 observed around the early 1980s. The relationship is weak during 1950/51-1983/84 (P1), but strong and statistically significant in 1984/85-2014/15 (P2). In P1, without the ENSO signal, EOF-1 related atmospheric circulation anomalies are confined mainly over the mid- to high-latitudes of the Northern Hemisphere, associated with the extratropical East Atlantic-Western Russia (EAWR) teleconnection. In P2, however, a close connection to the tropical Pacific is observed that includes a pronounced SST expression similar to that of ENSO. As a result of the stronger relationship between ENSO and EOF-1 in P2, the regional impact of EA-WR observed over CSWA in P1 is linearly superimposed by the anomalous hemispheric-wide atmospheric response forced by the ENSO conditions in the Pacific.

\subsection{Introduction}

Central southwest Asia (CSWA, Figure 4.1(a)), defined here as the domain bounded by $20^{\circ}-47^{\circ} \mathrm{N}, 40^{\circ}-85^{\circ} \mathrm{E}$ is a semiarid and a water-scarce region (Oki and Kanae 2006) prone to large interannual and inter-decadal precipitation variations (Hoell et al. 2015a). Dominated by high mountain ranges from west to east - the Alborz, Zagros, Hindu Kush, Pamirs, Karakoram and the Himalayas (Figure 4.1(a)), the complex orography of CSWA strongly modulates the weather systems and profoundly controls the regional distribution of precipitation (Barlow et al. 2005; Barlow and Tippett 2008; Rana et al. 2017). A large part of CSWA, which includes 
the western and the northern flanks of the domain, is beyond the usual reach of the Indian monsoon with little precipitation during the warm summer season (e.g. Figure 1.5 in Chapter 1).

For much of CSWA, precipitation primarily occurs during the winter and early spring season of November-April [(NDJFMA); see Figure 4.1 (c)] when the region is within the subtropical belt of the upper-tropospheric westerly jet stream (Krishnamurti 1961). The intensification and southward excursions of the subtropical westerly jet bring moisture-bearing mid-latitude synoptic storms into CSWA. As they traverse eastwards, they pass through a dense upper-air observing array over Europe, the Middle East, the Black Sea and the Caspian Sea regions (Sachar et al. 2004). The moisture advection associated with these storms is typically from the west, including the Atlantic, the Mediterranean Sea, the Red Sea, the Persian Gulf, the Caspian Sea and the Arabian Sea (Barlow et al. 2005, Kar and Rana 2014). While propagating from west to east, the moisture-laden winds modify the regional circulations as they encounter the high mountain ranges of CSWA and generate precipitation via upslope lifting (Cannon et al. 2016; Barlow et al. 2016).

The climatological precipitation displayed (Figure 4.1(b)) closely follows the principal mountain ranges of the region, with heaviest amounts falling on the western slopes of the high mountains. Yearly precipitation can exceed $1000 \mathrm{~mm}$ in some areas of the high mountains of western Iran, the Hindu-Kush Karakoram, as well as along the southern (eastern) shores of the Caspian (Black) Sea (Barlow et al. 2005). Regionally, wintertime precipitation demonstrates a high degree of spatial coherence (Hoell et al., 2015a) and makes a dominant contribution $(>65 \%)$ to the annual precipitation totals as seen in Figure 4.1(c). This precipitation is mostly in the form of snow over the high mountain ranges, which accumulates as a seasonal snowpack throughout the cold months. The melting of this snow is an important source of water during the spring-summer season, which happens to coincide with the time of year when the regional water demand is highest. In addition to snow, winter rainfall in the sub-mountainous and low elevation areas is crucial for the widespread subsistence agriculture, industrial needs, and livelihood. 


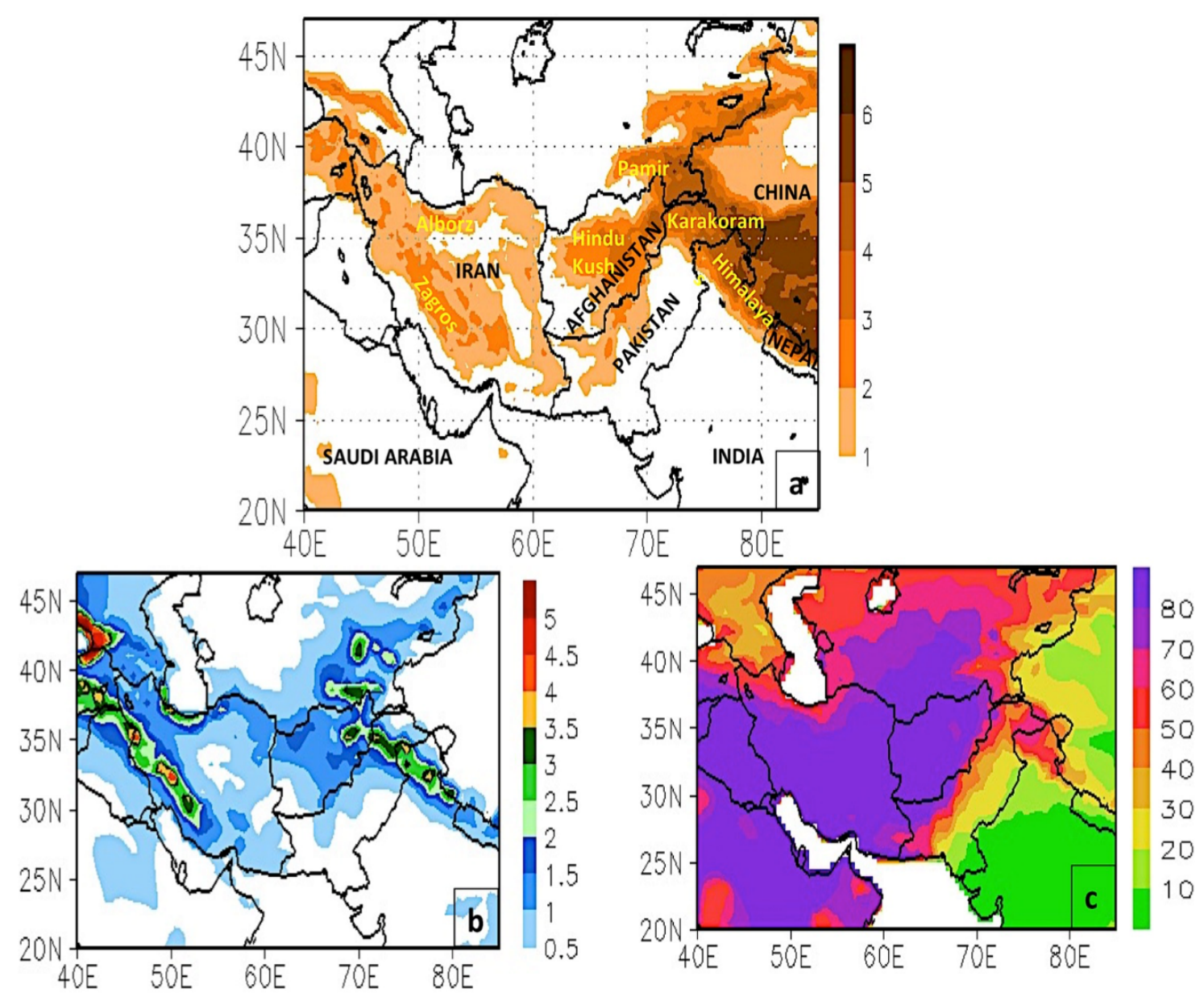

Figure 4.1: (a) Topography (km) of CSWA $\left(20^{\circ}-47^{\circ} \mathrm{N}, 40^{\circ}-85^{\circ} \mathrm{E}\right)$, (b) spatial distribution of winter season precipitation (mm/day), and (c) percentage contribution of NDJFMA precipitation to the total annual precipitation over CSWA for 1950/51-2014/15.

CSWA winter precipitation is strongly influenced by several large-scale modes of climate variability such as the El Nino-Southern Oscillation (ENSO), Pacific Decadal Oscillation (PDO), North Atlantic Oscillation (NAO), East Atlantic-Western Russia (EA-WR) pattern, Polar/Eurasian Pattern (PE), Indian Ocean Dipole (IOD) and others [for more details see Barlow et al. (2016)] at time scales ranging from subseasonal to seasonal and interannual to decadal (Barlow et al. 2005; Barlow and Tippett 2008; Hoell et al. 2012; 2013; 2015b; Kar and Rana 2014; Yin et al. 2014). A comprehensive review of boreal wintertime teleconnection studies highlights ENSO as an important driver of CSWA's winter precipitation climate. Both observational and model analyses show that the two phases of ENSO, El Niño or La Niña, are 
related to statistically significant region-wide increases or decreases of winter precipitation (Mariotti 2007; Hoerling and Kumar 2003; Hoell and Funk 2013; Hoell et al. 2015a, 2017; Rana et al. 2017; 2018) by way of both baroclinic (Barlow et al. 2002; Hoell et al. 2012) and barotropic (Hoell et al. 2013, Shaman and Tziperman 2005) Rossby wave teleconnection mechanisms.

As evidenced by previous research, ENSO-related precipitation modifications are substantial over CSWA. However, with the competing influence of various tropical and extratropical teleconnections on CSWA climate, the regional precipitation anomalies can be influenced by other concomitant non-ENSO modes of climate variability. These modes, depending on their relative strengths and phase combinations, tend to modify the seasonal precipitation either directly (during nonENSO years) or by way of partly modulating the strength of the ENSO response (e.g. Yin et al. 2014; Barlow and Hoell 2015; Barlow et al. 2016; Liu et al. 2017; Rana et al. 2018). The above mechanisms are not mutually exclusive and a high degree of uncertainty remains in our understanding of their individual role in CSWA's wintertime precipitation variability. Therefore, one of the motivations of this study is to statistically characterise the leading spatial and temporal patterns of CSWA wintertime precipitation variability using the conventional empirical orthogonal function (EOF) analysis (Wilks 2006) and examine the large-scale teleconnection links that govern the leading precipitation modes.

Furthermore, we focus on the leading mode [(EOF1) of CSWA winter precipitation] that explains a relatively large proportion of the region's precipitation variability and has a close relationship with tropical Pacific ENSO forcing as reported in Hoell et al (2017). Those authors also documented that the long-term relationship between wintertime ENSO (Niño-3.4) and CSWA precipitation varied in strength throughout the 20th century (1901-2012) and was strongest after the 1980s. Our recent study (Rana et al. 2018) also revealed that the influence of springtime Niño-3.4 (NAO) on CSWA winter precipitation strengthened to (weakened from) a statistically significant level around the early 1980s and continued to increase (decrease) thereafter. In particular, changes in ENSO characteristics including frequency, intensity, structure, and propagation during recent decades (Wang 1995; An and Wang 2000) have been shown to force stronger wintertime northern hemisphere circulations and significant precipitation modifications over CSWA (Hoell and Funk 
2013; Hoell et al. 2014a,b) resulting in higher predictability and predictive skill of the regional precipitation after the 1980s period (Rana et al. 2018).

These studies suggest a possible inter-decadal change of connection between wintertime ENSO and CSWA precipitation around the early 1980s. Since it is unclear whether this relationship will remain strong in future, it is of interest to investigate how the connection between CSWA winter precipitation and the global atmospheric circulation changed in the context of the above discussion. We believe that addressing these issues will deepen our understanding of CSWA wintertime precipitation variability and may provide useful information for seasonal forecasting of the regional precipitation.

The rest of the chapter is organized as follows. Section 4.3 describes the data and methods adopted in this study. Section 4.4 presents the spatial and temporal characteristics of the leading three (EOF-1, EOF-2, EOF-3) modes of winter (NDJFMA) precipitation variability over CSWA. The association between the three EOF modes of CSWA winter precipitation and the large-scale atmospheric circulations and global sea surface temperature (SST) anomalies are discussed in Section 4.5. Section 4.6 examines the inter-decadal change in ENSO - EOF-1 relationship and compares the circulations and SST anomalies before and after the inter-decadal change, followed by summary and discussion in section 4.7.

\subsection{Materials and Methods}

\subsubsection{Observed and reanalysis data}

The present study employs two monthly-mean observed precipitation datasets over land. They are (1) the Global Precipitation Climatology Centre (GPCC) full data reanalysis version 7 (Schneider et al. 2014) available from http://gpcc.dwd.de for the period 1901-2013 and (2) the Climatic Research Unit (CRU) time series (TS) version 3.24.01 available from https://crudata.uea.ac.uk/cru/data/ for the period 1901-2015 (Harris et al. 2014). The current analysis uses $0.5^{\circ}$ latitude/longitude resolution for both GPCC and CRU data.

It is important to note that throughout the CSWA region, considerable uncertainty exists in the accuracy of gridded precipitation estimates (Barlow and Tippett 2008; Rana et al. 2015, 2017; Hoell et al. 2017). Some of the factors that 
contribute to this uncertainty are: sparse or non-existent precipitation observation network, political sensitivity, extreme topography, snow measurement errors and so on. In order to gain a better understanding of some of these issues, Rana et al. (2017) performed a comprehensive assessment of various precipitation datasets for CSWA and reported that in comparison to some of the currently available observational datasets (including CRU), GPCC precipitation estimates are qualitatively more realistic and reliable in this region. Therefore, the present study uses GPCC precipitation records from 1950 up to 2013 and the CRU dataset thereafter. The spatial maps of the CSWA wintertime precipitation climatology and its seasonal percentage contribution to the total annual precipitation for the analysis period (1950/51-2014/15) are shown in Figure 4.1(b) and Figure 4.1(c), respectively.

Estimates of monthly mean observed SST $\left({ }^{\circ} \mathrm{C}\right)$ data are drawn from the National Oceanic and Atmospheric Administration (NOAA) extended reconstructed SST version 5 (Huang et al. 2017; http://www.esrl.noaa.gov/psd/data/gridded/). This SST dataset is produced on a fixed $2^{\circ}$ latitude-longitude resolution and is available from 1854 to the present. In this study, ENSO variability is represented by the Niño3.4 index which is defined as the area averaged SST anomaly over the region $5^{\circ} \mathrm{S}-$ $5^{\circ} \mathrm{N}, 170^{\circ}-120^{\circ} \mathrm{W}$.

Reanalysis atmospheric variables including monthly-mean sea level pressure (SLP), the geopotential height at 500-hPa (Z500) and 200-hPa (Z200), zonal and meridional components of winds at 700-hPa (U700; V700) and 200-hPa (U200; V200) are drawn from the National Centers for Environmental Prediction (NCEP)National Center for Atmospheric Research (NCAR) at a fixed $2.5^{\circ}$ x $2.5^{\circ}$ latitudelongitude grid for 1948-2015.

\subsubsection{Methods}

As outlined in Chapter 2, EOF analysis is a widely-used statistical technique to reduce the dimensionality of a complex data set into linear combinations of fewer new variables that represent the maximum possible fraction of the variance contained in the original data (Wilks 2006). In this study, we use EOF analysis over CSWA by constructing an area-weighted covariance matrix of the observed winter precipitation for 1950/51 - 2014/15 period; and the first three patterns that explain nearly $45 \%$ of the total domain variance are analysed. Correlation and regression analyses are further 
applied to identify the physical mechanisms responsible for the connection between the three standardized EOF time series of CSWA precipitation with the wintertime global SST and large-scale atmospheric circulations.

Here, correlation coefficients are computed using equation (3.4) described in Chapter 3. Statistical significance of the correlation coefficient is assessed at $90 \%$ (pvalue $<0.10)$ and $99 \%$ ( -value $<0.01)$ confidence level using the two-tailed Student's t-test statistics expressed as:

$t_{n-2}=\frac{r \sqrt{n-2}}{\sqrt{1-r^{2}}}$

where $r$ is the correlation coefficient and $n$ is the sample size.

Regression analysis is carried out to estimate the regression coefficient or the slope $(\beta)$ of the regression line. The regression line is given as:

$y=\beta x+a$

where $y$ is the dependent variable, $x$ is the independent variable, $a$ is the intercept, and $\beta$ is regression coefficient (slope) that represents the rate of change in $y$ as $x$ changes.

To document the inter-decadal change in the wintertime ENSO - CSWA precipitation relationship, we divide the entire analysis period $(1950 / 51-2014 / 15)$ into two sub-periods: (1950/51-1983/84, P1) and (1984/85-2014/15, P2). The selection of the two sub-periods is based on the 17-yr sliding correlation of Niño-3.4 index with the leading (EOF-1) time series of CSWA precipitation. The sliding correlation is calculated using the following equations:

$r_{n}=\frac{\sum_{i=t-n+1}^{t}\left(x_{i}-\bar{x}\right)\left(y_{i}-\bar{y}\right)}{\sqrt{\sum_{i=t-n+1}^{t}\left(x_{i}-\bar{x}\right)^{2} \sum_{i=t-n+1}^{t}\left(y_{i}-\bar{y}\right)^{2}}}$

$\bar{x}=\frac{1}{n} \sum_{i=t-n+1}^{t}\left(x_{i}\right) \quad$ and $\quad \bar{y}=\frac{1}{n} \sum_{i=t-n+1}^{t}\left(y_{i}\right)$

where $t=n, n+1, n+2, n+3, \ldots \ldots .$. . Here, $n$ is the length of sliding or running window (i.e. 17-yr considered for this study). 
Further, the underlying mechanisms pre- and post- the inter-decadal change of the ENSO impact on CSWA winter precipitation climate are investigated.

\subsection{Characteristics of leading three EOF modes of CSWA winter precipitation}

The spatial patterns of the first three EOF modes of CSWA winter precipitation and time series of the corresponding principal components (hereafter PC) are shown in Figure 4.2. The first EOF mode (Figure 4.2 (a)) explains $19 \%$ of the total domain variance and is characterised by a mono-sign pattern, with positive loadings over much of the region. This spatial pattern reflects the coherent variability of winter precipitation over the entire domain, consistent with the findings of previous studies (Hoell et al. 2015a, Kar and Rana 2014). The positive (negative) fluctuations in the polarity and amplitude of EOF1 are indicative of region-wide wetter (drier) winter conditions. The PC time series associated with this mode (Figure 4.2 (b)) is positively correlated with the seasonally averaged year-to-year winter precipitation over CSWA $(r=0.93)$ and with ENSO $(r=0.49)$, both statistically significant at the $99 \%$ confidence level. More details on these linkages is provided in section 4.5.

The second EOF (Figure 4.2 (b)) of winter precipitation, explaining 15\% of the total variance, displays a meridional dipole structure with a negative centre of action in the north and a positive one in the south. The zero line of the dipole pattern is confined close to the climatological position of the winter tropospheric jet that lies between $20^{\circ} \mathrm{N}$ to $35^{\circ} \mathrm{N}$ (Krishnamurti 1961), suggesting that the second EOF mode of winter precipitation is presumably related to the fluctuations in the latitudinal position/intensity of wintertime jets over CSWA. Strong links have been established between the NAO and the variability in the speed and mean position of the midlatitude westerly jet stream during the boreal winter (Rogers 1997; Luo et al. 2007; Strong and Davis 2007; Woollings et al. 2010). For example, Luo et al. (2007) reported that the positive (negative) NAO phase is related to the poleward (equatorward) shift of the westerly jet from its climatological position in the northern Hemisphere. However, in our case the PC2 time series associated with the second EOF mode does not demonstrate a significant linkage to the wintertime (NDJFMA) NAO index. A possible reason for this could be that a combination of different 
concomitant climatic modes such as the East Atlantic pattern (EA), the Scandinavian pattern (SCA), the EA-WR pattern and atmospheric blocking events can modulate the geographical location and intensity of the NAO's centres of action from the classic locations, used to compute the conventional station-based NAO indices (Woollings et al. 2010; Moore and Renfrew 2012; Comas-Bru and McDermott 2013). Moreover, various regional circulation patterns and large-scale atmospheric processes including tropical and extratropical teleconnections (e.g. ENSO, EA-WR, PE and Siberian High) have been linked to changes in the westerly storm-tracks accompanied by shifts in wintertime jet stream flow pattern over the CSWA region (Yin et al. 2014; Barlow et al. 2016; Cohen et al. 2014; Lioubimtseva 2015; Wolff et al. 2017) either directly or by way of partly modulating the strength of the associated teleconnections (Rana et al. 2018). It may be for these reasons that the PC2 time-series is not strongly correlated with any particular mode. See section 4.5 for more details.

The third EOF mode of CSWA winter precipitation (Figure 4.2 (c)) explains $10 \%$ of the total variability and mostly features a zonal dipole with opposite precipitation variations in the western and eastern parts of the region. Structurally, the pattern represents longitudinal variations in the mean structure and flow (ridges and troughs) of Rossby waves associated with the subtropical jet stream over CSWA. It has been noted that the strength of the jet stream is influenced by the magnitude of the meridional temperature gradient between the equatorial regions and the higher latitudes, such that the reduction in the north-south temperature gradient slows down the jet-stream zonal velocity and increases its tendency to meander (Francis and Vavrus 2012; Hassanzaded et al. 2014). A similar west-east precipitation dipole structure across CSWA has been reported in Hoell et al. (2017) and Rana et al. (2018), who used different statistical approaches to characterise the long-term precipitation variability over the CSWA region. The PC3 time series displaying the temporal component of this mode shows a period of moderate variability before the mid-1990s, followed by a mild upward trend and increased variability, likely associated with an increase in the frequency of dry conditions over CSWA linked to the rapid warming of the Indo-west Pacific and the Atlantic Ocean SSTs in the recent decades (Compo and Sardeshmukh 2010; Hoell and Funk 2014; McGregor et al. 2014). 

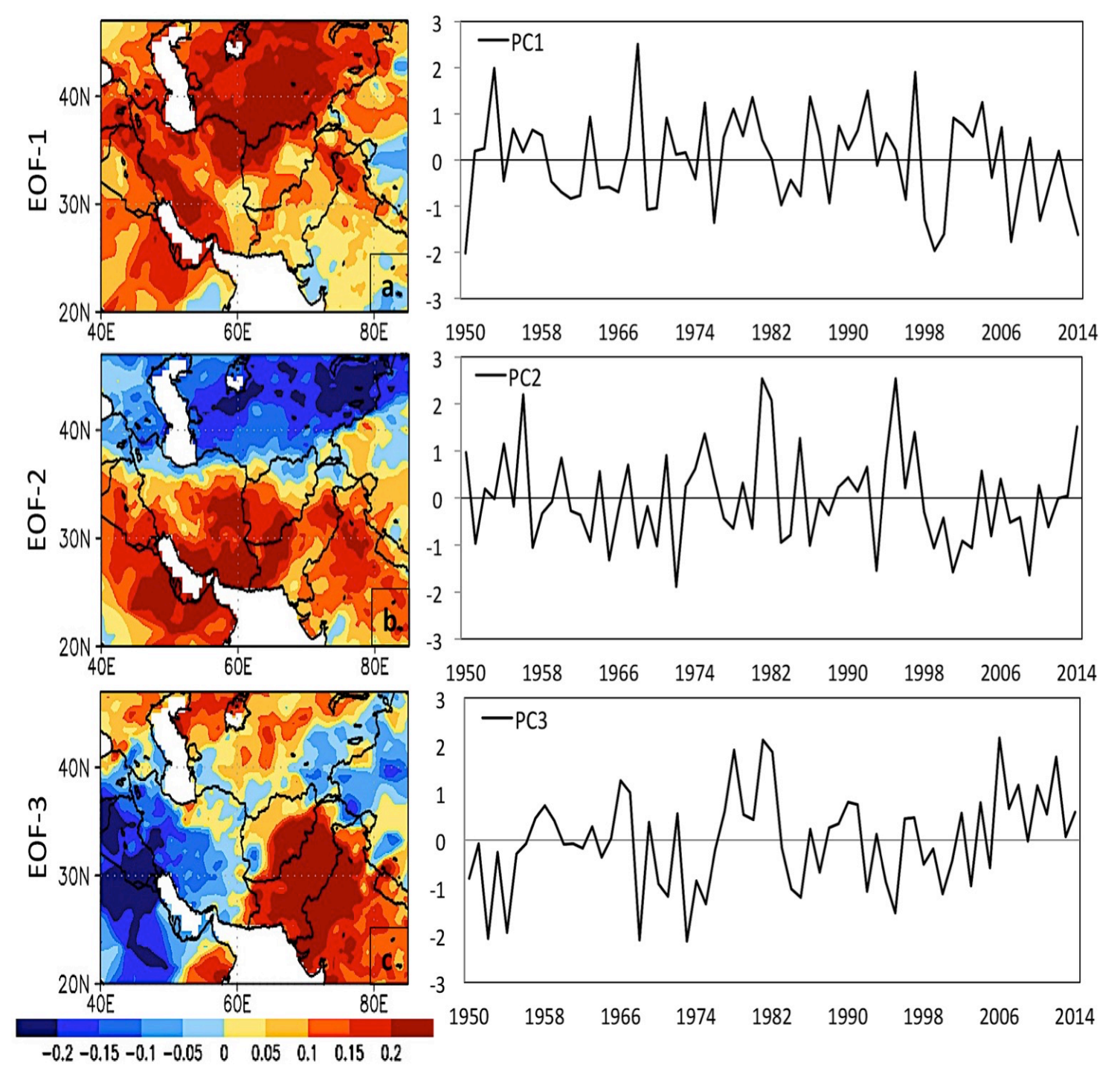

Figure 4.2: The spatial patterns and their corresponding normalized PC time series for the (a) first (EOF-1: 19\%), (b) second (EOF-2: 15\%), and (c) third (EOF-3: $10 \%)$ EOF modes of CSWA wintertime (NDJFMA) precipitation for the period $1950 / 51-2014 / 15$.

\subsection{Association with global SST and large-scale atmospheric circulation anomalies}

To demonstrate the physical sense of the three leading EOF modes of CSWA winter precipitation and to verify their relationship with the large-scale patterns of climate variability; spatial maps of SST, SLP, geopotential height, zonal and meridional winds anomalies were obtained using regression of the corresponding fields onto PC1 (Figure 4.3), PC2 (Figure 4.4) and PC3 (Figure 4.5) time series. 


\subsubsection{EOF-1 associated climate anomalies}

In Figure 4.3(a), the SST anomaly pattern for PC1 shows strong and statistically significant positive SST anomalies in the central-eastern tropical Pacific accompanied by negative anomalies over the western Pacific sector. This pattern is spatially similar to the warm phase of the ENSO cycle; that has its origin in the tropical Pacific Ocean with teleconnections reaching far beyond the Pacific sector (Latif and Barnett 1995; Neelin et al. 1998). Consistent with the distribution of SST anomalies associated with PC1, the SLP map in Figure 4.3(b) exhibits a large-scale seesaw pattern of statistically significant SLP anomalies in the tropical Indo-western Pacific and the eastern Pacific Ocean, characteristic of the negative phase of the Southern Oscillation. In the North Atlantic sector, the SST anomalies bear some resemblance to the negative phase of the NAO cycle, which is usually observed during El Niño winters (Gershunov and Barnett 1998; Graf and Zanchettin 2012) and has been linked with the formation and persistence of atmospheric blocking episodes in the North Atlantic sector (Shabbar et al. 2001). Supporting the above, a blocking-like dipole structure is evident in the SLP regression map (Figure 4.3(b)) with a positive centre of action sitting over western Europe and a secondary centre of opposite sign over Greenland and further south, which is fairly similar to the blocking pattern described in Cassou et al. (2004).

Previous research has shown that the key system that bridges the ENSO-related variations in the Pacific Ocean and CSWA's regional precipitation climate is through an eastward propagating Rossby wave train that emanates from the central equatorial Pacific Ocean and extends eastwards over North America, the Atlantic, and the Middle East into western Asia (Shaman and Tziperman 2005; Barlow and Tippett 2008). Large-scale equivalent barotropic Rossby waves propagate over the CSWA region (Hoell et al. 2013, 2015a; Rana et al. 2018) as evidenced by the statistically significant geopotential height anomalies of the same sign at Z500 hPa and Z200 hPa in Figure 4.3(c) and Figure 4.3(d), respectively. In addition to the stationary barotropic Rossby wave mechanism that impacts CSWA from the west, ENSO teleconnections also influence the regional climate of CSWA by the westwardpropagating baroclinic Rossby waves (Barlow et al. 2002; Barlow et al. 2007; Hoell et al. 2012) associated with the Gill-Matsuno-type circulation response (Matsuno 1966; Gill 1980). 

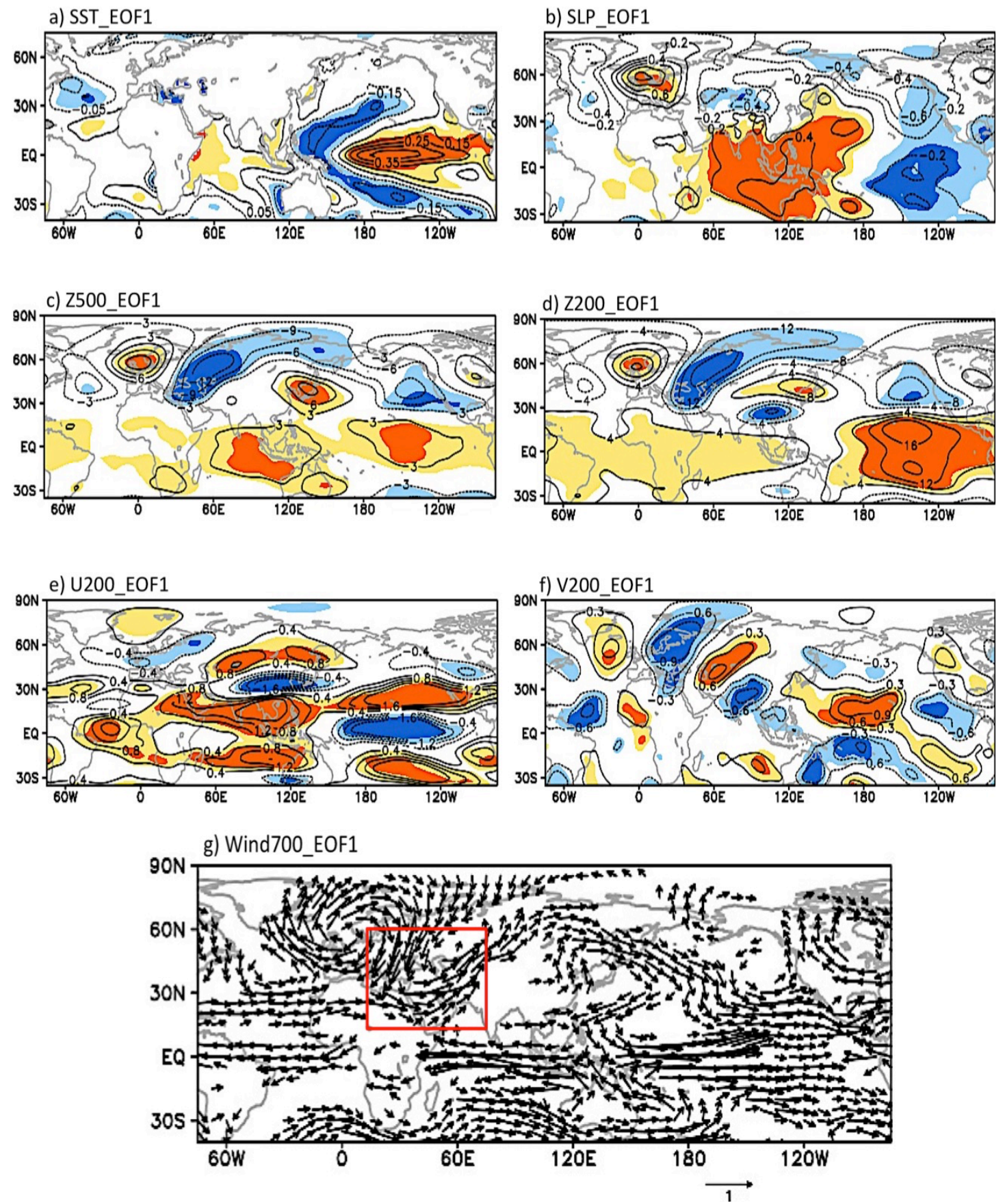

Figure 4.3: Regression maps of (a) SST, (b) SLP, (c) geopotential height at 500-hPa, (d) geopotential height at 200-hPa, (e) zonal wind at 200-hPa, (f) meridional wind at 200-hPa, and (g) wind vectors at 700-hPa onto PC1 time-series associated with EOF1 for the period 1950/51-2014/15. Solid (dashed) contours denote positive (negative) values and zero lines are omitted. The contour interval is $0.1^{\circ} \mathrm{C}$ in (a); $0.2 \mathrm{hPa}$ in (b); $3 \mathrm{~m}$ in (c); $4 \mathrm{~m}$ in (d); $0.4 \mathrm{~m} / \mathrm{s}$ in (e) and 0.3 in (f). The light and dark shadings in the figures (a-f) indicate that the correlation coefficients are significant are significant at $p<0.10$ and $p<0.01$, respectively. 
In Figure 4.3, the tropically forced baroclinic response can be seen over India and China $\left(\sim 30^{\circ} \mathrm{N}, 120^{\circ} \mathrm{E}\right)$ in the $\mathrm{Z} 200 \mathrm{hPa}$ and $\mathrm{U} 200 \mathrm{hPa}$ fields, but is somewhat overshadowed by the hemispheric-wide strong equivalent barotropic signal. These results show that anomalous warming in the equatorial eastern Pacific associated with El Niño induces an anomalously cold-core cyclonic trough (low pressure) over CSWA; that interacts with the mean mid- and upper-level tropospheric jet flows, resulting in a thermodynamically-forced warm temperature advection and precipitation-enhancing anomalous ascent over CSWA that extends throughout the troposphere (Hoell et al. 2013; 2017). The reverse is true during La Niña years (Rana et al. 2018).

Correspondingly, the regression of the zonal wind component at $200-\mathrm{hPa}$ (Figure 4.3(e)) onto PC1 shows statistically significant negative anomalies (easterly flow anomalies) across the equatorial Pacific Ocean, indicative of a weaker-thannormal Walker Circulation in response to El Niño conditions. Another prominent feature is the zonally-elongated band of positive (westerly) wind anomalies, circumnavigating the upper troposphere, and meridionally confined to latitudes $\sim 25^{\circ}-$ $30^{\circ}$ in the region of the subtropical westerly jet. Graf and Zanchettin (2012) showed that during warm ENSO events, in particular for central Pacific El Niños, the Rossby waves generated by anomalous atmospheric heating in equatorial latitudes may become meridionally trapped by the subtropical jet and propagate eastward within the jet waveguide causing perturbations over the Atlantic and European sector. In fact, the 200-hPa meridional wind anomalies shown in Figure 4.3(f) reflects a Rossby wave-like structure that appears to be originating from the equatorial Pacific (around the dateline) and propagating eastward as a series of cyclonic and anticyclonic features that are well observed over the Atlantic, Europe and western Asia. Furthermore, the significantly deepened trough as noted in the height anomalies appears as anomalous cyclonic circulation over CSWA at the lower 700-hPa level as shown in Figure 4.3(g). The circulation around this cyclonic center is associated with an enhanced southwesterly flow pattern across much of the CSWA region (within the red box in Figure 4.3(g), which advects moist air from the adjoining Arabian Sea and Indian Ocean basin, thereby increasing the regional winter precipitation during the warm ENSO phase. 


\subsubsection{EOF-2 associated climate anomalies}

For the second EOF mode, the regression maps of SST (Figure 4.4(a)) and SLP (Figure 4.4(b)) onto PC2 show notably different sources of variability and associated atmospheric circulation structures, compared to those obtained for PC1. The SST anomalies are much weaker in magnitude with significance occurring only over limited areas of the three ocean basins. In the North Pacific sector, the SST pattern manifest features similar to the second mode of North Pacific SST variability, which is termed as the Victoria mode (Bond et al. 2003) or the North Pacific Gyre Oscillation (NPGO; Di Lorenzo et al., 2008). The corresponding atmospheric response to NPGO appears as a meridional pressure dipole between Alaska and Hawaii that has a strong resemblance to the North Pacific Oscillation (NPO) signature (e.g. Figure 2 in Furtado et al. 2011; Linkin and Nigam 2008) and was first identified by Walker and Bliss (1932). Significant positive SLP anomalies also occur over a large part of East Asia with a spatial structure that represents a southward migration and a westward extension of the Siberian High from its climatological position of $40^{\circ}-60^{\circ} \mathrm{N}, 80^{\circ}-120^{\circ} \mathrm{E}$. Based on the above it appears that the intensity and location of the Siberian High also plays a role in EOF-2 variability. Further, in the North Atlantic sector, the low-pressure anomalies over the Icelandic region and throughout the Arctic combined with high-pressure anomalies spanning the central latitudes of the North Atlantic between $35^{\circ}-45^{\circ} \mathrm{N}$ represent a pressure dipole structure, reminiscent of NAO anomalies. Here, the most notable feature is that the atmospheric anomalies associated with PC2 are confined largely to the mid-to-high-latitudes of the Northern Hemisphere; implying that the tropical forcing plays a lesser role in the variability of the second EOF mode of CSWA winter precipitation, unlike the first EOF mode.

The regression map of Z500 (Figure 4.4 (c)) and Z200 (Figure 4.4(d)) display a zonally oriented tripolar pattern of negative-positive-negative height anomalies extending in the meridional direction over the Northern Hemisphere. Meanwhile, the height anomalies in the Pacific Ocean broadly resemble the western Pacific (WP) teleconnection pattern, which is the upper-air signature of the NPO variability in SLP (Linkin and Nigam 2008). The similar sign of height anomalies at 500-hPa and 200$\mathrm{hPa}$ feature an equivalent barotropic vertical structure. The shape and the location of the twin statistically significant narrow bands of negative geopotential height anomalies (cyclones) located around $25^{\circ} \mathrm{N}$ and $60^{\circ} \mathrm{N}$ correspond to a slight equatorward and poleward shift in the position of the subtropical and polar front jet 
stream, respectively. The two jets are well separated from each other by a strong positive height anomaly centre located over central Russia and Mongolia associated with the Siberian anticyclone.
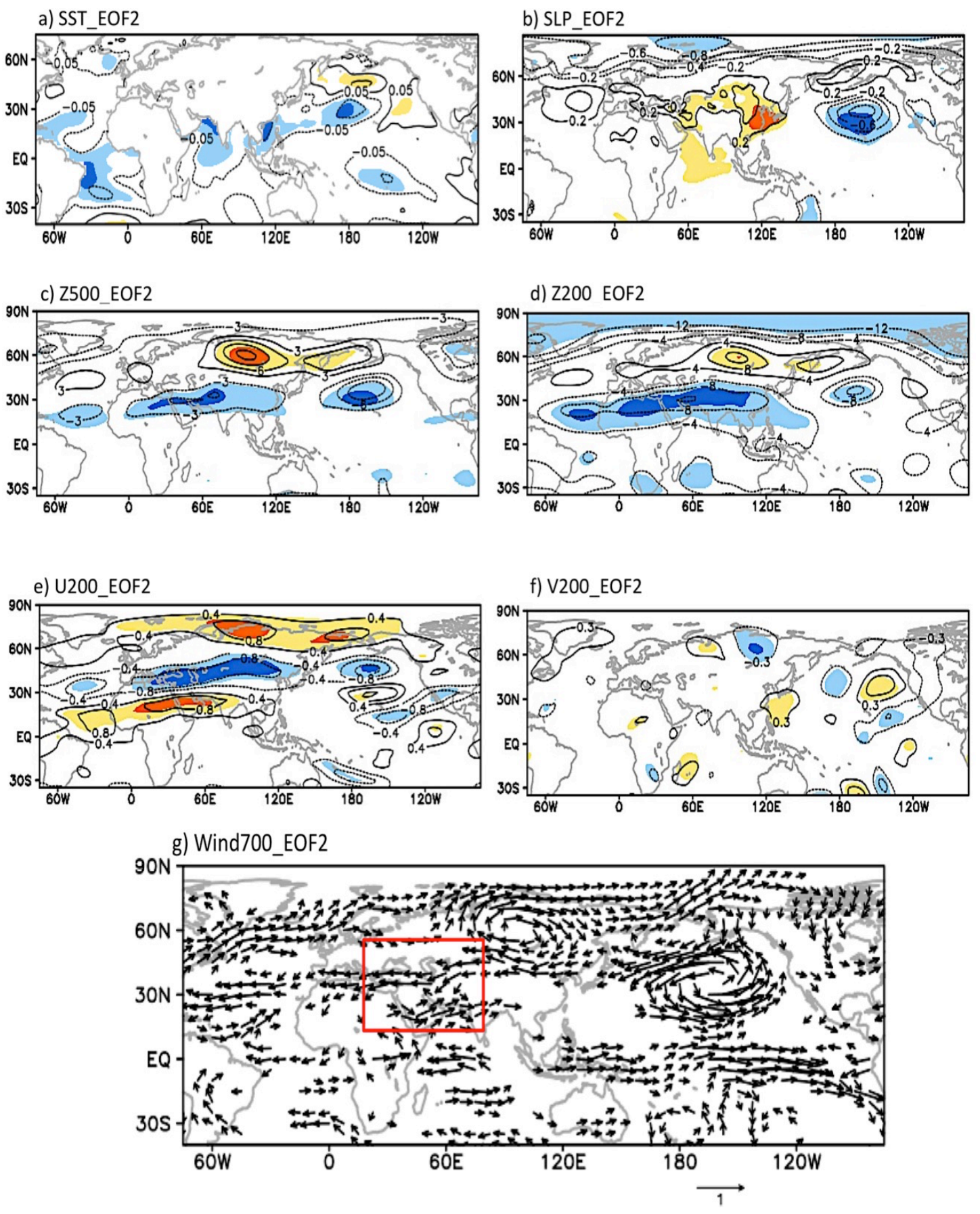

Figure 4.4: As in Figure 4.3, but for PC2 time-series associated with EOF-2.

These results are further supported by the 200-hPa zonal wind regression map (Figure 4.4(e)) that exhibit a more prominent tripolar structure with zonally elongated and meridionally tighter zonal wind anomalies spanning the entire Northern 
Hemisphere. Statistically significant positive (westerlies) zonal wind anomalies are noted along the two jet axis, while the occurrence of negative (easterlies) wind anomalies at latitudes in between the jets suggest a weakening of the background westerlies in conjunction with the anticyclonic flow coming from the westward progression of the Siberian High over northern central Asia. The relationship between PC2 and the 200-hPa meridional wind component is rather weak or almost nonexistent as seen in Figure 4.4(f). Hence the second mode of CSWA winter precipitation appears to be dominated by variations in the latitude and strength of the subtropical jet and zonal flow across Eurasia.

An interesting feature to note in the regressed wind anomalies at $700-\mathrm{hPa}$ (Figure $4.4(\mathrm{~g})$ ) is that the out-of-phase meridional dipole observed in the North Pacific SLP and geopotential height anomalies give rise to a dominant anticyclonecyclone couplet that is associated with a strong easterly flow anomaly close to the nodal point $\left(\sim 48^{\circ} \mathrm{N}\right)$ and strengthens the prevailing easterlies of the Siberian anticyclone. Previous works have indicated the role of Siberian High in modifying the influence of the westerly storm systems over Northern Hemisphere mid-latitudes (Makorgiannis et al. 1981; Hasanean et al. 2013; Panagiotopoulos et al. 2005; Cannon et al. 2014; Wolff et al. 2017). Consistent with the above findings, our results show that the westward extension of the Siberian anticyclone into central Asia and Europe, along with the northwestward nudging of the NPO/WP pattern contributes towards the maintenance of upper-level ridges over northern CSWA. This ridge blocks the eastward propagating westerly storm systems, restricting their flow to a more southerly track that results in more precipitation on the southern side of the CSWA region as shown in Figure 4.2(b).

\subsubsection{EOF-3 associated climate anomalies}

For the third EOF mode of CSWA winter precipitation, the SST regression map (Figure 4.5(a)) associated with PC3 reveals three distinct tropic-wide areas of statistically significant positive SST anomalies. This pattern is fairly similar to the observed tropical SST trend noted for the last half century (e.g. Figure 3a in Shin and Sardeshmukh 2011), the principal feature of which is the long-term warming of the Indian and the Pacific Ocean (Hoerling et al. 2001). The above result is consistent with the findings of Hoell et al. (2017), who reported that the west-east precipitation 
dipole pattern over CSWA (similar to the one depicted in Figure 4.2(c)) is related to the warming of the Indian and Pacific Ocean SST. Also in Figure 4.5(b), the SLP response associated with PC3 depicts a strong midlatitude-tropical link, marked by a sharp tri-polar meridional pressure gradient with statistically significant negative pressure anomalies in the mid-to-high latitudes of the cold Eurasia/North Atlantic and two separate positive anomaly centres situated over the adjacent warm western Pacific/Australia and Africa/South Atlantic. Since the subtropical jet stream is a thermally driven phenomenon, a weaker (stronger) thermal contrast or SLP gradient tends to favour (inhibit) the north-south excursions i.e. wave amplitude and waviness of the jet stream. In other words, an increased north-south meandering of the jet stream results in slower progression of weather systems and more frequent atmospheric blocking events that can lead to extreme weather events (Hassanzaded et al. 2014; Barriopedro and Garcia-Herrera 2006).

The above results provide reasonable evidence that the west-east precipitation pattern across CSWA (represented as EOF-3) is potentially related to the longitudinal changes in the zonal velocity of the westerly jet stream that occurs in proportion to the temperature/pressure changes forced by the meridional gradient of the diabatic heating. In response to the anomalous surface heating, the geopotential height anomalies at 500-hPa (Figure 4.5(c)) and 200-hPa (Figure 4.5(d)) associated with PC3 indicate a strong connection to the tropics with statistically significant positive height anomalies spanning the entire tropical region. Upstream of the Indian Ocean, an accompanying feature in the extratropical Northern Hemisphere is a less significant negative geopotential height anomaly pattern stretching from the North Atlantic to the Ural region, between positive anomalies positioned over the Mediterranean Sea and over southern Siberia. The tripolar pattern bears a close resemblance to the type 1 Eurasian pattern (Barnston and Livezey 1987), the Scandinavian pattern (Bueh and Nakamura 2007; Liu et al 2014) or the Ural-Siberian blocking (Cheung et al., 2012). Here it is important to note that Liu et al. (2014) identified an important role of cold (warm) Indian Ocean SST anomalies in the formation and maintenance of the positive (negative) Scandinavian pattern during the winter months.

In Figure 4.5(e), the regressed upper-tropospheric zonal wind anomalies associated with PC3 exhibit a weak westerly flow over North Africa and the Middle Eastern region. A zonally oriented band of positive (westerly) wind anomalies is observed at $60^{\circ} \mathrm{N}$ latitude that extends southeastwards over the Black Sea and the 
Caspian Sea region into CSWA. In the tropical and subtropical central Pacific, the zonal wind anomalies are similar to those related to the warm phase of ENSO. Meanwhile, the 200-hPa meridional wind component in Figure 4.5(f) displays a prominent wave-like anomaly pattern with statistically significant centres of action encompassing much of the CSWA region.
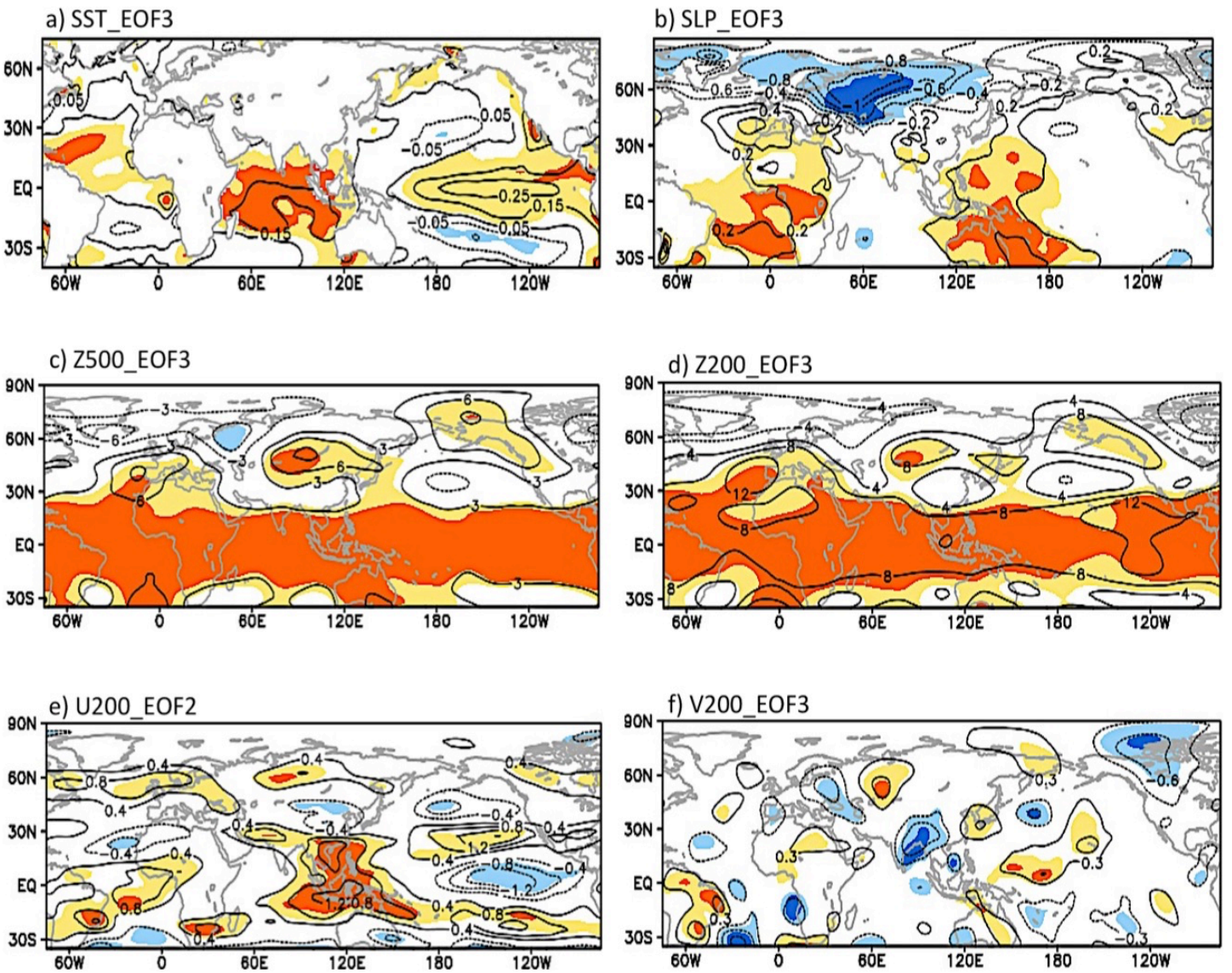

g) Wind700_EOF3

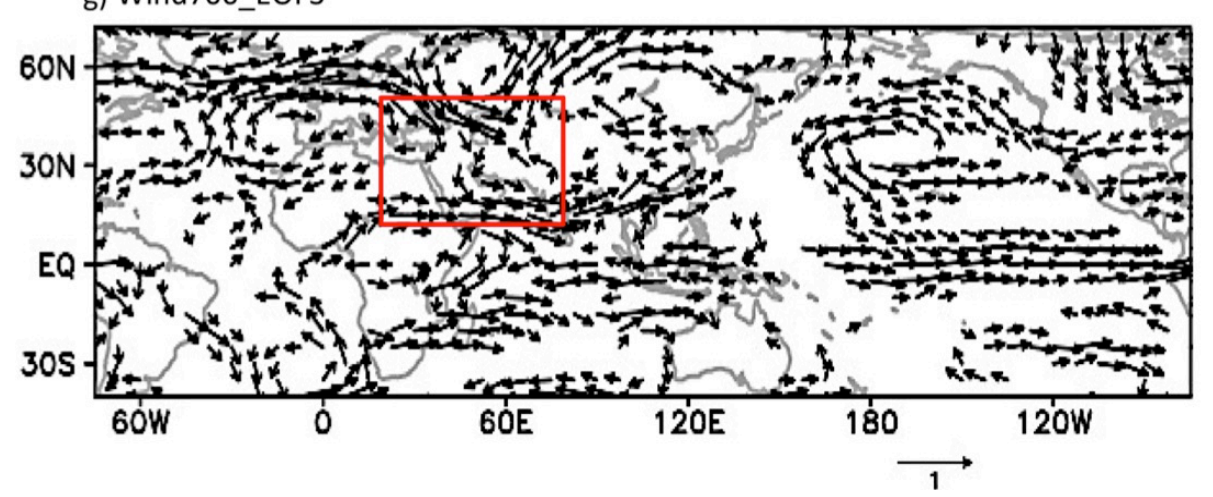

Figure 4.5: As in Figure 4.3, but for PC3 time-series associated with EOF-3.

At the surface, the regressed $700-\mathrm{hPa}$ wind field (Figure 4.5(g)) features a cyclonic centre at $\left(60^{\circ} \mathrm{N}, 60^{\circ} \mathrm{E}\right)$ sandwiched between two large anticyclones that 
occupy most of the North Atlantic-European region in the west and central Siberia in the East. This pattern corresponds well to the extratropical positive-negative-positive anomaly centres of the Scandinavian pattern noted in the regressed height anomaly map shown in Figure 4.5(c). Here, the circulation response associated with the anticyclone over Europe and the cyclone over the Ural mountains generates a colddry northerly flow over the western flank of the CSWA region, resulting in negative precipitation loadings over western CSWA that are consistent with the see-saw pattern depicted in Figure 4.2(c). On the other hand, a strong westerly flow is observed along the southern flank $\left(\sim 10^{\circ} \mathrm{N}\right.$ to $\left.20^{\circ} \mathrm{N}\right)$ of the CSWA region coming from Africa into the Arabian Sea, and extending up to central India and beyond. At the eastern periphery of the CSWA region (within the red box), the circulation pattern indicates a southerly flow into the eastern flanks of the CSWA region. This southerly flow from the Arabian Sea is associated with precipitation enhancing moist air advection into CSWA, consistent with the positive polarity of EOF loading pattern shown in Figure 4.2(c).

\subsection{Inter-decadal change of connection between the wintertime ENSO and EOF-1}

Here we focus on the inter-decadal change of the connection between ENSO and EOF-1 of CSWA winter precipitation variability. It has been established herein (Figure 4.3) and previously (Hoell et al. 2017) that the leading mode of CSWA winter precipitation is closely related to the ENSO phenomenon. Using the Niño-3.4 index as an indicator of ENSO, Figure 4.6(a) presents the interannual variability of the NDJFMA averaged Niño-3.4 index and the normalized PC time series (i.e. PC1) associated with EOF-1 for the period 1950/51-2014/15.

The year-to-year variations in the Niño-3.4 index and PC1 display both samesign and opposite-sign changes during the analysis period. A close examination shows that opposite-sign variations often occurred during the period from the 1950s through the early 1980s, while same-sign variations appear to dominate after the mid-1980s.

The sliding correlation between PC1 and the Niño-3.4 index with a 17-year window is shown in Figure 4.6(b). The impact of ENSO on EOF-1 variability is weak between 1950 and 1980, but strong and statistically significant after the mid-1980s. 
Many previous studies [e.g., Kumar et al. 1999; Van Oldenborgh and Burgers 2005; Lopez-Parages and Rodriguez-Fonseca 2012; Jia and Ge 2017] have found a nonstationary relationship between the surface climate and the ENSO teleconnections in different regions around the globe. These variations are often explained by changes in the background climate related to (i) the interdecadal variability of the midlatitude atmosphere (Gershunov and Barnett 1998; Diaz et al. 2001) (ii) the influence of global warming (Stevenson 2012; Cai et al. 2015) (iii) or by mere chance in which the low-frequency SST variations did not exert a modulating effect (Sterl et al. 2007). Since a similar change in the impact of ENSO teleconnection has been reported for CSWA (Hoell et al. 2017; Rana et al. 2018); therefore in the following two separate sub-periods are discussed, with one sub-period defined from 1950/51-1983/84 (P1) and the other from 1984/85-2014/15 (P2).
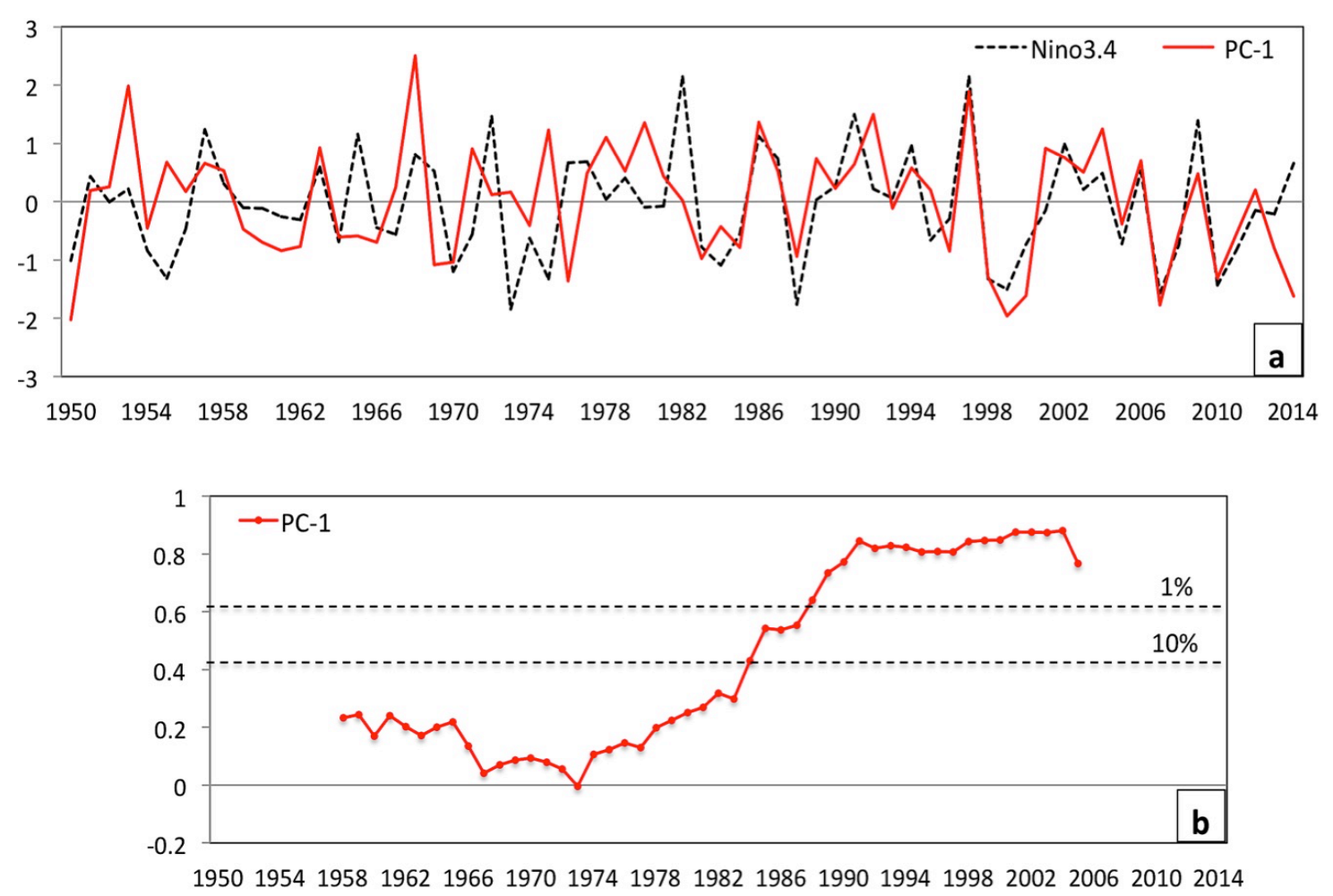

Figure 4.6: (a) Time series of the wintertime (NDJFMA) Niño-3.4 index and the normalized PC1 time-series associated with EOF-1 during 1950/51-2014/15. (b) Sliding correlations between Niño-3.4 index and the PCl time-series displayed at the central year of a 17-year window. The horizontal dotted lines in (b) indicates the correlation is significant at the 10\% (0.41) and 1\% (0.61) confidence level. 


\subsubsection{The EOF-1 associated global SST and large-scale atmospheric circulation anomalies in $\mathbf{P 1}$ and $\mathbf{P 2}$}

Regression maps of SST and SLP onto PC1 time series associated with EOF-1 are examined for the two periods P1 and P2 and depicted in Figure 4.7. During P1, the SST anomalies linearly correlated with EOF-1 are weak (Figure 4.7(a)) while during P2 (Figure 4.7(b)) there is a clear SST anomaly contrast between the warm centraleastern and cold western tropical Pacific Ocean, mimicking an El Niño-like structure. The regression map of SST (Figure 4.7(a)) and SLP onto PC1 (Figure 4.7(c)) shows that without the influence of ENSO, the atmospheric response anomalies in P1 are mainly constrained over the mid- to high-latitudes of the Northern Hemisphere; whereas a significant connection to the tropical Pacific is observed in P2 (Figure 4.7(d)) indicating that ENSO has a closer and more persistent relationship with EOF-1 after the 1980s.
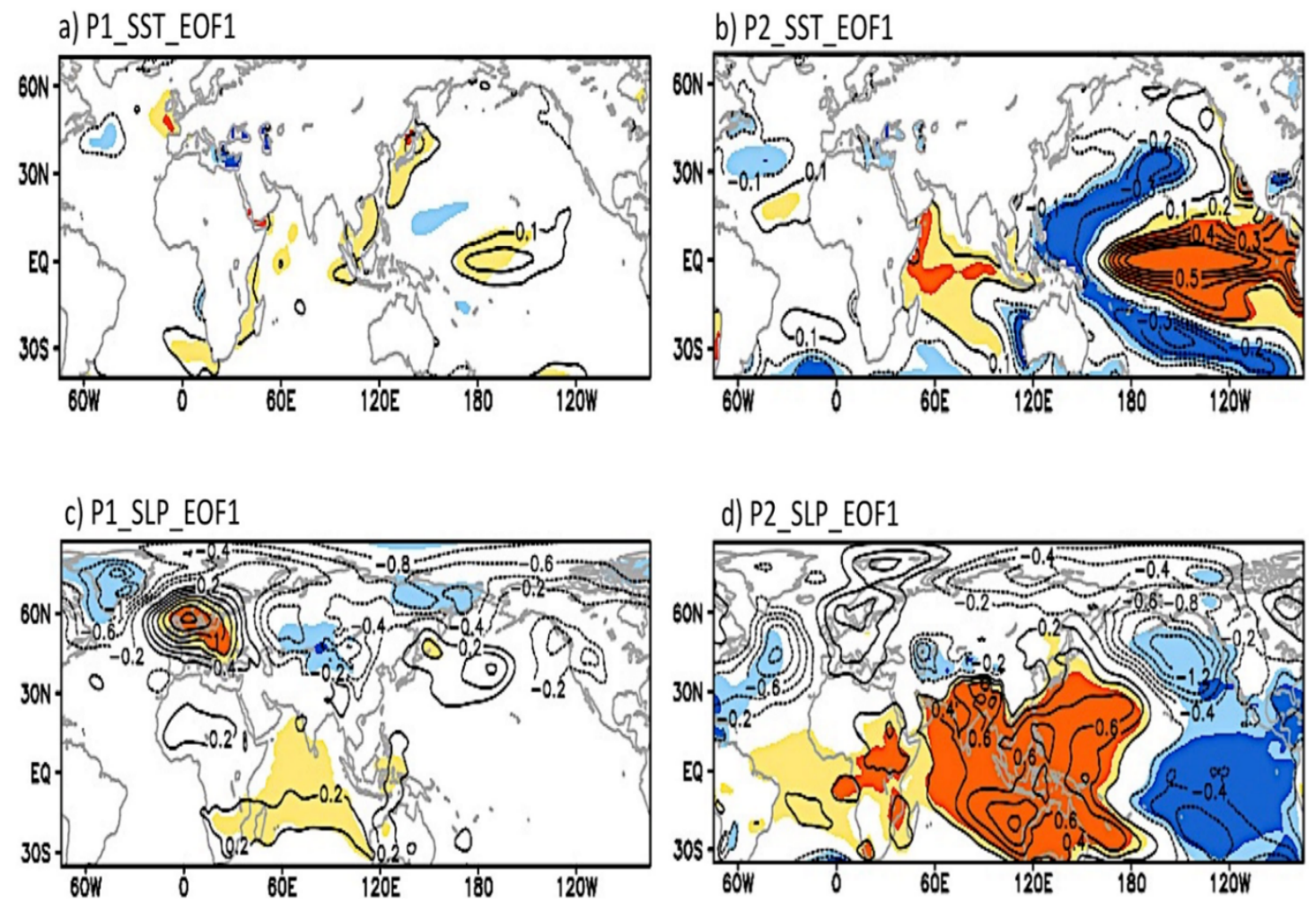

Figure 4.7: The regression maps of ( $a$ and b) SST and ( $c$ and d) SLP onto the PC1 time series associated with EOF-1 for P1 [1950/51-1983/84] (Figure a and c) and P2 [1984/85-2014/15] (Figure $b$ and d). Solid (dashed) contours denote positive (negative) values and zero lines are omitted. The contour interval is $0.1^{\circ} \mathrm{C}$ in (a), (b); and $0.2 \mathrm{hPa}$ in (c), (d). The light and dark shadings in the figures ( $a-d)$ indicate that the correlation coefficients are significant are significant at $p<0.10$ and $p<0.01$, respectively. 
The EOF-1 related atmospheric circulations at the mid- and upper-tropospheric levels for the two sub-periods are depicted in Figure 4.8. The 500-hPa and $200-\mathrm{hPa}$ regressed height anomalies associated with EOF-1 for P1 (Figure 4.8(a) and Figure 4.8(c)) are analogous to those of SLP, dominated by a zonally oriented wave train-like pattern covering the entire extratropical Northern Hemisphere. Here, the most prominent features are the two dominant positive centres of action located over Western Europe and the mid-latitude Asian sector accompanied by an anomalously strong negative anomaly centre over western Russia, north of the Caspian Sea. This stationary wave structure of large-amplitude ridges and troughs is quasi-barotropic (Figure 4.7(c), Figure 4.8(a) and Figure 4.8(c)) and seems a reminiscent of the positive phase of the EA-WR teleconnection (Liu et al. 2014; Lim and Kim 2016; Gao et al. 2016) or the type 2 Eurasian pattern described in Barnston and Livezey (1987). This result shows that in P1, EOF-1 variability is more closely related to the Northern Hemisphere extratropical teleconnections rather than to tropical forcings.
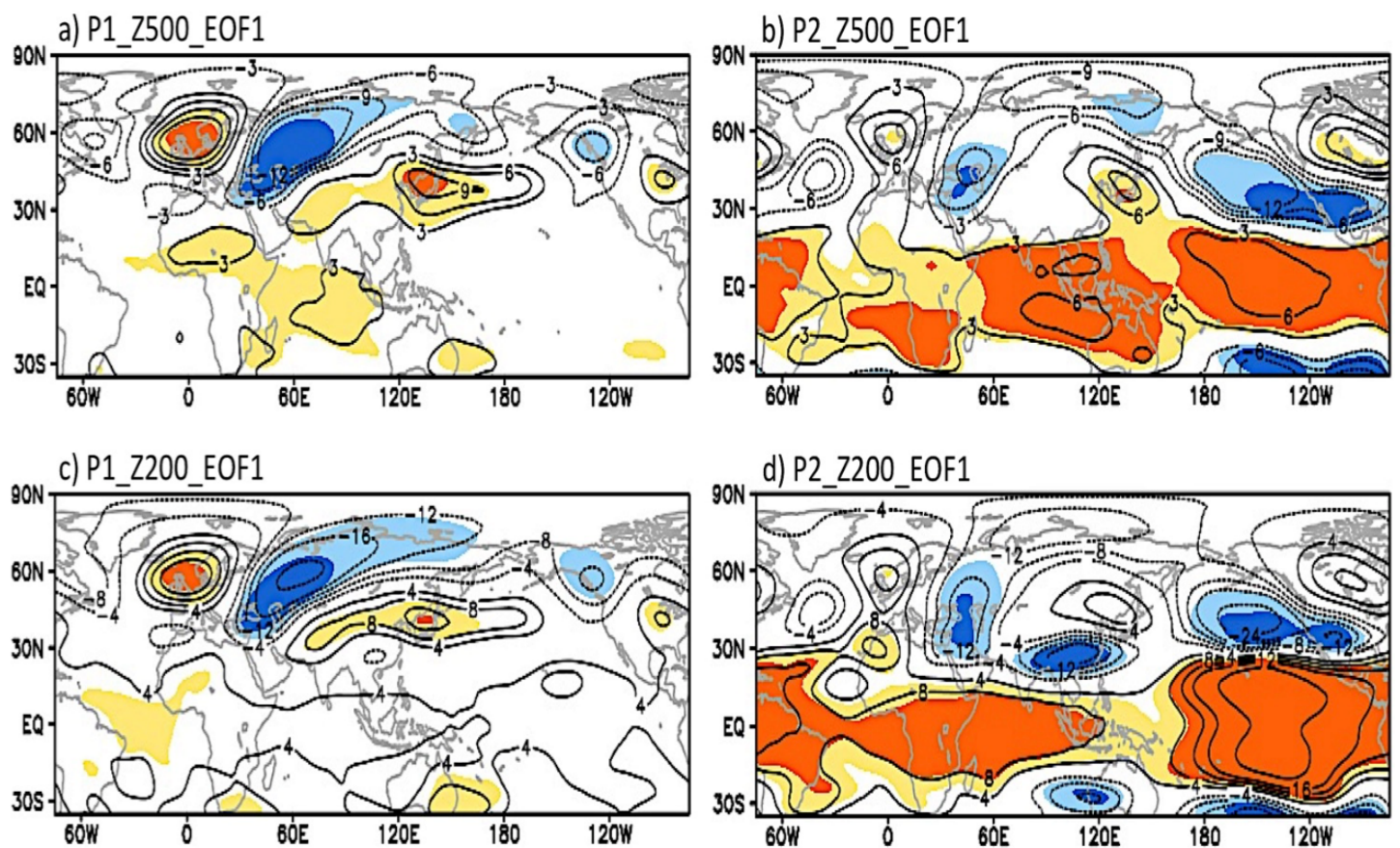

Figure 4.8: Regression maps of ( $a$ and b) geopotential height at 500-hPa and (c and d) geopotential height at 200-hPa SLP onto the PC1 time series associated with EOF-1 for P1 [1950/51-1983/84] (Figure $a$ and c) and P2 [1984/85-2014/15] (Figure $b$ and d). Solid (dashed) contours denote positive (negative) values and zero lines are omitted. The contour interval is $3 \mathrm{~m}$ in (a), (b); and $4 \mathrm{~m}$ in (c), (d). The light and dark shadings in the figures $(a-d)$ indicate that the correlation coefficients are significant are significant at $p<0.10$ and $p<0.01$, respectively. 
In P2, the atmospheric circulation anomalies that are related to EOF-1 are notably different in structure and source from that of $\mathrm{P} 1$. Pronounced positive height anomalies dominate the tropics in P2, accompanied by a Rossby wave train that emanates from the tropics to the extratropics in response to the El Niño-related forcing and produces both eastward- and westward-propagating stationary waves in the upper troposphere as described in Shaman and Tziperman (2016). An important feature apparent in 500-hPa (Figure 4.8(b)) and 200-hPa (Figure 4.8(d)) regressed height anomalies for $\mathrm{P} 2$ is that in addition to the extratropical barotropic wave response induced by the ENSO-related diabatic heating; two westward-propagating baroclinic waves, symmetric about the equator in both hemispheres, are much clearer and stronger in the recent P2 period than for the full-period relationship observed in Figure 4.3. A further comparison of the atmospheric circulation anomalies in Figure 4.8 with those in Figure 4.3 suggest that in the full-period analysis (i.e., Figure 4.3) much of the strength of the barotropic signal appears to comes from the early P1 period when CSWA precipitation is not related to ENSO.

In a recent study on central Asia, Yin et al. (2014) indicated that both EA-WR and ENSO are related to the regional wintertime precipitation variability through changes in the winter westerly circulation flow and intensity. These changes can be seen clearly in the regressed zonal and meridional wind component anomalies obtained at 200-hPa for P1 and P2 in Figure 4.9. In P1, associated with the positive EA-WR phase noted in height anomalies, a westerly zonal anomaly flow appears over the CSWA region between $25^{\circ} \mathrm{N}$ to $45^{\circ} \mathrm{N}$ latitude (Figure 4.9(a)). Correspondingly, a large-scale wave train-like pattern can be seen embedded in the regressed meridional wind for P1 (Figure 4.9(c)) with maximum amplitude waves over the high latitude North Atlantic, Europe, and western Russia, with the structure quite similar to the EA/WR wave pattern observed in Figure 1d of Lim and Kim (2016). Here the combined effect of the upper-tropospheric zonal and meridional wind anomalies over CSWA creates an anomalous large-scale anticyclone-cyclone couplet at the surface $(700-\mathrm{hPa}$, Figure 4.9(e)). This couplet exerts a strong meridional flow to the west of the CSWA region, accompanied by a weaker zonal flow to the south that appears to be coming from the Atlantic Ocean along the path across North Africa to CSWA between $25^{\circ} \mathrm{N}$ and $30^{\circ} \mathrm{N}$ latitude. The prevailing conditions result in a stronger surface cyclonic activity and an enhanced southwesterly flow over the CSWA region, bringing moisture from the Arabian Sea to 
as far as the Atlantic. On the other hand in P2, the El Niño-related upper-tropospheric zonal wind circulation anomalies over CSWA are associated with the intensification and equatorward shift of the subtropical westerly jet stream (Figure 4.9(b)) and a conspicuous wave-like structure over the Atlantic-European sector in the meridional wind anomalies (Figure 4.9(d)). This pattern favours enhanced southwesterly winds and moisture advection into CSWA from the Arabian Sea and tropical Africa (Figure $4.9(\mathrm{f}))$.
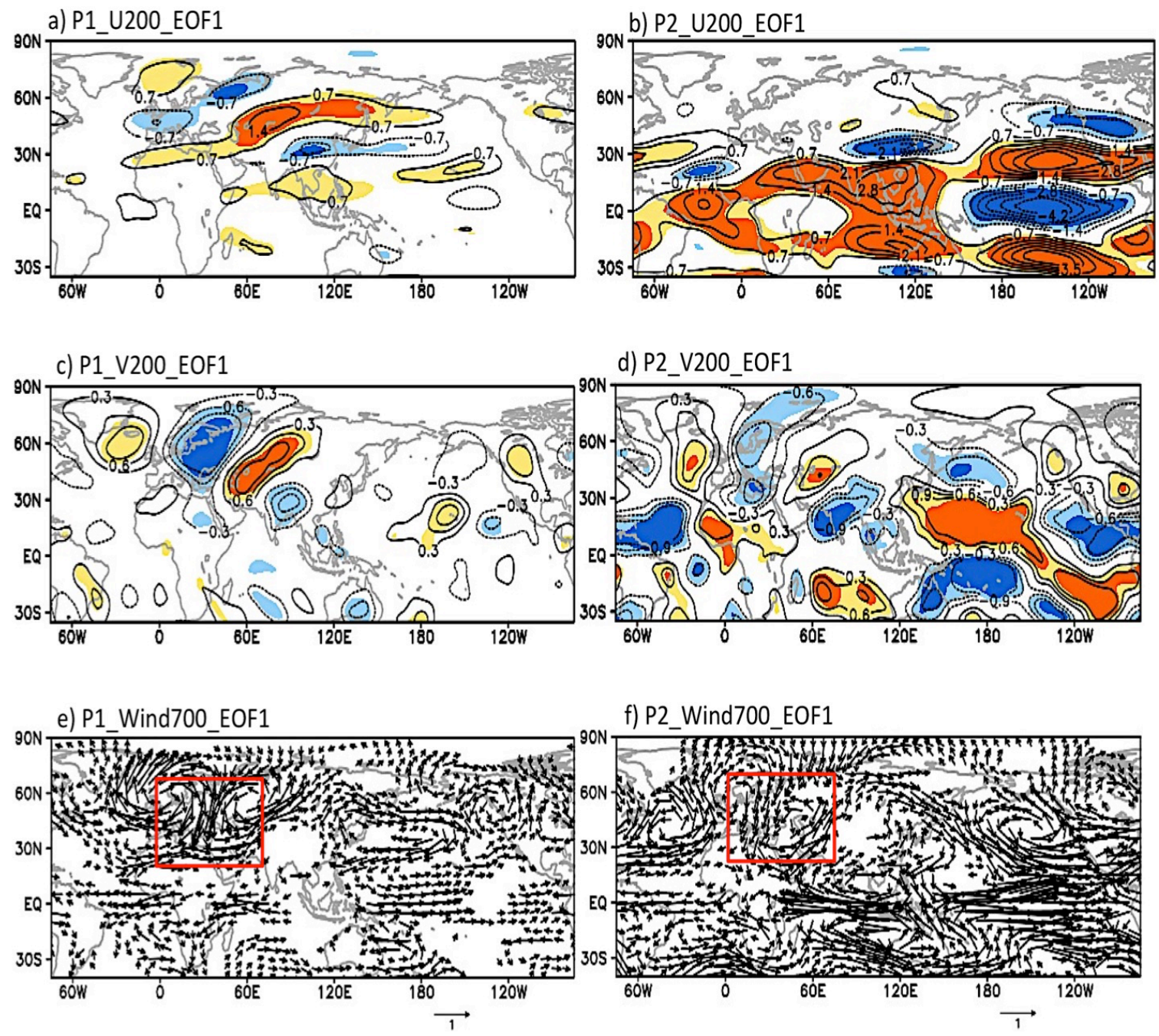

Figure 4.9: Regression maps of ( $a$ and b) zonal winds at 200-hPa, (c and d) meridional winds at 200-hPa, and (e and f) wind vectors at 700-hPa onto the PCl time series associated with EOF-1 for P1 [1950/51-1983/84] (Figure a, $c$ and e) and P2 [1984/85-2014/15] (Figure b, $d$ and f). Solid (dashed) contours denote positive (negative) values and zero lines are omitted. The contour interval is $0.7 \mathrm{~m} / \mathrm{s}$ in (a), (b); and $0.3 \mathrm{~m} / \mathrm{s}$ in (c), (d). The light and dark shadings in the figures (a-d) indicate that the correlation coefficients are significant are significant at $p<0.10$ and $p<0.01$, respectively. 
The results shown here indicate that the leading EOF mode of CSWA winter precipitation is associated with notably different circulation structures and sources of variability in P1 and P2. However, general characteristics of the large-scale circulation anomalies associated with EOF-1 in P2 share many similarities with those obtained for the full analysis period (1950/51-2014/15; Figure 4.3) discussed in section 4.5.1. A closer inspection, however, reveals some notable differences between the two periods most of which are confined locally over mid-latitude Eurasia. For example, the EOF-1 associated atmospheric circulation anomalies in the regressed SLP and geopotential height fields are more pronounced and significant at the $99 \%$ confidence level over the European mainland and CSWA region in the period 1950/51-2014/15 (Figure 4.3(b) to (d)), compared to those in P2. Also, the 200-hPa zonal wind anomalies for (1950/51-2014/15) period in Figure 4.3(e) exhibits a bifurcation of the westerly jet at approximately $30^{\circ} \mathrm{N}-58^{\circ} \mathrm{E}$ with one branch propagating southward of the CSWA region and the other northeastward over to southern Siberia and then towards north Japan. In P2 (Figure 4.9(a)) no such regional bifurcation is observed in the upper-level zonal wind anomalies, other than the El Nino-related southward displacement of the subtropical jet close to $28^{\circ} \mathrm{N}$ latitude. Furthermore, the regressed meridional wind anomalies depicted in Figure 4.3(f) displays a wave train pattern dominated by strong (significant at $99 \%$ confidence level) anticyclonic-cyclonic regional circulation centres over western Europe-CSWA region, in comparison to those observed in P2 (Figure 4.9(d)).

Our analysis suggests that on the regional scale many of the above-noted spatial differences are a result of the extratropical teleconnection response observed in P1 (i.e. 1950/51-1984/85); that without the ENSO signal, are constrained mainly over the mid-to-high latitudes of the Northern Hemisphere. However, with the significant inter-decadal change of the connection between ENSO and EOF-1 around the early 1980s, the strong atmospheric circulation anomalies associated with extratropical processes (e.g. positive EA-WR pattern) in P1 are linearly superimposed by the anomalous atmospheric circulations forced by the warm ENSO conditions throughout the Northern Hemisphere in P2. In fact, the teleconnection pathway or the atmospheric bridge through which the aforementioned modes of climate variability influence the EOF-1 variability in P1 and P2 are quite similar in spatial structure and geographical position over much of Western Europe and Central Asia, as evidenced by the individual stationary barotropic Rossby wave pattern in Figure 4.8. This 
feature likely favours the superposition of the atmospheric circulation anomalies in P2 onto those observed over the mid-to-high latitudes in $\mathrm{P} 1$, resulting in a linearly combined atmospheric response which is similar to the one obtained for the full period (1950-51 - 2014/15) in Figure 4.3.

The above results corroborate the findings of Hoell et al. (2014) who showed that the leading mode of CSWA winter precipitation is related to SST anomalies associated with the ENSO phenomenon. However, it has been identified in this study that in addition to ENSO the EA-WR pattern also contributed significantly to the variability of EOF-1; but it is the ENSO's response that appears more pronounced given its significant relationship with EOF-1 in recent years.

\subsubsection{The interdecadal change of ENSO-related circulations in P1 and P2.}

Many of the previous studies have reported that changes in ENSO characteristics since the late 1970s (Wang 1995; Gu and Philander 1997; An and Wang 2000) have affected the variability and predictability of the tropicalextratropical teleconnections in the Northern Hemisphere, and their associated seasonal climate anomalies (Larkin and Harrison 2005; Jia et al. 2014; Rana et al. 2018; Hoell et al. 2018; Ahmadi et al. 2019). Consistent with the research cited above, our results also demonstrate that the impact of ENSO on CSWA wintertime precipitation climate significantly increased after the mid-1980s. To support these findings, we briefly investigate the changes in ENSO-related circulation anomalies from P1 to P2, for which regression maps of SST, SLP, and Z200 onto Niño-3.4 index are generated and presented in Figure 4.10.

Corresponding to a positive Niño 3.4 index, significant positive SST anomalies are observed over the tropical central-eastern Pacific Ocean along and negative SST anomalies in the Western Pacific for both P1 (Figure 4.10(a)) and P2 (Figure 4.10(b)). Here the most notable difference in the ENSO-related SST anomalies is the increase in the strength of the tropical and extratropical Pacific SST anomalies in P2, with a sharp gradient in equatorial SST anomalies between the western and central Pacific Ocean. These results suggest that the enhanced SST anomaly contrast in the west Pacific Ocean, due to the increased SST anomalies in the western Pacific sector since the mid-1980s (as seen in Figure 4.10(b)) has contributed to the changes in the strength of ENSO teleconnections both globally and over 
southwest Asia (e.g., Barlow et al. 2002; Hoell and Funk 2013; Hoell et al. 2014).

a) P1_SST_Niño-3.4

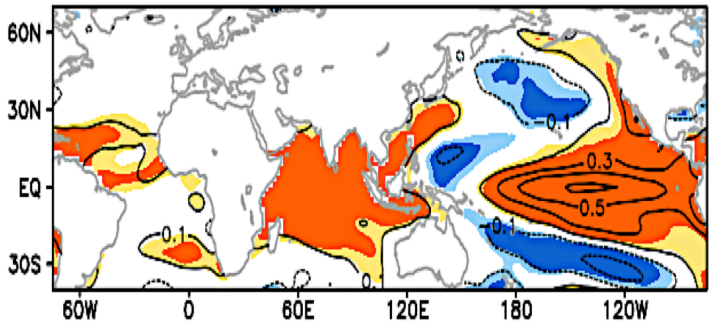

c) P1 SLP Niño-3.4

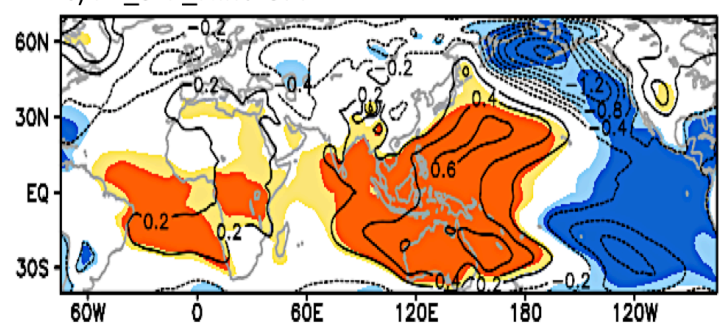

e) P1_Z200_Niño-3.4

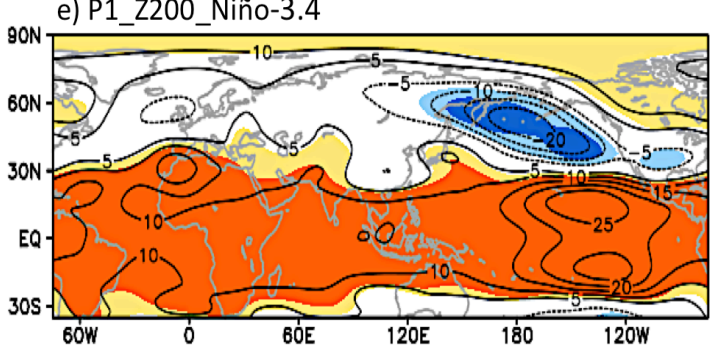

b) P2_SST_Niño-3.4

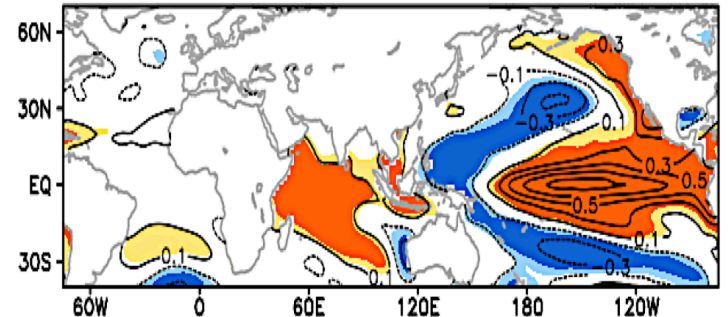

d) P2_SLP_Niño-3.4
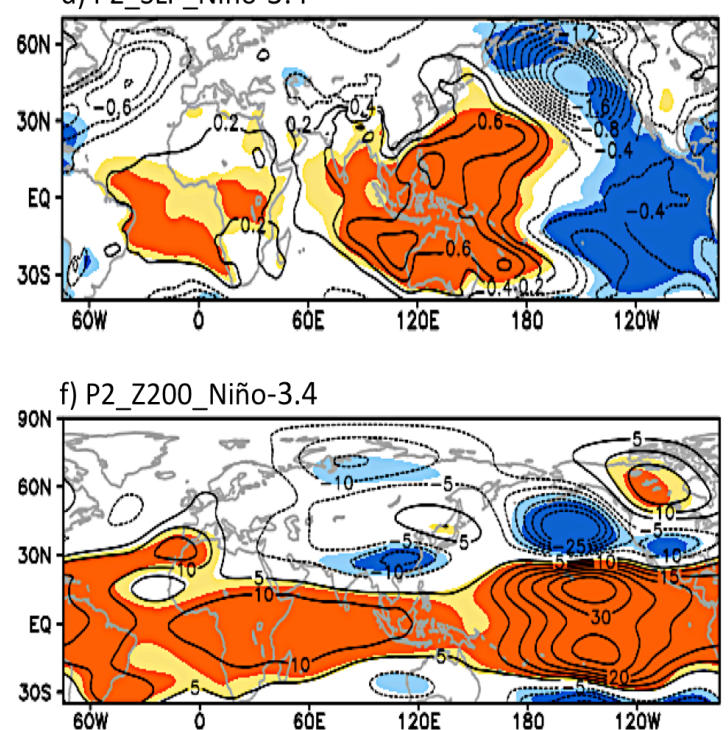

Figure 4.10. The regression maps of ( $a$ and $b)$ SST, $(c$ and $d)$ SLP and (e and $f$ ) geopotential height at 200-hPa onto Niño-3.4 index for P1 [1950/51-1983/84] (Figure a, c, and e) and P2 [1984/85-2014/15] (Figure b, d, and f). Solid (dashed) contours denote positive (negative) values and zero lines are omitted. The contour interval is $0.1{ }^{\circ} \mathrm{C}$ in (a), (b); $0.2 \mathrm{hPa}$ in $(c),(d)$; and $5 \mathrm{~m}$ in $(e),(f)$. The light and dark shadings in the figures $(a-f)$ indicate that the correlation coefficients are significant at $p<0.10$ and $p<0.01$, respectively.

Consistent with the SST anomalies spatial structure, the regression maps of SLP onto Niño-3.4 index for P1 (Figure 4.10(c)) and P2 (Figure 4.10(d)) resemble the Southern Oscillation pattern in the tropics, with significant anomalous negative SLP anomalies over the North Pacific Ocean for both the periods. Although similar in spatial distribution, the magnitude of SLP anomalies in P2 are comparatively stronger to those in P1, suggesting a more close relationship between the tropical Pacific SST 
variability and the North Pacific atmospheric circulations in recent decades as reported in Jo et al. (2015) and Yeh et al. (2015). Additionally, the regression maps generated for the 200-hPa geopotential height fields display quite different height anomaly patterns over the Northern Hemisphere in P1 (Figure 4.10(e)) and P2 (Figure 4.10(f)). As evidenced by the statistically significant circulation anomalies in the midto-high latitudes of Asia, it is apparent that the strength of ENSO-induced atmospheric teleconnection increased substantially in P2. It is also worth noting that the ENSO-related atmospheric circulation anomalies in P2 (Figure 4.10(f)) are fairly similar to those obtained for EOF-1 in P2 (Figure 4.8(b) and Figure 4.8(d)), implying that in this period CSWA precipitation variability was strongly linked to the atmospheric teleconnection forced by ENSO. On the other hand, a clear difference exists between ENSO-forced (Figure 4.10(e)) and EOF-1 related circulation anomalies (Figure 4.8(a) and Figure 4.8(b)) in P1, suggesting that prior to the mid1980s CSWA precipitation was likely controlled by the non-ENSO modes.

Based on the findings of the studies cited above and the results obtained here, it can be suggested that the possible mechanism that influenced the interdecadal changes of the relationship between ENSO and CSWA wintertime precipitation after the mid-1980s was related to the increased warming in the tropical western Pacific relative to the central Pacific Ocean.

\subsection{Summary and discussion}

In this study, we analysed the spatial-temporal variability of the leading three modes of CSWA winter precipitation for the period 1950/51 - 2014/15. We also investigated the relationship of these modes with the large-scale atmospheric circulations and the global SST. Results show that the first mode (Figure 4.2(a)) is characterised by a spatially coherent mono-sign structure over the entire domain. It represents the year-to-year variability of CSWA winter precipitation that includes a strong contribution of ENSO. The PC1 time-series is significantly correlated at the $99 \%$ confidence level with both the observed wintertime precipitation $(r=0.93)$ and the Niño3.4 index $(r=0.49)$. El Niño-related Pacific SST anomalies produce an anomalous low pressure (trough) over CSWA via the equivalent barotropic and baroclinic atmospheric circulation response. These conditions favour a region-wide 
precipitation-enhancing ascent resulting in an enhanced southwesterly moisture flow from the Arabian Sea and Indian Ocean basin (Figure 4.3(g)) that is responsible for positive precipitation loadings over CSWA.

The second mode (Figure 4.2(b)) displays a meridional dipole structure with opposite variations in precipitation north-south of approximately $35^{\circ}-37^{\circ} \mathrm{N}$ latitude, indicating a meridional shift in the position and/or intensity of the subtropical wintertime westerly jet over CSWA. The atmospheric circulation anomalies associated with EOF-2 (Fig. 4) are confined mainly over the mid-to-high latitudes of the Northern Hemisphere. It appears that this mode is influenced by a combination of teleconnection processes, including both extratropical and tropical (e.g. NAO, EAWR, Siberian High, ENSO, and others) that have been previously linked to the changes in the Northern Hemisphere storm track dynamics (Yin et al. 2014; Cohen et al. 2014, Lioubimtseva 2015) either directly or by way of partially modulating the strength of the concomitant teleconnections (Rana et al. 2018). Our results suggest that among other physical processes, the two underlying mechanisms that likely play a role in modulating the strength of the westerly circulation flow over CSWA is related to the westward extension of the Siberian High and the northwestward nudging of the NPO/WP pattern. While further analyses need to be done in this line, here it can only be hypothesised that the combined response of the two forcings (Figure 4.4(g)) directs the eastward propagating storm systems to a more southerly track, resulting in positive (negative) precipitation loadings on the southern (northern) side of the CSWA region.

The third mode (Figure 4.2(c)) of CSWA winter precipitation is expressed as a west-east dipole pattern across the study region. This mode is possibly related to the longitudinal variations in the mean structure and flow (ridges and troughs) of the subtropical jet stream over CSWA which in turn are closely linked to the magnitude of the meridional temperature/pressure gradient between the equatorial regions and higher latitudes. The most prominent spatial characteristics of the large-scale anomalies associated with EOF-3 are its strong and statistically significant relationship with the tropical Ocean SSTs and a clear midlatitude-tropical link in the atmospheric circulation anomalies (Figure 4.5). Another distinct feature in the extratropical Northern Hemisphere is a tripolar structure similar to the type 1 Eurasian pattern or the Scandinavian pattern. It is likely (in agreement with Liu et al. 2014), the observed pattern is related to the significant (99\% confidence level) SST anomalies 
observed in the tropical Indian Ocean (Figure 4.5(a)). The air-sea interaction is through a well-organized wave train located upstream of the Indian Ocean that forms an anomalous anticyclone-cyclone couplet over Europe and the Ural region (Figure $4.5(\mathrm{~g}))$, resulting in regional precipitation changes over the western and eastern flanks of CSWA.

In this study, we also investigated the inter-decadal change of connection between ENSO and the first EOF mode of CSWA winter precipitation for two subperiods, 1950/51-1983/84 (P1) and 1984/85-2014/15 (P2). Using the Niño-3.4 index as an indicator of ENSO, the sliding correlation between PC1 and the wintertime Niño-3.4 index showed that the impact of ENSO on EOF-1 was weak in P1; but strong and statistically significant in P2 (Figure 4.6). Notable differences were observed in the climate anomalies associated with EOF-1, before (P1) and after (P2) the 1980s. In P1, the EOF-1 related atmospheric circulation anomalies are confined over the mid- to high-latitudes of the Northern Hemisphere and are characterised by a large-scale zonally oriented quasi-barotropic Rossby wave structures with distinct centres of action over the European continent, Western Russia and East Asia, similar to the positive phase of the EA-WR teleconnection (Figure 4.7 and Figure 4.8). In P2, significant El Niño-type SST anomalies are observed over the tropical Pacific Ocean with anomalous atmospheric circulations extending throughout the Northern Hemisphere (Figure 4.7). The underlying teleconnection mechanisms are fairly similar in spatial structure and impact area to those associated with EOF-1 for the full analysis period (1950/51-1983/84; Figure 4.3).

It is a noteworthy finding that even though the large-scale climate anomalies associated with EOF-1 display markedly different characteristics in P1 and P2, the teleconnection pathway through which EA-WR and ENSO impact the regional climate of CSWA are quite similar for both the sub-periods. Based on the results presented herein, it can be suggested that the EOF-1-related atmospheric circulation anomalies that appeared to be forced by El Niño conditions in the full analysis period (1950/51-1983/84) are likely a linear superimposition of atmospheric circulations associated with the extratropical EA-WR pattern in P1 by those associated with El Niño in P2. Detailed identification of the dynamical causes related to the inter-decadal change of connection between ENSO and the first EOF mode of CSWA winter precipitation is beyond the scope of the present study. Nonetheless, to gain insights on the possible mechanisms that may have contributed to this change were briefly 
examined (Figure 4.10). Consistent with the findings of some of the previous studies, our results demonstrated that the strong SST anomaly gradient between the western and the central Pacific Ocean played a significant role in forcing anomalous ENSOrelated atmospheric response over the CSWA region.

The study improves our understanding of CSWA's wintertime precipitation climate and its relationships with the large-scale global and regional teleconnections. These findings have important implications for CSWA, given the fact that an improved understanding of the impact and role of the dominant forcings can eventually lead to improvements in the seasonal predictive skill of the regional precipitation. However, a closer investigation into the role of Siberian High and the NPO pattern in modulating the atmospheric circulation over CSWA would be desirable to support some of the physical mechanisms proposed in the study. 


\section{Chapter 5 Seasonal Prediction of Winter Precipitation Anomalies over Central Southwest Asia: A Canonical Correlation Analysis Approach}

Published in the Journal of Climate (Rana et al. 2018)

\section{CITATION}

Rana, S., J. Renwick, J. McGregor, and A. Singh, 2018: Seasonal Prediction of Winter Precipitation Anomalies over Central Southwest Asia: A Canonical Correlation Analysis Approach. J. Climate, 31, 727-741

Authorship contributions to this research article include the following:

Sapna Rana - Wrote the manuscript and managed all co-author feedback, reviewer comments, and editing of proofs. This author developed the prediction model, made initial interpretations, and produced all figures.

James Renwick - Academic Supervisor; provided extensive feedback on drafts and was involved in the interpretation of results and text edits.

James McGregor - Academic Supervisor; provided feedback on drafts and text edits.

Ankita Singh - Helped with the model development. 


\subsection{Abstract}

Central southwest Asia (CSWA; $\left.20^{\circ}-47^{\circ} \mathrm{N}, 40^{\circ}-85^{\circ} \mathrm{E}\right)$ is a water-stressed region prone to significant variations in precipitation during its winter precipitation season of November-April. Wintertime precipitation is crucial for regional water resources, agriculture, and livelihood; however, in recent years droughts have been a notable feature of CSWA interannual variability. Here, the predictability of CSWA wintertime precipitation is explored based on its time-lagged relationship with the preceding months' (September-October) sea surface temperature (SST), using a canonical correlation analysis (CCA) approach. For both periods, results indicate that for CSWA much of the seasonal predictability arises from SST variations in the Pacific related to El Niño-Southern Oscillation (ENSO) and the Pacific decadal oscillation (PDO). Additional sources of skill that play a weaker predictive role include long-term SST trends, North Atlantic variability, and regional teleconnections. CCA cross-validation skill shows that the regional potential predictability has a strong dependency on the ENSO phenomenon, and the strengthening (weakening) of this relationship yields forecasts with higher (lower) predictive skill. This finding is validated by the mean cross-validated correlation skill of 0.71 and 0.38 obtained for the 1980/81-2014/15 and 1950/51-2014/15 CCA analyses, respectively. The development of cold (warm) ENSO conditions during September-October, in combination with cold (warm) PDO conditions, is associated with a northward (southward) shift of the jet stream and a strong tendency of negative (positive) winter precipitation anomalies; other sources of predictability influence the regional precipitation directly during non-ENSO years or by modulating the impact of ENSO teleconnection based on their relative strengths.

\subsection{Introduction}

Central southwest Asia (CSWA), bounded by the domain $20^{\circ}-47^{\circ} \mathrm{N} ; 40^{\circ}-85^{\circ} \mathrm{E}$ (Figure 5.1), comprises a region that is water-stressed and societally vulnerable (Barlow and Tippett 2008). Characterised by semiarid to arid climate, the complex topography of CSWA plays a dominant role in the seasonal and regional distribution of precipitation (Rana et al. 2017). A large part of the region lies beyond the usual reach of the Indian summer monsoon and receives most of its annual precipitation 
during winter and early spring season [November-April (NDJFMA); see Figure 5.2(c) herein] associated with eastward-propagating midlatitude cyclones (Martyn 1992). The winter precipitation, which mostly falls as snow over the mountain ranges and as rainfall in sub-mountainous and low elevation plains, is of major importance for local water resources, agriculture production, industrial needs, and livelihood.

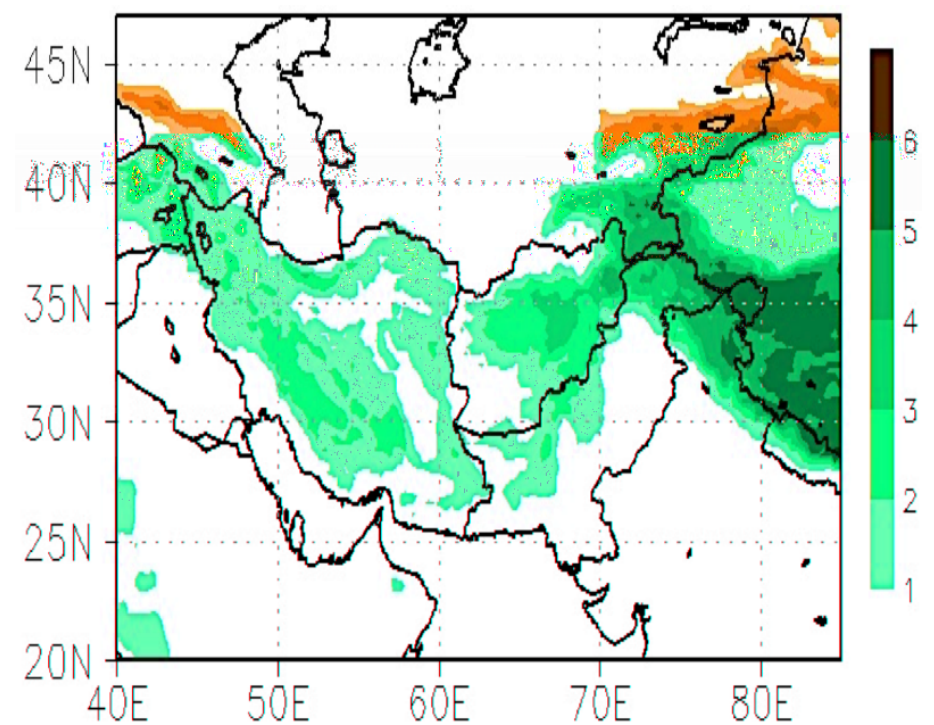

Figure 5.1:Topography $(\mathrm{km})$ of central southwest Asia (CSWA) region.

CSWA winter precipitation displays considerable interannual variability (Figure 5.2 (a)) with frequent and notable droughts (Mariotti 2007; Barlow et al. 2016). For example, CSWA has experienced two catastrophic droughts in 1999-2001 (Barlow et al. 2002, 2016) and 2007/08 (Trigo et al. 2010; Hoell et al. 2012) that adversely affected the region's water supplies, crops, food supplies, livestock, and quality of life, and further resulted in large population migration and political instability (Agrawala et al. 2001; Gall 2008). Evidence indicates that prolonged periods of suppressed winter precipitation over CSWA are related to negative sea surface temperature (SST) anomalies in the central, eastern tropical, and eastern extratropical Pacific in combination with positive SST anomalies in the warm tropical and extratropical western Pacific Ocean (Barlow et al. 2002; Hoerling and Kumar 2003; Hoell et al. 2015a). The physical mechanism connecting the western Pacific convection and SST anomalies with CSWA precipitation is through modification of the regional circulation by means of exciting baroclinic (Barlow et al. 2002, 2005; Hoell et al. 2012) and barotropic (Hoell et al. 2013) stationary Rossby waves over CSWA. 

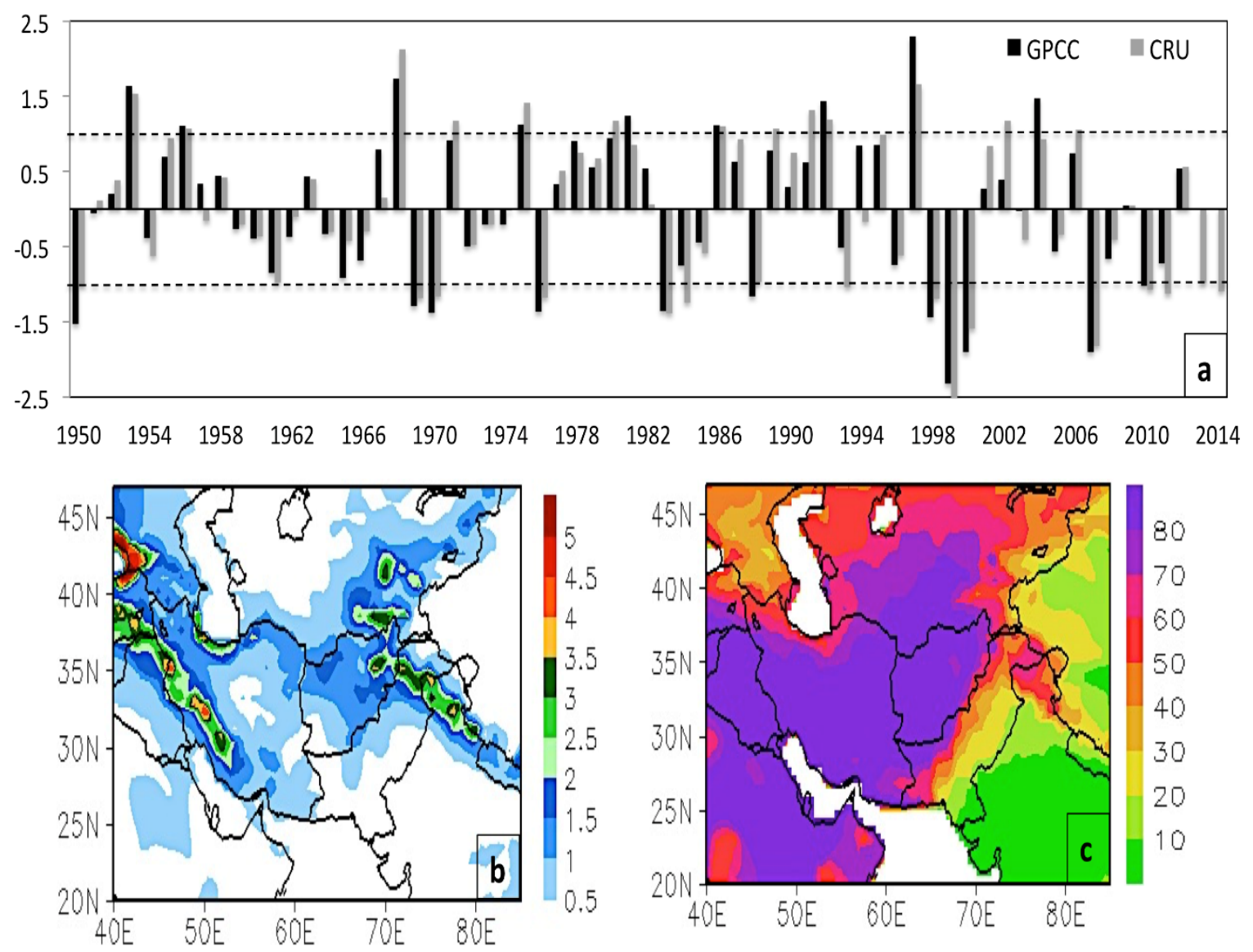

Figure 5.2: (a) Area-averaged winter season (November-April \{NDJFMA\}) standardized precipitation anomaly, (b) Spatial distribution of winter season precipitation ( $\mathrm{mm} / \mathrm{day})$, and (c) Precentage contribution of NDJFMA precipitation to the total annual precipitation over CSWA for 1950/51 - 2014/15.

Links between CSWA winter precipitation and Maritime Continent convection have also been explored. An observational study by Lau and Boyle (1987) showed that the extratropical circulation is more sensitive to convection and heating over the Maritime Continent than to convection over the central Pacific. It has been noted that enhanced Maritime Continent convection leads to upper-level divergence and a southerly flow into the subtropical Northern Hemisphere (Tippett et al. 2003), resulting in strong anticyclonic circulations over the CSWA region (Liebmann 1987). Recently, Barlow et al. (2005) and Hoell et al. (2012, 2015a) reported that enhanced (reduced) convection over the eastern Indian Ocean and Maritime Continent excites warm (cold) core anticyclones (cyclones) over southwest Asia, resulting in suppressed (enhanced) wintertime precipitation over the CSWA region. 
The above findings provide strong evidence that CSWA precipitation is strongly linked to tropical Pacific forcing, with circulation anomalies influencing the regional precipitation through changes in moisture transport (Barlow et al. 2002; Mariotti 2007; Barlow and Tippett 2008; Hoell and Funk 2013; Kar and Rana 2014). These linkages suggest the possibility of potential predictability over CSWA and can form an important basis for predicting seasonal climate anomalies over the region at both intraseasonal and interannual time scales (Tippett et al. 2003, 2005; Barlow et al. 2005, 2016). Nonetheless, very few assessments have been reported that explore the predictability of the observed seasonal precipitation anomalies over CSWA using these relationships.

The objective of this study is to determine whether the above-discussed linkages are statistically robust enough to provide skillful seasonal prediction of CSWA wintertime precipitation anomalies via timelagged relationships between the regional wintertime (NDJFMA) precipitation and the SST variability in the preceding months (September-October). To explore this, we develop a statistical prediction model based on the canonical correlation analysis (CCA) approach.

CCA is a multivariate statistical technique that has been widely used in atmospheric sciences, mostly for the purpose of identifying linearly related patterns of variability between two datasets (predictors and predictands) by maximizing the temporal correlation between them (Barnett and Preisendorfer 1987; Bretherton et al. 1992; Barnston and Smith 1996; Yu et al. 1997; Tippett et al. 2008). The reason for considering CCA over other statistical techniques is its ability to operate on full fields and to objectively define the most highly related patterns of predictor and predictand (Barnett and Preisendorfer 1987). Moreover, CCA gives an extensive set of diagnostics that offer useful insights into the physical basis of the relationships used to form the predictions (Barnston et al. 1996).

The outline of the study is arranged as follows. In section 5.3, we present the datasets and a brief discussion on the methods of analysis, including the CCA statistical technique. The choice of potential predictor and CCA prediction results are discussed in section 5.4, followed by the large-scale teleconnection dynamics in section 5.5. Finally, section 5.6 summarizes our major findings. 


\subsection{Materials, Method of analysis and prediction model development}

\subsubsection{Materials}

\section{Observed precipitation}

Monthly gridded observational precipitation data are obtained from the Global Precipitation Climatology Centre (GPCC) full data reanalysis version 7 (Schneider et al. 2014). The data are available from http://gpcc.dwd.de for the period 1901-2013 at $0.5^{\circ}, 1.0^{\circ}$, and $2.5^{\circ}$ latitude- longitude resolutions. The current analysis uses $0.5^{\circ}$ data from 1950 to 2013. In addition to the GPCC data, the Climatic Research Unit (CRU) time series (TS) version 3.24.01 monthly gridded precipitation records are available from https://crudata.uea.ac.uk/cru/data/. The dataset covers the period 1901-2015 at a $0.5^{\circ}$ resolution (Harris et al. 2014). Here data from 1950 to 2015 are used. Figure 5.2(a) shows the CSWA winter season (NDJFMA) precipitation time series calculated as the area average of standardized precipitation anomalies from each of the GPCC (1950/51-2012/13) and CRU (1950/51-2014/15) datasets. Because of the sparseness of ground-based measurements in CSWA, the accuracy of gridded precipitation datasets is limited over much of this region (Barlow and Tippett 2008; Rana et al. 2015). However, a recent analysis by Rana et al. (2017) showed that in this region GPCC precipitation estimates are more realistic and reliable compared to some of the currently available observational datasets including CRU. Therefore, for our analysis GPCC precipitation records are used from 1950 up to 2013 and CRU data thereafter. The spatial maps of the CSWA wintertime precipitation climatology and its seasonal percentage contribution to the total annual precipitation for the analysis period (1950/51-2014/15) are shown in Figure 5.2(b) and Figure 5.2(c), respectively. More details, including CSWA winter precipitation regimes and performance assessment of various available gridded precipitation datasets (observations, reanalysis, and satellite-derived data), can be found in Rana et al. (2017).

\section{SST data}

The global monthly observed SST $\left({ }^{\circ} \mathrm{C}\right)$ data were obtained from the Extended Reconstructed Sea Surface Temperature (ERSST) analysis version 5 (Huang et al. 2017). This dataset is produced on a fixed $2^{\circ}$ latitude- longitude resolution, available 
from https://www.esrl. noaa.gov/psd/data/gridded/data.noaa.ersst.v5.html for the period 1854 to the present.

\section{Reanalysis winds}

Monthly zonal and meridional components of winds $\left(\mathrm{m} \mathrm{s}^{-1}\right)$ at 300, 500, and $850 \mathrm{hPa}$ were taken from the European Centre for Medium-Range Weather Forecasts (ECMWF) interim reanalysis (ERA-Interim; http:// rda.ucar.edu/datasets/ds627.0/). The ERA-Interim data are available from 1979 to the present, at 37 atmospheric levels and different horizontal resolutions $\left(0.25^{\circ}, 0.75^{\circ}\right.$, and $\left.1.5^{\circ}\right)$ for the entire globe (Dee et al. 2011). Here we use $0.75^{\circ}$ wind field data.

\subsubsection{Methodology}

The relationship between CSWA year-to-year wintertime (NDJFMA) precipitation variations and the global precursor field [mean SST (SeptemberOctober)] is examined using covariance analysis. Note that the lagged relationship signal between CSWA winter precipitation and September-October mean SSTs was slightly stronger in comparison to that with August-October mean SSTs. Here, covariance between the predictor and predictand field is calculated using the following equation:

$C O V_{x y}=\frac{\sum_{i=1}^{n}\left(x_{i}-\bar{x}\right)\left(y_{i}-\bar{y}\right)}{n-1}$

where $x_{i}$ and $y_{i}$ are the $i^{\text {th }}$ value of the predictor and predictand field; and $\bar{x}$ and $\bar{y}$ are their respective means calculated using equation 3.2 described in Chapter 3, for $n$ number of data points.

The statistical significance of the computed covariance matrix is assessed at each grid point at $95 \%$ (p-value $<0.05$ ) confidence level using the $F$ statistics formula given by: 
$F=\frac{S_{1}^{2}}{S_{2}^{2}}$

where $S_{1}$ and $S_{2}$ are the standard deviations of the predictor or predictand fields that can be calculated using equation 2.2 discussed in Chapter 2. Note: the numerator $\left(S_{1}^{2}\right)$ is always the larger of the two variances.

The spatial covariance map result helps to isolate the dominant predictive signatures that are important for CSWA precipitation variations, and can potentially be used in the construction of the CCA prediction scheme.

\subsubsection{Prediction model development}

CCA is a multivariate statistical technique that computes linear combinations of a set of predictors that maximizes relationships, in the least squares sense, to the similarly calculated linear combinations of a set of predictands (Barnston and Ropelewski 1992). In the simplest sense, the aim of CCA is to find the most highly correlated patterns between the predictor and predictand fields. The linear combinations are called canonical variates, and the correlation between the pairs of canonical variates is referred to as the canonical correlation. More details on CCA can be found in Barnett and Preisendorfer (1987), Yu et al. (1997), and Marzban et al. (2014). Extensive treatment of the mathematical basis of CCA is provided in Graham et al. (1987).

In this study, CCA experiments are performed for two sets of time periods, $1950 / 51-2014 / 15$ (65 yr) and 1980/81-2014/15 (35 yr), using the SST anomaly as the predictor dataset and the CSWA wintertime precipitation anomaly as the predictand. The choice of SST as a predictor is based on the rationale that the slow timescale response of the oceans constitutes an important source of predictability at various time scales ranging from seasonal to interannual (Barnston and Smith 1996). Prior to conducting CCA, the predictor and the predictand matrices are standardized and orthogonalized using the standard EOF analysis technique discussed in detail in Chapter 2. In this case, the EOF analysis reduces the large dimensionality of the original data matrices by retaining a limited number of EOF modes, and helps to avoid overfitting. In addition, incoherent variability (noise) is also filtered out since 
EOF analysis focuses mostly on the dominant patterns of variability within each input dataset. As there is no universally agreed procedure for determining how many EOF modes should be retained ( $\mathrm{Yu}$ et al. 1997), the number retained here is such that the maximum variance explained by the chosen number of modes is $85 \%$ for the predictor and $75 \%$ for predictand. Based on this, the leading 22 (15) EOFs of the predictor and 21 (13) EOFs of the predictand matrices are used for the period 1950/51-2014/15 (1980/81-2014/15), respectively. The EOF time components are cross-correlated and the resulting cross-correlation matrix is diagonalized to determine the maximal (canonical) correlations and associated canonical variates. Further, a simple linear regression model is constructed that relates the predictand canonical variates to the predictor canonical variates (Wilks 1995) and forecast skill assessment is undertaken using the leave-one-out cross-validation approach, wherein each year in the time series is held out in turn and the remaining years are used for developing the CCA model.

The mathematical development of the CCA prediction model is as follows:

Assuming that $X_{m, t}$ and $Y_{o, t}$ are the matrices for predictor and predictand where $m$ and $o$ are the number of grid boxes for the predictor and predictand, respectively, and $t$ is the number of years. Performing EOF analysis on $X_{m, t}$ and $Y_{o, t}$ leads to

$$
\begin{aligned}
& X_{m, t}=E_{m, m} T_{m, t} \\
& Y_{o, t}=E_{o, o} T_{o, t}
\end{aligned}
$$

where $E_{m, m}$ and $E_{o, o}$ represent spatial EOF modes computed for the predictor and predictand matrices, respectively, and $T_{m, t}$ and $T_{o, t}$ are their time coefficients.

In equations (5.3) and (5.4) we approximate $X$ and $Y$ using fewer EOF modes. Therefore, using the process of pre-orthogonalization the first $i$ modes for $X$ and $j$ modes for $Y$ are selected. The transformed canonical variables $\mathrm{Z}$ and $\mathrm{W}$ are defined as the linear combination of canonical vectors (canonical loadings) $u$ and $v$,

$$
Z=u^{\prime} T_{i, t}, \text { and } W=v^{\prime} T_{j, t}
$$


The basic idea behind forecasting using CCA is the simple linear regression between the canonical variables obtained from equation (5.5). The simple linear regression relates the canonical predictand $\mathrm{W}$ to the predictor canonical variable $\mathrm{Z}$,

$$
w_{q}=\hat{\beta}_{o, q}+\hat{\beta}_{1, q} z_{q} \quad q=1 \ldots . Q
$$

In equation (5.6), the estimated regression coefficients are indicated by $\beta . Q$ is the number of canonical variables. The equation is solved using simple least square methods as the canonical variables are independent of each other. Therefore, the regression coefficients can be estimated as follows,

$$
\begin{array}{ll}
\hat{\beta}_{1, q}=\frac{n \operatorname{Cov}\left(z_{q}, w_{q}\right)}{n \operatorname{var}\left(v_{m}\right)}=\frac{n s_{z} s_{w} r_{z, w}}{n s_{z}^{2}}=r_{z, w}=r_{C_{q}}, & q=1 \ldots . Q \\
\hat{\beta}_{o}=\bar{w}_{m}-\hat{\beta}_{1} \bar{z}_{m}=v^{\prime} E\left(T_{i, t}\right)-\hat{\beta}_{1} u^{\prime} E\left(T_{j, t}\right)=0, & q=1 \ldots . Q
\end{array}
$$

In the equation the intercept term becomes zero as the mean of the canonical variables is zero, because they are centred to mean zero. The $r_{C_{q}}$ are the canonical correlations between the canonical variables $\mathrm{Z}$ and $\mathrm{W}$. Therefore, the estimates of the canonical predictand can be obtained using equations (5.6), (5.7), and (5.8) as:

$$
\hat{W}=A_{Q Q} Z
$$

Here $A_{Q Q}$ is the diagonal matrix of correlation between the canonical variables known as the matrix of canonical correlation of $\operatorname{order} Q \times Q$, where $Q=\operatorname{minimum}(i, j)$.

The prediction equation (5.9) for lead time $t+l$ can be rewritten as:

$$
\hat{T}_{j, t+l}=\left(V^{\prime}\right)^{-1} A_{Q Q} U^{\prime} T_{i, t+l}
$$


Using the orthogonalilty characteristics of EOF modes, equations (5.3) and (5.4) can be written as:

$T_{i, t}=\left(E_{m, i}\right)^{\prime} X_{m, t}$

$Y_{o, t}=E_{o, j} T_{j, t}$

Using equations (5.11) and (5.12), $T_{j, t+l}$ can thus be transformed back to predictand values as:

$\hat{Y}_{o, t+l}=E_{o, j}\left(V^{\prime}\right)^{-1} A_{Q Q} U^{\prime}\left(E_{m, i}\right)^{\prime} X_{m, t+l}$

For the two CCA experiments performed in this study, the above developed prediction model is verified using a leave-one-out cross-validation approach and a cross-validated CSWA wintertime precipitation forecast time series is generated for the periods 1950/51-2014/15 (65 yr) and 1980/81-2014/15 (35 yr) separately.

Detailed model validation is carried out for the 1980/81-2014/15 prediction experiment, for which dry (negative precipitation anomalies) and wet (positive precipitation anomalies) years are identified in the area-averaged time series using the bottom and top 20 percentiles, respectively. The seven driest years (1983/84, 1988/89, 1998/ 99, 1999/2000, 2000/01, 2007/08, and 2010/11) and seven wettest winter precipitation years $(1980 / 81,1981 / 82,1986 / 87,1992 / 93,1995 / 96,1997 / 98$, and 2004/05) are selected. Three verification statistics: 1) mean bias, 2) root-mean-square error (RMSE), and 3) temporal anomaly correlation between forecast and observed precipitation anomalies are computed using the methods described in Chapter 2 and Chapter 3. The model's predictive skill is evaluated for out-of-sample prediction against a null/climatology model (mean rainfall) and memory/persistence model (last year's rainfall as this year's prediction using the following skill score (SS):

$$
S S=100\left(1-\frac{M S E_{C C A}}{M S E_{C \text { lim }}}\right) \quad \text { and } \quad S S=100\left(1-\frac{M S E_{C C A}}{M S E_{\text {Pers }}}\right)
$$


where MSE is the mean square error computed using forecasts for CCA ( $\left.M S E_{C C A}\right)$, Climatology $\left(M S E_{C l i m}\right)$, and Persistence ( $\left.M S E_{\text {Pers }}\right)$ models.

$$
\begin{aligned}
& M_{C C E_{C A}}=\frac{1}{n} \sum_{i=1}^{n}\left(F_{i}-O_{i}\right)^{2} \\
& M S E_{C \lim }=\frac{1}{n} \sum_{i=1}^{n}\left(\bar{O}-O_{i}\right)^{2} \\
& M S E_{\mathrm{Pr} e s}=\frac{1}{n} \sum_{i=1}^{n}\left(O_{i-1}-O_{i}\right)^{2}
\end{aligned}
$$

$O_{i}$ and $F_{i}$ are the observed and cross-validated predictand value at time $i$, respectively. $O_{i-1}$ is the observed predictand value at the previous time $(i-1)$, and $\bar{O}$ is the observed predictand climatology for $n$ number of years.

Furthermore, for a better understanding of the dynamic precursors that lead to wintertime precipitation variations over CSWA, concomitant seasonal mean circulation anomalies are examined at different levels $(300,500$, and $850 \mathrm{hPa})$ for the aforementioned dry and wet year composites.

\subsection{Results}

\subsubsection{Potential predictors}

To explore the seasonal lead-lag relationships between September-October SST variability and CSWA winter (NDJFMA) precipitation, a spatial covariance map is generated to isolate the large-scale coupled patterns of linear variability between the two variables. Previous work has identified that one of the most dominant perturbations responsible for CSWA interannual precipitation variations is related to ENSO (Barlow et al. 2002; Mariotti 2007; Hoell et al. 2014a,b, 2017). However, other modes of variability such as the North Atlantic Oscillation (NAO) (Cullen et al. 2002; Filippi et al. 2014; Kar and Rana 2014), the east Atlantic-western Russia (EAWR) pattern (Yin et al. 2014; Krichak et al. 2014), the Madden-Julian oscillation (MJO) (Barlow et al. 2005; Hoell et al. 2012), Pacific decadal variability (PDV), and long- 
term change in global sea surface temperatures (Hoell et al. 2015b) have also been linked to CSWA precipitation variations at various time scales.

In Figure 5.3 the lagged covariability pattern between CSWA precipitation and SSTs between $35^{\circ} \mathrm{S}$ and $50^{\circ} \mathrm{N}$ strongly resembles the El Niño-Southern Oscillation (ENSO) pattern (Deser et al. 2010; Johnson 2013). The spatial pattern reveals that enhanced (reduced) wintertime precipitation anomalies over CSWA are related to a warm (cold) central, eastern tropical, and eastern extratropical Pacific Ocean in cooccurrence with cold (warm) western tropical and western extratropical Pacific Ocean. The large-amplitude pattern of zonally strong positive SST anomalies across two-thirds of the equatorial Pacific Ocean, flanked by relatively strong negative anomalies in the western Pacific and eastern Indian Ocean, reinforces the finding that ENSO-related Pacific SST forcing is one of the primary causes of CSWA wintertime precipitation variations (Barnston and Smith 1996; Hoerling and Kumar 2003; Hoell et al. 2014a).

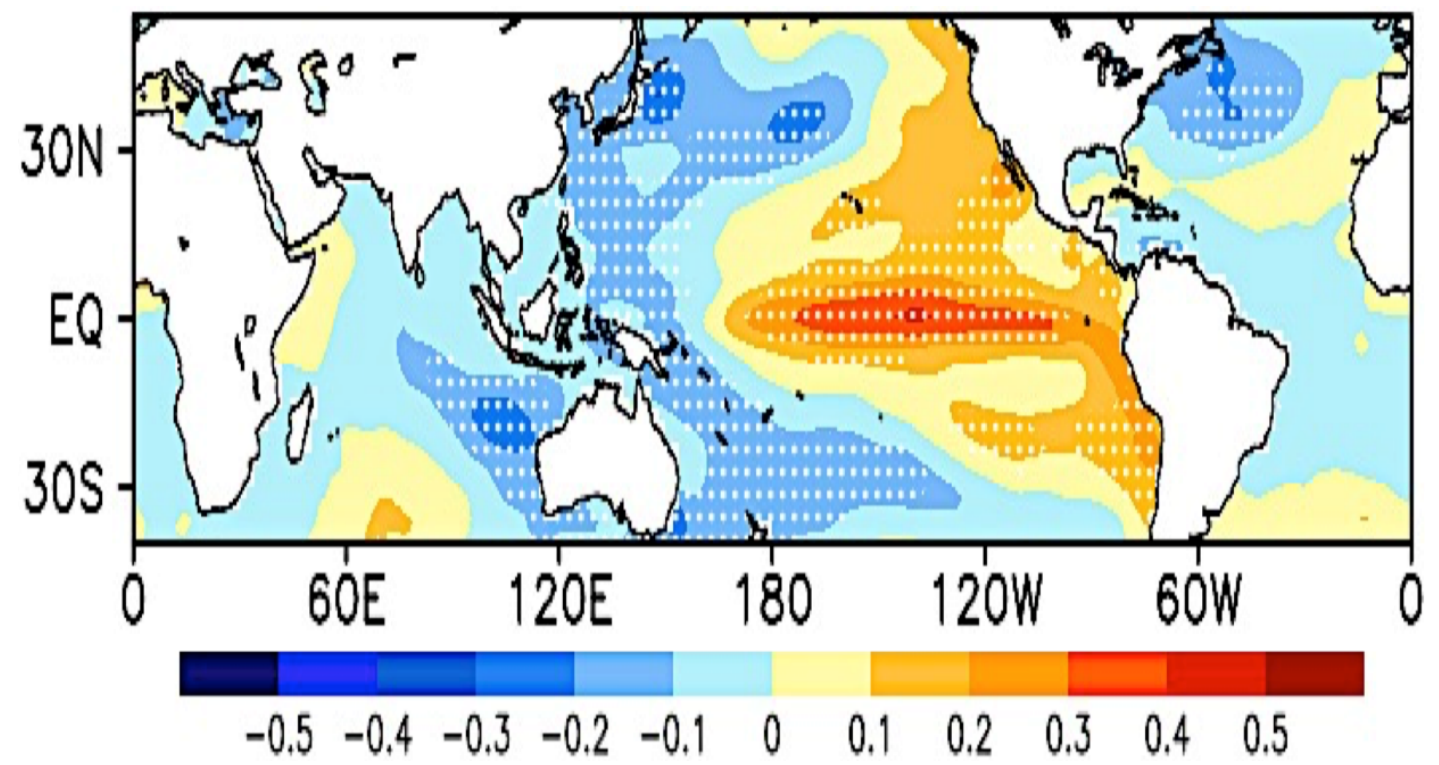

Figure 5.3: Covariance map between CSWA winter precipitation ( $\mathrm{mm} /$ day) and the preceding months (September-October) mean SST $\left({ }^{\circ} \mathrm{C}\right.$ ) for 1950/51 - 2014/15. Stippling indicates covariance significant at 5\% level ( $F$-statistics).

The distribution of weaker positive SST anomalies on the eastern side of the tropical Atlantic Ocean along with statistically significant negative SST anomalies southeast of Newfoundland is characteristic of an NAO pattern (Cassou et al. 2004; Czaja and Frankignoul 2002). This result suggests that the negative (positive) phase 
of the NAO is associated with increased (reduced) winter precipitation activity over CSWA. Evidence also suggests that the positive (negative) NAO phase is associated with more meridional (zonal) surface winds and storm tracks in the North Atlantic sector, resulting in cool/dry (warm/ wet) winters in the Mediterranean region and into the Middle East (Cullen and deMenocal 2000; Aizen et al. 2001).

Based on the above, we infer that CSWA winter precipitation is influenced by both ENSO-related SST forcing and Atlantic Ocean variability modulated by the NAO. However, in a recent study Hoell et al. (2017) noted that the long-term (19012012) relationship between wintertime ENSO and CSWA precipitation has varied in strength throughout time. To explore this, in Figure 5.4 we compute the 17-yr sliding correlation between CSWA winter precipitation and the preceding months' (September-October) Niño-3.4 and NAO index (available at https://www.esrl.noaa.gov/psd/gcos_wgsp/Timeseries/) using equations (4.3 and 4.4) described in Chapter 4.

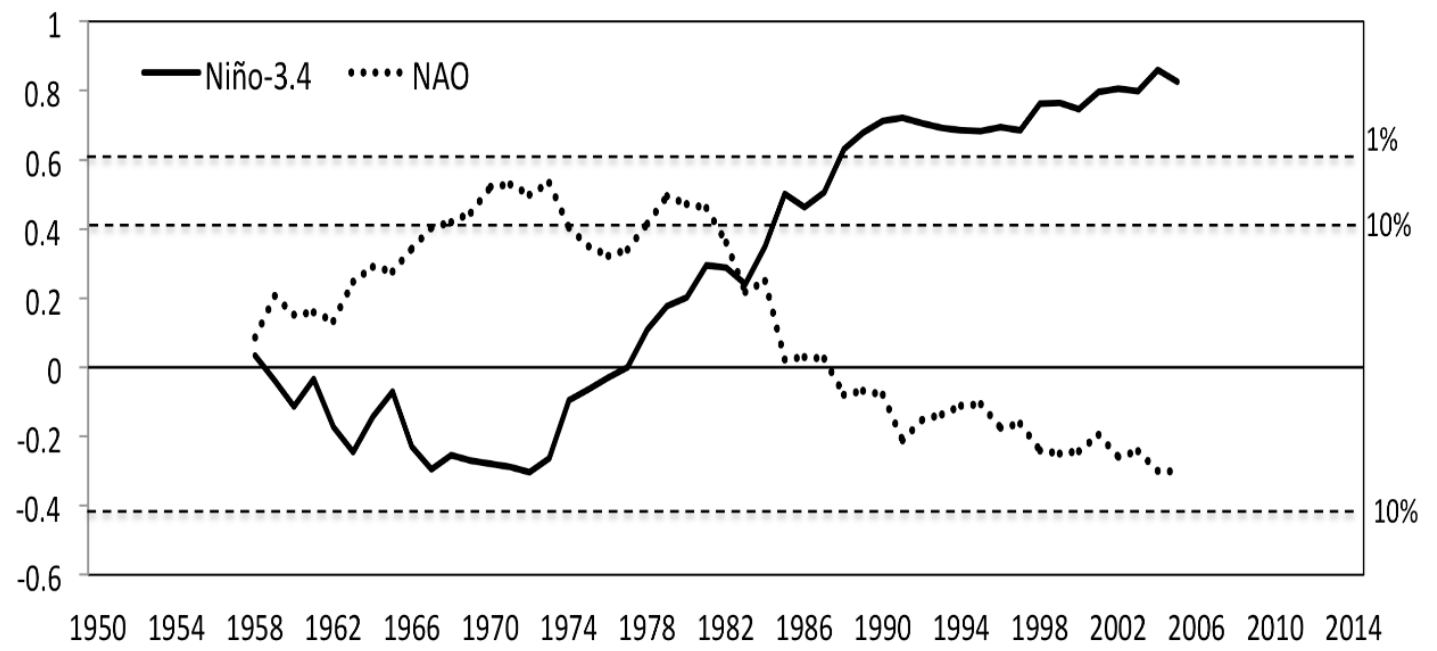

Figure 5.4: Sliding correlation between CSWA winter precipitation anomalies and (September-October) Niño-3.4 (solid line) and NAO (dotted line) index on 17-year window. Values are plotted at the centre of each 17-year period and statistical significance at $10 \%$ and $1 \%$ confidence level is achieved by two tailed Student's ttest for correlations greater than 0.41 and 0.61 , respectively, indicated by horizontal dashed lines.

As illustrated by the temporal fluctuations in Figure 5.4, the Niño-3.4 (NAO) influence on CSWA precipitation strengthened to (weakened from) a statistically significant level around the early $1980 \mathrm{~s}$ and continued to increase (decrease) 
thereafter. Given the notable change in the relationships among CSWA precipitation, Niño-3.4, and the NAO, two separate time periods, 1950/51-2014/15 (65 yr) and $1980 / 81-2014 / 15$ (35 yr), are considered to test the robustness of the CCA prediction approach adopted here.

CCA-based forecasts are typically sensitive to the choice and size of the predictor domain (Recalde-Coronel et al. 2014). Therefore, to test the sensitivity of our prediction model CCA experimental runs were conducted using different predictors [outgoing longwave radiation (OLR), upper-level winds, and SST] along with a combination of predictor domains that included the Indo-Pacific, Pacific, and the Atlantic Ocean domains. See Appendix for more details on the individual CCA experiments and model performance scores on the addition/removal of predictors used over different predictor domains [for e.g., OLR (Indo-Pacific domain: $25^{\circ} \mathrm{S}-20^{\circ} \mathrm{N}$ and $100^{\circ} \mathrm{E}-208^{\circ} \mathrm{E}$ ) and SST (North Pacific domain: $10^{\circ} \mathrm{S}-38^{\circ} \mathrm{N}$ and $128^{\circ} \mathrm{E}-280^{\circ} \mathrm{E}$ )]. The highest overall skill (domain average) was achieved for the quasi-global $\left(40^{\circ} \mathrm{S}-\right.$ $55^{\circ} \mathrm{N}$, all longitudes) SST predictor domain that we use as input in the CCA model predictions described below. As mentioned previously, the CCA technique finds canonical variate pairs with the highest possible Pearson's correlation coefficient. The respective canonical variate values, known as loadings, measure the contribution of the corresponding original variable to the transformed canonical variate (Marzban et al. 2014). Examination of these loadings often helps in deriving a meaningful interpretation of the physical processes related to that canonical variate pair. In the following section, we interpret the physical meaning of the loading patterns and the corresponding amplitude time series generated for the leading two modes of maximally correlated canonical variate pairs in our predictor and the predictand matrices.

\subsubsection{CCA maps}

The spatial predictor-predictand loadings for the first two CCA modes and the associated canonical component time series for the period 1950/51-2014/15 and 1980/81-2014/15 are displayed in Figure 5.5 and Figure 5.6, respectively. Previous work has identified that the main sources of predictability on the seasonal and interannual time scales come from the long-term trends in SSTs and the ENSO (Barnston and Smith 1996; Goddard et al. 2001). Here, the first predictor mode 
(Figure 5.5(a)) for the period 1950/51-2014/15 explains 27\% of the domain variance and exhibits broad positive SST loadings over the tropical Pacific and along the west coast of North America accompanied by negative SST anomalies in the central and western North Pacific. The spatial structure resembles the ENSO-like decadal variability of Zhang et al. (1997), a global signature of the Pacific decadal oscillation (PDO) described in Newman et al. (2016). This mode also features a distinct warming of the southern oceans as indicated by the like-signed positive SST anomalies mainly south of the equator and negative SSTs in the central North Pacific and the North Atlantic. A similar SST warming trend has been reported in Shabbar et al. (2011) and Smith and Reynolds (2003).
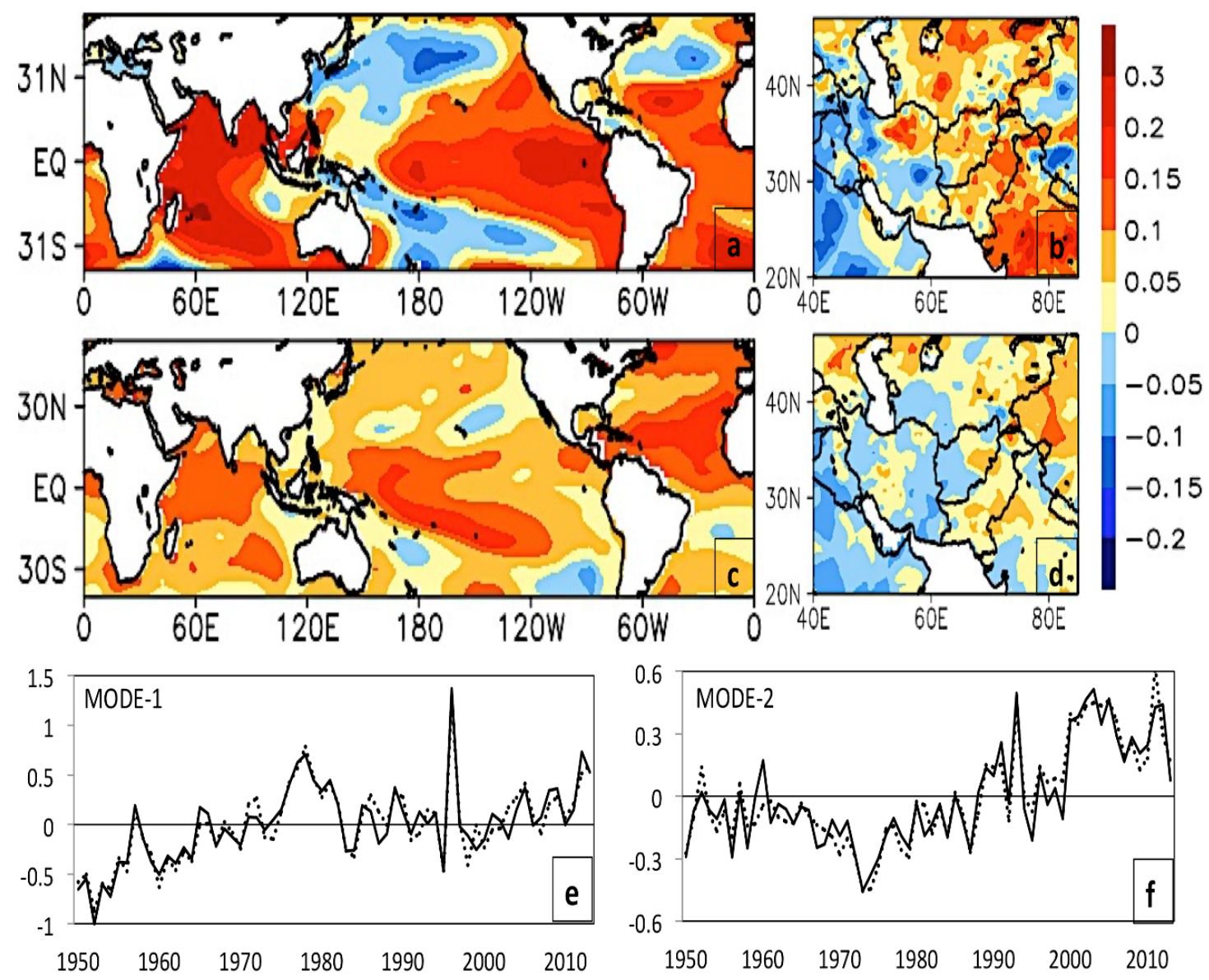

Figure 5.5: The Predictor (September-October: SSTS) and Predictand (NDJFMA: CSWA precipitation) loading patterns for CCA-Mode1 ( $a$ and b); Mode-2 (c and d); and the corresponding canonical component normalized time series (SST: dotted, Precipitation: solid) for 1950/51 - 2014/15.

The leading predictand loading pattern of CSWA winter precipitation (Figure $5.5(b))$ accounts for $19 \%$ of the total domain variance and is characterised largely by a 
west-east precipitation dipole pattern. Given the anomalous temperature gradient of the tropical and the Northern Hemisphere midlatitude SSTs seen in Figure 5.5(a), the west- east precipitation loadings could possibly be related to the shift in the mean structure and flow (troughs and ridges) of the Rossby waves associated with the subtropical jet stream over CSWA. The corresponding canonical component time series associated with CCA mode 1 (Figure 5.5(e)) have a high correlation coefficient of 0.95 . The time series indicate a moderate amount of year-to-year variability superimposed by the influence of the long-term changes in CSWA winter precipitation related to the SSTs in the heavily loaded regions.

The second CCA mode (Figure 5.5(c)) explains 20\% of the total domain variance and is associated with the overall warming of the global oceans over the period 1950/51-2014/15, with three distinct areas of significantly warm SST anomalies. Evidence suggests that the global oceans were significantly cooler than average prior to mid-1970s, followed by the abrupt warming of the Indian Ocean, the western Pacific, and the Atlantic in the following decades (Compo and Sardeshmukh 2010; Hoell and Funk 2014; McGregor et al. 2014; Hoell et al. 2017). The associated mode-2 canonical component time series (Figure 5.5(f)) captures the above features with a slight cooling trend from 1950 to 1973 and a warming influence thereafter. The rapid rise post-1999 is probably associated with the prominent warming of the western Pacific and the Atlantic Ocean [see Figure 5 in Hoell and Funk (2014)]. The mode-2 predictand loading pattern (Figure 5.5(d)) explains $16 \%$ of the total variance and is fairly similar to the west-east precipitation dipole structure displayed in Figure 5.5(b) for mode 1 . The similarity between the two modes indicates that the changes in CSWA winter precipitation are also related to the global SST trends.

As seen in Figure 5.6(a), the leading SST-predictor mode for the period 1980/81-2014/15 is dominated by an ENSO like response with extensive negative SST loadings covering a wide region of the central and eastern Pacific accompanied by positive SST anomalies in the western Pacific sector. This mode explains $27 \%$ of the total domain variance. Notably, the strongest negative SST anomalies occur along a narrow band that extends southwestward off the North American coastline and in the equatorial central Pacific region that includes the Niño-3.4 domain $(58 \mathrm{~S}-58 \mathrm{~N}$, 1708-1208W). In this polarity, the SST loadings manifest features that have a resemblance to the cold phase of the Pacific decadal variability (Barlow et al. 2001) combined with the recent prevalence of central Pacific La Niña events relative to the 
eastern Pacific La Niña events (Lee and McPhaden 2010). This scenario also includes the NAO-like signature in the North Atlantic (Robertson et al. 2000) and a dipole with weak centers of opposite-signed SST anomalies over the tropical western and southeastern Indian Ocean, with some similarities to the Indian Ocean dipole (IOD) (Saji et al. 1999).
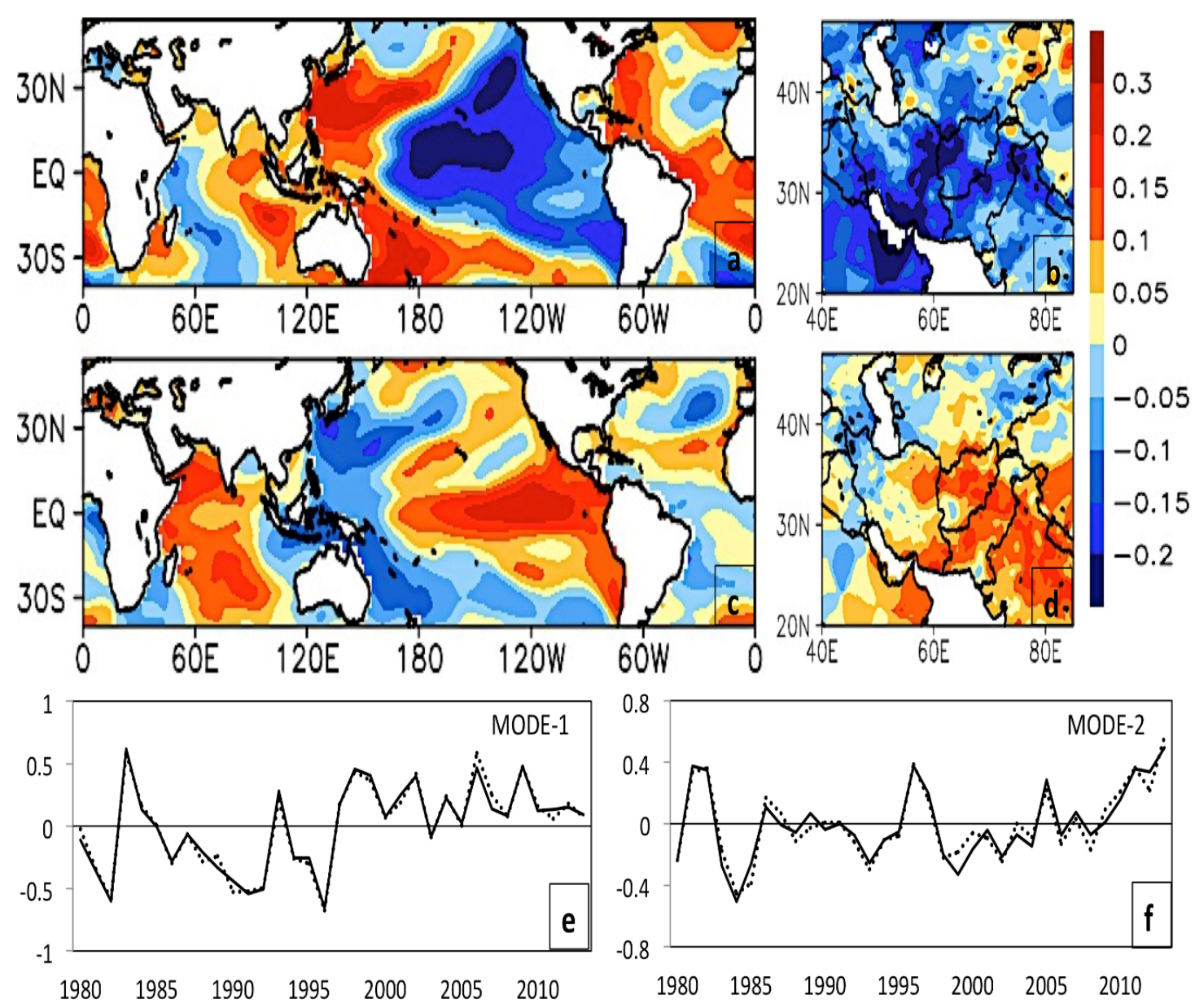

Figure 5.6: The Predictor (September-October: SSTS) and Predictand (NDJFMA: CSWA precipitation) loading patterns for CCA-Mode1 ( $a$ and b); Mode-2 (c and d); and the corresponding canonical component normalized time series (SST: dotted, Precipitation: solid) for 1980/81 - 2014/15.

The leading predictand loading pattern of CSWA winter precipitation (Figure $5.6(\mathrm{~b})$ ) accounts for $23 \%$ of the total variance and is characterised by a monopole pattern with large negative loadings over Iran, Afghanistan, Pakistan, and northeastern parts of Arabian Peninsula. The spatial features exhibit a close similarity to the precipitation deficit anomaly map associated with the recent extreme droughts 
over the CSWA region [see Figure 1 in Barlow et al. (2016)]. It appears that the strong loadings are concentrated over regions that are most sensitive to the modifications in winter season precipitation amount influenced by the SST variations discussed above. Notably, the region with the largest same-sign loadings is the region with maximum winter-fraction precipitation (Figure 5.2(c)). The canonical component time series (Figure 5.6(e)) associated with this mode exhibit a very high correlation coefficient of 0.99 and contains both interannual and decadal variability, with an increased frequency of positive anomalies evident after the mid-1990s. Mantua and Hare (2002) reported that from 1976/77 through at least the mid-1990s the PDO exhibited a warm (i.e., positive) phase, which is typically associated with enhanced frequency of El Niño events (Verdon and Franks 2006) and an increase in CSWA regional precipitation (Mariotti 2007; Rana et al. 2017). However, from 1999 onward a negative phase of PDO occurred, which was in line with the increased frequency of La Niña events and an increase in the occurrence of drought episodes over CSWA (Hoell and Funk 2014; Lyon et al. 2014).

The second CCA mode for the period 1980/81-2014/15 shown in Figure 5.6(c) shows a zonal anomaly pattern of strong positive SST anomalies spanning the tropical equatorial Pacific extending from the west coast of South America to the western Pacific and northward along the west coast of North America. An anomaly of opposite sign covers the equatorial western tropical Pacific, extending northeast and southeast into the subtropics. This pattern accounts for $18 \%$ of the total domain variance and resembles the ENSO mode displayed in Kawamura (1994). Strong positive SST loadings are also observed over the tropical Indian Ocean that are possibly related to the strong ENSO-induced changes in the Walker circulation that result in positive SST anomalies across the entire Indian Ocean (Klein et al. 1999). The predictand loadings (Figure 5.6(d)) depict an ENSO-related precipitation anomaly pattern with positive loadings over much of the CSWA region and account for $18 \%$ of the total domain variance. The corresponding canonical time series in Figure 5.6(f) contains some evidence of the ENSO-related fluctuations in CSWA winter precipitation with a mild upward trend since the late 1990s, likely associated with the increased frequency of central Pacific ENSO events and the recent decadal shift in the Pacific SST (Lyon et al. 2014; Hoell et al. 2014b). 


\subsubsection{CCA cross-validated skill}

Cross-validation is conducted to evaluate the overall forecasting skill of the CCA model. The standardized year-to-year time series of observations and cross-validated precipitation forecasts obtained for the periods 1950/51-2014/15 (Figure 5.7(a)) and 1980/81-2014/15 (Figure 5.7(b)) yields a domain average correlation skill of 0.38 and 0.71, respectively. For the period 1950/51-2014/15 the time series in Figure 5.7(a) depicts an improved level of agreement between the observed and the model estimated precipitation time series after the mid-1970s. Prior to this period, the forecast skill is relatively low and less reliable, as a result of which the model produces a moderate correlation score of 0.38 for the overall experiment. A close comparison of results shows that the time period (1950-76) during which the CCA model displayed a lower predictive skill is concomitant with the period in which the influence of ENSO on CSWA winter precipitation was rather weak (Figure 5.4) and that of NAO was relatively strong. This, however, is a limitation of the prediction approach adopted here, namely that in the absence of a robust historical predictorpredictand relationship or trend, the model fails to establish a reliable physical link and is unable to reproduce the predictor response correctly.

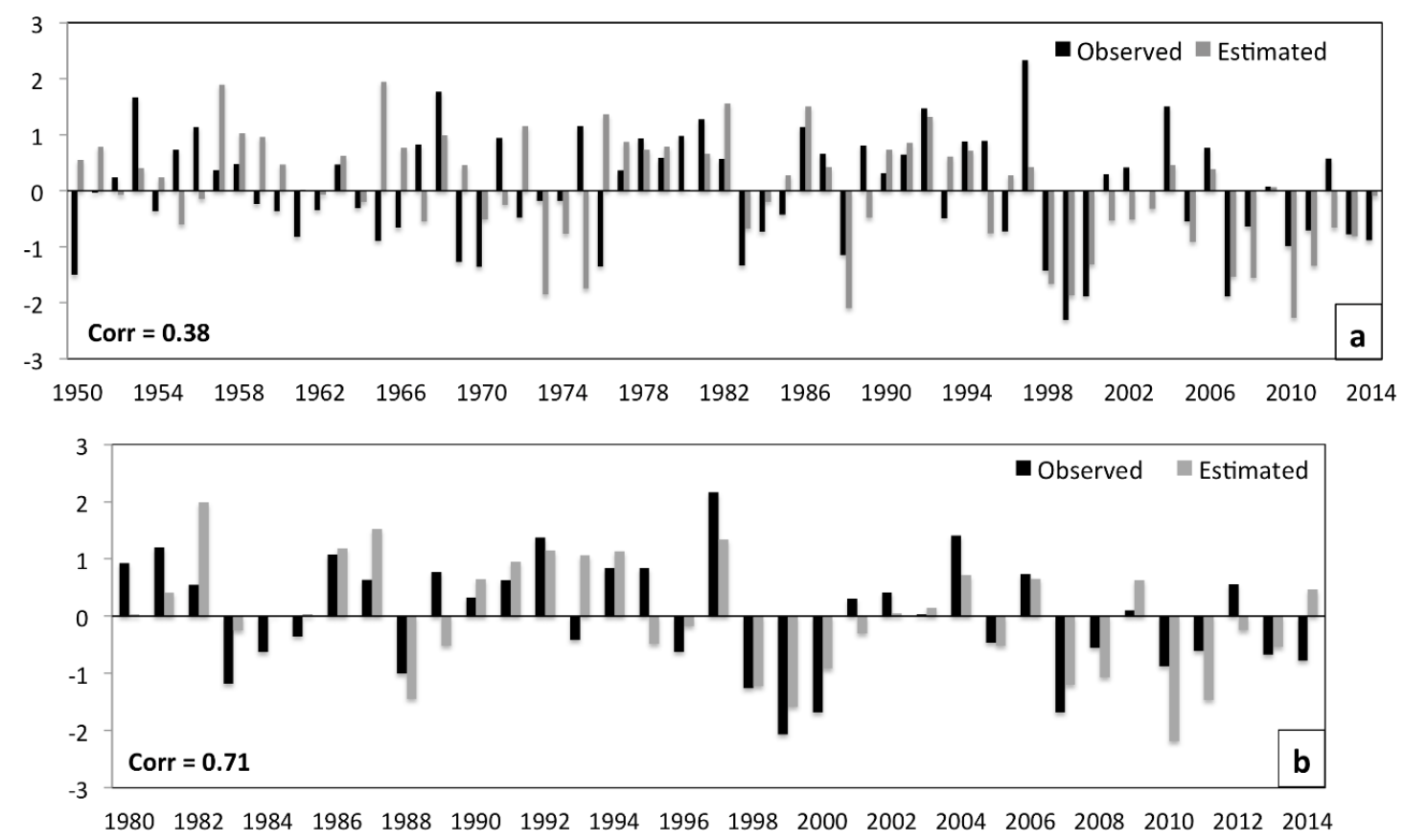

Figure 5.7: Standardized wintertime (NDJFMA) precipitation time series of observation and forecasts over CSWA region for 1950/51 - 2014/15 (top) and 1980/81 - 2014/15 (bottom), using the leave-one-out approach. 
For the period 1980/81-2014/15 (Figure 5.7(b)) the crossvalidated CCA-based forecasts indicate considerable predictive skill by capturing the interannual variations in CSWA winter precipitation for most years. The model performs impressively with a high and potentially usable predictive skill of 0.71 ; however, for some extreme (driest and wettest) years discrepancies are apparent between the model estimates and observation. For example, during 1995/96 the model failed to capture the observed precipitation pattern, whereas for $1980 / 81$ and $1981 / 82$ the model was unable to capture the overall magnitude of the observed seasonal precipitation.

For 1995/96, which was a weak La Niña year, the model failed to capture the observed precipitation anomaly pattern because the low positive NAO index (September-October average index: 0.5) suddenly changed to a strong negative value (21.5) in the following winter months. Previous findings on CSWA have recognised that other than the direct influence of tropical Pacific SST forcing, the region is also connected to the Pacific through the Middle East and the Atlantic Ocean (Barlow and Tippett 2008; Hoell et al. 2013; further discussed in the following section). Therefore, it is possible that during 1995/96 the indirect ENSO response on CSWA precipitation was significantly dampened by the strong positive phase of the NAO, leading to an increased precipitation activity over the region. Furthermore, the years 1980/81 and $1981 / 82$ for which the model was unable to capture the overall magnitude of the observation were dominated by strong negative EAWR phase. According to Yin et al. (2014) the negative (positive) phase of EAWR contributes in reducing (enhancing) precipitation activity over CSWA.

All of the above results indicate that the potential predictability of CSWA wintertime precipitation has a strong dependency on the ENSO phenomenon, and the strengthening (weakening) of this relationship yields forecasts of higher (lower) predictive skill. In particular for the period 1980/81-2014/15 the forecasts are more skillful for years classified as strong to very strong ENSO years, suggesting that the regional precipitation anomalies are largely decided by the phase of ENSO. However, there are indications that, depending on the relative strength of the concomitant regional or largescale teleconnections, regional precipitation anomalies can be modified either directly (during non-ENSO years) or by way of partly modulating the strength of the ENSO-induced precipitation forcing. A recent example of this is the 2013/14 regional drought of CSWA discussed in Barlow and Hoell (2015). In 
addition to the aforementioned factors, random atmospheric variability may also result in the circulation and precipitation modifications over the CSWA region.

For the period 1980/81-2014/15, the wintertime precipitation anomaly composite maps for the seven driest and wettest years from observations (Figure 5.8(a),(c)) and SST-predicted (Figure 5.8(b),(d)) precipitation estimates are displayed. In general, this result showcases the ability of the CCA model to effectively reproduce and predict the spatial distribution pattern of CSWA observed precipitation anomalies during extreme precipitation years. The model-estimated precipitation demonstrates useful prediction skill by capturing the characteristic features of the spatial anomaly pattern similar to the observations. In particular, the success of the CCA approach in predicting the recent drought conditions over CSWA (as seen in Figure 5.7(b) and Figure 5.8(b)) is highly encouraging, given that the region is water stressed and prone to frequent severe droughts (Barlow et al. 2016).

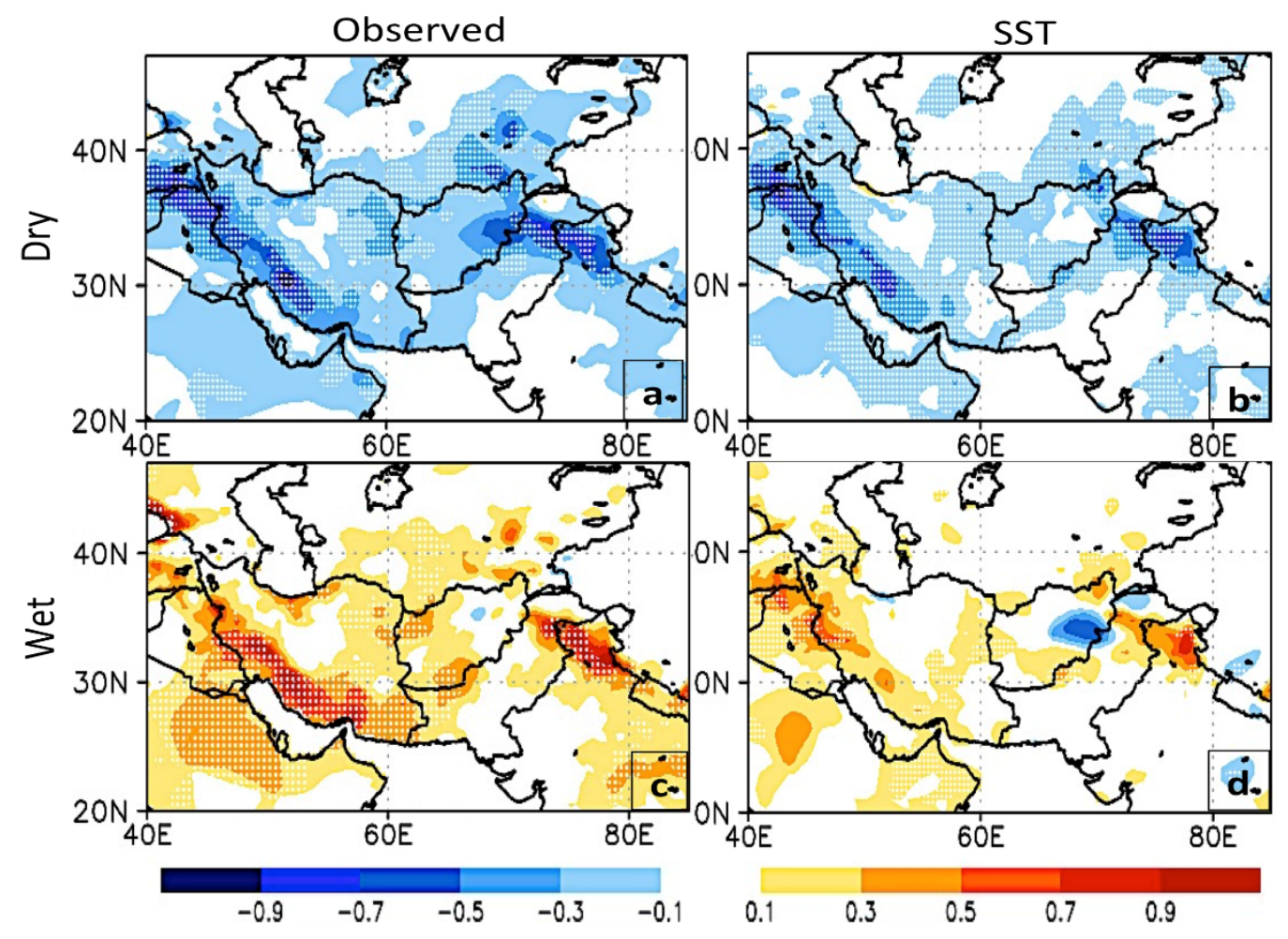

Figure 5.8: The wintertime (NDJFMA) precipitation ( $\mathrm{mm} /$ day) anomaly composites for the seven driest and wettest years in the observed (left) and SSTpredicted (right) precipitation for 1980/81 - 2014/15. Stippling indicates composite anomalies significant at 5\% level. 
For further assessment, additional spatial skill scores-mean bias ( $\mathrm{mm} /$ day), RMSE (mm/day), and temporal anomaly correlation - are computed for the period 1980/81-2014/15 and shown in Figure 5.9. The important aspects that contribute substantially to the final skill of the model include the relatively low biases (Figure 5.9(a)) and modest correlation coefficients (Figure 5.9(c)) distributed over areas that receive a significant amount of winter season precipitation as seen in Figure 5.2(c). The RMSE values are high over the mountainous regions and closely resemble the region's seasonal climatology (Figure 5.2(b)) and standard deviation pattern [see Figure 1c in Tippett et al. (2003)]. Combining the above information, it appears that in our prediction model the random error dominates over the systematic bias that is likely related to the year-to-year variations in the winter season precipitation. Finally, we compare the accuracy skill of our CCA prediction scheme against the climatology and persistence benchmark models for the period 1980/81-2014/15. Here the climatology model assumes the long-term mean as the forecast at all times (i.e., zero anomaly); the persistence model uses last year's observation as this year's forecast and the accuracy skill score is computed using the Nash-Sutcliffe efficiency criteria (Krause et al. 2005). A negative skill score indicates that the CCA model is inferior to the reference model, whereas a $100 \%$ score signifies a perfect model. We find that the overall predictive skill of our model with respect to climatology and persistence is $47 \%$ and $58 \%$, respectively, which further confirms the success of the prediction approach adopted here.

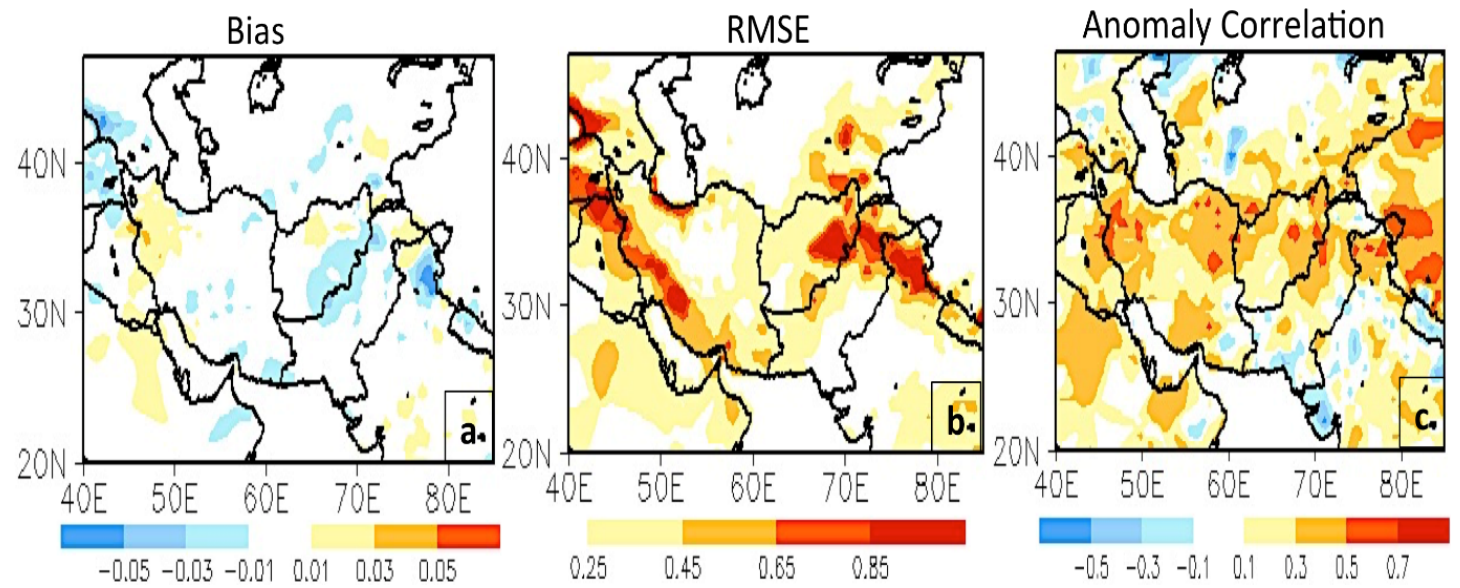

Figure 5.9: The spatial maps for (a) Bias, (b) RMSE and (c) Anomaly correlation between the observed and SST-predicted winter precipitation over CSWA for 1980/81 $-2014 / 15$. 


\subsection{Large-scale SST forcing}

Figure 5.10 shows the composite anomaly maps of the preceding months' (September-October) SST variations corresponding to the seven driest (Figure 5.10(a)) and wettest (Figure 5.10(b)) winter precipitation years for the period 1980/81-2014/15. These results indicate that strong and statistically significant variations in the Pacific sector (which include signatures of both ENSO and the PDO) lead to substantial precipitation modifications across the CSWA region. In the case of dry winter years the observed September-October SST expression along the equatorial belt shows strong similarities with the SST phase-3 La Niña pattern discussed in Johnson (2013), while the subtropical and extratropical signature resembles a developing cold phase of PDO similar to that in Hoell et al. (2015b).

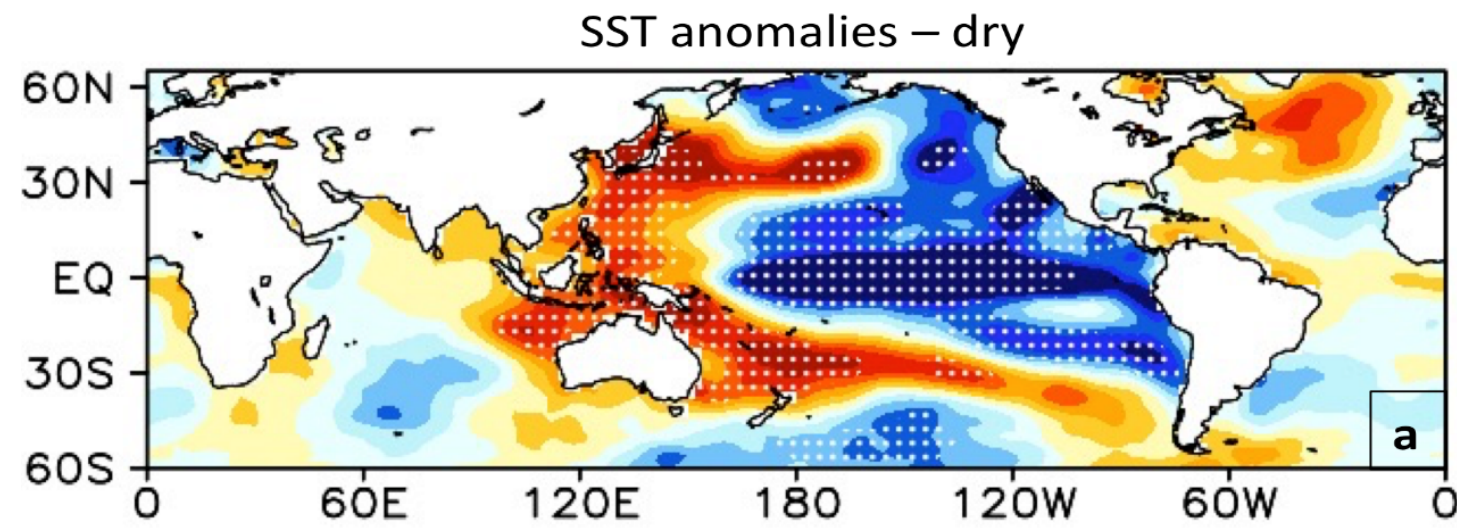

SST anomalies - wet

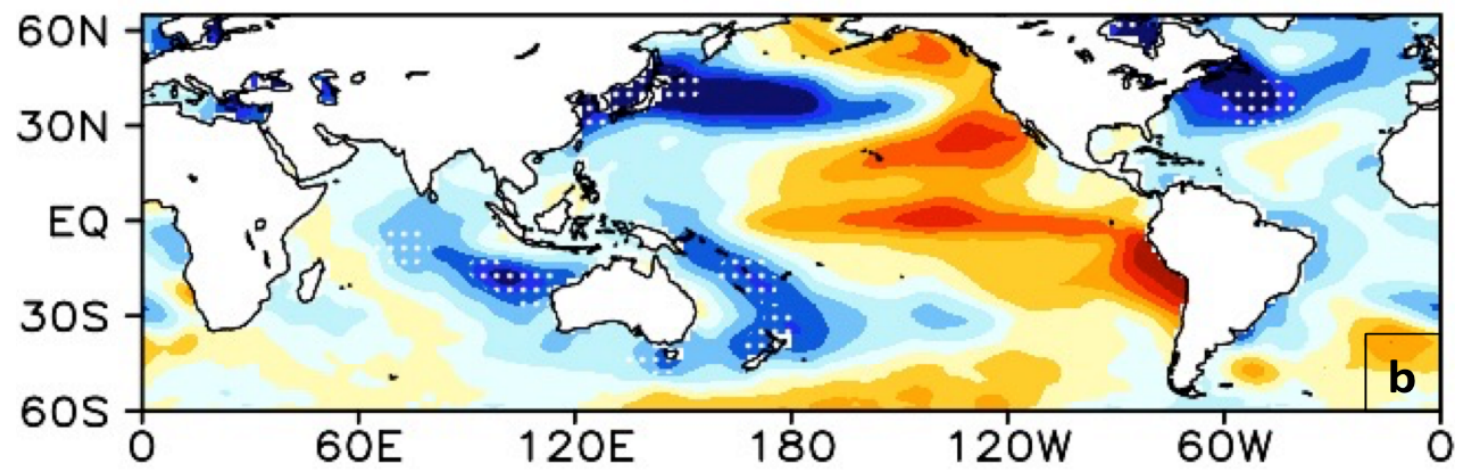

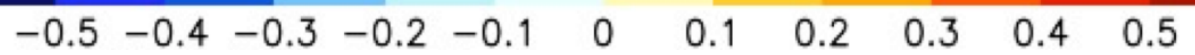

Figure 5.10: Composite of SST $\left({ }^{\circ} \mathrm{C}\right)$ anomalies for (September-October) months preceding the seven driest and wettest years winter (NDJFMA) precipitation years for 1980/81 - 2014/15. Stippling indicates composite anomalies significant at 5\% level. 
Likewise, for the wet years the SST anomaly pattern in Figure 5.10(b) appears 
Kumar and Ouarda (2014) showed that during El Niño years the uppertropospheric westerly jet stream shifts equatorward nearly $3^{\circ}-4^{\circ}$ of latitude over the Middle East and is responsible for above-normal precipitation over the region. These circulation features strengthen considerably during the following winter months (NDJFMA), with upper-level cyclonic (Figure 5.11(a)) and anticyclonic (Figure 5.11(b)) circulation anomalies straddling the equator, often discernible in the case of La Niña and El Niño events, respectively.

Previous studies have shown that anomalous diabatic heating in the tropical Pacific excites baroclinic (Barlow et al. 2002) and equivalent barotropic (Shaman and Tziperman 2005; Hoell et al. 2012, 2013) stationary Rossby waves that influence CSWA climate through modification of the regional circulation patterns. Shaman and Tziperman (2005) proposed a teleconnection mechanism that the wintertime ENSO conditions in the central Pacific produce stationary barotropic Rossby waves in the troposphere that propagate northeastward throughout the Northern Hemisphere over North America, the Atlantic, and the Middle East into western Asia, influencing the regional circulation (Barlow and Tippett 2008; Hoell et al. 2013). Recently, Niranjan Kumar et al. (2016) reported that during La Niña and El Niño events the wind anomalies over the Middle East region are easterlies and westerlies, respectively, in the upper and lower troposphere. Consistent with the above results, Figure 5.11 indicates that for much the CSWA region the extratropical circulation response to the anomalous tropical Pacific SSTs (Figure 5.10) consists of an anticyclonic (cyclonic) equivalent barotropic wave structure throughout the depth of the troposphere. Therefore during extreme dry (wet) winter years the reduced (enhanced) wintertime precipitation anomalies over the CSWA are typically associated with a strong northeasterly (southwesterly) wind flow from the Tibetan Plateau (Arabian Sea) responsible for advecting less (more) moisture into the region previously discussed in Hoell et al. (2012) and Mariotti (2007).

\subsection{Summary and Discussion}

Central southwest Asia (CSWA), bounded by the domain $20^{\circ}-47^{\circ} \mathrm{N}, 40^{\circ}-85^{\circ} \mathrm{E}$, comprises a region that is water-stressed, societally vulnerable, and prone to large variations in precipitation during its primary precipitation season of November-April 
(NDJFMA). Evidence suggests that CSWA winter precipitation is strongly influenced by the Pacific sector SST forcing, much of which is attributed to the ENSO cyclerelated interannual variability and the ENSO-like interdecadal variability (Hoerling and Kumar 2003; Barlow and Tippett 2008; Lyon et al. 2014; Barlow et al. 2016; Hoell et al. 2015b). To a large extent, these relationships are of significant value and have potential predictive capabilities for forecasting CSWA winter precipitation anomalies at various time scales (Barlow et al. 2002; Tippett et al. 2003; Barlow et al. 2005; Tippett et al. 2005; Hoell and Funk 2013).

In this study, we examined the predictability of CSWA wintertime precipitation anomalies for two sets of time periods 1950/51-2014/15 and 1980/81-2014/15 using the CCA approach. CCA is designed to find the most well-correlated patterns between a set of the predictors and predictands. The potential predictor patterns/modes of variability are identified using covariance analysis (Figure 5.3) between the winter season (NDJFMA) precipitation and the preceding months' (September-October) SSTs. The lead-lag covariance pattern depicted SST expressions similar to ENSO and the NAO pattern, based on which quasi-global SST field $\left(40^{\circ} \mathrm{S}-55^{\circ} \mathrm{N}\right.$, all longitudes) was considered as the most optimal predictor domain for CCA diagnostics.

The leading predictor modes of the two CCA experiments (Figure 5.5 and Figure 5.6 revealed that for CSWA a substantial component of the predictive skill comes from the SST variability in the Pacific associated with both the interannual (ENSO) and the interdecadal (PDO) climate variations. The regional precipitation response to the large-scale Pacific forcing is such that the in-phase development of ENSO and PDO anomalies (El Niño and warm PDO or La Niña and cold PDO) tends to produce negative (positive) precipitation anomalies over CSWA in the following winter months (Figure 5.10). The teleconnection mechanism linking the Pacific sector variability to CSWA precipitation modifications is through the interaction of the westerly jet stream with the upper-tropospheric Rossby wave train that shifts the westerly jet track north (south) of its mean position, resulting in anticyclonic (cyclonic) circulations over CSWA throughout the troposphere (Figure 5.11).

The cross-validated forecast skill of the two CCA experiments (Figure 5.7) showed that on the interannual time scale skillful predictability of CSWA winter precipitation arises as a result of the influence of ENSO, and years with strongest ENSO conditions yield forecasts with more usable skill levels. The superior domain average correlation skill of 0.71 obtained for the 1980/81-2014/15 CCA experiment 
validates the above results. However, on longer time scales the influence of ENSO on CSWA winter precipitation varied in strength (Figure 5.4), and the strengthening (weakening) of this relationship was strongly associated with the higher (lower) predictability of the regional precipitation as seen in the case of 1950/51-2014/15 cross-validated forecast skill.

Other than the ENSO-related sources, random atmospheric variability may also result in anomalous circulation and precipitation modifications over CSWA. On a positive note, the North Atlantic variability and the long-term SST trends have shown to provide weaker but useful regional predictive information on interannual and longer time scales. A close assessment of the cross-validated forecast skill has shown that nonENSO-related patterns, in particular the NAO, do not contribute materially to the seasonal predictive skill despite their important role in the regional precipitation variability (Figure 5.3). There are indications that, depending on the relative strength of the concomitant regional or large-scale teleconnections, the regional precipitation anomalies tend to get modified either directly (during non-ENSO years) or by way of partly modulating the strength of the ENSO-induced forcing. Overall the results presented in this study are highly encouraging. The regional forecasts for the 1980/81-2014/15 period indicate considerable predictive skill and can potentially contribute to early planning and preparedness. Further improvements in the model performance can focus on the inclusion of regional predictors that contribute quantitatively to the predictive skill of the model. 


\section{Chapter 6 Research Summary and Future Work}

The research presented in this thesis focused on bridging the gap in our knowledge of Central Southwest Asia's precipitation climate, by providing a detailed investigation of the regional winter (November-April, NDJFMA) season precipitation from three different perspectives:

1) Quantification of the uncertainty and reliability of multi-source gridded precipitation datasets for monitoring seasonal precipitation variability over the Indian subcontinent (Chapter 2), and the Central Southwest Asia (CSWA) region (Chapter 3).

2) Characterization of the long-term spatiotemporal variability of CSWA's wintertime precipitation, and its association with large-scale patterns of climate variability (Chapter 4).

3) Development of a statistical-empirical scheme for predicting the year-toyear variations in winter season precipitation over CSWA (Chapter 5).

In working to achieve the above specific goals, this research led to the following conclusions:

CFSR and ERA-Interim reanalyses generally overestimate, while CPC-uni underestimates, the total precipitation for all seasons over the Indian subcontinent. The degree of variability in precipitation estimates also varied by region, with large discrepancies occuring in areas with low gauge densities such as the mountainous and arid regions of the Indian subcontinent.

Chapter 2 evaluated the performance of some of the high quality and widely used gauge-based, satellite-derived, and reanalysis precipitation datasets (APHRODITE, CPC-uni, GPCP, 3B42-V6, 3B42-V7, CFSR, and ERA-Interim) over the Indian 
Subcontinent. Results showed that all examined products, despite having different spatial resolutions, coherently reproduced the large-scale characteristics of the seasonal precipitation regime; however, the degree of uncertainty in estimates varied by type of precipitation (e.g. convective, solid) and regions (e.g. topographic relief).

On the seasonal and regional scale, both reanalyses exhibited higher precipitation estimates in comparison to all other datasets underlining that caution should be taken when using CFSR and ERA-Interim datasets for hydrological and climatological assessment of precipitation across the Indian Subcontinent. For the monsoon and post-monsoon season, the gauge-only CPC-uni performed reasonably well over the Indian region but captured well the lowest precipitation totals for the winter and pre-monsoon season.

Based on the comparisons and our statistical assessments of results, use of CPCuni as a ground-truth dataset is not recommended in areas of high topographic relief and low gauge density (e.g. northwest India, foothills of the Himalayas, and Myanmar) where additional gauge information is critical to improving the accuracy of its precipitation estimates. Spatial discrepancies were also observed between satellitegauge merged GPCP and the satellite-derived TRMM 3B42-V6 and 3B42-V7 products. For all seasons, GPCP failed to capture the orographic nature of the regional precipitation pattern; while 3B42-V7 outperformed its previous counterpart (3B42V6) during the winter and pre-monsoon season gaining some confidence in the usability of the dataset for monitoring precipitation over the topographically complex and gauge network-sparse northwestern region of the Indian subcontinent.

It is important to note that for the northwestern region of the Indian subcontinent, our results should be interpreted carefully owing to the challenges lack of sufficient gauge observations, extreme terrain, socio-political instability, orographic dependency, and intermittency of seasonal precipitation that may, in part, add to substantial uncertainties in the estimation of regional precipitation. These factors limited our ability to formulate a qualitative recommendation on the accuracy and uncertainty of precipitation estimates for the winter and pre-monsoon season, thereby motivating us for continuous and concentrated research efforts at the regional scale. It was for this reason that a detailed intercomparison of the avaiable and widely-used precipitation estimates was performed for the CSWA region, and presented in Chapter 3. 
GPCC is a suitable observational dataset for wintertime climatological precipitation analysis over CSWA. Comparatively, the satellite-derived TRMM 3B42-V7 and the

MERRA reanalysis perform reasonably well.

Chapter 3 addressed the above information gap by providing the first comprehensive evaluation of four gauge-only (APHRODITE, CPC-uni, CRU and GPCC), three reanalyses (CFSR, ERA-Interim and MERRA) and three satellitederived (3B42-V6, 3B42-V7 and GPCP) precipitation products over a larger domain, which included the northwestern region of the Indian subcontinent, and was referred to as the Central Southwest Asia (CSWA) region. The analysis was performed for the winter months of December-April (DJFMA), for which uncertainties in the precipitation estimates were largest as described in Chapter 2. Given the low gauge density of in situ stations across CSWA, an ensemble of gauge-only datasets was constructed to reduce the contribution of observational errors and to use it as reference data. Here an ensemble of direct observations was used as a reference since gauges are still considered as a relatively accurate and trusted source of precipitation measurements at a single point.

Evaluation of the precipitation estimates against the reference data showed that $\mathrm{CPC}$-uni strongly underestimated the seasonal precipitation and exhibited little skill in the accurate representation of regional precipitation both spatially and temporally. CRU (APHRODITE) performed reasonably well but lacked accuracy in representing the spatial pattern (interannual variability) of seasonal precipitation, making the potential use of these datasets questionable over the CSWA region. Among all gaugeonly datasets, GPCC was in closest agreement to the reference data with high correlation, small error/bias, and in capturing the spatial details and magnitude for the El Niño and La Niña - related impacts on the regional precipitation distribution. These results make GPCC a suitable observational data for long-term climatological analysis of precipitation over CSWA.

In the reanalysis category, CFSR and MERRA in comparison to ERA-Interim reproduced the regional pattern and the local details of the seasonal precipitation fairly well. All products overestimated the magnitude of precipitation with strongest overestimations being those of CFSR followed by ERA-Interim and MERRA. Based on skill scores, MERRA performed better than the other two reanalyses but showed weakness in resolving the magnitude of observed precipitation departure for La Niña 
events. Our assessment suggests that the MERRA reanalysis is satisfactory for studying CSWA precipitation; however, care should be taken when using MERRA for analysis of extremes.

Finally, among the satellite-derived products the results obtained for the CSWA region were nearly similar to those obtained for the wintertime precipitation in Chapter 2. The dataset showed a good agreement with the ensemble mean and other observational data sets such as GPCC and APHRODITE. In comparison to 3B42-V6 and GPCP, 3B42-V7 exhibited the best performance in depicting the spatial pattern and temporal variations of winter precipitation, making it a potentially reliable alternative to gauge measurements.

The above results provided valuable information on the reliability and usability of multiple-source datasets to represent wintertime precipitation climate of CSWA. Using this information a long-term (1950/51-2014/15) observational analysis was performed to gain a more complete understanding of the spatial and temporal patterns of CSWA's winter season precipitation and its variability.

The influence of ENSO on wintertime CSWA precipitation went through a significant inter-decadal change in the early 1980s. The regional precipitation variability was closely related to the extratropical EA-WR (tropical ENSO) teleconnection before (after) the 1980's. Changes in the strength of ENSO teleconnections, both globally and over CSWA, have been attributed to the observed changes in the ENSO properties since the late 1970s of which the enhanced SST anomaly gradient between the western and the central Pacific Ocean was an important factor.

Chapter 4 contributed towards an improved understanding of CSWA's wintertime (NDJFMA) precipitation climate by identifying the dominant spatiotemporal modes of regional precipitation variability and quantifying their relationships with global SST and large-scale atmospheric circulation fields. Three leading patterns of CSWA's winter precipitation were generated using empirical orthogonal function analysis.

The first mode (19\% of total variance) showed a uniform distribution over the entire CSWA domain. This mode was found to be related to ENSO, which under El Niño conditions force widespread changes in CSWA's regional circulations by way of 
exciting both barotropic and baroclinic Rossby waves that result in a precipitationenhancing anomalous ascent from the Arabian Sea and the Indian Ocean basin, into the CSWA region.

The second mode (15\% of total variation) depicted a contrast between the northern and the southern part of the CSWA region. Results showed that this mode is related to the shift in the latitudinal position/intensity of the westerly circulations, the strength of which can change due to the competing influences and complex interactions of both extratropical and tropical teleconnections (e.g., ENSO, NAO, Siberian High, EA-WR, and others). For this mode, a significant relationship between CSWA winter precipitation and the Siberian High was identified. Results suggest that among other physical processes that tend to modulate the mid-latitude storm tracks, the westward extension of the Siberian High along with the northwestward nudging of the NPO/WP pattern can also influence the westerly systems over CSWA. While further analysis is required to support the above finding, therefore, it can only be hypothesised here that the combined response of the two forcings likely directs the westerly storms to a more southerly track that perhaps contributes in generating positive (negative) precipitation anomalies on the southern (northern) side of the CSWA region.

The third mode ( $10 \%$ of total variation) showed a west-east regional dipole pattern linked to the longitudinal variations in the zonal velocity of the westerly jet flow. Results showed that this mode is related to the long-term warming of the tropical Indian and Pacific Oceans SSTs. A close connection to the extratropical type-1 Eurasian pattern was also observed, with a well-organised anticycloniccyclonic couplet in the circulation field north of the CSWA region. This couplet modifies the regional circulation by inducing a strong dry/northerly flow over the western flanks of CSWA and pushing the moist southerly winds from the neighbouring Arabian sea to the eastern extent of the region.

The second part of this work focussed on the first mode of CSWA precipitation that exhibited a close relationship with wintertime ENSO. Results showed that the influence of ENSO on CSWA precipitation was insignificant and weak (significant and pronounced) before (after) the early 1980's. For the period P1 (1950/51-1982/83), when the connection with ENSO was weak, the extratropical EA-WR pattern played an active role in CSWA precipitation variability. This association, however, changed during the period P2 (1983/84-2015/16) due to the increased influence of ENSO- 
related forcing on CSWA climate, associated with the changes in the tropical Pacific ENSO characteristics post-1980s. Our results further illustrated that the Rossby wave teleconnection mechanisms through which the extratropical EA-WR pattern impacted the regional climate across Western Europe, Central and Southwest Asia in P1(1950/51-1982/83) was linearly superimposed by the anomalous large-scale circulation response forced by the ENSO conditions in P2 (1983/84-2015/16), thereby, resulting in much stronger and statistically significant circulation modifications and regional precipitation departures.

The results presented in this study improved our understanding of CSWA's wintertime precipitation climate and provided useful insights into the role of tropical (ENSO) and extratropical (EAWR) teleconnections patterns in the regional precipitation variability. Building a prediction model for CSWA using these teleconnections can perhaps lead to skilful seasonal/subseasonal precipitation forecasts. This research question was explored and addressed in Chapter 5.

ENSO played a dominant role in creating skilful predictions for CSWA winter seasonal precipitation in recent years. For the quasi-global SST predictor domain of $\left[40^{\circ} \mathrm{S}-55^{\circ} \mathrm{N}\right.$, all longitudes] a mean correlation skill of $0.38(0.71)$ was obtained for the period 1950/51-2014/15 (1980/81-2014/15) during which the impact of ENSO on CSWA's winter precipitation was insignificant/weak (significant/strong).

Chapter 5 assessed the predictability of CSWA year-to-year wintertime (NDJFMA) precipitation based on its strong links to the tropical Pacific SST variability. The approach followed in this work involved the careful selection of potential predictors and predictor domains, statistical model building using multivariate Canonical Correlation Analysis (CCA), and testing model forecasts using standard statistical performance measures. Observed SST in the preceding months (September-October) in the domain $\left[40^{\circ} \mathrm{S}-55^{\circ} \mathrm{N}\right.$ (all longitudes)] was used as a predictor, because of its highest skill among other predictors (OLR, winds) and various combinations of predictor domains that included the Indo-Pacific, Pacific and the Atlantic Ocean (see Appendix for further detals). 
Using the aforementioned SST predictor domain, CCA experiments were performed for two sets of time periods, 1950/51-2014/15 (65 years) and 1980/812014/15 (35 years). Results showed that ENSO-related interannual and inter-decadal variations are the main source of predictive skill for CSWA's winter season precipitation. Among other sources, long-term SST trends and the North Atlantic variability also provided weaker but useful regional predictive information. Between the observations and cross-validated precipitation forecasts, a considerably higher (lower) correlation skill of 0.71 (0.38) was obtained for the period 1980/81-2014/15 (1950/51-2014/15), which was due to the stronger (weaker) impact of ENSO on CSWA winter precipitation as discussed in findings of this work and Chapter 4. These results indicated that ENSO plays a dominant role in creating skilful predictions.

Model validation carried out for the 1980/81-2014/15 CCA prediction showed that the model performed reasonably well by skilfully capturing the precipitation variations for the extreme years, in particular, the recent droughts. These results further demonstrated the usable predictive skill of the model with relatively low biases and modest correlation coefficients observed spatially. Composite maps of SST and wind anomalies for the seven driest and wettest years displayed that the development of cold (warm) ENSO conditions during September-October, in combination with cold (warm) PDO conditions, is associated with a northward (southward) shift of the jet stream and a strong tendency of negative (positive) precipitation anomalies over CSWA region during the winter months.

In summary, the research contributes the following:

1) Provided valuable insights into the usability and limitations of the frequently used precipitation products over the Indian Subcontinent and CSWA region.

2) Advanced our knowledge on how mid-latitude and tropical modes of climate variability impact CSWA's precipitation on the seasonal time-scale.

3) Developed a statistical forecasting scheme to predict winter precipitation for the societally vulnerable and drought-prone CSWA region. 


\subsection{Future Directions}

Guided by the results of this thesis, we suggest the following points for further investigation:

More work is needed to validate the findings of Chapter 4, which may include modelling experiments to isolate the impact of the tropics and explore the role of midlatitude teleconnections on CSWA precipitation climate. It is expected that investigating the role of extratropical teleconnections, in particular, the role of EAWR will provide a clearer understanding of the extent and strength of its influence on the regional year-to-year precipitation variability; including its relationship to changes in the position and intensity of the westerly storm tracks.

Following the findings of Chapter 4 and the results obtained in Chapter 5, a question arises whether the predictability of CSWA winter precipitation would increase with the use of additional predictors (e.g. SLP, geopotential height). We believe that including these variables in addition to SST as a predictor may provide a potential source of predictability during the period when the impact of ENSO on CSWA precipitation was weak, and that of extratropical influences was relatively strong. Future work is planned to perform further extensions and improvements to the CCA model.

In addition to the work presented in Chapter 3, future work could also look into how Coupled Model Inter-comparison Project phase 6 (CMIP6) global climate models perform in replicating the observed features of CSWA's winter precipitation against GPCC historical observations, and how such may change as the climate continues to warm. 


\section{REFERENCES}

Adler RF et al. (2003) The version-2 global precipitation climatology project (GPCP) monthly precipitation analysis (1979-present) Journal of hydrometeorology 4:11471167.

Agrawala S, Barlow M, Cullen H, Lyon B (2001) The drought and humanitarian crisis in central and southwest Asia: A climate perspective.

Ahmadi M, Salimi S, Hosseini SA, Poorantiyosh H, Bayat A (2019) Iran's precipitation analysis using synoptic modeling of major teleconnection forces (MTF), Dynamics of Atmospheres and Oceans, 85: 41-56

Aizen EM, Aizen VB, Melack JM, Nakamura T, Ohta T (2001) Precipitation and atmospheric circulation patterns at mid-latitudes of Asia International Journal of Climatology 21:535-556.

Aizen VB, Aizen EM, Melack JM, Dozier J (1997) Climatic and hydrologic changes in the Tien Shan, central Asia Journal of Climate 10:1393-1404.

Almazroui M, Islam MN, Dambul R, Jones P (2014) Trends of temperature extremes in Saudi Arabia International Journal of Climatology 34:808-826.

AlSarmi S, Washington R (2011) Recent observed climate change over the Arabian Peninsula Journal of Geophysical Research: Atmospheres 116.

Amin A et al. (2017) Comparison of future and base precipitation anomalies by SimCLIM statistical projection through ensemble approach in Pakistan Atmospheric Research 194:214-225.

Amitai E, Llort X, Liao L, Meneghini R A framework for global verification of space-borne radar estimates of precipitation based on rain type classification. In: 2nd TRMM International Science Conference, 2004.

An S-I, Wang B (2000) Interdecadal change of the structure of the ENSO mode and its impact on the ENSO frequency Journal of Climate 13:2044-2055.

Andermann C, Bonnet S, Gloaguen R (2011) Evaluation of precipitation data sets along the Himalayan front Geochemistry, Geophysics, Geosystems 12.

Anders AM, Roe GH, Hallet B, Montgomery DR, Finnegan NJ, Putkonen J (2006) Spatial patterns of precipitation and topography in the Himalaya Special Papers-Geological Society of America 398:39.

Barlow M, Cullen H, Lyon B (2002) Drought in central and southwest Asia: La Niña, the warm pool, and Indian Ocean precipitation Journal of climate 15:697-700.

Barlow M, Hoell A, Colby F (2007) Examining the wintertime response to tropical convection over the Indian Ocean by modifying convective heating in a full 
atmospheric model.Geophys. Res. Lett., 34, L19702, doi:10.1029/2007GL030043.

Barlow M, Hoell A (2015) Drought in the Middle East and Central-Southwest Asia During Winter 2013/14 Bulletin of the American Meteorological Society 96:S71-S76.

Barlow M, Nigam S, Berbery EH (2001) ENSO, Pacific decadal variability, and US summertime precipitation, drought, and stream flow Journal of climate 14:2105-2128.

Barlow M, Wheeler M, Lyon B, Cullen H (2005) Modulation of Daily Precipitation over Southwest Asia by the Madden-Julian Oscillation Monthly Weather Review 133:3579-3594 doi:10.1175/mwr3026.1.

Barlow M, Zaitchik B, Paz S, Black E, Evans J, Hoell A (2016) A Review of Drought in the Middle East and Southwest Asia Journal of Climate 29:8547-8574 doi:10.1175/jcli-d13-00692.1.

Barlow MA, Tippett MK (2008) Variability and predictability of central Asia river flows: Antecedent winter precipitation and large-scale teleconnections Journal of Hydrometeorology 9:1334-1349.

Barnett T, Preisendorfer R (1987) Origins and levels of monthly and seasonal forecast skill for United States surface air temperatures determined by canonical correlation analysis Monthly Weather Review 115:1825-1850.

Barnett TP, Adam JC, Lettenmaier DP (2005) Potential impacts of a warming climate on water availability in snow-dominated regions Nature 438:303.

Barnston AG, Livezey RE (1987) Classification, seasonality and persistence of lowfrequency atmospheric circulation patterns Monthly weather review 115:1083-1126.

Barnston AG, Ropelewski CF (1992) Prediction of ENSO episodes using canonical correlation analysis Journal of climate 5:1316-1345.

Barnston AG, Smith TM (1996) Specification and prediction of global surface temperature and precipitation from global SST using CCA Journal of Climate 9:2660-2697.

Barnston AG, Thiao W, Kumar V (1996) Long-lead forecasts of seasonal precipitation in Africa using CCA Weather and Forecasting 11:506-520.

Barriopedro D, García-Herrera R, Lupo AR, Hernández E (2006) A climatology of Northern Hemisphere blocking Journal of Climate 19:1042-1063.

Bates B, Kundzewicz Z, Shaohong W, Palutikof J Climate Change and Water-IPCC Technical Paper VI.

Becker A, Finger P, Meyer-Christoffer A, Rudolf B, Schamm K, Schneider U, Ziese M (2013) A description of the global land-surface precipitation data products of the Global Precipitation Climatology Centre with sample applications including centennial (trend) analysis from 1901-present Earth System Science Data 5:71-99. 
Bernauer T, Siegfried T (2012) Climate change and international water conflict in Central Asia Journal of Peace Research 49:227-239.

Bond N, Overland J, Spillane M, Stabeno P (2003) Recent shifts in the state of the North Pacific Geophysical Research Letters 30.

Bookhagen B, Burbank DW (2010) Toward a complete Himalayan hydrological budget: Spatiotemporal distribution of snowmelt and rainfall and their impact on river discharge Journal of Geophysical Research: Earth Surface 115.

Bosilovich MG, Chen J, Robertson FR, Adler RF (2008) Evaluation of global precipitation in reanalyses Journal of applied meteorology and climatology 47:2279-2299.

Bosilovich MG, Kennedy J, Dee D, Allan R, O’Neill A (2013) On the reprocessing and reanalysis of observations for climate. In: Climate Science for Serving Society. Springer, pp 51-71.

Bosilovich MG, Robertson FR, Chen J (2011) Global energy and water budgets in MERRA Journal of Climate 24:5721-5739.

Bothe O, Fraedrich K, Zhu X (2012) Precipitation climate of Central Asia and the large-scale atmospheric circulation Theoretical and Applied Climatology 108:345-354.

Bretherton CS, Smith C, Wallace JM (1992) An intercomparison of methods for finding coupled patterns in climate data Journal of climate 5:541-560.

Brunetti M, Colacino M, Maugeri M, Nanni T (2001) Trends in the daily intensity of precipitation in Italy from 1951 to 1996 International Journal of Climatology 21:299316.

Bucchignani E, Mercogliano P, Panitz H-J, Montesarchio M (2018) Climate change projections for the Middle East-North Africa domain with COSMO-CLM at different spatial resolutions Advances in Climate Change Research 9:66-80.

Bueh C, Nakamura H (2007) Scandinavian pattern and its climatic impact Quarterly Journal of the Royal Meteorological Society: A journal of the atmospheric sciences, applied meteorology and physical oceanography 133:2117-2131.

Cai WJ et al. (2015) ENSO and greenhouse warming. Nat. Clim. Change5, 849-859.

Cannon F, Carvalho LM, Jones C, Hoell A, Norris J, Kiladis GN, Tahir AA (2017) The influence of tropical forcing on extreme winter precipitation in the western Himalaya Climate Dynamics 48:1213-1232.

Cannon F, Carvalho LM, Jones C, Norris J (2016) Winter westerly disturbance dynamics and precipitation in the western Himalaya and Karakoram: a wave-tracking approach Theoretical and applied climatology 125:27-44.

Cannon F, Carvalho LMV, Jones C, Bookhagen B (2014) Multi-annual variations in winter westerly disturbance activity affecting the Himalaya Climate Dynamics 44:441-455 
doi:10.1007/s00382-014-2248-8.

Carius A, Maas A, Fritzsche K (2009) Climate Change and Security: Three Scenarios for South West Asia. Paper para a Comissão Europeia.

Cassou C, Deser C, Terray L, Hurrell JW, Drévillon M (2004) Summer sea surface temperature conditions in the North Atlantic and their impact upon the atmospheric circulation in early winter Journal of Climate 17:3349-3363.

Cassou C, Terray L, Hurrell JW, Deser C (2004) North Atlantic winter climate regimes: Spatial asymmetry, stationarity with time, and oceanic forcing Journal of Climate 17:1055-1068.

Chen M, Shi W, Xie P, Silva VB, Kousky VE, Wayne Higgins R, Janowiak JE (2008). Assessing objective techniques for gauge-based analyses of global daily precipitation Journal of Geophysical Research: Atmospheres 113.

Chen S et al. (2013) Performance evaluation of radar and satellite rainfalls for Typhoon Morakot over Taiwan: Are remote-sensing products ready for gauge denial scenario of extreme events? Journal of hydrology 506:4-13.

Chen Y, Li W, Deng H, Fang G, Li Z (2016) Changes in central Asia's water tower: past, present and future Scientific reports 6:35458.

Cheung HN, Zhou W, Mok HY, Wu MC (2012) Relationship between Ural-Siberian blocking and the East Asian winter monsoon in relation to the Arctic Oscillation and the El Niño-Southern Oscillation Journal of Climate 25:4242-4257.

Christensen JH et al. (2007) Regional climate projections. In: Climate Change, 2007: The Physical Science Basis. Contribution of Working group I to the Fourth Assessment Report of the Intergovernmental Panel on Climate Change, University Press, Cambridge, Chapter 11. pp 847-940.

Cohen J et al. (2014) Recent Arctic amplification and extreme mid-latitude weather Nature geoscience 7:627.

Comas-Bru L, McDermott F Impacts of the EA and SCA patterns on the 20th century NAOwinter precipitation relationship in Europe. In, 2013.

Compo GP, Sardeshmukh PD (2010) Removing ENSO-related variations from the climate record Journal of Climate 23:1957-1978.

Cowan P (2007) Geographic usage of the terms Middle Asia and Central Asia Journal of Arid Environments 69:359-363.

Cruz RV (2007) Asia Climate Change 2007: Impact, Adaptation and Vulnerability Contribution of Working Group II to the Fourth Assessment Report of the Intergovernmental Panel on Climate Change:469-506.

Cullen HM, Demenocal PB (2000) North Atlantic influence on Tigris-Euphrates streamflow 
International Journal of Climatology: A Journal of the Royal Meteorological Society 20:853-863.

Cullen HM, Kaplan A, Arkin PA (2002) Impact of the North Atlantic Oscillation on Middle Eastern climate and streamflow Climatic Change 55:315-338.

Czaja A, Frankignoul C (2002) Observed impact of Atlantic SST anomalies on the North Atlantic Oscillation Journal of Climate 15:606-623.

Davi NK et al. (2015) A long-term context (931-2005 CE) for rapid warming over Central Asia Quaternary Science Reviews 121:89-97.

Dee DP et al. (2011) The ERA-Interim reanalysis: Configuration and performance of the data assimilation system Quarterly Journal of the royal meteorological society 137:553597.

Deng H, Chen Y (2017) Influences of recent climate change and human activities on water storage variations in Central Asia Journal of Hydrology 544:46-57 doi:10.1016/j.jhydrol.2016.11.006.

Deser C, Alexander MA, Xie S-P, Phillips AS (2010) Sea surface temperature variability: Patterns and mechanisms Annual review of marine science 2:115-143.

Di Lorenzo E et al. (2008) North Pacific Gyre Oscillation links ocean climate and ecosystem change Geophysical Research Letters 35.

Diaz HF, Hoerling MP, Eischeid JK (2001) ENSO variability, teleconnections and climate change, Int. J. Climatol. 21, 1845-1862.

Dimri A (2007) The transport of momentum, sensible heat, potential energy and moisture over the western Himalayas during the winter season Theoretical and Applied Climatology 90:49-63.

Ding Q, Wang B (2005) Circumglobal teleconnection in the Northern Hemisphere summer Journal of Climate 18:3483-3505.

Dinku T, Ceccato P, Connor SJ (2011) Challenges of satellite rainfall estimation over mountainous and arid parts of east Africa International journal of remote sensing $32: 5965-5979$.

Dinku T, Ceccato P, Grover-Kopec E, Lemma M, Connor S, Ropelewski C (2007) Validation of satellite rainfall products over East Africa's complex topography International Journal of Remote Sensing 28:1503-1526.

Droogers P, Immerzeel W, Terink W, Hoogeveen J, Bierkens M, Van Beek L, Debele B (2012) Water resources trends in Middle East and North Africa towards 2050 Hydrology and Earth System Sciences 16:3101-3114.

Ebert EE, Janowiak JE, Kidd C (2007) Comparison of near-real-time precipitation estimates from satellite observations and numerical models Bulletin of the American Meteorological Society 88:47-64. 
El-Fadel M, Bou-Zeid E (2001) Climate change and water resources in the Middle East: vulnerability, socio-economic impacts, and adaptation.

Eriksson M, Xu J, Shrestha AB, Vaidya RA, Santosh N, Sandström K (2009) The changing Himalayas: impact of climate change on water resources and livelihoods in the greater Himalayas. International centre for integrated mountain development (ICIMOD).

Filippi L, Palazzi E, von Hardenberg J, Provenzale A (2014) Multidecadal variations in the relationship between the NAO and winter precipitation in the Hindu KushKarakoram Journal of Climate 27:7890-7902.

Fowler H, Archer D (2006) Conflicting signals of climatic change in the Upper Indus Basin Journal of Climate 19:4276-4293.

Francis JA, Vavrus SJ (2012) Evidence linking Arctic amplification to extreme weather in mid-latitudes Geophysical Research Letters 39.

Fricke K, Sterr T, Bubenzer O, Eitel B (2009) The Oasis as a Megacity: Urumqi's Fast Urbanisation in a Semiarid Environment Die Erde 140:449.

Funk CC, Hoell A (2015) The Leading Mode of Observed and CMIP5 ENSO-Residual Sea Surface Temperatures and Associated Changes in Indo-Pacific Climate Journal of Climate 28:4309-4329 doi:10.1175/jcli-d-14-00334.1.

Furtado JC, Di Lorenzo E, Schneider N, Bond NA (2011) North Pacific decadal variability and climate change in the IPCC AR4 models Journal of Climate 24:3049-3067.

Gall C (2008) War and drought threaten Afghan food supply New York Times 19:A1

Gao T, Yu J-y, Paek H (2017) Impacts of four northern-hemisphere teleconnection patterns on atmospheric circulations over Eurasia and the Pacific Theoretical and Applied Climatology 129:815-831.

Gebregiorgis AS, Hossain F (2015) How well can we estimate error variance of satellite precipitation data around the world? Atmospheric Research 154:39-59.

Gershunov A, Barnett TP (1998) Interdecadal modulation of ENSO teleconnections Bulletin of the American Meteorological Society 79:2715-2726.

Gill AE (1980) Some simple solutions for heat-induced tropical circulation. Quart. J. Roy. Meteor. Soc., 106, 447-462.

Goddard L, Mason SJ, Zebiak SE, Ropelewski CF, Basher R, Cane MA (2001) Current approaches to seasonal to interannual climate predictions International Journal of Climatology 21:1111-1152.

Goswami B, Mohan RA (2001) Intraseasonal oscillations and interannual variability of the Indian summer monsoon Journal of Climate 14:1180-1198. 
Goswami BN, Venugopal V, Sengupta D, Madhusoodanan M, Xavier PK (2006) Increasing trend of extreme rain events over India in a warming environment Science 314:14421445 .

Graf HF, Zanchettin D (2012) Central Pacific El Niño, the "subtropical bridge," and Eurasian climate Journal of Geophysical Research: Atmospheres 117.

Graham NE, Michaelsen J, Barnett TP (1987) An investigation of the El Niño-Southern Oscillation cycle With statistical models: 2. Model results Journal of Geophysical Research: Oceans 92:14271-14289.

Gruber A, Su X, Kanamitsu M, Schemm J (2000) The comparison of two merged rain gauge-satellite precipitation datasets Bulletin of the American Meteorological Society 81:2631-2644.

Gu D, Philander S (1997) Interdecadal climate fluctuations that depend on exchanges between the tropics and extratropics. Science, 275, 805-807.

Guhathakurta P, Rajeevan M (2008) Trends in the rainfall pattern over India International Journal of Climatology 28:1453-1469.

Guo H, Bao A, Liu T, Ndayisaba F, Jiang L, Kurban A, De Maeyer P (2018) Spatial and temporal characteristics of droughts in Central Asia during 1966-2015 Science of The Total Environment 624:1523-1538.

Hamada A, Arakawa O, Yatagai A (2011) An automated quality control method for daily rain-gauge data Global Environ Res 15:183-192.

Harris I, Jones PD, Osborn TJ, Lister DH (2014) Updated high-resolution grids of monthly climatic observations-the CRU TS3. 10 Dataset International journal of climatology 34:623-642.

Hartmann H, Buchanan H (2014) Trends in extreme precipitation events in the Indus River Basin and flooding in Pakistan Atmosphere-Ocean 52:77-91.

Hasanean H, Almazroui M, Jones P, Alamoudi A (2013) Siberian high variability and its teleconnections with tropical circulations and surface air temperature over Saudi Arabia Climate dynamics 41:2003-2018.

Hassanzadeh P, Kuang Z, Farrell BF (2014) Responses of midlatitude blocks and wave amplitude to changes in the meridional temperature gradient in an idealized dry GCM Geophysical Research Letters 41:5223-5232.

Hijioka Y et al. (2014) Asia Climate Change 2014: Impacts, Adaptation, and Vulnerability Part B: Regional Aspects Contribution of Working Group II to the Fifth Assessment Report of the Intergovernmental Panel on Climate Change:1327-1370.

Hoell A, Barlow M, Cannon F, Xu T (2017) Oceanic origins of historical Southwest Asia precipitation during the boreal cold season Journal of Climate 30:2885-2903. 
Hoell A, Barlow M, Saini R (2012) The Leading Pattern of Intraseasonal and Interannual Indian Ocean Precipitation Variability and Its Relationship with Asian Circulation during the Boreal Cold Season Journal of Climate 25:7509-7526 doi:10.1175/jcli-d11-00572.1.

Hoell A, Barlow M, Saini R (2013) Intraseasonal and Seasonal-to-Interannual Indian Ocean Convection and Hemispheric Teleconnections Journal of Climate 26:8850-8867 doi:10.1175/jcli-d-12-00306.1.

Hoell A, Barlow M, Xu T, Zhang T (2018) Cold Season Southwest Asia Precipitation Sensitivity to El Niño-Southern Oscillation Events. J. Climate, 31, 4463-4482.

Hoell A, Funk C (2013) The ENSO-related west Pacific sea surface temperature gradient Journal of Climate 26:9545-9562.

Hoell A, Funk C (2014) Indo-Pacific sea surface temperature influences on failed consecutive rainy seasons over eastern Africa Climate dynamics 43:1645-1660.

Hoell A, Funk C, Barlow M (2014) La Niña diversity and Northwest Indian Ocean Rim teleconnections Climate Dynamics 43:2707-2724 doi:10.1007/s00382-014-2083-y.

Hoell A, Funk C, Barlow M (2014) The regional forcing of Northern hemisphere drought during recent warm tropical west Pacific Ocean La Niña events Climate dynamics 42:3289-3311.

Hoell A, Funk C, Barlow M (2015) The forcing of southwestern Asia teleconnections by low-frequency sea surface temperature variability during boreal winter Journal of Climate 28:1511-1526.

Hoell A, Funk C, Magadzire T, Zinke J, Husak G (2015) El Niño-Southern Oscillation diversity and southern Africa teleconnections during austral summer Climate dynamics 45:1583-1599.

Hoell A, Shukla S, Barlow M, Cannon F, Kelley C, Funk C (2015) The forcing of monthly precipitation variability over Southwest Asia during the Boreal Cold Season Journal of Climate 28:7038-7056.

Hoerling M, Kumar A (2003) The perfect ocean for drought Science 299:691-694 doi:10.1126/science.1079053.

Hoerling MP, Hurrell JW, Xu T (2001) Tropical origins for recent North Atlantic climate change Science 292:90-92 doi:10.1126/science.1058582.

Horel JD (1981) A rotated principal component analysis of the interannual variability of the Northern Hemisphere 500 mb height field Monthly Weather Review 109:2080-2092.

Houghton JT, Meiro Filho L, Callander BA, Harris N, Kattenburg A, Maskell K (1996) Climate change 1995: the science of climate change Climatic Change:584.

Hu Z, Zhang C, Hu Q, Tian H (2014) Temperature changes in Central Asia from 1979 to 
2011 based on multiple datasets Journal of Climate 27:1143-1167

Huang A, Zhou Y, Zhang Y, Huang D, Zhao Y, Wu H (2014) Changes of the annual precipitation over central Asia in the twenty-first century projected by multimodels of CMIP5 Journal of Climate 27:6627-6646.

Huang B et al. (2017) Extended reconstructed sea surface temperature, version 5 (ERSSTv5): upgrades, validations, and intercomparisons Journal of Climate 30:8179-8205

Huang J-p, Guan X-d, Ji F (2012) Enhanced cold-season warming in semi-arid regions Atmospheric Chemistry and Physics 12:5391-5398.

Huffman G, Bolvin D, Nelkin E, Adler R Highlights of version 7 TRMM multi-satellite precipitation analysis (TMPA). In: Proceedings of the 5th International Precipitation Working Group Workshop, Hamburg, Germany, 2010. pp 11-15.

Huffman GJ et al. (2001) Global precipitation at one-degree daily resolution from multisatellite observations Journal of hydrometeorology 2:36-50.

Huffman GJ, Bolvin DT (2013) TRMM and other data precipitation data set documentation NASA, Greenbelt, USA 28.

Huffman GJ et al. (2007) The TRMM multisatellite precipitation analysis (TMPA): Quasiglobal, multiyear, combined-sensor precipitation estimates at fine scales Journal of hydrometeorology 8:38-55.

Immerzeel WW, Droogers P, De Jong S, Bierkens M (2009) Large-scale monitoring of snow cover and runoff simulation in Himalayan river basins using remote sensing Remote sensing of Environment 113:40-49.

Immerzeel WW, Van Beek LP, Bierkens MF (2010) Climate change will affect the Asian water towers Science 328:1382-1385.

IWMI. (2008). Areas of physical and economic water scarcity. UNEP/GRID-Arendal Maps and Graphics Library.

Iqbal MF, Athar H (2017) Variability, trends, and teleconnections of observed precipitation over Pakistan Theoretical and Applied Climatology:1-20.

Javanmard S, Yatagai A, Nodzu M, BodaghJamali J, Kawamoto H (2010) Comparing highresolution gridded precipitation data with satellite rainfall estimates of TRMM_3B42 over Iran Advances in Geosciences 25:119-125.

Jia X, Ge J (2017) Interdecadal changes in the relationship between ENSO, EAWM, and the wintertime precipitation over China at the end of the twentieth century. J Clim 30(6):1923-1937.

Jia X, Lee J-Y, Lin H, Hendon H, Ha K (2014) Interdecadal change in the Northern Hemisphere seasonal climate prediction skill: part II. Predictability and prediction skill. Clim. Dyn. 43:1611-1630. 
Jiang L, Bao A, Guo H, Ndayisaba F (2017) Vegetation dynamics and responses to climate change and human activities in Central Asia Science of the Total Environment 599:967-980.

Jo H-S, Yeh S-W, Lee S-K (2015) Changes in the relationship in the SST variability between the tropical Pacific and the North Pacific across the 1998/99 regime shift. Geophys Res Lett 42:7171-7178.

Johnson NC (2013) How many ENSO flavors can we distinguish? Journal of Climate 26:4816-4827.

Joshi MK, Rai A, Pandey A (2013) Validation of TMPA and GPCP 1DD against the ground truth rain-gauge data for Indian region International Journal of Climatology 33:26332648 .

Kaniewski D, Van Campo E, Weiss H (2012) Drought is a recurring challenge in the Middle East Proceedings of the National Academy of Sciences:201116304.

Kao H-Y, Yu J-Y (2009) Contrasting eastern-Pacific and central-Pacific types of ENSO Journal of Climate 22:615-632.

Kar SC, Rana S (2014) Interannual variability of winter precipitation over northwest India and adjoining region: impact of global forcings Theoretical and applied climatology 116:609-623.

Karthe D, Chalov S, Borchardt D (2014) Water resources and their management in central Asia in the early twenty first century: status, challenges and future prospects Environmental Earth Sciences 73:487-499 doi:10.1007/s12665-014-3789-1.

Kawamura R (1994) A rotated EOF analysis of global sea surface temperature variability with interannual and interdecadal scales Journal of physical oceanography 24:707715 .

Kidd C, Bauer P, Turk J, Huffman G, Joyce R, Hsu K-L, Braithwaite D (2012) Intercomparison of high-resolution precipitation products over northwest Europe Journal of Hydrometeorology 13:67-83.

Klein SA, Soden BJ, Lau N-C (1999) Remote sea surface temperature variations during ENSO: Evidence for a tropical atmospheric bridge Journal of Climate 12:917-932.

Krause P, Boyle D, Bäse F (2005) Comparison of different efficiency criteria for hydrological model assessment Advances in geosciences 5:89-97.

Krichak SO, Breitgand JS, Gualdi S, Feldstein SB (2013) Teleconnection-extreme precipitation relationships over the Mediterranean region Theoretical and Applied Climatology 117:679-692 doi:10.1007/s00704-013-1036-4.

Kripalani R, Kumar P (2004) Northeast monsoon rainfall variability over south peninsular 
India vis-à-vis the Indian Ocean dipole mode International journal of climatology 24:1267-1282.

Krishnamurthy V, Shukla J (2000) Intraseasonal and interannual variability of rainfall over India Journal of Climate 13:4366-4377.

Krishnamurti TN (1961) The subtropical jet stream of winter Journal of Meteorology 18:172191.

Kucera PA et al. (2013) Precipitation from space: Advancing Earth system science Bulletin of the American Meteorological Society 94:365-375.

Kug J-S, Jin F-F, An S-I (2009) Two types of El Niño events: cold tongue El Niño and warm pool El Niño Journal of Climate 22:1499-1515.

Kuligowski RJ (1997) An overview of National Weather Service quantitative precipitation estimates. US Department of Commerce, National Oceanic and Atmospheric Administration, National Weather Service, Office of Systems Development, Techniques Development Laboratory.

Kumar A, Zhang L, Wang W (2013) Sea surface temperature-precipitation relationship in different reanalyses Monthly Weather Review 141:1118-1123.

Kumar KK, Rajagopalan B, Cane MA (1999) On the weakening relationship between the Indian monsoon and ENSO, Science, 284, 2156-2159.

Kumar KN, Ouarda TB, Sandeep S, Ajayamohan RS (2016) Wintertime precipitation variability over the Arabian Peninsula and its relationship with ENSO in the CAM4 simulations Climate dynamics 47:2443-2454.

Kumar P, Kumar KR, Rajeevan M, Sahai A (2007) On the recent strengthening of the relationship between ENSO and northeast monsoon rainfall over South Asia Climate Dynamics 28:649-660.

Larkin NK, Harrison D (2005) Global seasonal temperature and precipitation anomalies during El Niño autumn and winter Geophysical Research Letters 32.

Latif M, Barnett TP (1995) Interactions of the tropical oceans Journal of Climate 8:952-964.

Lau K, Boyle J (1987) Tropical and extratropical forcing of the large-scale circulation: A diagnostic study Monthly weather review 115:400-428.

Lee T, McPhaden MJ (2010) Increasing intensity of El Niño in the central-equatorial Pacific Geophysical Research Letters 37.

Lelieveld J et al. (2012) Climate change and impacts in the Eastern Mediterranean and the Middle East Climatic Change 114:667-687.

Li Z, Chen Y, Fang G, Li Y (2017) Multivariate assessment and attribution of droughts in Central Asia Sci Rep 7:1316 doi:10.1038/s41598-017-01473-1. 
Liebmann B (1987) Observed relationships between large-scale tropical convection and the tropical circulation on subseasonal time scales during Northern Hemisphere winter Journal of the atmospheric sciences 44:2543-2561.

Lim Y-K, Kim H-D (2016) Comparison of the impact of the Arctic Oscillation and Eurasian teleconnection on interannual variation in East Asian winter temperatures and monsoon Theoretical and applied climatology 124:267-279.

Linkin ME, Nigam S (2008) The North Pacific Oscillation-west Pacific teleconnection pattern: Mature-phase structure and winter impacts Journal of Climate 21:1979-1997.

Lioubimtseva $\mathrm{E}$ (2015) A multi-scale assessment of human vulnerability to climate change in the Aral Sea Basin Environmental Earth Sciences 73:719-729.

Lioubimtseva E, Cole R (2007) Uncertainties of Climate Change in Arid Environments of Central Asia Reviews in Fisheries Science 14:29-49 doi:10.1080/10641260500340603.

Lioubimtseva E, Cole R, Adams J, Kapustin G (2005) Impacts of climate and land-cover changes in arid lands of Central Asia Journal of Arid Environments 62:285-308.

Lioubimtseva E, Henebry GM (2009) Climate and environmental change in arid Central Asia: Impacts, vulnerability, and adaptations Journal of Arid Environments 73:963977.

Liu H, Liu X, Dong B (2017) Intraseasonal variability of winter precipitation over central asia and the western tibetan plateau from 1979 to 2013 and its relationship with the North Atlantic Oscillation Dynamics of Atmospheres and Oceans 79:31-42.

Liu Y, Wang L, Zhou W, Chen W (2014) Three Eurasian teleconnection patterns: spatial structures, temporal variability, and associated winter climate anomalies Climate Dynamics 42:2817-2839 doi:10.1007/s00382-014-2163-z.

Lopez-Parages J, Rodriguez-Fonseca B (2012) Multidecadal modulation of El Niño influence on the Euro-Mediterranean rainfall, Geophys. Res. Lett., 39, L02704, doi:10.1029/2011GL050049.

Lorenz C, Kunstmann H (2012) The hydrological cycle in three state-of-the-art reanalyses: Intercomparison and performance analysis Journal of Hydrometeorology 13:13971420 .

Luo D, Lupo AR, Wan H (2007) Dynamics of eddy-driven low-frequency dipole modes. Part I: A simple model of North Atlantic Oscillations Journal of the Atmospheric Sciences 64:3-28.

Lyon B, Barnston AG, DeWitt DG (2013) Tropical pacific forcing of a 1998-1999 climate shift: observational analysis and climate model results for the boreal spring season Climate Dynamics 43:893-909 doi:10.1007/s00382-013-1891-9. 
Ma L, Zhang T, Frauenfeld OW, Ye B, Yang D, Qin D (2009) Evaluation of precipitation from the ERA-40, NCEP-1, and NCEP-2 Reanalyses and CMAP-1, CMAP-2, and GPCP-2 with ground-based measurements in China Journal of Geophysical Research: Atmospheres 114.

Mahanta R, Sarma D, Choudhury A (2013) Heavy rainfall occurrences in northeast India International Journal of Climatology 33:1456-1469.

Makorgiannis T, Giles B, Flocas A (1981) The problem of the extension of the Siberian Anticyclone towards southeast Europe, and its relation to atmospheric circulation anomalies over the Northern Hemisphere Archives for meteorology, geophysics, and bioclimatology, Series A 30:185-196.

Malik KM, Mahmood A, Kazmi DH, Khan JM (2012) Impact of climate change on agriculture during winter season over Pakistan Agric Sci 3:1007-1018

Mann ME (2002) Large-scale climate variability and connections with the Middle East in past centuries Climatic Change 55:287-314.

Mannig B et al. (2013) Dynamical downscaling of climate change in Central Asia Global and planetary change 110:26-39.

Mantua NJ, Hare SR (2002) The Pacific decadal oscillation Journal of oceanography 58:3544.

Mariotti A (2007) How ENSO impacts precipitation in southwest central Asia Geophysical Research Letters 34.

Martyn D (1992) Climates of the World. Elsevier, 436 pp.

Marzban C, Sandgathe S, Doyle JD (2014) Model tuning with canonical correlation analysis Monthly Weather Review 142:2018-2027

Matsuno T (1966) Quasi-geostrophic motions in the equatorial area. J. Meteor. Soc. Japan, 44, $25-42$.

McGregor S, Timmermann A, Stuecker MF, England MH, Merrifield M, Jin F-F, Chikamoto Y (2014) Recent Walker circulation strengthening and Pacific cooling amplified by Atlantic warming Nature Climate Change 4:888.

Mishra V, Smoliak BV, Lettenmaier DP, Wallace JM (2012) A prominent pattern of year-toyear variability in Indian Summer Monsoon Rainfall Proceedings of the National Academy of Sciences 109:7213-7217.

Misra V, Pantina P, Chan S, DiNapoli S (2012) A comparative study of the Indian summer monsoon hydroclimate and its variations in three reanalyses Climate dynamics 39:1149-1168.

Mohtar RH, Assi AT, Daher BT (2017) Current water for food situational analysis in the Arab region and expected changes due to dynamic externalities. In: The Water, 
Energy, and Food Security Nexus in the Arab Region. Springer, pp 193-208.

Moore G, Renfrew I (2012) Cold European winters: interplay between the NAO and the East Atlantic mode Atmospheric Science Letters 13:1-8.

Nair A, Acharya N, Singh A, Mohanty U, Panda T (2013) On the predictability of northeast monsoon rainfall over south peninsular India in general circulation models Pure and Applied Geophysics 170:1945-1967.

Nazemosadat M, Ghaedamini H (2010) On the relationships between the Madden-Julian oscillation and precipitation variability in southern Iran and the Arabian Peninsula: Atmospheric circulation analysis Journal of Climate 23:887-904.

Neelin JD, Battisti DS, Hirst AC, Jin FF, Wakata Y, Yamagata T, Zebiak SE (1998) ENSO theory Journal of Geophysical Research: Oceans 103:14261-14290.

New M, Todd M, Hulme M, Jones P (2001) Precipitation measurements and trends in the twentieth century International Journal of Climatology: A Journal of the Royal Meteorological Society 21:1889-1922.

Newman M et al. (2016) The Pacific decadal oscillation, revisited Journal of Climate 29:4399-4427.

Niranjan Kumar K, Ouarda T (2014) Precipitation variability over UAE and global SST teleconnections Journal of Geophysical Research: Atmospheres 119:10,313-310,322.

Novikov V, Kelly C (2017) Climate Change and Security in Central Asia - Regional Assessment Report. https://www.osce.org/secretariat/355471

Oki T, Kanae S (2006) Global hydrological cycles and world water resources science 313:1068-1072 doi:10.1126/science.1128845.

Osman Y, Abdellatif M, Al-Ansari N, Knutsson S, Jawad S (2017) Climate Change and Future Precipitation in Arid Environment of Middle East: Case study of Iraq Journal of Environmental Hydrology 25:1-18.

Ozturk T, Turp MT, Türkeş M, Kurnaz ML (2017) Projected changes in temperature and precipitation climatology of Central Asia CORDEX Region 8 by using RegCM4.3.5 Atmospheric Research 183:296-307 doi:10.1016/j.atmosres.2016.09.008.

Palazzi E, Von Hardenberg J, Provenzale A (2013) Precipitation in the Hindu-Kush Karakoram Himalaya: observations and future scenarios Journal of Geophysical Research: Atmospheres 118:85-100.

Panagiotopoulos F, Shahgedanova M, Hannachi A, Stephenson DB (2005) Observed trends and teleconnections of the Siberian high: A recently declining center of action Journal of climate 18:1411-1422.

Pattanaik D, Rajeevan M (2010) Variability of extreme rainfall events over India during southwest monsoon season Meteorological Applications 17:88-104. 
Petty GW, Krajewski WF (1996) Satellite estimation of precipitation over land Hydrological sciences journal 41:433-451

Prakash S et al. (2015) Seasonal intercomparison of observational rainfall datasets over India during the southwest monsoon season International Journal of Climatology 35:23262338 .

Qi J, Evered KT (2008) Environmental problems of Central Asia and their economic, social and security impacts. Springer Science \& Business Media.

Rahman S, Sengupta D, Ravichandran M (2009) Variability of Indian summer monsoon rainfall in daily data from gauge and satellite Journal of Geophysical Research: Atmospheres 114.

Rajeevan M, Bhate J (2009) A high resolution daily gridded rainfall dataset (1971-2005) for mesoscale meteorological studies Current Science:558-562.

Rajeevan M, Gadgil S, Bhate J (2010) Active and break spells of the Indian summer monsoon Journal of earth system science 119:229-247.

Rajeevan M, Unnikrishnan C, Bhate J, Niranjan Kumar K, Sreekala P (2012) Northeast monsoon over India: variability and prediction Meteorological Applications 19:226236.

Ramankutty N, Evan AT, Monfreda C, Foley JA (2008) Farming the planet: 1. Geographic distribution of global agricultural lands in the year 2000 Global biogeochemical cycles 22 .

Rana S, McGregor J, Renwick J (2015) Precipitation seasonality over the Indian subcontinent: An evaluation of gauge, reanalyses, and satellite retrievals Journal of Hydrometeorology 16:631-651.

Rana S, McGregor J, Renwick J (2017) Wintertime precipitation climatology and ENSO sensitivity over central southwest Asia International Journal of Climatology 37:14941509.

Rana S, Renwick J, McGregor J, Singh A (2018) Seasonal Prediction of Winter Precipitation Anomalies over Central Southwest Asia: A Canonical Correlation Analysis Approach Journal of Climate 31:727-741.

Rasmussen $\mathrm{R}$ et al. (2012) How well are we measuring snow: The NOAA/FAA/NCAR winter precipitation test bed Bulletin of the American Meteorological Society 93:811829.

Recalde-Coronel GC, Barnston AG, Muñoz ÁG (2014) Predictability of December-April rainfall in coastal and Andean Ecuador Journal of Applied Meteorology and Climatology 53:1471-1493.

Reyer CP et al. (2017) Climate change impacts in Central Asia and their implications for 
development Regional environmental change 17:1639-1650.

Richards F, Arkin P (1981) On the relationship between satellite-observed cloud cover and precipitation Monthly Weather Review 109:1081-1093.

Richman M (1986) Rotation of principal components. J Climatol 6 (3): 293-335 Google Scholar.

Rienecker MM et al. (2011) MERRA: NASA's modern-era retrospective analysis for research and applications Journal of climate 24:3624-3648.

Robertson AW, Mechoso CR, Kim Y-J (2000) The influence of Atlantic sea surface temperature anomalies on the North Atlantic Oscillation Journal of Climate 13:122138.

Rogers JC (1997) North Atlantic storm track variability and its association to the North Atlantic Oscillation and climate variability of northern Europe Journal of Climate 10:1635-1647.

Roshan GR, Grab S (2012) Regional climate change scenarios and their impacts on water requirements for wheat production in Iran.

Roy SS (2006) The impacts of ENSO, PDO, and local SSTs on winter precipitation in India Physical Geography 27:464-474.

Rudolf B, Rubel F (2005) Global precipitation. In Observed Global Climate. LandoltBörnstein. Vol. 6, Hantel M (ed). Springer Berlin Heidelberg, doi: 10.1007/10730550_28, 11.01-11.53.

Russo S, Sterl A (2012) Global changes in seasonal means and extremes of precipitation from daily climate model data Journal of Geophysical Research: Atmospheres 117.

Ryan J, Sommer R, Ibrikci H (2012) Fertilizer best management practices: A perspective from the dryland West Asia-North Africa region Journal of Agronomy and Crop Science 198:57-67.

Saha S et al. (2010) The NCEP climate forecast system reanalysis Bulletin of the American Meteorological Society 91:1015-1058.

Saji N, Goswami B, Vinayachandran P, Yamagata T (1999) A dipole mode in the tropical Indian Ocean Nature 401:360.

Schär C, Vasilina L, Pertziger F, Dirren S (2004) Seasonal runoff forecasting using precipitation from meteorological data assimilation systems Journal of Hydrometeorology 5:959-973.

Schiemann R, Lüthi D, Vidale PL, Schär C (2008) The precipitation climate of Central Asia-intercomparison of observational and numerical data sources in a remote semiarid region International Journal of Climatology: A Journal of the Royal Meteorological Society 28:295-314. 
Schneider U, Becker A, Finger P, Meyer-Christoffer A, Ziese M, Rudolf B (2014) GPCC's new land surface precipitation climatology based on quality-controlled in situ data and its role in quantifying the global water cycle Theoretical and Applied Climatology 115:15-40.

Schneider U, Fuchs T, Meyer-Christoffer A, Rudolf B (2008) Global precipitation analysis products of the GPCC Global Precipitation Climatology Centre (GPCC), DWD, Internet Publikation 112 .

Sen Roy S (2009) A spatial analysis of extreme hourly precipitation patterns in India International Journal of Climatology 29:345-355.

Sevruk B Correction of precipitation measurements summary report. In: Correction of precipitation measurements, 1985. Swiss Federal Institute of Technology.

Shabbar A, Bonsal BR, Szeto K (2011) Atmospheric and oceanic variability associated with growing season droughts and pluvials on the Canadian Prairies Atmosphere-Ocean 49:339-355.

Shabbar A, Huang J, Higuchi K (2001) The relationship between the wintertime North Atlantic Oscillation and blocking episodes in the North Atlantic International Journal of Climatology 21:355-369.

Shah R, Mishra V (2014) Evaluation of the reanalysis products for the monsoon season droughts in India Journal of Hydrometeorology 15:1575-1591.

Shaman J, Tziperman E (2005) The effect of ENSO on Tibetan Plateau snow depth: A stationary wave teleconnection mechanism and implications for the South Asian monsoons Journal of Climate 18:2067-2079.

Shaman J, Tziperman E (2016) The Superposition of Eastward and Westward Rossby Waves in Response to Localized Forcing Journal of Climate 29:7547-7557.

Shea J, Sontakke A (1995) The annual cycle of precipitation over the Indian subcontinent: daily, monthly and seasonal statistics.

Shen Y, Xiong A, Wang Y, Xie P (2010) Performance of high-resolution satellite precipitation products over China Journal of Geophysical Research: Atmospheres 115.

Singh SP, Bassignana-Khadka I, Singh Karky B, Sharma E (2011) Climate change in the Hindu Kush-Himalayas: the state of current knowledge. International Centre for Integrated Mountain Development (ICIMOD).

Smith TM, Reynolds RW (2003) Extended reconstruction of global sea surface temperatures based on COADS data (1854-1997) Journal of Climate 16:1495-1510.

Sohn SJ, Tam CY, Ashok K, Ahn JB (2012) Quantifying the reliability of precipitation datasets for monitoring large-scale East Asian precipitation variations International 
Journal of Climatology 32:1520-1526.

Solomon S, Qin D, Manning M, Averyt K, Marquis M (2007) Climate change 2007-the physical science basis: Working group I contribution to the fourth assessment report of the IPCC vol 4. Cambridge university press.

Sorg A, Bolch T, Stoffel M, Solomina O, Beniston M (2012) Climate change impacts on glaciers and runoff in Tien Shan (Central Asia) Nature Climate Change 2:725.

Srinivasan V, Ramamurthy K (1973) Comprehensive articles on selected topics, Northeast monsoon FMU Report, No IV 18.

Sterl A, Van Oldenborgh GJ, Hazeleger W, Burgers G (2007) On the robustness of ENSO teleconnections, Clim. Dyn., 29(5), 469-485, doi:10.1007/s00382-007-0251-z

Stevenson SL (2012) Significant changes to ENSO strength and impacts in the twenty-first century: Results from CMIP5, Geophys. Res. Lett., 39, L17703, doi:10.1029/2012GL052759

Stocker TF et al. (2013) Climate change 2013: the physical science basis. Intergovernmental panel on climate change, working group I contribution to the IPCC fifth assessment report (AR5) New York.

Strong C, Davis RE (2007) Winter jet stream trends over the Northern Hemisphere Quarterly Journal of the Royal Meteorological Society: A journal of the atmospheric sciences, applied meteorology and physical oceanography 133:2109-2115.

Syed F, Giorgi F, Pal J, King M (2006) Effect of remote forcings on the winter precipitation of central southwest Asia part 1: observations Theoretical and Applied Climatology $86: 147-160$.

Syed FS, Giorgi F, Pal JS, Keay K (2009) Regional climate model simulation of winter climate over Central-Southwest Asia, with emphasis on NAO and ENSO effects International Journal of Climatology:n/a-n/a doi:10.1002/joc.1887.

Tabari H, Willems P (2018) Seasonally varying footprint of climate change on precipitation in the Middle East Sci Rep 8:4435 doi:10.1038/s41598-018-22795-8.

Tanarhte M, Hadjinicolaou P, Lelieveld J (2012) Intercomparison of temperature and precipitation data sets based on observations in the Mediterranean and the Middle East Journal of Geophysical Research: Atmospheres 117.

Thomas R (2008) Opportunities to reduce the vulnerability of dryland farmers in Central and West Asia and North Africa to climate change Agriculture, Ecosystems \& Environment 126:36-45.

Tippett MK, Barlow M, Lyon B (2003) Statistical correction of central southwest Asia winter precipitation simulations International Journal of Climatology 23:1421-1433.

Tippett MK, DelSole T, Mason SJ, Barnston AG (2008) Regression-based methods for 
finding coupled patterns Journal of Climate 21:4384-4398.

Tippett MK, Goddard L, Barnston AG (2005) Statistical-dynamical seasonal forecasts of central-southwest Asian winter precipitation Journal of climate 18:1831-1843.

Trenberth KE (2011) Changes in precipitation with climate change Climate Research 47:123138.

Trenberth KE, Fasullo JT, Mackaro J (2011) Atmospheric moisture transports from ocean to land and global energy flows in reanalyses Journal of Climate 24:4907-4924.

Treydte KS, Schleser GH, Helle G, Frank DC, Winiger M, Haug GH, Esper J (2006) The twentieth century was the wettest period in northern Pakistan over the past millennium Nature 440:1179.

Trigo RM, Gouveia CM, Barriopedro D (2010) The intense 2007-2009 drought in the Fertile Crescent: Impacts and associated atmospheric circulation Agricultural and Forest Meteorology 150:1245-1257.

TRMM Precipitation Radar Team (2011) Tropical Rainfall Measuring Mission (TRMM) Precipitation Radar algorithm instruction manual for version 7. Tech. Rep., JAXA/NASA, 170 pp. [Available online at www.eorc.jaxa.jp/TRMM/documents/ R_algorithm_product_information/pr_manual/PR_Instruction_Manual_V7_L1.pdf.]

Turk FJ, Arkin P, Sapiano MR, Ebert EE (2008) Evaluating high-resolution precipitation products Bulletin of the American Meteorological Society 89:1911-1916.

Turner AG, Annamalai H (2012) Climate change and the South Asian summer monsoon Nature Climate Change 2:587.

Uppala S (2007) Use of satellite data in reanalyses. In: ECMWF seminar on recent development in the use of satellite observations in NWP. pp 3-7.

Van Oldenborgh GJ, Burgers G (2005) Searching for decadal variations in ENSO precipitation teleconnections, Geophys. Res. Lett., 32,L15701, doi:10.1029/2005GL023110

Verdon DC, Franks SW (2006) Long-term behaviour of ENSO: Interactions with the PDO over the past 400 years inferred from paleoclimate records Geophysical Research Letters 33 .

Walker GT, Bliss EW (1932) World Weather V. Memoirs of the Royal Meteorological Society, 4, 53-84.

Wang B (1995) Interdecadal changes in El Nino onset in the last four decades Journal of Climate 8:267-285.

Wang B, Ding Q (2006) Changes in global monsoon precipitation over the past 56 years Geophysical Research Letters 33. 
Waple A et al. (2002) Climate assessment for 2001 Bulletin of the American Meteorological Society 83:S1-S62.

Watson RT, Zinyowera MC, Moss RH, Dokken DJ (1998) The regional impacts of climate change An assessment of vulnerability: A Special Report of IPCC Working Group II:517.

Wegerich K (2011) Water resources in Central Asia: regional stability or patchy make-up? Central Asian Survey 30:275-290.

Wilks DS (2006) Statistical Methods in the Atmospheric Sciences (International Geophysics Series; V. 91). Academic Press.

Wolff C, Plessen B, Dudashvilli AS, Breitenbach SF, Cheng H, Edwards LR, Strecker MR (2017) Precipitation evolution of Central Asia during the last 5000 years The Holocene 27:142-154.

Woollings T, Hannachi A, Hoskins B (2010) Variability of the North Atlantic eddy-driven jet stream Quarterly Journal of the Royal Meteorological Society 136:856-868.

Xie P et al. (2003) GPCP pentad precipitation analyses: An experimental dataset based on gauge observations and satellite estimates Journal of Climate 16:2197-2214.

Yao T et al. (2012) Different glacier status with atmospheric circulations in Tibetan Plateau and surroundings Nature climate change 2:663.

Yatagai A, Arakawa O, Kamiguchi K, Kawamoto H, Nodzu MI, Hamada A (2009) A 44-year daily gridded precipitation dataset for Asia based on a dense network of rain gauges Sola 5:137-140.

Yatagai A, Kamiguchi K, Arakawa O, Hamada A, Yasutomi N, Kitoh A (2012) APHRODITE: Constructing a long-term daily gridded precipitation dataset for Asia based on a dense network of rain gauges Bulletin of the American Meteorological Society 93:1401-1415.

Yatagai A, Xie P Utilization of a rain-gauge-based daily precipitation dataset over Asia for validation of precipitation derived from TRMM/PR and JRA-25. In: Remote Sensing and Modeling of the Atmosphere, Oceans, and Interactions, 2006. International Society for Optics and Photonics, p 64040M.

Yatagai A, Xie P, Alpert P (2008) Development of a daily gridded precipitation data set for the Middle East Advances in Geosciences 12:165-170.

Yeh SW, Wang X, Wang CZ, Dewitte B (2015) On the relationship between the North Pacific climate variability and the central Pacific El Niño. J Clim 28:663-677

Yilmaz KK, Hogue TS, Hsu K-l, Sorooshian S, Gupta HV, Wagener T (2005) Intercomparison of rain gauge, radar, and satellite-based precipitation estimates with emphasis on hydrologic forecasting Journal of Hydrometeorology 6:497-517. 
Yin Z-Y, Wang H, Liu X (2014) A Comparative Study on Precipitation Climatology and Interannual Variability in the Lower Midlatitude East Asia and Central Asia Journal of Climate 27:7830-7848 doi:10.1175/jcli-d-14-00052.1.

Yohe G, Malone E, Brenkert A, Schlesinger M, Meij H, Xing X, Lee D (2006) A synthetic assessment of the global distribution of vulnerability to climate change from the IPCC perspective that reflects exposure and adaptive capacity CIESIN (Center for International Earth Science Information Network), Columbia University, Palisades http://ciesin columbia edu/data/climate/Access date July 8:2008.

Yu Z-P, Chu P-S, Schroeder T (1997) Predictive skills of seasonal to annual rainfall variations in the US affiliated Pacific islands: Canonical correlation analysis and multivariate principal component regression approaches. Journal of Climate 10:25862599.

Zhang Q, Körnich H, Holmgren K (2013) How well do reanalyses represent the southern African precipitation? Climate dynamics 40:951-962.

Zhang X et al. (2005) Trends in Middle East climate extreme indices from 1950 to 2003 Journal of Geophysical Research: Atmospheres 110.

Zhang Y, Wallace JM, Battisti DS (1997) ENSO-like interdecadal variability: 1900-93 Journal of climate 10:1004-1020.

Zhao M, Dirmeyer PA (2003) Production and analysis of GSWP-2 near-surface meteorology data sets vol 159. Center for Ocean-Land-Atmosphere Studies Calverton.

Zyadin A (2013) Water Shortage in MENA Region: An Interdisciplinary overview and a suite of practical solutions Journal of Water Resource and Protection $5: 49$ 


\section{Appendix A}

\section{Chapter 5: Supplementary information}

As noted in Chapter 5 (Section 5.4.1), CCA-based forecasts are typically sensitive to the choice and size of the predictor domain. Therefore, to determine the most optimal prediction model a number of CCA experiments were performed with different possible predictors [outgoing longwave radiation (OLR), upper-level winds, and seas surface temperature (SST)] and combinations of predictor domains that included the Indo-Pacific, Pacific, and the Atlantic Ocean domains.

Some of the experimental results obtained for SST (North Pacific domain), and OLR (Indo-Pacific domain) as the predictor fields are presented in the following section.

\section{A.1 SST and OLR data}

The global monthly SST $\left({ }^{\circ} \mathrm{C}\right)$ data [NOAA_OI_SST_V2; National Oceanic and Atmospheric Administration Optimum Interpolation SST (OISST) Version 2] (Reynolds et al. 2002) used here was obtained from Earth System Research Laboratory (ESRL), USA (http://www.esrl.noaa.gov/psd/). This dataset is available at a fixed $1^{\circ} \mathrm{X} 1^{\circ}$ latitude-longitude grid for the period (1982-present).

Similarly, global monthly OLR (Wm-2) dataset was obtained from NOAA/ESRL climate data records (http://www.esrl.noaa.gov/psd/). This product is available at a fixed $1^{\circ} \mathrm{X} 1^{\circ}$ latitude-longitude grid for the period (1979-2012).

\section{A.2 Predictor domain selection}

For the purpose of developing a statistical prediction model, covariance analysis between the seasonal (DJFMA) mean precipitation and the preceding seasonal (SON) mean - SST, OLR global fields were performed and are shown in Figure A1. 

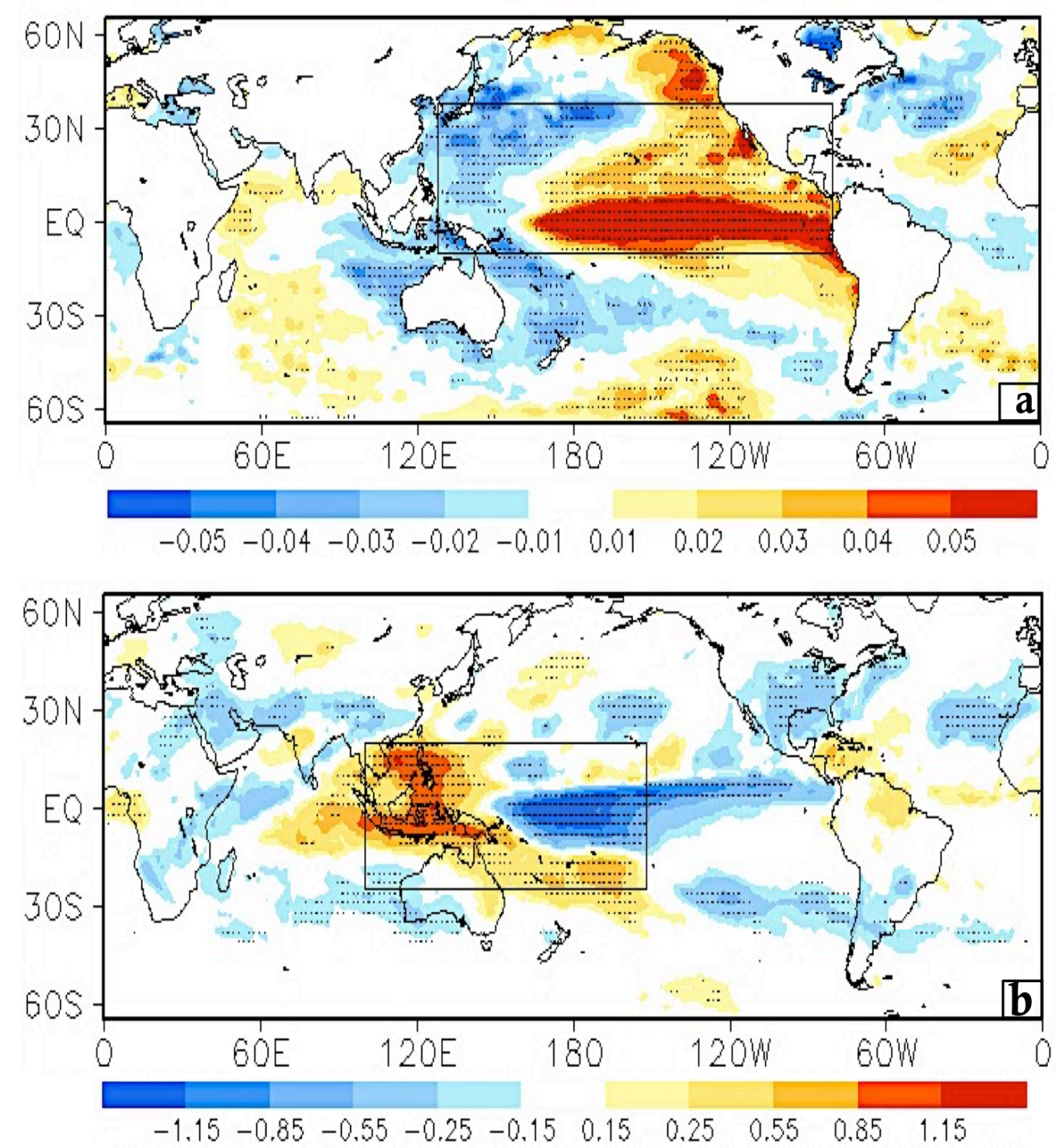

Figure A1. Covariance analysis maps between CSWA winter (DJFMA) precipitation and the preceding season's (SON) fields (a) SST $\left({ }^{\circ} \mathrm{C}\right)$ and (b) OLR $\left(\mathrm{Wm}^{-2}\right)$, for the period 1982-2009. Stippling indicates covariance significant at 5\% level (Fstatistics).

The maximum magnitude covariance areas marked as rectangular boxes in Figure A1 were selected as the optimum predictor domains for SST $\left(10^{\circ} \mathrm{S}-38^{\circ} \mathrm{N}\right.$ and $\left.128^{\circ} \mathrm{E}-280^{\circ} \mathrm{E}\right)$ and $\mathrm{OLR}\left(25^{\circ} \mathrm{S}-20^{\circ} \mathrm{N}\right.$ and $\left.100^{\circ} \mathrm{E}-208^{\circ} \mathrm{E}\right)$ fields and are further used as inputs in separate CCA experiments. 


\section{A.3 CCA maps for the selected SST ad OLR predictor domains}
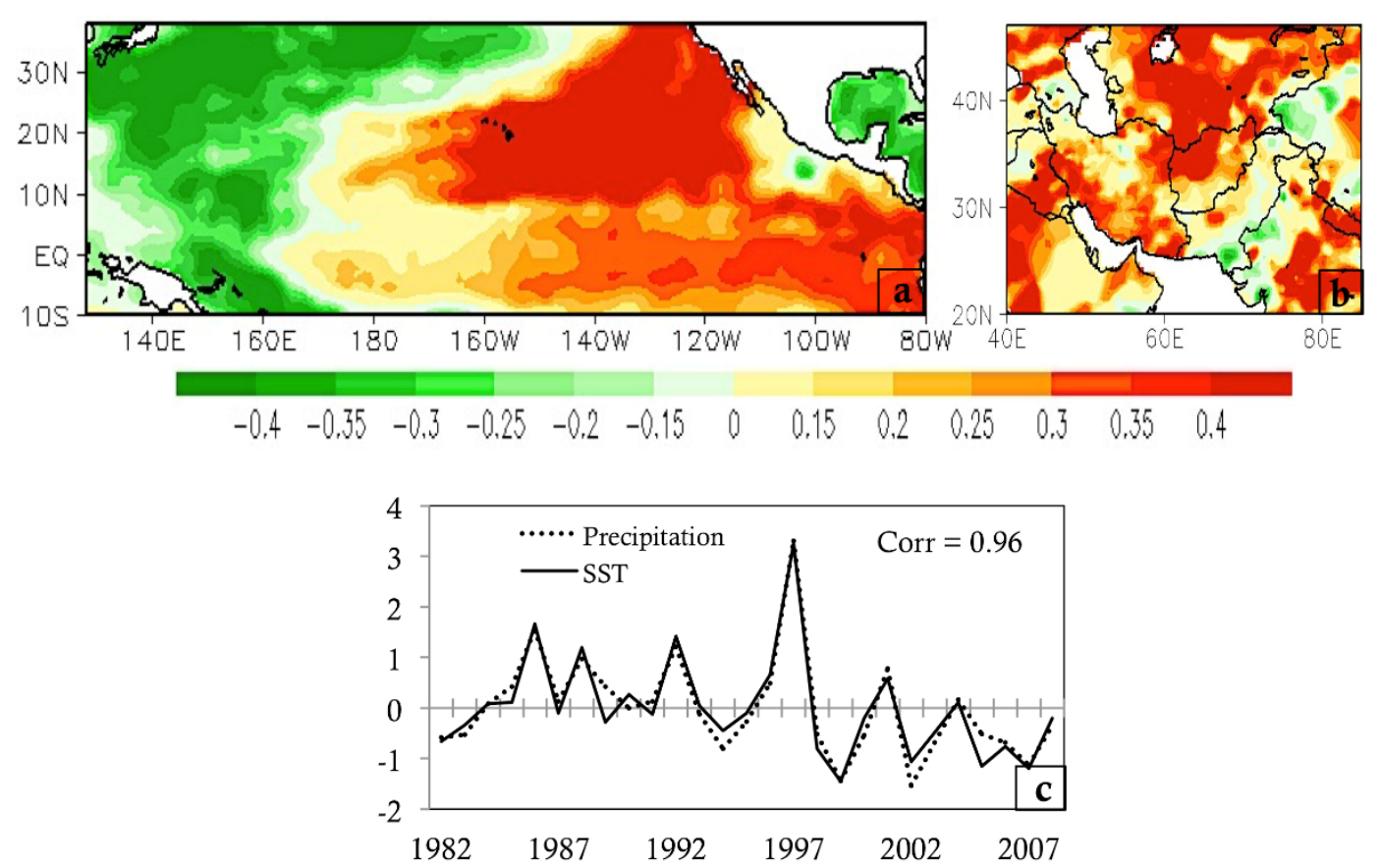

Figure A2. The principal loading patterns and the corresponding canonical component time series of mode-1 for (SON) SSTs $\left({ }^{\circ} \mathrm{C}\right)$ and the following season's (DJFMA) precipitation. (a) SST-predictor domain loading pattern (43\% variance explained); (b) Predictand loading pattern (28\% variance explained); (c) canonical component time series in normalized values, for the period 1982-2009.
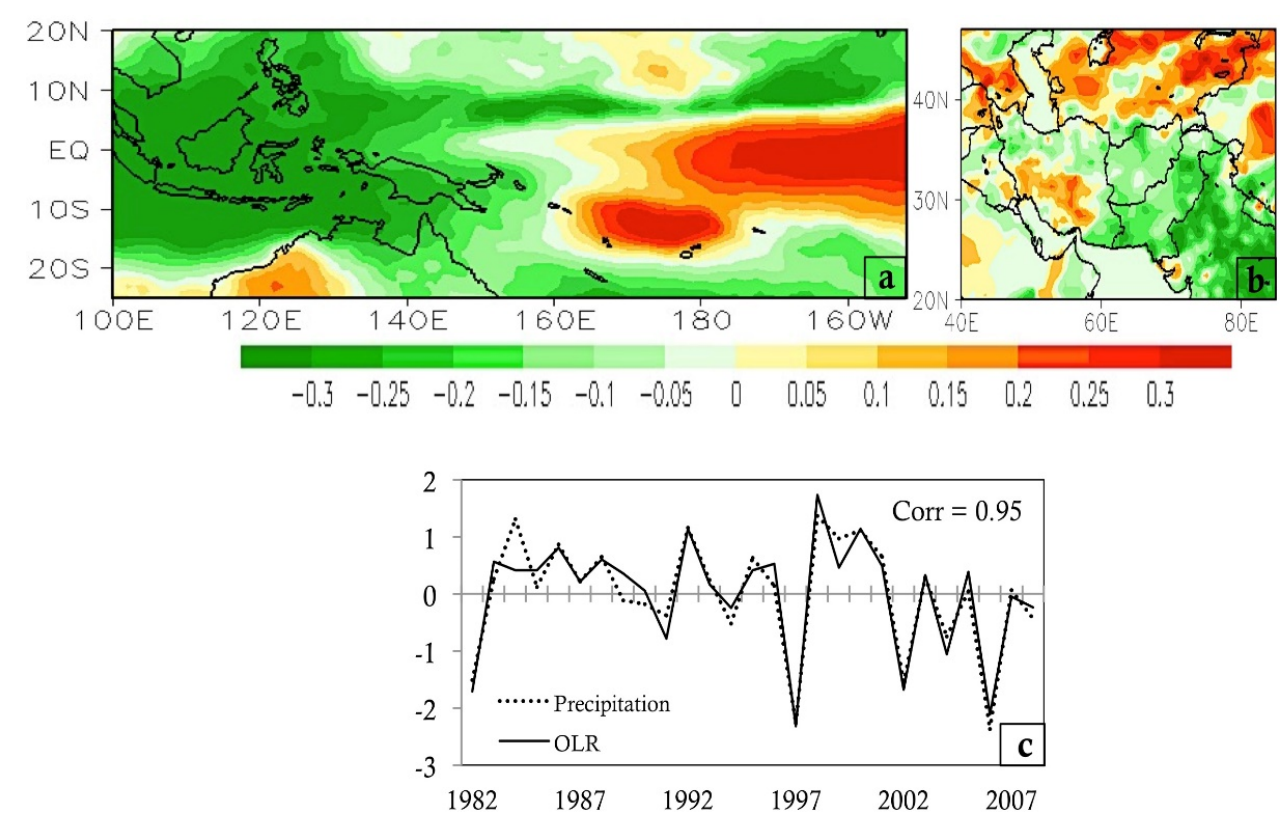

Figure A3. Same as Figure A2, but for OLR-predictor domain. (a) OLR-predictor (41\% variance explained); (b) Predictand (28\% variance explained) 


\section{A.4 CCA cross-validated skill using leave-one-out cross-validation approach}

Correlation of observed precipitation with predicted ( 0.68 for SST-predictor) and

( 0.57 for OLR-predictor)

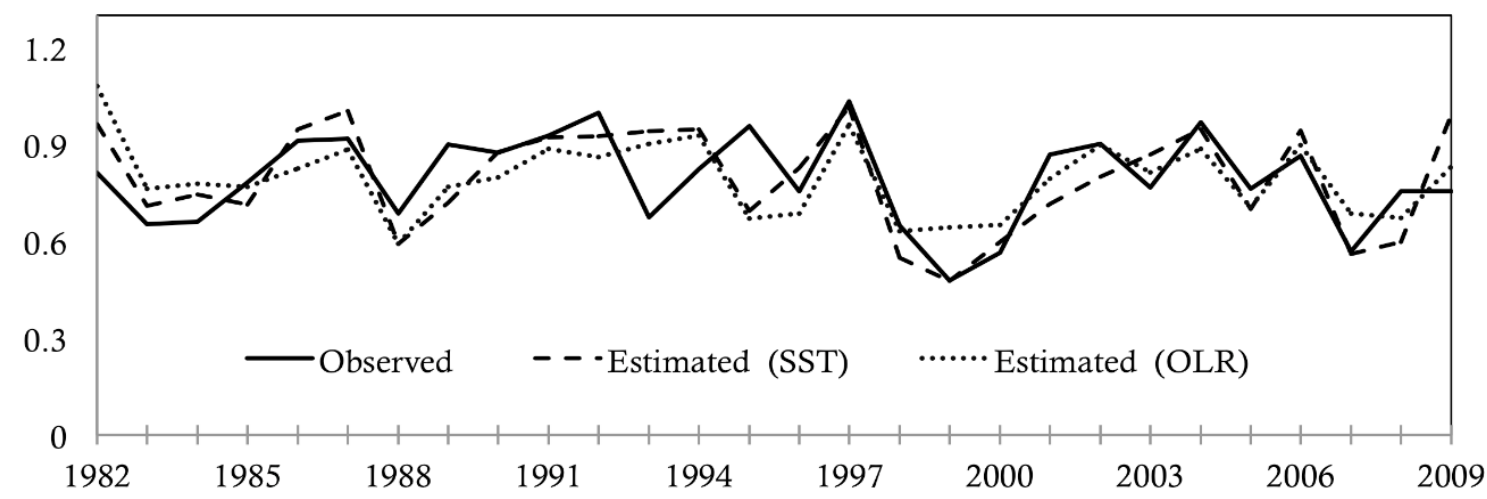

Figure A4. Wintertime (DJFMA) precipitation time series (mm/day) of forecasts and observation over CSWA for the period (1982/83 - 2009/10). Observation (solid line); SST-predictor (dashed line); OLR-predictor (dotted lines).

\section{A.5 Predictive skill of the CCA model against observed for extreme precipitation years.}

Dry years (1983-1984; 1998-1999; 1999-2000; 2000-2001; 2007-2008)

Wet years (1991-1992; 1992-1993; 1995-1996; 1997-1998; 2004-2005)
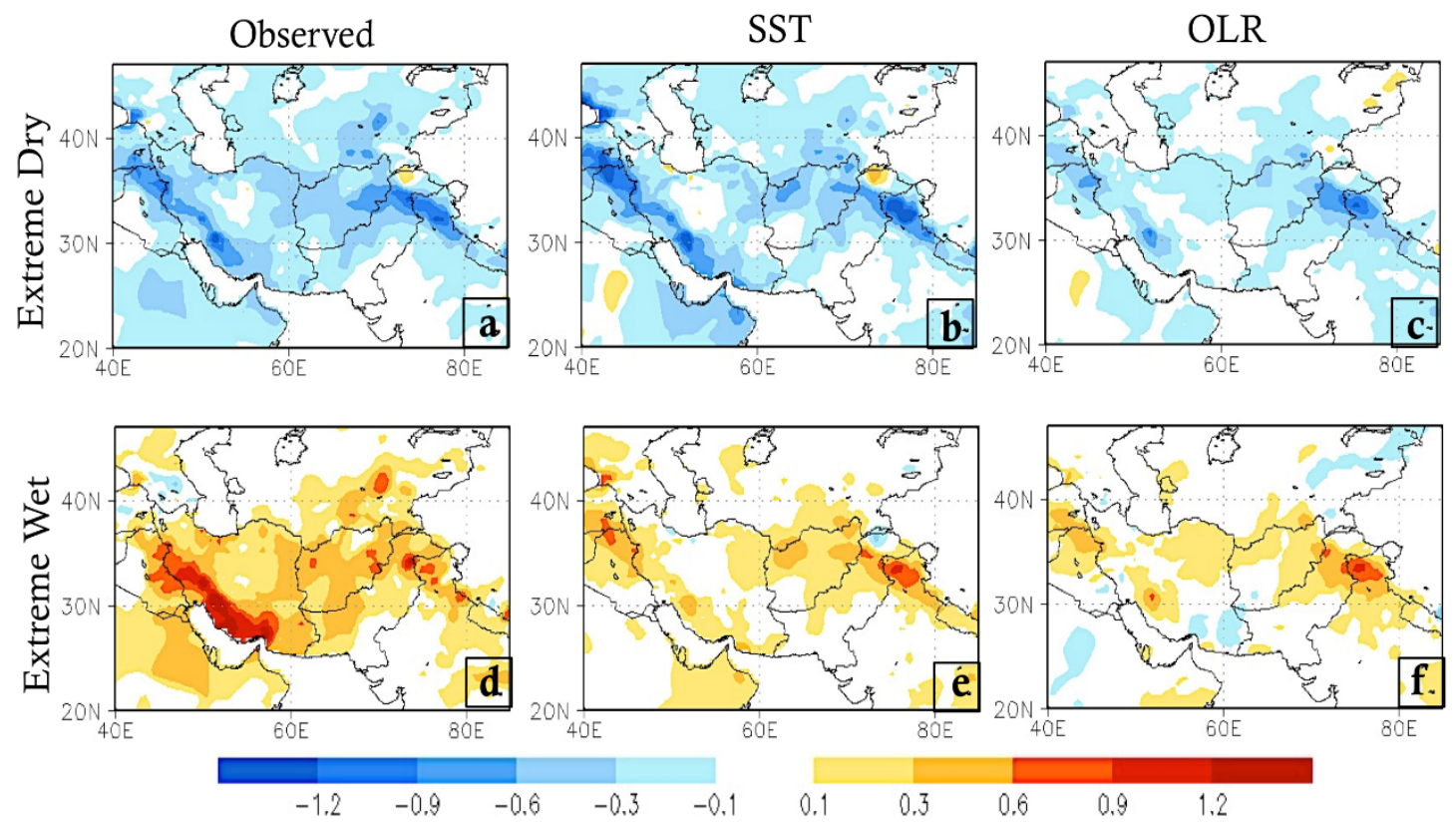

Figure A5. The wintertime (DJFMA) precipitation anomaly composites for the top five extreme-dry and -wet years corresponding to observation (extreme left), SST (middle) and OLR (extreme right) panel 
A6. Large-scale SST and OLR forcing for extreme precipitation years.
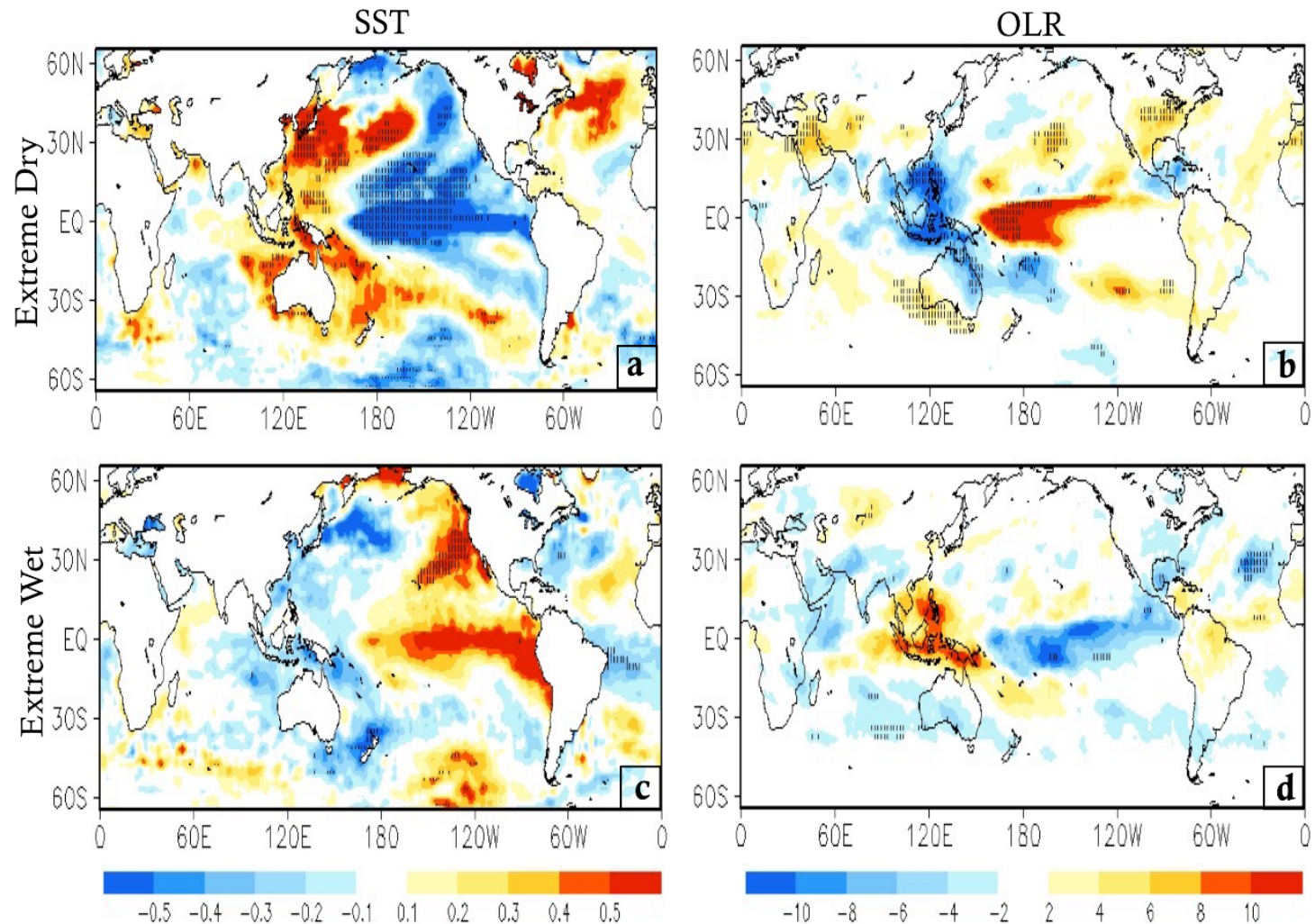

Figure A6. SST (left) and OLR (right) anomaly composites of (SON) season preceding the five extreme-dry and-wet winter precipitation years. Stippling indicates composite anomalies significant at $5 \%$ level. 